\title{
Estudo da formação de bolhas em líquidos viscosos \\ (Uma abordagem usando a Teoria do Caos)
}

\section{Alberto Tufaile}

Orientador: Prof. Dr. José Carlos Sartorelli

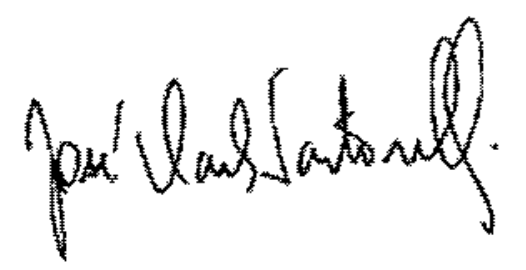

Tese apresentada ao Instituto de. Fisica da Universidade de São Patulo para a obtenção do título de Doutor em Ciências

Banca examinadora:

Prof. Dr. José Carlos Sartorelli - IFUSP

Profa. Dra. Coraci Pereira Malta - IFUSP

Prof. Dr. Jorge Manuel Sotomayor Tello - IME/USP

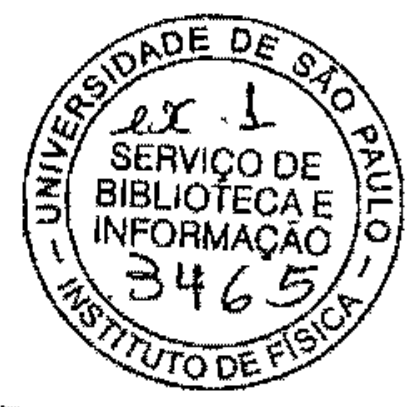

Prof. Dr. Paulo Batista Gonçalves - PUC/RIO

Prof. Dr. Thomas Braun - UFRGS

São Paulo 2000

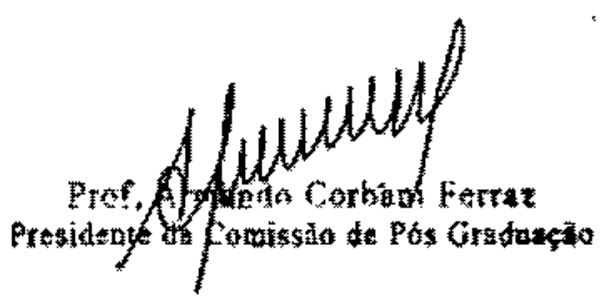


$530 \cdot 155352$

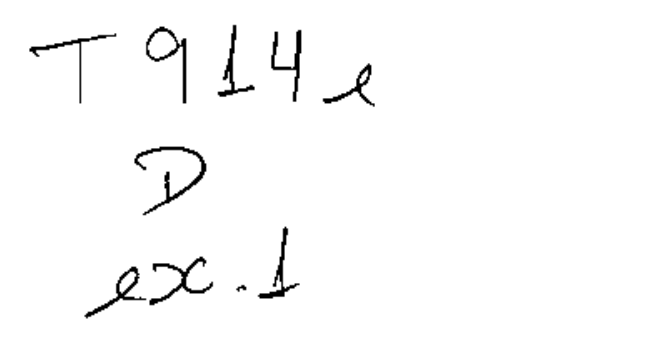

FICHA CATALOGRÁFICA

Preparada pelo Serviço de Biblioteca e Informação do Instituto de Física da Universidade de São Paulo

Tufaile, Alberto

Estudo da Formação de Bolhas em Liquidos Viscosos (Uma Abordagem usando a Teoria de Caos).

São Paulo, 2000.

Tese (Doutoramento) - Universidade de São Paulo. Instituto de Física - Departamento de Física Geral

Orientador: Prof. Dr. José Carlos Sartorelli Área de Concentração: Física

Unitermos: 1. Caos; 2. Bolhas; 3. Mapa do Círculo; 4. Sistemas Dinâmicos. 
A minha amada esposa Adriana. 


\section{Agradecimentos}

Nos anos em que realizei este trabalho, vånias pessoas colaboraram de muitas formas para que ele se realizasse. Expresso aqui meus agradecimentos àlgumas delas:

Ao meu orientador Prof. José Carios Sartorelli pela orientaçăo e o apoio que me foram dados durante todos esses anos.

Aos meus colegas do LFNL: Whilk, Reynaldo, Marcelo, Thiago e Ciro, pelo companheirismo de todas as horas.

A Comissão de Pós-Graduação do Instituto de Física da USP, na pessoa do Prof. Armando Corbani Ferraz.

Aos funcionários do Departamento de Física Geral, Dirce, Ivone, Alexandre, Jairo, Rubens e Marcelino.

Ao grupo de Mecânica Estatística, nas pessoas do Prof, Salinas e do Prof, Mário Josẻ de Oliveira.

Ao Prof. Tberê Luiz Caldas e seu grupo: Murilo Batista, Kai, Renê, Elinei, Atselmo e Tomás.

A secretária Márcia, todo o pessoal da Biblioteca, aos téenicos do Laboratório Didático, como o Cláudio, Fábio, Dionísio, Manế, Marcos e Canela.

A todos do Departamento de Materiais e Mecânica, principalmente ao Iran, Ivete, Eliane, Tacko, Sérgio, Marcelo e Toninho.

Aos meus pais, Jamil e Alaide, que me conduziram durante boa parte da vida e me educaram com muito carinho, aos meus irmãos: Elysângela, Aristóteles, Linda e Susy, que são muito importantes para mim.

Aos meus sogros, Roberto e Cleusa, que me amparam com a seu apoio carinhoso, amizade e suas preces. Aos meus cunhados, Lincoln e Adriana Midori, pessoas pelas quais tenho profunda admiração, que tambèm me ajudam e ao meu sobrinho Tiago.

Agradeço ao Conselho Nacional de Pesquisa (CNPq) e à FAPESP pelo importantíssimo apoio financeiro.

Finalmente, agradeço apaixonadamente à minha adorada esposa Adriana. 
Neste instante gigantesco, vi milhoes de atos agradaveis $e$ atrozes; nenhum me assombrou mais que ofato ke todos ocuparen o mesmo ponto, sem superpossę̧āo e sem transparência. $O$ que ntaus olhos viram fot simultâneo; o qut manscreveret será sucessivo, pois a linguagem o $\hat{b}$.

Jorge Luís Borges, O Aleph. 


\begin{abstract}
We have constructed an experimental apparatus to study the dynamics of the formation of air bubbles in a nozzle submerged in a water/glycerin solution inside a cylindrical tube. The time delay between successive bubbles was measured with a Iaser/photodiode system.

The results were interpreted by means of Chaos Theory, and it was observed bifurcations, chaotic behavior, and sudden changes in a periodic regime as a function of decreasing air flow rate issued through the nozzle.

Besides bubbling regime transitions, we also observed dynamical effects by applying a sound wave tuned to the fundamental frequency of the air column above the liquid of the bubble formation. As a function of the sound wave amplitude, we obtained limit cycle, flip bifurcation, chaotic behavior, and synchronization of the bubbling with the sound wave frequency.

Applying metrical as well as topological characterization to some chaotic attractors, we could establish relation with a Hênon-like dynamics. The Henon-like behavior is a particular case of the dissipative two-dimenstonal circle-map dynamics, and by varying the amplitude of a sound wave, we have observed features present in the circle map dynamics, such as transition from quasiperiodic to chaotic behavior, period doubling cascade, and Chaps:
\end{abstract}




\section{Resumo}

Construmos um aparato experimental para estudar a dinârnica da formaçăo de bolhas de ar em um bico submerso em uma soluçăo de água/glicerina dentro de am tubo cilindrico. O tempo entre bolhas sucessivas foi medido com um sistema laserfotodiodo.

Os resultados experimentais foram interpretados usando a Teoria do Caos. Foram observados bifurcaçőes, comportamento caótico e saltos no regine periódico, em função da

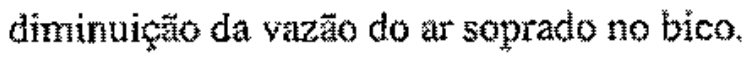

Além das transiçôes dos regimes do borbulhamento, nós também observamos efeitos na dinâmica do borbuhamento quando aplicamos uma onda sonora sintonizada na frequência fundamental da coluna đe ar acima do líquido onde as bolhas eram formatas. Em funçắo da amplitude da onda sonora, nos obtivemos ciclo limite, bifurcaçấo flip, comportamento caótico e sincronizaçä̌ do bortbulbamento com a frequêneia da onda sonora.

Utilizando caracterizaçöes métrica e topológica em alguns atratores, pudemos relacionă-los com uma dinâmica tipo-Henon cujo comportamento é um caso particular da dinâmica do mapa do círculo bidimensional. Observamos carncterísticas presentes nat dinâmica do mapa do círculo na formą̧ăo das bolhas variando a amplitude da onda sonora, tais como transição para o Caos via quase-periodicidade, cascata de duplicaçöes de periodo e Caos. 


\section{Índice}

1. Introduçäo 1

2. Aspectos teóricos 6

2.1. Fluxos e reconèncias 6

2.2. Mapas de retorno 7

2.3. O Mapa quadrático 8

2.4. Dimensōes 12

2.5. Expoentes de Lyapunov 12

2.6. O mapa de Hénon 14

2.7. Redução de nuido 16

2.8. Espectro de Fourier 16

2.9. O Mapa do Circulo 18

2.10. Transformação de ponto fixo 24

2.11. Plano Simbólico 25

3. Aparato experimental 27

3.1. O tubo borbulhador $\quad 27$

3.2. Sistema de aquisiçẫo 28

3.3. Medidor de vazẫo 29

3.4. Controlador de vazăo $\quad 30$

3.5. Vátvula solenóide proporcional 31

3.6. O bico borbuthatdor 32

3.7. O sistema pneumático 33

3.8. O sistema sonoro 33

3.9 .0 líquido

3.10. Imagens 38

3.11. O Experimento da Torneira Gotejante 40

4. Resultados e Análise 41 
4.1. A torneira gotejante 41

4.2. Dinâmica das bolhas

4.2.1. Formaçăo quasemestática 45

4.2.2. Formaçäo de bolhas com vazzão constante 46

4.2.3. Bifurcaçós 48

4.2.4. Vetas liquidas $\quad 52$

4.2.5. A estabilidade de dols fluidos sobrepostos 54

4.2.6. Instabilidade da superficie da bolha 56

4.2.7. Freqü̂ticia de borbulhamento 59

4.2.8. Duplicaçoses de periodo 62

4.2.9. Salto e coalescêneia 62

4.2.10. Antibolhas 69

4.3. A onda sonora e as bolhas 72

4.3.1. A formaçấo de bolhas perturbadas pelas ondas sonoras 73

4.3.2. Atratores do tipo Hénon 78

4.3.2. A. Caracterização métrica $\quad 80$

4.3.2.B. Caracterizaçăo topolögica 81

4.3.2.C. Plano Simbólico 83

4.4. Oseilaçöes brçadas $\quad 85$

4.5. Comportamento geral 87

4.6. Comparação entre atratores 92

4.7. Modulação do Parâmatro de Controle

5. Conclusôes 97

6. Referênciass 100

Apêndices

1. Simulations in a dripping faucet experiment

2. Chaotic behavior in bubble formation dynamics

3. Hénon-like attractor in air bubble formation 


\section{Introdução}

Com o advento da Teoria do Caos [Li Y Yorke, 1975], foi proposto que certos sistemas nấ-lineares com poucos graus de liberdade poderiam gerar uma tinâmica muito complexa, como comportamento periódico, quase-periódico e caótico, que dependeriam dos parâmetros de controle do sistema. Tais sistemas no estado caótico se tomam imprevisiveis enquanto o tempo avanç, devido a uma propriedade básica dos sistemas caóticos, conhecida como sentibilidade às condiços iniciats. Podemos ancontrar exemplos destes sistemas ao nosso redor, como nas orbitas planetárias, sístemas quänticos [Bertelsen et al., 1999], variaçöes climáticas [Lorenz, 1980], tomeiras pingando [Shaw, 1984; Martien at al, 1985, Sartorelli at al, 1994; Goncalves, 1996; Pinto et al., 20001, reaçōes químicas, abalos sísmicos circuitos elétricos [Jackson, 1995]. Podemos também encontrálos dentro de nós mesmos nos impulsos nervosos [Rapp et al., 1990], pulsaçōes cardiacas, reproduçăo celular e muitos outros ritmos biológicos [Jackson, 1995].

Seguindo uma sugestäo de Rösller [Rossler, 1977$]$ de que uma torneira pingando poderia set um exemplo do sistema de equaçöes diferenciais que exibe comportamento caótico, Shaw [Shaw, 1984] desenvolveu o experimento da lomeira gotejante que se mostrou mais complexo que o sistema proposto por Rösller. No Laboratóno de Fenômenos Năo-Lineares (LFNL) do Instituto de Fisica da Universidade de Săo Paulo foi construido um experimento semelhante ao experimento da torneira gotejante de Shaw [Sartorelli et al, 1994], e esta experiencia permitiu observar uma enorme variedade de comportamentos dinämicos, tais como Crises [Grebogi et al, 1982], intermitências, duplicaçoes de período ótbitas homoclínicas. Para explicar tais comportamentos, foram desenvolvidas algumas técnicas para análise das sêries temporais [Gonçalves, 1996; Pinto, 1999].

Desta forma o conhecimento adquirido com o experimento da torneira gotejante nos permitiu propor e desenvolver um experimento, para estudar a dinämica da formaçäo de bolhas em um liquido, onde medimos o tempo da formaçăo de bolhas de ar sopradas em uma mistura de água e glicerina, utilizando as técnicas semelhantes às atilizadas no experimento da torneira gotejante. Este experimento, que chamamos de nubo borbulhador [Tufatle Sartorelli, 2000a, Apendice 2; Tufatle e Sartorelli, 2000b, Apêndice 3]. $\dot{a}$ de interesse tanto no estudo dos sistemas dinämicos, quanto nas aplicaçós em fluxos com duas fases [Ruzicka et al, 2000]. Além dos efeitos da vazăo 
do ar na formação de bolhas, estudamos os efeitos de uma onda sonora nos intervalos de tempo da formaçăo de bolhas.

A geraçăo de bolhas é importante em uma vasta gama de fenômenos onde temos a dispersăo de um gás num liquido, desde ocasiöes comiqueiras como no preparo de uma maionese, até em Engenharia Química nos chamados equipamentos de mistura de fases. Para citar apenas algumas situaçöes, temos a criaçăo te bolhas em colunas de borbuhamento, vasos de fermentação, equipamentos de limpeza extração, cavitação acústica em bombas hidráulicas e válvulas de controle, reatores, caldeiras e ruído em transmissües de ondas sonoras no oceano [Clift et $a{ }_{*}, 1978$ ].

Basicamente, podemos ter quatro formas de formaçăo de bolhas em líquidos:

a) Soprando um gás através de um liquido;

b) Quando a alta velocitade do liquido diminui a pressão de forma drástica, (abaixo da pressão de vapor do líquido), uma cavidade preenchida com vapor do liquido se forma, ocorrendo o processo que é conhecido como cavitação;

c) Quando um aquecimento local faz com que a pressäto de vapor do liquido ultrapasse a pressão local do liquido, uma cavidade de vapor se forma por ebuliçäo;

d) A diminưçã̃o brusca da pressão no líquido faz com que gases dissolvidos formem bolhas no seu interior, que ocorre quando abrimos uma garrafa de rafrigerante, ou em situaçōes mais letais, como as bolhas que causatn embolia em mergulhadores que sofrem descompressżo.

Neste trabalho focalizaremos o primeiro caso da formaçă de bolhas principalmente em liquidos viscosos, usando uma abordagem da Teoria do Caos.

O estudo da formação de bolhas interdisciplinar devido às aplicaçöes encontradas em Engenharia, Física, Química, Geofisica, Matemática Aplicada e Medicina Clift e colaboradores [Clift et al, 1978] publicaram o live intitulado Bubble, Drops, and Particles, no qual eles procuram dar uma revisão dos trabalhos envolvendo o movimento de particulas em fluidos, e criação movimento de bothas a gotas em futudos. Esta é uma referência muito comum nos trabahos envolvendo formação de bolhas, Nesta obra sobre bolhas, gotas e particulas, podemos ver que os principais obstáculos, no estudo dos fenômenos que envolvem a interą̧ão do estado líquido com o estado gasoso, são a compressibilidade dos gases e a não-linearidade intrínseca dos fluidos, que levam muitas vezes a modelos empiricos e com validade de aplicação limitada. A idéia central quando se aplica a Hidrodinamica tradicional é a de se caracterizar diferentes regimes de gotejamento ou borbulhamento, como transiçoes de 
inslabinctades [Chandrasekhar, 1981]. Tais transiçôes ocartem com o aumento de um parämetro caracteristíco do sistema, como por exemplo o nimero de Reynolds. Utilizando principios variacionais procura-se explicar como ocorre um tipo particular de mudança de regime, como a transiçă do regime laminar para a turbuléncia.

A aplicacăo da Teoria do Caos a estes sistemas nos dá novas perspectivas de análise a amenta nossa intuiçăo com relaçà̃o aos fenômenos complexos observados. $\mathrm{A}$ formaçäo de bolhas em líquitos viscosos e sua relaçăo com comportamento caótico, já foram relatados em trabalhos de Triton [Tritton ef ai, 1993] e Mittoni [Mittoni ef al, 1995]. No primeiro trabalho, wm medidor de fluxo anemométrico, que consiste de um resistor sensivel ao fluxo de um fuido que passa sobre ele, foi colocado proximo do bico onde as bolhas eram formadas, informava sobre a formacöo das mesmas atraves da variação da tensão sobre o resistor. Com ente sinal de tensẫo, Tritton construiu seções de Poincare, e afraves delas ele observou duplicação de periodo no terupo entre bolhas, e tambén obteve algumas series de sinnais com padrões nâporiódicos. Tritton classificou os padröes de comportamento mais simples como Caos Fraco, e os de comportamento mais complexo como Caos Forte. $O$ trabalho é inovador no sentido de que é a primeira vez que técnicas deste tipo säo utilizadas para o estudo da formação de bolhas. Mas as criticas com relą̧ão a este trabalho levam em conta que o metodo de mediçẫo é invasivo, isto é, a formaçấo das bolhas ẻ afetada pelo medidor, pois, a caracterizaça do comportamento caótico foi feita de modo subjetivo. No segundo trabalho, Mittoni e colaboradores [Mitton et al., 1995] utilizaram como elemento sensor da formaçăo de bolhas num tubo borbulhador um transdutor de pressäo, obteve séries de sinais caóticos através de técnicas não-invasivas e aplicou a caracterizą̧ữo metrica sobre elas, obtendo expoentes de Lyammow positivos (algoritmo de Wolf [Wolf et al., 1985]).

Como exemplo do interesse da Engenharia Quimica pela formaçäo de bolhas temos o grupo da Universidade do Tenessee [Finney, 2000], nos Estados Unidos, denominato $C R G$, abreviatura de Chaos Research Gromp que estuda deste 1992, entre outros sistemas, a dinämica de uma coluna de bolhas ascendente formada por um bico. Segundo eles, o principal foco da pesquisa é explorar a rota de duplicacazo de período até o Caos, a natureza espaço-temporal das interaçōes entre as bolhas, alem de focalizar as aplicaçöes de técnicas de controle de Caos.

Além deste grupo, foram encontrados outros trabalhos envolvendo engenheiros quimicos estudando formaça de bolhas através análise de séries temporais. $\mathrm{Li}$ e 
colaboradores [Li ef $a l$, , 1997], estudaram a coalescência entre bollhas através do espectro de potências dos dados obtidos experimentalmente. Ruzicka e colaboradores [Ruzicka et al., 1997], focalizaram sua pesquisa na transição do estado de borbulhamento para o jateamento do ar em liquidos. Eles encontraram um movimento complexo das bolhas envolvendo disparos da vazäo do ar mudando do regime de borbuhamento para o jateamento do ar no líquido. Eles classificaram os disparos utilizando a terminologia đa Teoria do Caos como uma intermitência do tipo III.

Os métodos de análise das séries temporais sẫo baseados na téchica de reconstruçuto do espaço de fases, a partir de uma coleção de dados conhecida como série temporal e podemos classificá los como métodos métricos e topológricos. Basicanente temos uma análise das propriedades métricas desta reconstruçăo devido aos estudos desenvolvidos por Packard [Packard et al, 1980], Mañe [Mañe, 1981] e Takens [Takens, 1981]. Alám disso temos a caracterizaçă丶 atraves de expoentes ale Lyzptmov, com um algoritmo rmito popular desenvolvido por Wolf [Woif et al, 1985] para o cálculo destes expoentes para estas séries. Além do estudo da estabilidade das séries temporais, também é associado a elas o conceito de dimensão. Femat e colaboradores [Femat et al., 1998] acompanharam a evolução de séries temporais provenientes de sensores capacitivos en um experimento de borbulhamento em uma coluna vertical, eles obtiveram os expoentes de Lyapunov e fizeram análises espectrais dos dados referentes à bolhas que se elevavam na coluna. A caracterizacão topologica de dados experimentais de sistemas nẩo-lineares usando dinamica simbollica foi feita por Gonçalves e colaboradores para o experimento da torneira gotejante lGonçalves et al., 1998]. Pinto [Pinto et at, 2000] aplicou o estudo das variedates invariantes para caracterização da Catastrofe do Cék Azul, também no experimento da torneira gotejante, assim como algoritmos de localizaçăo de Orbitcs Periódicas Instáveis (OPI) de So [So el al., 1996$]$

Neste trabalho observamos as condiçôes que levam aos diferentes regimes de borbulhamento e classificamos estes regimes de acordo com as teorias dos sistemas dinâmicos, assim como registramos algumas observaçסes intrigantes na evolução destes sistemas, como por exemplo o aparecimento de antibolhas [Stong, 1986], que são basicamente cascas esféricas de ar aprisionadas dentro jo liquido. Colocando oleo junto

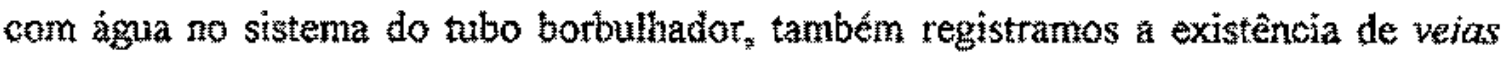
liquidas, que são colunas d’água sustentadas por bolhas dentro do óleo. 
Veremos também o tubo borbulhador como um novo exemplo da classe dos sistemas caóticos, devido à sua relaçã̃o com o moqa bidimensional do circulo [Argyris ef al., 1994]. Muitos sistemas fisicos caracterizados por pelo menos duas frequêencias exibem um comportamento chamado de sincronizaçzô, ou tambetm chamado de trowamento de frequencias. Outro comportamento muito freqüente na associacaão de osciladores e comportamento quase-periodico, que pode ser representado pela associaçẩo de dois osciladores funcionando com a relação entre as frequências dada por um número irracional. Todos esses compotamentos aparecem naturalmente no experimento do tubo borbulhador $e$, além disso, este experimento nos permite explorar a interação entre os sistemas nâo-lineares, e como ocorrem as transiçöes entre os regimes periỏdico e cábico na emissão de bolhas sujeitas à uma onda sonora. 


\section{Aspectos teóricos}

Séries temporais näo-lineares podem ser analisadas com métodos métricos a mêtodos topológicos. $\mathrm{O}$ mêtodo mêtrico é muito proximo das noçoes intuitivas de distẳncia, ărea, volume e dimensāo que temos. Por este método podemos dimensionar e comparar objetos, num determinado espaço. Também podemos analisar a estabilidade de um sistema com base no valor de mểilas temporais da convergência ou civergencia da vizinhança de um ponto destes objetos, chamados de atratores.

O método de análise e caracterizaçâno topológica é um dos meíos mats importuntes de investigar problemas näo lineares. Este método, considera a sêrie temporal nâ̆o como uma funço expltcita do tempo, mas como curvas no espaço de fasces que säo soluçöes do sistema dinâmico. Descobertas consicieraveis nos aspectos qualitativos e algumas informaçóes quantitativas, podem ser obtidas através dos atratores reconstrutidos.

Os métodos empregados neste trabalho foram obtidos da literatura, ou desenvolvidos no LFNL. A finalidade da utilizaçāo de tais metodos e testar e justificar algumas hipóteses feitas para os dados obtidos com twbo borbulhador e para a torneira gotejante. Para avitar redundźncia da derivaçăo dos métodos amplamente encontrados em livos/texto e artizos, as derivaçöes dos métodos seräo simplificadas. Para matores informaçöes dos algoritmos empregados poderáo ser consultados os trabalhos de Hegger, Kantz e Schreiber [Hegger et al, 1999], Elner [Ellner et al, 1992], So [So at al., 1996] e Gonçalves [Gonçalves et al., 1998].

\subsection{Fluxos e recorrências}

Os sistemas dinâmicos deterministicos são descritos pela evolução temporal de um subconjunto A em um espaço euclidiano d-dimensional. Eles podem ser expressos, por exemplo, por equações diferenciatis ordinárias [Sotomayor, 1979]:

$$
\dot{x}=f(t) \text {, }
$$

ou com um tempo discreto $t=n \Delta t$, por mapas [Collet Eckmann, 1980]:

$$
x_{n+1}=f\left(x_{n}\right) \text {. }
$$

Uma sétie temporal ế uma sequiencia de observaçōes igualmente espaçadas no tempo. Uma serrie de eventos ê uma secü̈encia de intervalos de tempos, entre os quais ocorreu um determinado evento. 


\subsection{Mapas de retorno}

Uma série de eventos da forma $\{x\}=\left(x_{1}, x_{2}, x_{3}, \ldots, x_{n}\right)$, nä̌o é exătamente o espaço de fases do sistema dinâmico, sendo necessário empregar alguma técnica de reconstrução para revelar a estrutura nulti-dimensional desta sétie. Umm dos mais importantes tipos de técnica de reconstruçẳo do espaço de fases é o mapa de retomo, ou tambén chamado de coordenadas de atraso. Vetores no espaço de imerzão são criados a partir de atrasos na serie. $O$ conjunto das duplas $\left(x_{j}, x_{j+1}\right)$ forma o mapa de primeiro retorno, e o conjunto das duplas $\left(x_{j}, x_{1}+2\right)$ forma o mapa de segundo retorno e assim por diante $\mathrm{O}$ número de elementos destes vetores dá a dimensä̌ de espaço de imersẫo. $\mathrm{O}$ teorema de imersáo de Takens [Takens, 1981], estabelece que se uma medida dinamicamente importante para o sistema, ela contém toda informaçăo contida neste șistema dinâmico.

Em modelos matemáticos de sistemas dinâmicos, a evoluçăo do processo é visualizada no espaco de fases, cuja dimenșẫo é dada pelo número de variáveis independentes. Em experimentos, o espaco de fases é usualmente desconhecido a principio e frequîtentemente uma única variável escalar do sistema pode ser medida. 0 método mais comum de reconstruçắo do espaço de fase, a partir de uma série temporal, foi proposto por Packard, Crutchield, Farmer e Shaw [Packard at al, 1980], para se analisar os dados do experimento da torneira gotejante. A dinămica de uma série temporal $\{x\}$ em sistemas dissipativos é completamente descrita pelo atrator em um espaço de fases d-dimensional, $\mathbb{R}^{d}$, com $\mathbf{D}$ sendo a dimensão do atrator. Genericamente, qualquer atrator é completamente envolvido no espaço de fases por sua propria bacia de atraçäo, consequentemente, todos os movimentos transientes inicializados em uma pequena vizinhança do atrator, movem-se assintoticamente na direcäo do atrator. Os atratorés podem ser periódicos, quase-periódicos e caóticos.

Neste trabalho os dados experimentais obtidos são apresentados em mapas de primeiro retarno bidimensionais, cujos elementos das duplas $\left(T_{n}, T_{n+1}\right)$ săo intervalos de tempo entre duas bolhas consecutivas. Tambẻm serăto apresentados mapas de primeiro retorno tridimensionais, através das tripla $\left(\mathrm{T}_{\mathrm{n}}, \mathrm{T}_{\mathrm{n}+1}, \mathrm{~T}_{\mathrm{n}+2}\right)$. Outras representaçöes necessárias serä̃o especificadas no local onde estas forem utïlizadas. 


\subsection{O Mapa quadrático}

As principais características dos sistemas dinâmicos são observados e analisados em mapas unidimensionais, como no mapa quadrático do tipo:

$$
f\left(x_{\text {势 }}\right)=x_{x}^{2}-a,
$$

onde $x_{n}$ é a tariável iterata do mapa e ca o parâmetro de controle. O diagrama de bifurcaçōes deste mapa pode ser visto na Fig. 2.l.

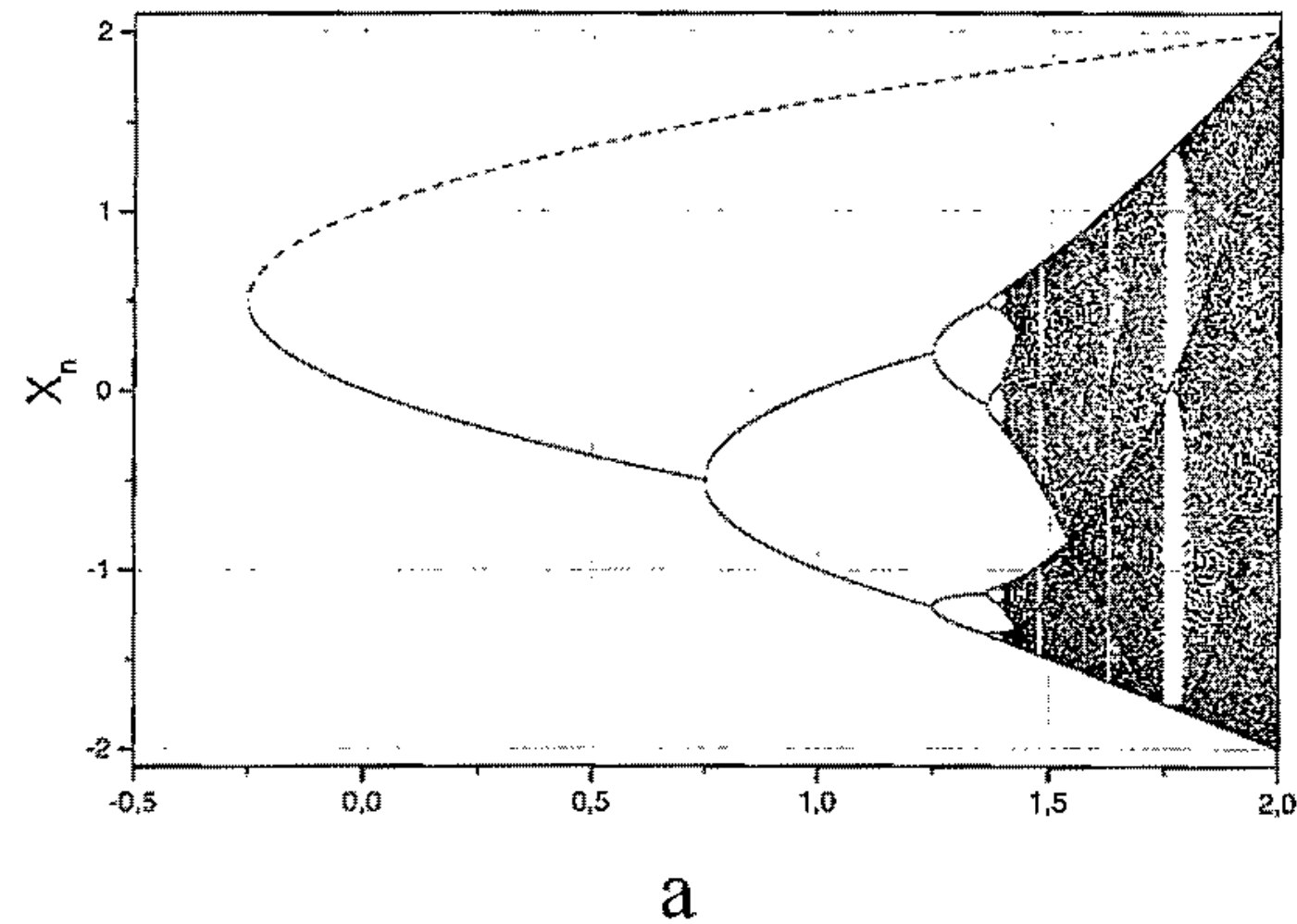

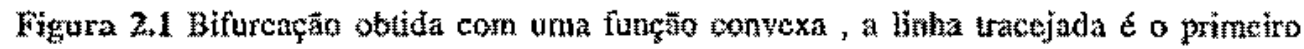

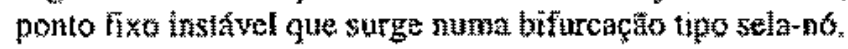

Neste diagrama vemos os valores possiveis de x para uma variaçuto do parâmetro de controle $a$ entre $-0,25$ e 2,0 . Os valores do mapa para $a$ entre $-0,25$ e 1,25 podem ser calcuiados analiticamente, impondo a condiçăo de que o valor da variável iterada anterior seja igual ao valor da variável iterada seguinte:

$$
x=x^{2}-a
$$

que nos fornece tois pontos fixos, $x_{f}$;

$$
\begin{aligned}
& x_{11}=\left[1+(1+4 a)^{1 / 2}\right] / 2 \\
& x_{12}=\left[1-(1+4 a)^{3 / 2}\right] / 2
\end{aligned}
$$


A estabilidade dos pontos fixos de qualquer mapa unidimensional é obtida com as condiçôes:

$$
\begin{aligned}
& \left|f^{\prime}\left(x_{f}\right)\right|<1 \Rightarrow x_{f} \text { é um ponto fixo estavel; } \\
& \left|f^{\prime}\left(x_{f}\right)\right|>1 \Rightarrow x_{f} \text { é um ponto fixo instável. }
\end{aligned}
$$

Deste modo, para valores de $a$ acima de $-0,25$ obtemos $x_{f 2}$ instável, enquanto $x_{f 2}$ e estável atè o parâmetro a chegar a 0,75. Para a igual a $-0,25$ no mapa da equaçăo (2.3) experimenta uma bifucação selamó. A linha tracejada na Fig. (2.1) è a trajetoria instável $x_{f}$ e o ramo estavel $x_{f}$ están simetricamente abaixo até $o$ valor de $a$ igual a 0,75 .

Quando o parâmetro de controle $a$ atinge 0,75 , as trajetónias do mapa sofrem uma mudança de comportamento. Nesse caso, a partir deste valor do parâmetro dè controle a orbita oscila entre dois valores de $x$ *

$$
\begin{aligned}
& x_{53}=f\left(x_{54}\right), \\
& x_{14}=f\left(x_{53}\right)
\end{aligned}
$$
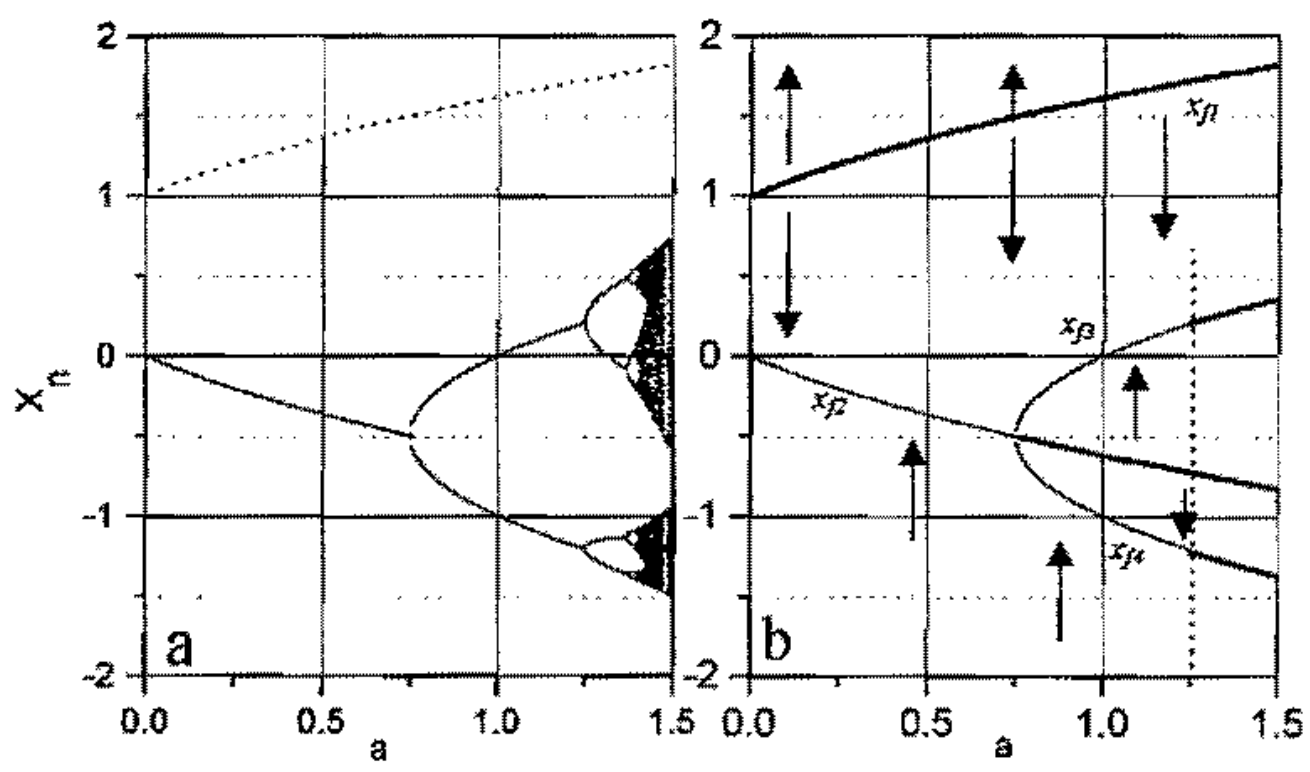

Figura 2.2 (a) Detalhe do disgrama de bifurcaxồ do mapa quadrático, a linha tracejada representa o ponto

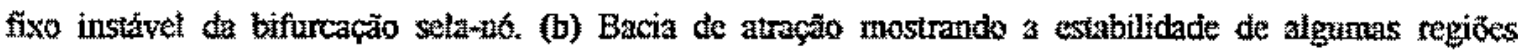
mostradas ent (a), gration as linhas vermelhas rcpresentam os ponios fixos instaveis, enquanto que as linhas pretas os pontos fixos estáveis. Podemos caniparar a troca de estabilidade de $x_{2}$ mostrado em (b) para a $=0,7500$ e diagrana mostrado em (a), assim camo o mesmo tipo de troca para $x_{f a}$ e $x_{4}$ para a $=1,25$ (linha pontillada). 
Para compreendermos o que ocorre, agora utilizando os criterios de estabilidade (2.6) e para calcular os novos pontos fixos, temos que recorrer a uma composiça do mapa com ele mesmo, da seguinte forma:

$$
g(x)=f(f(x))=x^{4}-2 a x^{2}+a^{2}-a
$$

que possui quatro pontos fixos, sendo dois deles os pontos fixos das equaçôes $2.7($ a) (b), agoră ambos instấveis, e dois outros estáveis dados por:

$$
\begin{aligned}
& x_{f 3}=\left[1+\left[1+4(a-1)^{1 / 2}\right\} / 2,\right. \\
& x_{f 4}=\left\{1-\left[1+4(a-1)^{1 / 2}\right) / 2 .\right.
\end{aligned}
$$

Na Fig. 2.2(a), vemos o aluagrama de bifurcaçöes no periodo 2 e no gráfico ao lato (b), representamos as b́rbitas instaveis (ramos vermethos), e os ramos estẩveis (ramos pretos). As setas indicam a atraçăo ou a repulsāo tos pontos fixos. Na Fig. 2.2(a) quando $a=1,25$, podemos notar que na sequiencia de bifurcaçbes aparece o período 4. Quando estes quatro pontos fixos se tornam instaveis, um periodo 8 aparece, e 0 processo de duplicação de perfodo se repete indefinidamente para faixas de as cada vez mais estreitas, até chegar no valor limite $a_{m}=1,40113 \ldots$, que pode ser visto na Fig. 2.3 . A partir teste valor to parametro de controle, os pontos no mapa visitam bandas periodicas, que se alargam e se sobrepôm aos pares, diminuindo o número de bandas num processo chamado de bifurcą̧äo reversa. Nesta sobreposição, os valores de $x$ evoluem periodicamente com relação às bandas, mas de modo errático dentro de cada uma delas, e tal movimento ê chamado de caótico.

No diagrama da Fig. 2.3, após o encontro las duas bandas caóticas, temos a ocorrêtncia de janelas periódicas de períodos ímpares, com uma janela mator de perído $3(a \equiv 1,75)$, e outra menor de periodo 5 , relacionadas com bifurcaçöes tangentes. A existência do periodo 3 o principal argumento para se utilizar um teorema que estubelece a existência de todos os outros periodos maiores. O Teorema de Sharkovskif [Jackson, 1995] nos dâ um esquema năo usual de ordenaçăo para os numeros naturais tal que, para cada número natural $n$, a existência de um ponto de periodo $n$ implica na existência de órbitas periödicas de todos os periodos maiores na ordenação do que n. Pelo teorema de Sharkovskii, a existencia de uma órbita de periodo 3 num mapa unidimensional nāo-monotônico com apenas um máximo, implica na existencia de todos os periodos. 
O teorema de Sharkovskif explicitamente é [Iackson, 1995]:

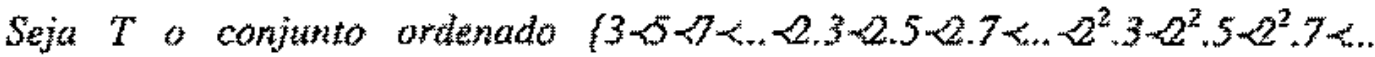
$<8<2<1)$ Seia f: uma aplicação suave do intervalo unitäro nele mesmo, tal que

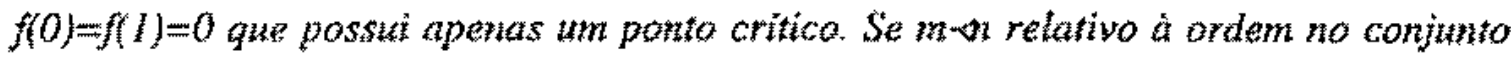
$T$, ef fem a menor óbita de periodo $m$, entäo f tem uma órbita de periodo $n$.

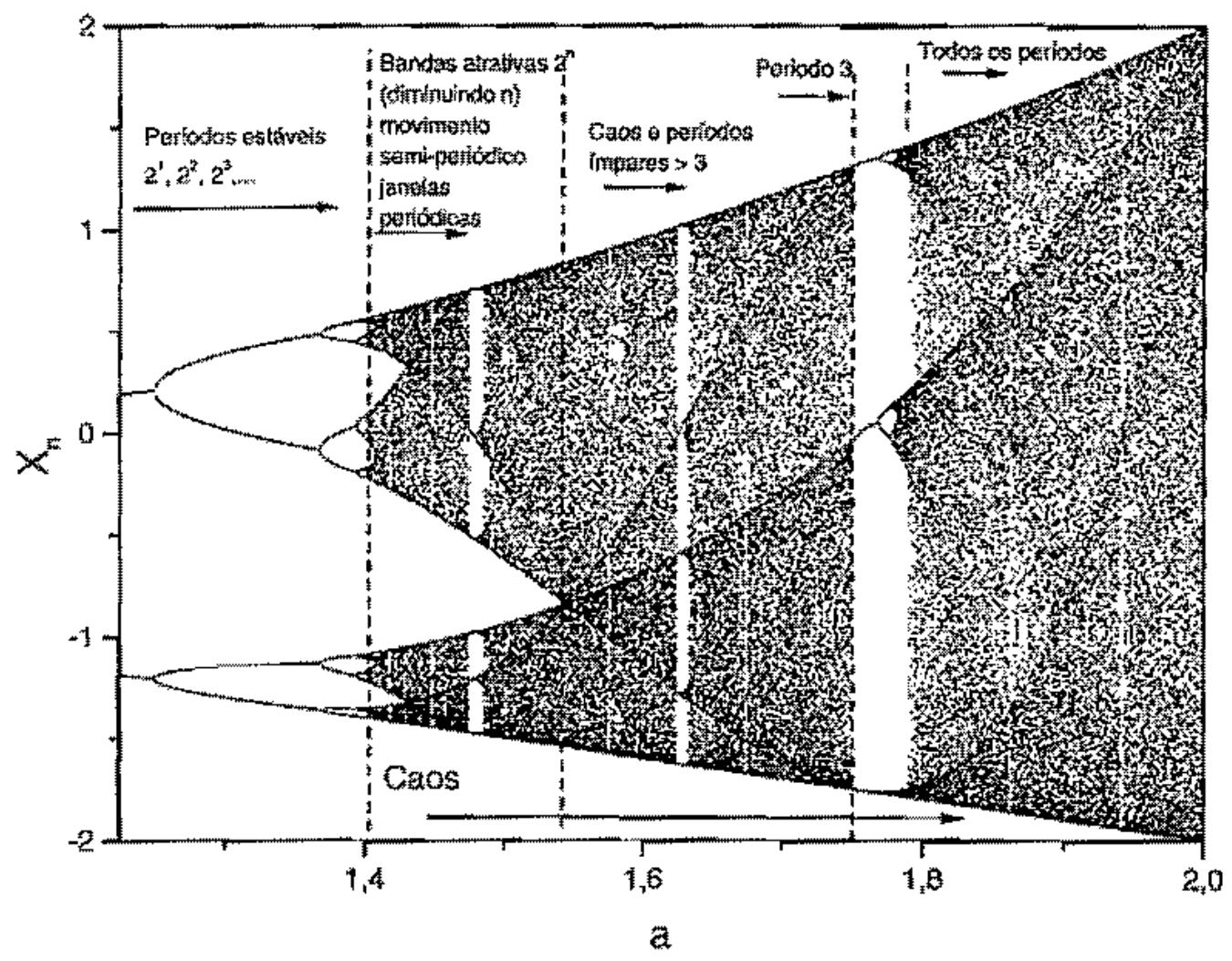

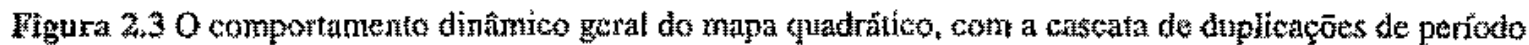
$(a<1,4)$. Para a $>1,4011 \ldots$, ocorre Caos com a dimintição das bandús atrativas, Apos a janela de pertodo 3 temos todos os periodos, como propüe o teorema de Sharkovskij. 


\subsection{Dimensões}

Un aspecto básico de um atrator obtido a partir te um sistema dinâmico é a sua dimensão, pois o comportamento do sistema é caracterizado pelo atrator. Após um transiente, alguns tipos de movimento desaparecem devido ao amortecimento, e o estado do sistema se aproxima de um atrator no qual o numero de variaveis independentes, gue determinam a dimensăo do atrator, e reduzido consideravelmente. Os atratores podem ter a dimensão de um ponto, linha ou plano, ou podem ser extremamente complicados, freqüentemente possuem estrutura fractal [Alligood et al., 1997]. Podemos medir essa fractalitade através de dimensbes generalizadas.

Associamos a dimensăo de um objeto com o número de vetores ortonormais que podem ser sobrepostos ao objeto. Embora seja muito importante, esta associaçä̃o de vetores nos restringe sempre a dimensões inteiras, mas existem outros conceitos de dimensão, entre eles a dimensāo de Hautsduff (bf) [Alligood et al., 1997], que ể baseada natidéia de um comprimento caracteristico $R$ em um conjunto de $N$ elementos.

$$
D_{i}=\frac{\log N}{\log R} \Leftrightarrow N-R^{D_{l}}
$$

A dimensão de Infomaçăo $\left(D_{i}\right)$ [Alligood et at, 1997] leva em conta as freqühencias de visitaçăo relativas e por isto é mais interessante para sistemas fisicos. Mutuas outras definições de dimensão existem, mas para os objetivos deste trabalho, utilizaremos apenas as dimensöes citadas anteriormente e dimensäo de Kaplan-Yorke $\left(D_{K y}\right),[$ Argyris extal, 1994]

Alén disso, a determinaçâto do valor de umátimensão, a partir dos dados experimentais de um processo dinamico, indica qual é a dimensionalidade do espaço de fases do sistema dinâmico matemático que deve ser usatia para modelar o sistema.

\subsection{Expoentes de Lyapunov}

Os sistemas caóticos exibem sensibilidade as condiçôs iniciaje. Esta afirmação tem sido utilizada para resumir uma das prineipais propriedades dos sistemas cáticos, que pequenas diferenças nas condiçōes iniciais, são magnificadas devido à dinâmica do 
sistema, de tal modo que em um tempo finito o sistema percorre estados totalmente diferentes. A noçato de sensibilidade às condiçðes nietais é feita de modo mais acurado através do expoente de Lyapunov E[Alligood et al., 1997]. Normalmente sistemas contendo pelo menos um expoente de Lyapunov positivo săo considerados caóticos. Isto significa que trajetórias partindo de dois pontos muito próximos, nâo importando quăo pequena seja a distância entre elas, ixão evoluir de modo diferente e se afastarão exponencialmente uma da outra com o tempo.

Podemos obter o expoente de Lyapunov máximo [Wolf et al., 1985] sem a construçü explicita de um modelo para a strie temporal. Uma caracterizaçãa confiável com expoente positivo exige que sejam garantidas a independência dos parâmetros de imersẵo e uma le de crescimento exponencial.

Existe também o cálculo do espectro de expoentes de Lyapunov [Hegger e Kantz, 1999], onde o ingrediente essencial a astimativa de Jacobianas locais, ou seja, uma dinâmica linearizada que regula o crescimento das perturbaçôes infinitestmais.

Para uma melhor compreensâto dos sistemas dinâmicos, uma conciliação entre características relativas às médian temporais e espaciais dos atratores foi feita atraves da teoria ergódica [Argyris et al. 1994]. Como o expoente de Lyapunov caracteriza a dinârnica do atrator, através de médias temporais da divergêneia ou convergência de uma vizinhança com relação a um ponto da orbita, o cáleulo dos expoentes de Lyapunov permite certas comparaçôes, como a conjectuma de Kaplan-Yonke [Argyris ot al. 1994] que estabelece que a dimensăo de Informaçäo deve coincidir com aimensão de Kaplan-Yorke, DKy, dada por:

$$
D_{k \gamma}=k+\frac{\sum_{i=1}^{k} \varepsilon_{i}}{\left|\varepsilon_{i+1}\right|}
$$

onde $k$ é um inteiro mâximo, tal que a soma dos $k$ expoentes máximos seja năo-regativa e $\varepsilon_{i}$ é o i- esimo expoente de Lyapunov. Tal conjectura foi verificada para uma boa parte dos sistemas dinarnicos dissipativos de baiza dimensäo [Hegger Kantz, 1999 . 


\subsection{0 mapa de Hếnon}

O mapa de Hếnon, é um mapa bidimensional do tipo:

$$
\begin{aligned}
& x_{n+1}=1-a x_{n}^{2}+y_{n}, \\
& y_{n+1}=b x_{n}
\end{aligned}
$$

Os pontos fixos do mapa sä́ dois e podem ser obtidos por:

$$
x^{*}=\left[(b-1) \pm \sqrt{(1-b)^{2}+4 a}\right] / 2 a, \quad y^{*}=b x^{*}
$$

e para cada um desses pontos fixos temos dois autovalores associados ${ }_{h}$.

$$
\lambda_{t}=-a x^{*} \pm \sqrt{\left(a x^{3}\right)^{2}+b}
$$

desta forma, com esses dois autovalores, podemos estudar a estabilidade de cada ponto

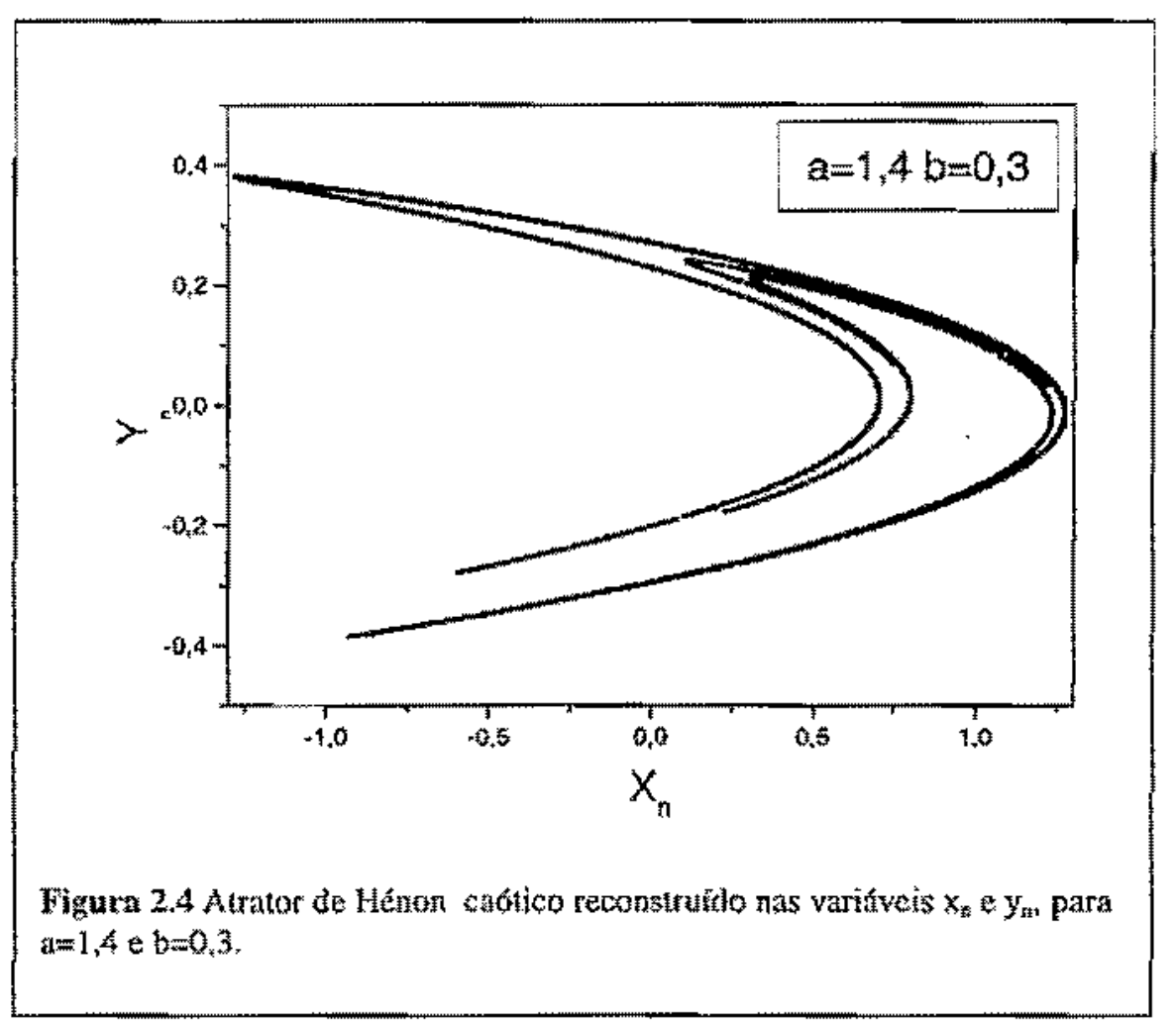
fixo, como foi feito para os mapas unidimensionais. Um atrator de Hénon cáotico bem conhecido mostrado na Fig. 2.4. 0 coeficiente $a$ esta relacionado com o estiramento do mapa, e coeficiente $b$ esta relacionado com a contração ไla ắrea do mapa de Hénon e esta coeficiente é

determinante da matriz jacobiana $J$ do atrator de Hénon com o sinal negativo:

$$
\operatorname{det} J=\left|\begin{array}{cc}
-2 a x & 1 \\
b & d
\end{array}\right|=-b
$$


Na Fig. 2.5 vemos as duas variâveís do mapa nos graficos de $x$ ws. $a$ e $y$ y. $a$, onde podemos notar a contraça da variável $y$ por $b$ na Fig. $2.5(b)$ en relaçầ aparece na Fig. 2.5(a), onde temos tambêm os pontos fixos $x_{1,2}$ da equação $(2.13)$.

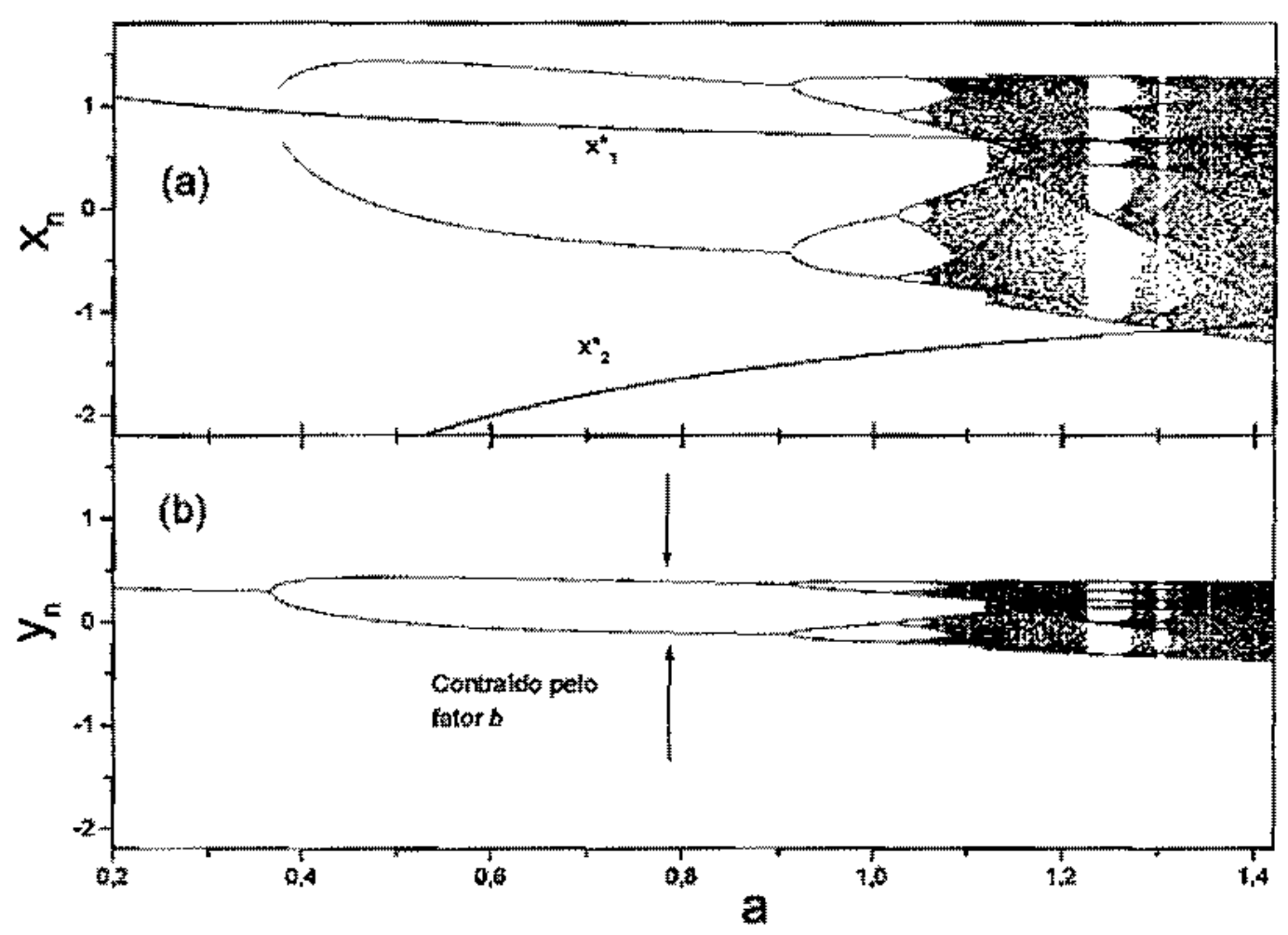

Figura 2.5 Diagramas de bifurcaç̃

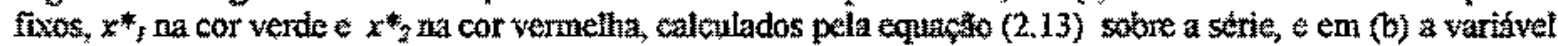
$y$ contraíta pelo fator $b$.

Para o caso do diagrama de bifurcaçôs da Fig. 2.5 o determinante de $J$ e constante e negativo, det $I=-0,3$, para todos os valores de $a$.

Os expoentes de Lyapunov do mapa te Hénon, $\varepsilon_{1}$ e $\varepsilon_{\text {, }}$ estão relacionados com a matriz facobiana pela relaçäo de contração [Argyris at al., 1994]:

$$
\varepsilon_{1}+\varepsilon_{2}=\ln |\operatorname{det}(n)|=\ln 0,3 \approx-1,2 \text {. }
$$

Esta relaçāo representa as propriedade de estiramento, $\varepsilon_{i}$, e dobra, $\varepsilon_{2}$, atuando uniformemente, $|\operatorname{det}(J)|=0,3$, dentro do espaco de fases para estabelecer o atrator. Para $a=1,4$ e $b=0,3$, temos $\varepsilon_{1} \approx 0,42$ e $\varepsilon_{1} \approx-1,62$. O valor $z_{1}>0$ nos dả um atrator cático. 


\subsection{Redução de ruído}

A tiltragem de sinais obtidos a partir de sistemas näo-lineares exige o uso de métodos especiais [Hegger e Kantz; 1999], já que os filtros lineares podem interagir desfavoravelmente com a estrutura näo-linear. Sinais irregulares de fontes näo-lineares exibern bandas de espectro realmente largas e näo existe justificativa para identificar qualquer componente no espectro de frequiências como ruído. Entretanto, existem certas dependências genêricas entre as medidas $[x]$ que criarẫo vetores $\{x\}$ para preencher $o$ espaço de imersäo ti-dimensional de un modo năo homogêneo. Métodos de filtragem linear procturam identificar as direçōes principais da distribuiçăo no espaço de fases e fazer projeçōes sobre elas. A reduçăo de ruído năo-linear leva em conta que sinais nãolineares formaräo estruturas curvas no mapa de retomo. A principal suposição do algoritmo utilizado e que ele deve ser aplicado para sistemas de baixa dimensảo (D-3).

\subsection{Espectro de Fourier}

Outro critétio para se analisar sêties temporais é atravếs da decomposiçẫo da sếrie numa integral de Fourier [Argytis et al., 1994]. Consiterando um sinal f(t), a expressäo pode ser expressa na forma:

$$
f(t)=\frac{1}{2 \pi} \int_{-\infty}^{+\infty} f(\omega) e^{i \omega t} d \omega,
$$

onde

$$
F(\omega)=\int_{-\infty}^{+\infty} f(t) e^{-i t a t} d t
$$

é definida como a transfomada de Fourter do sinal Itt.

O espactro de portucha $P(\omega)$ do sinal è dado a partir de $f(\omega)$.

$$
P(\omega)=|F(\omega)|^{2}=F(\omega) F^{d}(\omega)
$$

com $F$ ( $(\omega)$ sendo o complexo conjugado de $F(\omega)$. 

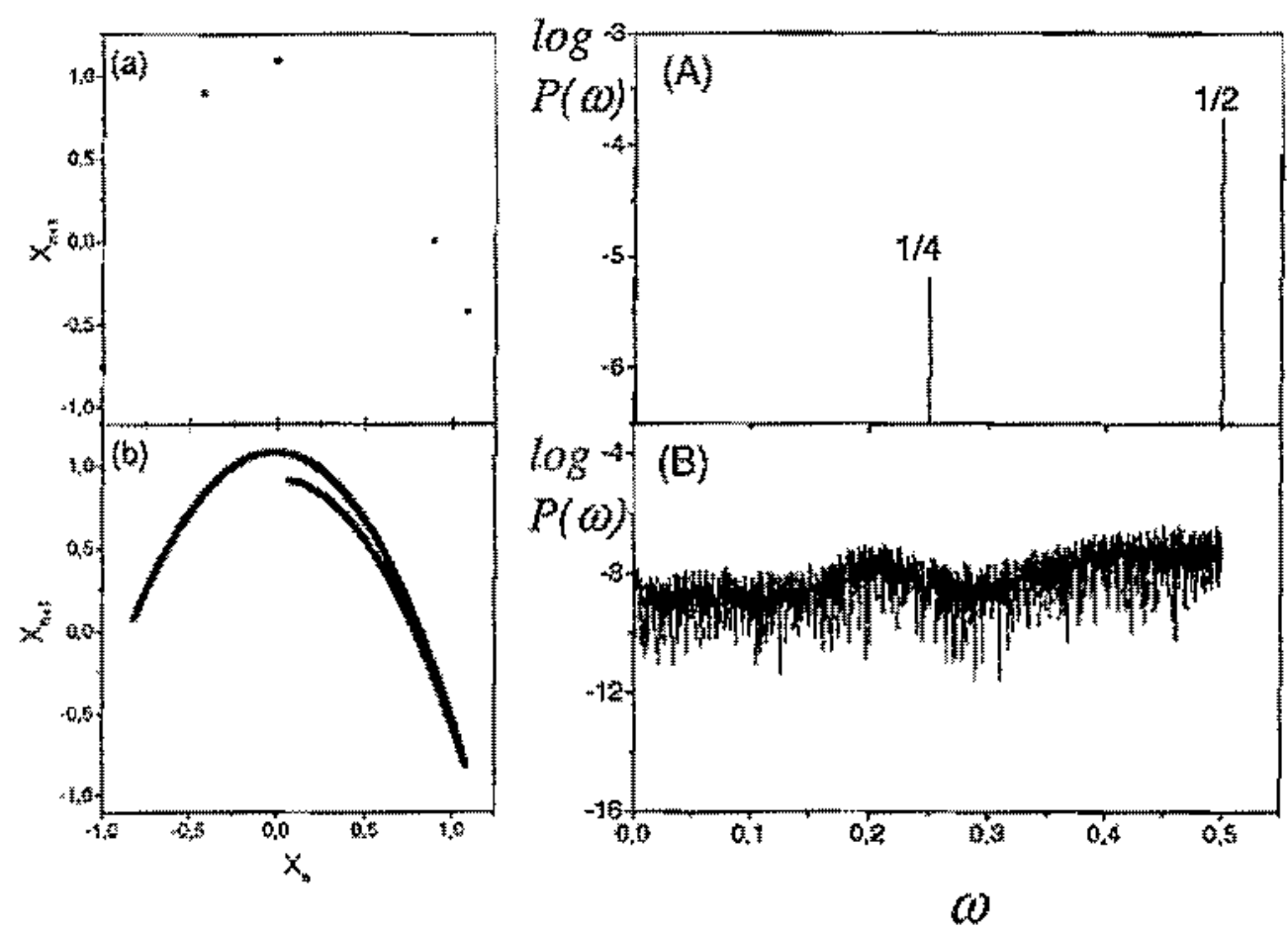

Figura 2.6 - (a) Peribdo 4 do mapa de Henon e em $(A)$ o seu espectro de potèncias, (b) atrator de

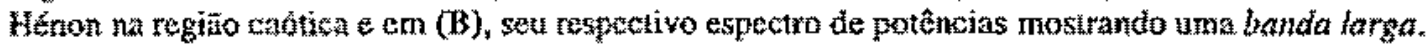

Ná Fig. 2.6 temos dois atratores obtidos a partir do mapa de Hénon, em (a) o comportarnento de período 4 , e em (A) o espectro que nos mostra o comportamento periódico com os dois picos indicando uma duplicação de período característica do atrator de Hénon. Para os parâmetros $a=1,55$ e $b=0,1$, temos um atrator de Hénon no regime cabtico em (b), e seu espectro de banda larga em (B).

Frequientemente atratores cáticos apresentam banda larga, por isso este é um método muito comum na identificação do comportamento caótico. Alếm disso, a análise da evolução dos sistemas dinâmicos atravếs de seus espectros permite definir a rota [Argyris et al., 1994] que leva o sistema ao Caos, pois, a evoluçăo das duplicações de período vista no mapa quadrático, e que tambẻm acontece no mapa de Hénon, é apenas uma dessas rotas. Na próxima seção veremos um outro mapa que nos mostra esta e outras rotas para o Caos. 


\subsection{O Mapa do Círculo}

O mapa do círculo modela a interação entre um oscilador "mestre" quando aplicado a um segundo oscilador namolinear [Argyris at al, 1994; Jackson, 1995]. A dinâmica E governada por dois parâmetros de controle, a razâo entre as frequencias dos osciladores desacoplados $\Omega$, e a intensidade de acoplamento $\mathrm{K}$ :

$$
\begin{aligned}
& \theta_{n+1}=\theta_{n}+\Omega-\frac{K}{2 \pi} \operatorname{sen} 2 \pi \theta_{n}+b r_{n} \quad(\bmod 1) \\
& r_{n+1}=b r_{n}-\frac{K}{2 \pi} \operatorname{sen} 2 \pi \theta_{n} .
\end{aligned}
$$

Aqui, $\theta_{n}$ é o ângulo de um rotor rígído logo após o enésimo impulso, e $r_{n}$ é proporcional à velocidade angular deste rotor sujeito a um impulso externo, do oscilador mestre e b estâ relacionado com o amortecimento.

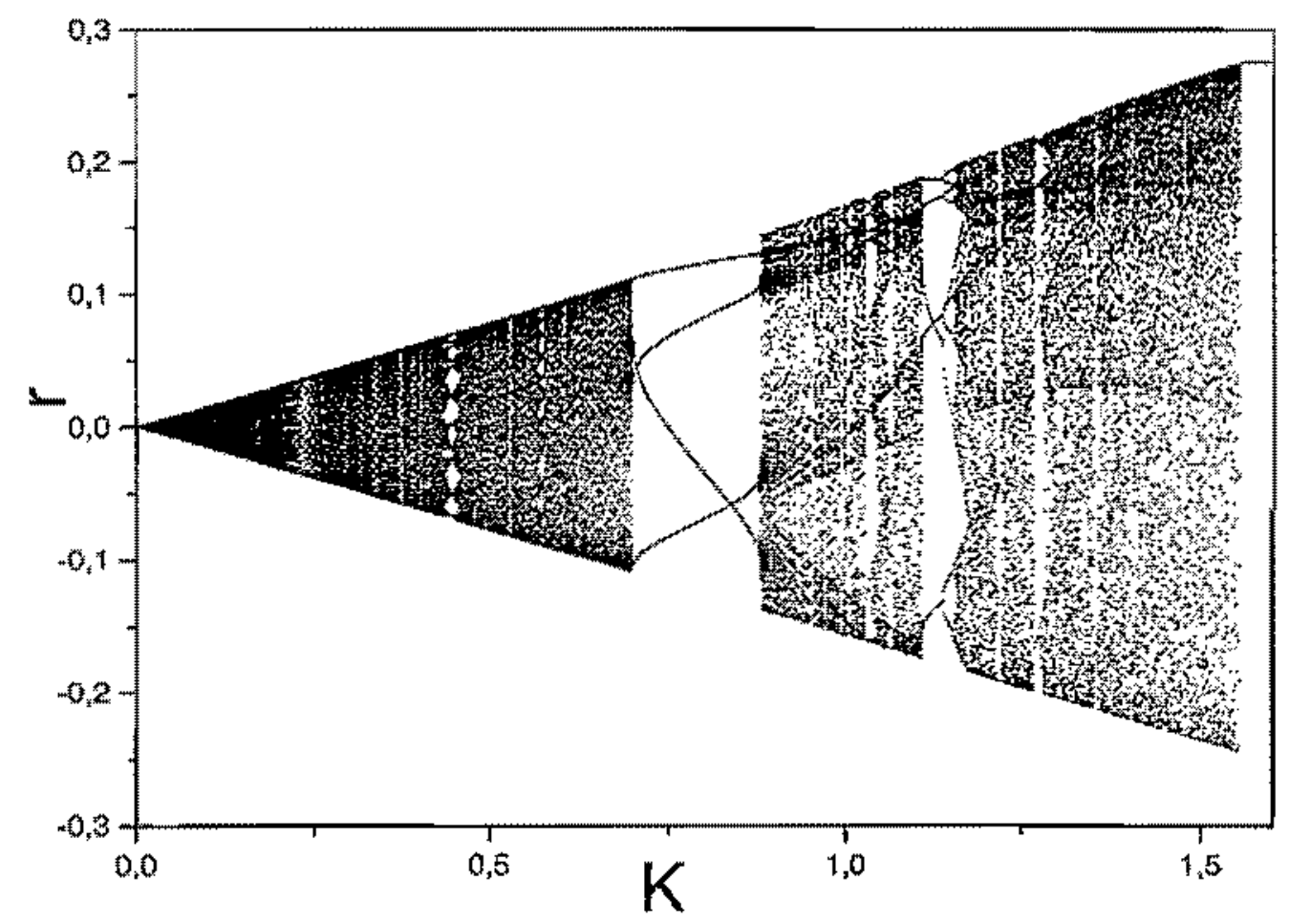

Figura 2.7 Diagrama de bifurcação do mapa do círculo para $b=0,1$ e $\Omega=0.725$ 
Na figura 2.7 podenos ver a série temporal do mapa do eírculo. Este tipo de mapa nos dá outro tipo de rota para o caos denominada de rota para o caos via quaseperiodicidade. Temos basicamente o aumento do taio de um ciclo limite quase-periodico intercalados com travamentos de frequêneta, e comportamento cático.

Para sistemas altamente dissipativos o termo $b$ se anula e o mapa pode ser estudado na forma puramente angular:

$$
\theta_{n+1}=\theta_{n}+\Omega-\frac{K}{2 \pi} \operatorname{sen}\left(2 \pi \theta_{n}\right)
$$

Um conceito importante para a andise do mapa do cítculo que foi introduzido por Poincare [Argyris et al., 1994; Alligood et ak., 1997] E número de rotaçäo W:

$$
W(K, \Omega)=\lim _{n \rightarrow \infty} \frac{\theta_{n}-\theta_{0}}{n}
$$

que ê a média da rotação do oscilador forçado por ciclo.

As propriedades de estabilidade para valores de $K_{2}<1$, para a equaço (2.21), seguem a partir da teoria de estabilidakle linear para mapas, como foi feito para o mapa quadrático:

$$
\frac{d}{d \theta} f(\theta, \Omega, K)=[1-K \cos (2 \pi \theta)]
$$

que é menor do que um se $a<1 / 4$ e e maior do que 1 se $6>1 / 4$, ou se $0>3 / 4$. Para um ponto กิx० extânel $\theta_{s}$ temos:

$$
\lim _{n \rightarrow \infty} \theta_{n}=\theta_{s} \Rightarrow W=0
$$

Substituindo na equaçẵo 2.21 obtemos a relaçäo entre $K$ e $\Omega$, dada por :

$$
\Omega= \pm \frac{K}{2 \pi}
$$

Estas relaçăo entre $K$ e $\Omega$ nos dá o espaço de parâmetros do mapa do crirculo onde podemos ver para quais valores podem ocorter a sincronizaçăo do oscilador forçado, conhecida como lingua de Amold [Ba-lin, 1989$]$ para o número de rotaçắo $W=0 /$.

Na figura 2.8(a) temos o mapa de primeira iteraçăo da funçẵo senoidal do mapa do círculo na regiảo onde ocorre uma bifurcação do tipo sela-nó. Para un valor fixo de $K$ entre 0 e 1 , trễs valores de $\Omega$ foram escolhidos. Para $\Omega>\Omega_{\mathrm{x}}$ o ponto fixo ainda nāo existe. Para $\Omega=\Omega_{k, 0}$ a função tangencia a bissetriz e um ponto $f x$ aparece. Diminuindo ainda mais o valor de $\Omega, \sigma$ ponto fixo se divide em dois, um estavel e outro instâvel, situaçăo 
característica de uma bifurcaçăo selàno. A figura $2.8(b)$ dă o diagrama de bifurcaçăo para $W=011$, para os valores positivos de $\Omega$ da equaçăo 2.25 .
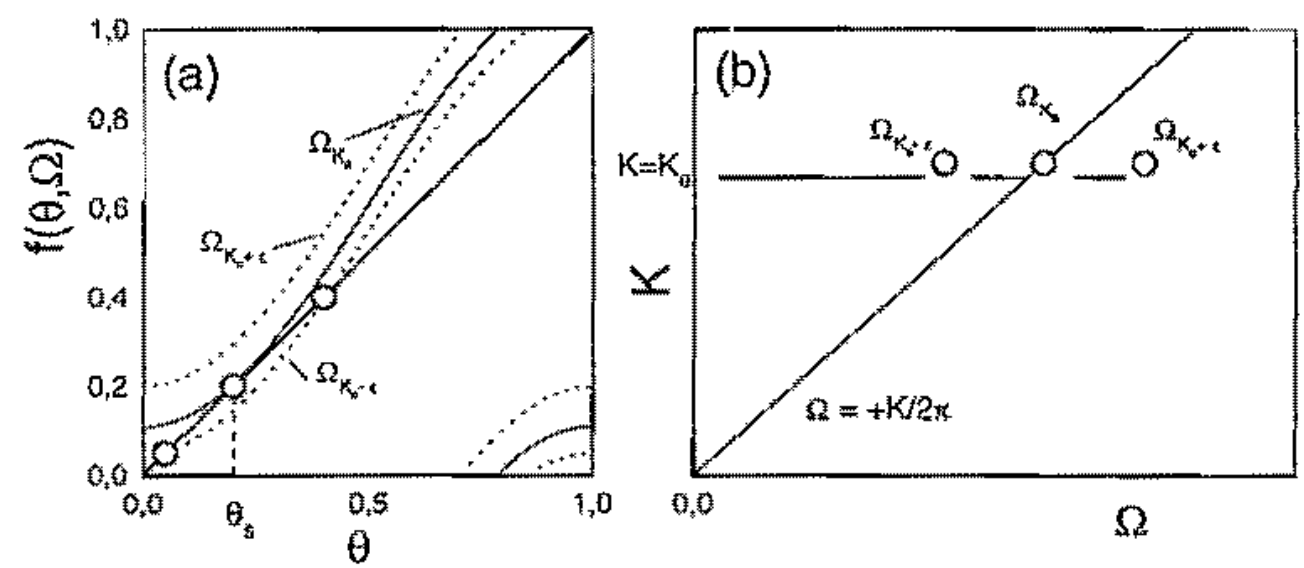

Figura 2.8 (a) Graficos do mâna do círculo em funçăo do parâmetro 2 na regiano do ponio de bifurcaçăo selanno. Em (b) a representaçán no espaço de parâmetros da língua de Arnold correspondente a $W=0 / l$, que ocorte para valorcs de $\Omega$ menoses que $\Omega_{\mathrm{K}} \mathrm{O}$

Para diferentes valores de $W$, quando $K<1$, ocorrem outras regióes de travamento de frequências sem ocorter sobreposiçüo entre elas, como está apresentado na Fig. 2.9, que mostra os limites de estabilidade dos domínios periódicos no plano $(K, \Omega)$, para alguns números de rotaçăo. Para as regiobes onde ocorrem a sincronizaçăo das frequêncitas entre os dois osciladores, o nimmero de rotaçăo W e um número racional plq. Deste moto para cada valor racional do exo $\Omega$, uma janela periódica surge e se expande quando aumentamos o valor de $K$. Com o aumento da natam linearidade através do partầmetro $K$, a sincronizaçāo das freqüências a se tornam mais dominantes.

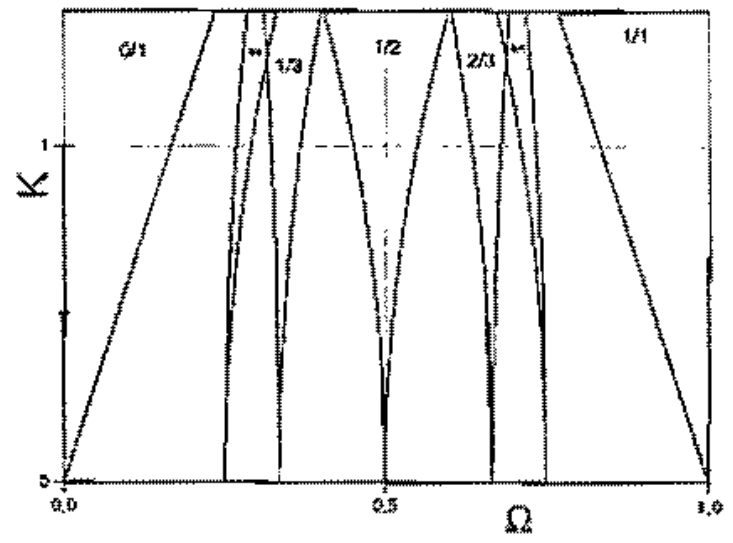

Figura 2,9 Diagrama das Linguas de Anold para o mapa do Circulo. 
Para valores de $\mathcal{K}>I_{2}$ as línguas de Arnold passam a se sobrepor, e o número de rotaçẫo nâo mais unicamente determinado, mas trocado por um intervalo de rotaçă $\left[W_{1}, W_{2}\right]$, e este embaralhamento toma o comportamento aperiódico.

Para mostrar algumas das características gerais do mapa no círculo, utilizaremos o conceito de expoente de Lyapunov. Lyapunov estudou uma vizinhança abstrata $\{\bar{x}$ ) de uma trajetória $\{x\}$, com $\mathrm{N}$ pontos, com o objetivo de verificar se estes pontos se afastavam ou convergiam para a trajetória. Tomando uma trajetória infinita e uma vizinhança tão pequena quanto se possa imaginar, ele associou um expoente que caracteriza se a trajetoria é periódica, indiferente ou caótica. Para o mapa do circulo na sua forma angular da equaça $(2.21) \mathrm{com} \Omega=0,25$, o expoente foi calculado numericamente com a expressão:

$$
\varepsilon=\frac{1}{N} \sum_{i=0}^{N-1}\left[n \mid l-K \cos \left(2 \pi \theta_{i}\right)\right]
$$

que esta representado na Fig. 2.10(a) e seu respectivo diagrama de bifurcaçōes na Fig. $2.10(\mathrm{~b})$. Inicialmente, os expoentes sảo ligeiramente negativos, da ordem de $-10^{-5}$, até $o$ valor de $K=1$, onde divergem para menos infinito. Órbitas com expoentes deste tipo, divergindo para menos infinito, são conhecidas como óbitas supermestóveis. Ao término desta janela, o sistema já possui comportamento caótico, e esta rota para o Caos é classiffcada de rota via quase-periodicidade [Baí-lin, 1989; Argyris at al, 1994; Jackson, 1995; Alligood et al., 1997), onde os expoentes de Lyapunov positivos não ultrapassam o valor de 0,3 . Aumentando $K_{2}$ o sistema trava em um periodo 1 , e inicia outra rota para o Caos, a rota via duplicaçóces de período ou rota de Feigenbaum, já discutida para o caso do mapa quadrático, na qual os expoentes se anulam nos pontos onde ocorrem as bifurcaçotes, neste caso temos o comportamento indiferente. Para $K-3,4$, o sistema experimenta um alargamento abrupto do atrator este alargamento é classificado como uma crise. Após a crise, os expoentes de Lyapunov máximos param de crescer e tếm valores na faixa entre 0,7 e 0,93 . Quando $K$ atinge aproximadamente 4,7 , o sistema volta a sofrer um travamento de freqüência em periodo 1 .

Do mesmo modo que o atrator de Hénon, o mapa do circulo bidimensional da equaçă丶 (2.20) contrai o espaço de fases uniformemente, como podemos ver através do deterninante da matriz jacobiana do mapa: 


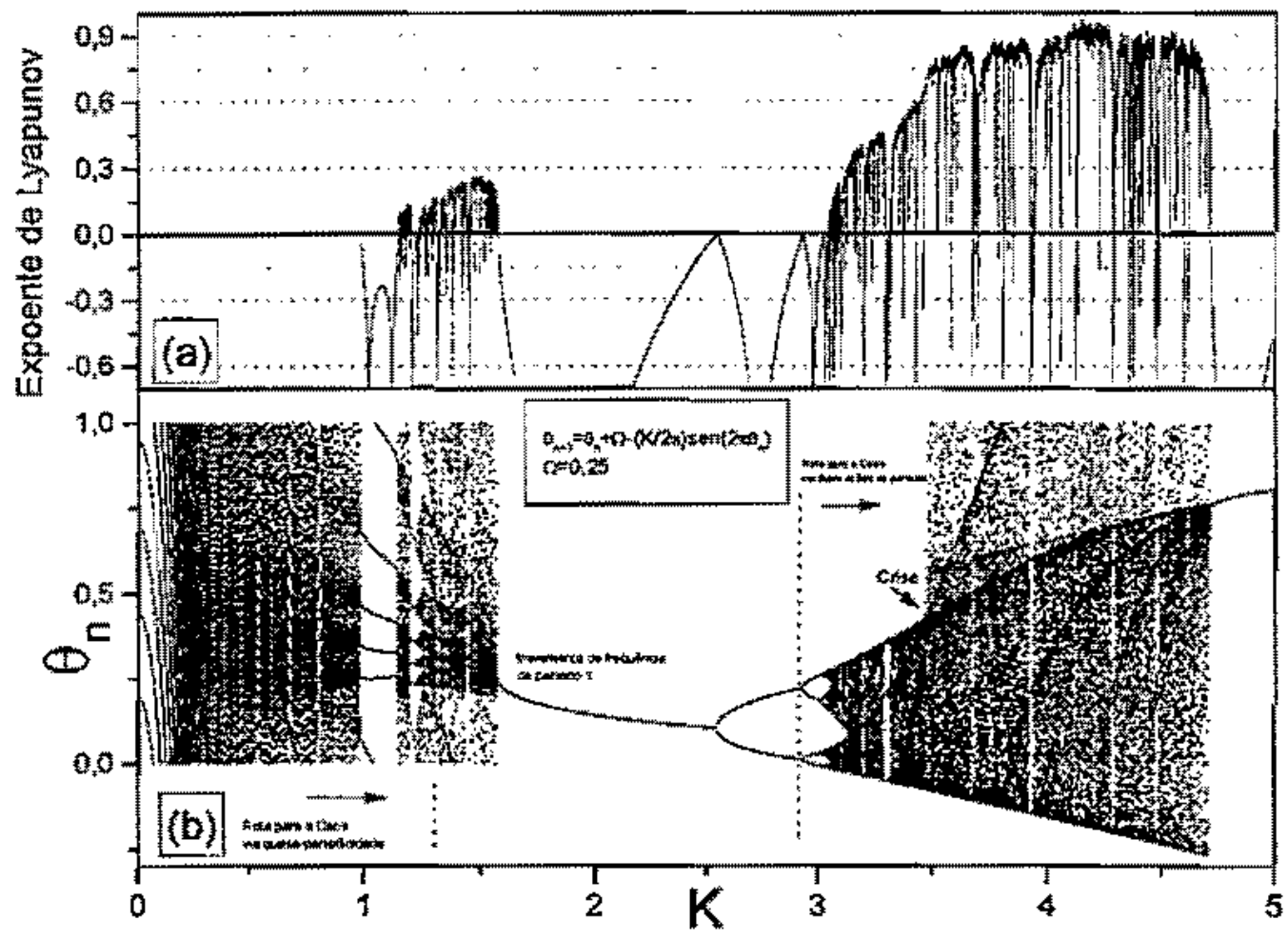

Figura 2.10 (a) Expoentes de Lyapunov do maxa do cifoulo com $\Omega=0,2.5 . \mathrm{Em}$ (b) o diagrana de

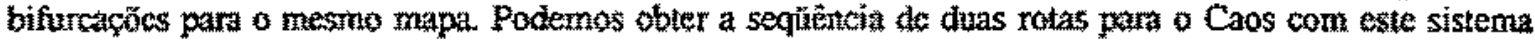

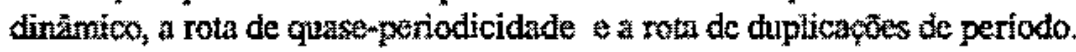

$$
\operatorname{det} J=\left|\begin{array}{cc}
1-K \cos 2 \pi \theta & b \\
-K \cos 2 \pi \theta & b
\end{array}\right|=b
$$

Os pontos fixos $r^{*}$ e $\theta^{*}$ de periodo 1 , logo após a regiäo quase-periódica para K1,55 da Fig. 2.7, são dádos por:

$$
\begin{aligned}
& r^{*}=-\Omega(\bmod 1) \text { se } \Omega(\bmod 1)<0,5 \text { ou } r^{*}=1-\Omega(\bmod 1) \text { se } \Omega(\bmod 1)>0,5, \\
& \theta^{*}=\frac{1}{2 \pi} \operatorname{arcsen}\left[\frac{2 \pi^{*}}{K}(b-1)\right]
\end{aligned}
$$

assim podemos determinar o ponto onde ocorre a primeira bifurcaçăo do tipo flip usando os critérios de estabilidade para a seguinte eqquação característica:

$$
\left|\begin{array}{cc}
1-K \cos 2 \pi \theta^{*}-\lambda & b \\
-K \cos 2 \pi \theta^{*} & b-\lambda
\end{array}\right|=0,
$$

que nos dá dois autovalores para cada ponto fixo. Para o ponto fixo $r^{*}$ os autovalores valem explicitamente: 


$$
\begin{aligned}
& \lambda_{1,2}=\frac{-\left\{K \cos 2 \pi\left[\frac{1}{2 \pi} \operatorname{arcsen}\left(\frac{2 \pi z^{*}}{K}(b-1)\right]+1+b\right]\right.}{2} \pm \\
& \pm \frac{\sqrt{\left[K \cos 2 \pi\left[\frac{1}{2 \pi} \operatorname{arcsen}\left(\frac{2 \pi r^{*}}{K}(b-1)\right]+1+b\right]^{2}-4 b\right.}}{2}
\end{aligned}
$$

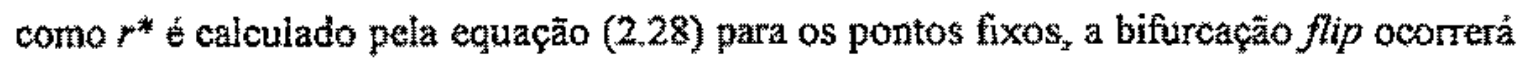
quando um dos valores de $\lambda$ aleanca o valor -1 .

Para valores da constante $b$ próximos de zero, deve ser feita uma corteçäo em primeira aproximaçăo nos valores das linguas de Arnold. Para as linguas correspondentes ao travamento de frequếneias de periodo 1 , como a equaçăo (2.25), as linguas podem ser calculadas através de:

$$
\Omega=\frac{K}{2 \pi(1-b)}
$$

O mapa do circulo é um sistema dinâmico que parte de um sistema físico ben definido [Argyris et al, 1994], que apresenta um comportamento muito rico, com relaçẵo aos elementos da Teoria do Caos.

Além do comportamento individual dos mapas vistos anteriormente, como o mapa quadrático, o mapa de Hẻnon e o mapa do ć́rculo, também é desenvolvida a pesquisa na área de sistemas dinâmicos espaço-temporais [Kaneko, 1992; Viana, 2000] através do acoplamento destes mapas formando uma rede. Com estes estudos pretendese explicar rotas típicas para turbulència, como, por exemplo, a sequência obtida com 0 acoplamento de mapas quadráticos: duplicações de periodo, formaçẫo de padrôts aleatónios na rede de mapas, selecẫo de alguns destes padrões, intermitência espaçotemporal e no final observa-se turbulência plenamente desenvolvida. Um exemplo de modelo de fluxo de um fluido usando mapas acoplados dado por Willeboordse [Willeboordse, 1992]. 


\subsection{Transformação de ponto fixo}

Para extrair as órbitas periódicas instaveis (OPI) imersas em um atrator com uma quantidade finita de dados ruidosos de um sistema unidimensional, So e colaboradores [So et al., 1996] fizeram a suposiço de que todos os pontos que estão em uma regiáco ao redor do ponto fixo $x^{*}=f\left(x^{*}\right)$ podem ser transformados para $\{x\}$ na vizinhança de $x^{*}$. A função densidade $\hat{\rho}(\hat{x})$ possut singularidades do tipo inverso da raiz quadrada nos pontos fixos, e un histograma para $\hat{\rho}(x)$ terá um pico definido em $x^{*}$. Alguns picos espúrios podem aparecer em $\hat{p}(x)$ tanto devido a singularidades näo relacionadas aos pontos fixos, quanto a zeros da derivada da funçăo de transformação $x=g(x, k)$. Os autores genaralizaram este método para um sistema com dimensâo de imersào d para obter as órbitas periódicas instáveis através da transformaçằ:

$$
\widehat{\mathbf{z}}_{n}=\left(\mathbf{1}-\mathbf{S}_{n}\right)^{-1}\left(\mathbf{z}_{n+1}-\mathbf{S}_{n} \mathbf{z}_{n}\right)
$$

onde

$$
\begin{aligned}
& \mathbf{S}_{n}=\left(\begin{array}{cc}
a_{n}^{\mathrm{l}} a_{n}^{2} \ldots a_{n}^{(d-1)} a_{n}^{d} \\
1 & 0
\end{array}\right)+k \mathbf{R}\left\|\mathbf{z}_{n+1}-\mathbf{z}_{n}\right\|
\end{aligned}
$$

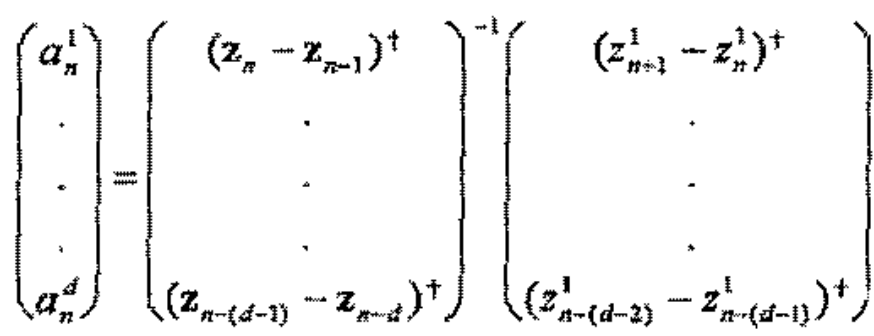

e os vetores $\left\{z_{n}\right\}$ foram reconstrutios a partir da série temporal $\{x\}$,

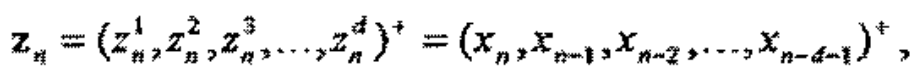

R é uma matriz aleatória $d \times d$ no intervalo $[-1,1]$ e $k$ está relacionado com a intensidade da geraçăo de numeros aletórios Os pontos fixos são dados por posiçóes dos picos de $\hat{\rho}(\hat{x})$. Como a localizaçă dos picos espúrios dependem do parânetro $k$,

eles são eliminados levando em conta a média $(\hat{\rho}(\vec{z}))$ para vărios vaiores tomados aleatoriamente.

Um ponto fxo instável do atrator do mapa do circulo com $\Omega=0$, é ponto $(0,0)$, mostrado na Fig. 2.11 (a), que foi determinado com este algoritmo, como está mostrado natig. 2.11 (b). Outras aplicações desta técnica podem ser encontradas no experimento da torneira gotejante [Pinto, 1999], para se mostrar a existência de óbitas homoclínicas. 

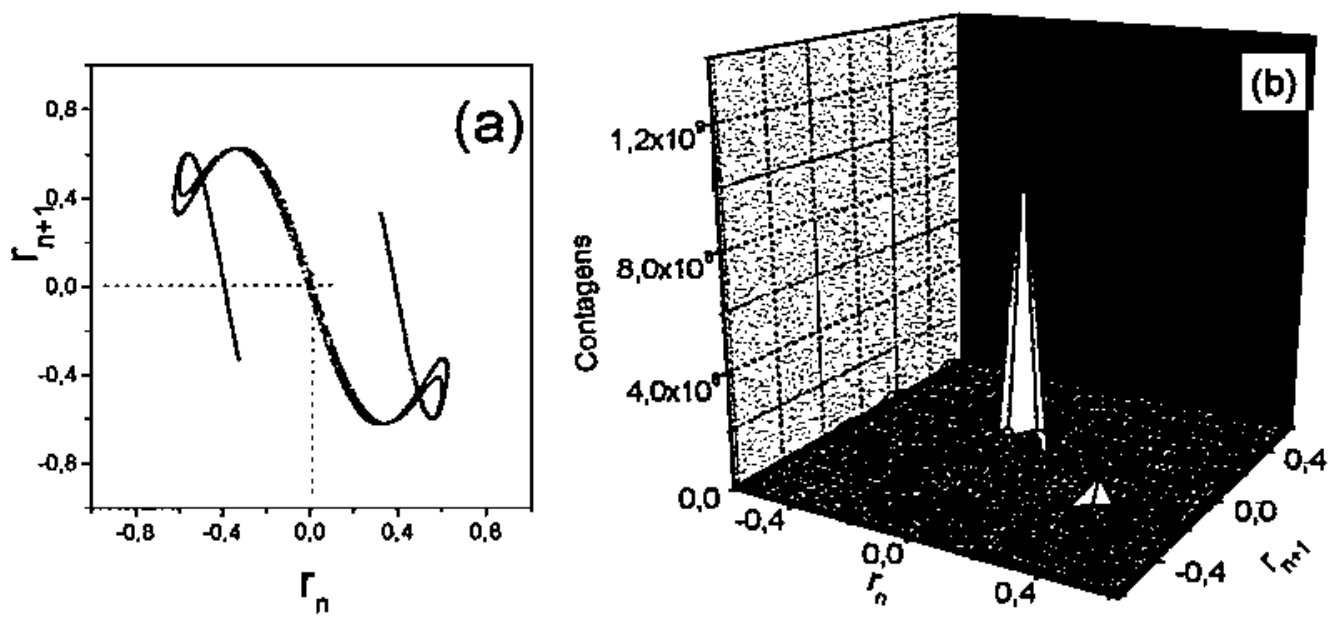

Figura 2.11 Atrator caótico simétrico em (a) do mapa bidimensionał do círculo, que possui um ponto de sela na origem. Em (b) a órbita periódica instável foi obtida mumericamente utilizando-se o método de detecção de órbitas periódicas instáveis de So et al.

Como a reconstrução dos atratores em espaços de imersão bidimensionais é suficiente, nós aplicamos esta técnica para $\mathrm{d}=2$, com $k=5$, e 1000 matrizes aleatórias. Mais informações sobre este método pode ser encontradas também no trabalho de Schemelcher e Diakonos [Schemelcher e Diakonos, 1998].

\subsection{Plano simbólico}

A obtenção de planos simbólicos, para a construção de máquinas topológicas mínimas no experimento da torneira gotejante, foi feita por Gonçalves [Gonçalves, 1996], no experimento da torneira gotejante. No experimento do tubo borbulhador, a geração de planos simbólicos foi utilizada principalmente para se comparar modelos com os dados experimentais.

Para estudarmos o plano simbólico particionamos um atrator em duas regiões da Fig. 2.12 ( $\mathrm{L}$ e $\mathrm{R}$ ) e atribuímos o valor 1 (ou -1 ) quando o sistema visita $L$ (ou $R$ ), obtendo um vetor $\ldots s_{m,}^{\prime} \ldots, s_{2}^{\prime}, s_{1}^{\prime}, S, s_{1}, s_{2}, s_{m}, \ldots$. Deste modo um plano simbólico $\alpha \beta$, característico de um atrator, é definido através do cálculo de $\alpha$ e $\beta$ como: 


$$
\alpha=\sum_{j=1}^{\infty} \mu_{i} 2^{-i}
$$

onde $\mu$ é um valor binário:

$$
\begin{gathered}
H_{i}=\left\{\begin{array}{c}
0 \\
1
\end{array} \text { se }(-1)^{i} \prod_{j=1}^{j} s_{j}=\left\{\begin{array}{l}
+1 \\
-1^{i}
\end{array}\right.\right. \\
\mathrm{e} \\
\beta=\sum_{i=1}^{\infty} v_{i} 2^{-i}
\end{gathered}
$$

onde $v_{l}$ é valor binário:

$$
u_{3}=\left\{\begin{array}{l}
0 \\
1
\end{array} \text { set } \prod_{j=1}^{*} s^{*},=\left\{\begin{array}{l}
-1 \\
+1
\end{array}\right.\right.
$$

Na Fig. 2.12 exemplificamos a obtenção do plano simbólico (b) para o atrator do mapa do círculo bidimensional (a), com suas respectivas partiçôes $L$ R. $O$ parâmetro $b$ é igual a 0,1 . As regía em branco no plano simbólico são chamadas de regiōes proibidas.
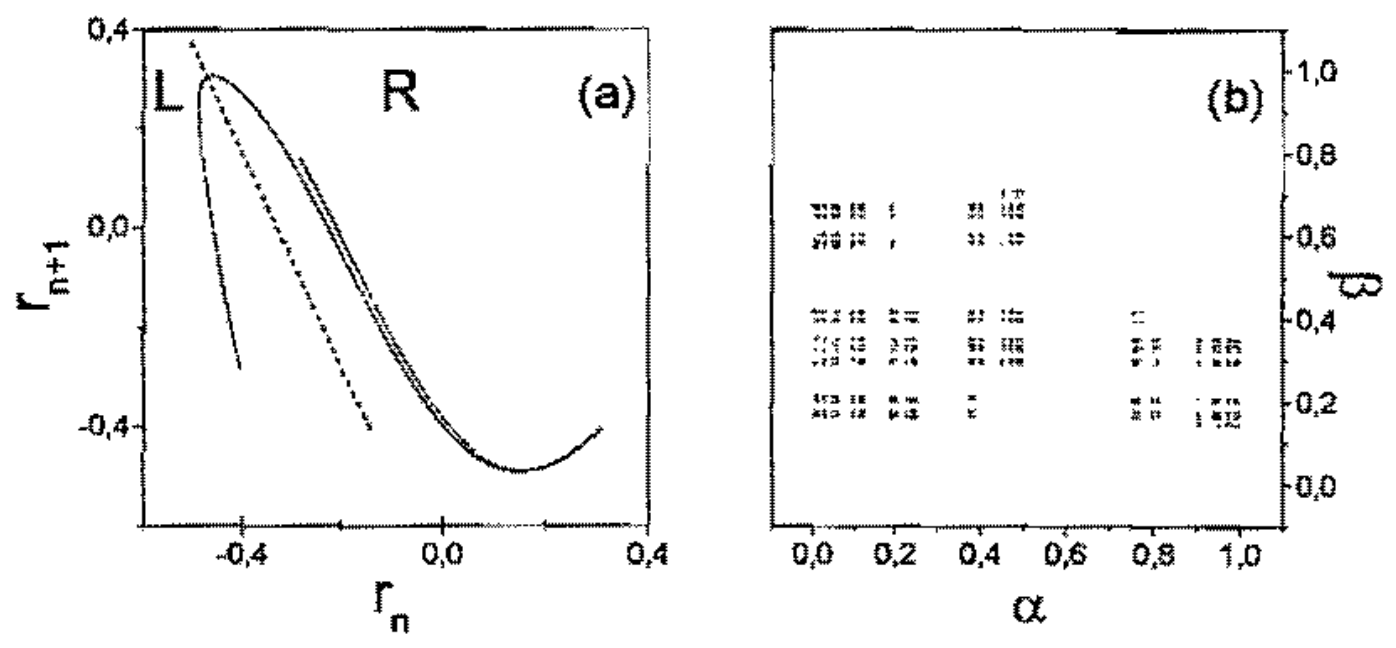

Figura 2.12 (a) $O$ atrator do mapa do circulo reconsiruido com o maja de primeiro retomo na variável $r$ e suia partiçãa, en (b) seu respectivo plano simbólico. 


\section{Aparato experimental}

Neste capitulo descrevemos os aparatos do tubo borbulhator e da torneira gotejante. Tanto o experimento do tubo borbulhador, assim como o experimento da torneira gotejute, foram inteiramente desenvolvidos no LFNL-USP. Algumas das principuis atividades experimentais deste trabalho foram o desenvolvimento e construção do tubo borbuhthador, a aquisiçấo e análise dos dados.

\section{1. $O$ tubo borbulhador}

Na Fig. 3.I temos a representação esquemática do aparato do experimento do tubo borbulhador, gue consiste de um tubo acrílico transparente, com uma tampa (superior) e uma base de PVC, onde está conectada uma seringa hipodérnica pela qual é soprado ar numa solţ̧ăo de água com glicerina. Dentro deste tubo ocorre a formação de bolhas que são estudadas neste trabalho. $O$ experimento pode ser dividido en quatro partes principais; o tubo borbulhador, o circuito pneumático $0_{4} 0$ sistema de aquisiçăo, e sistema sonoro.

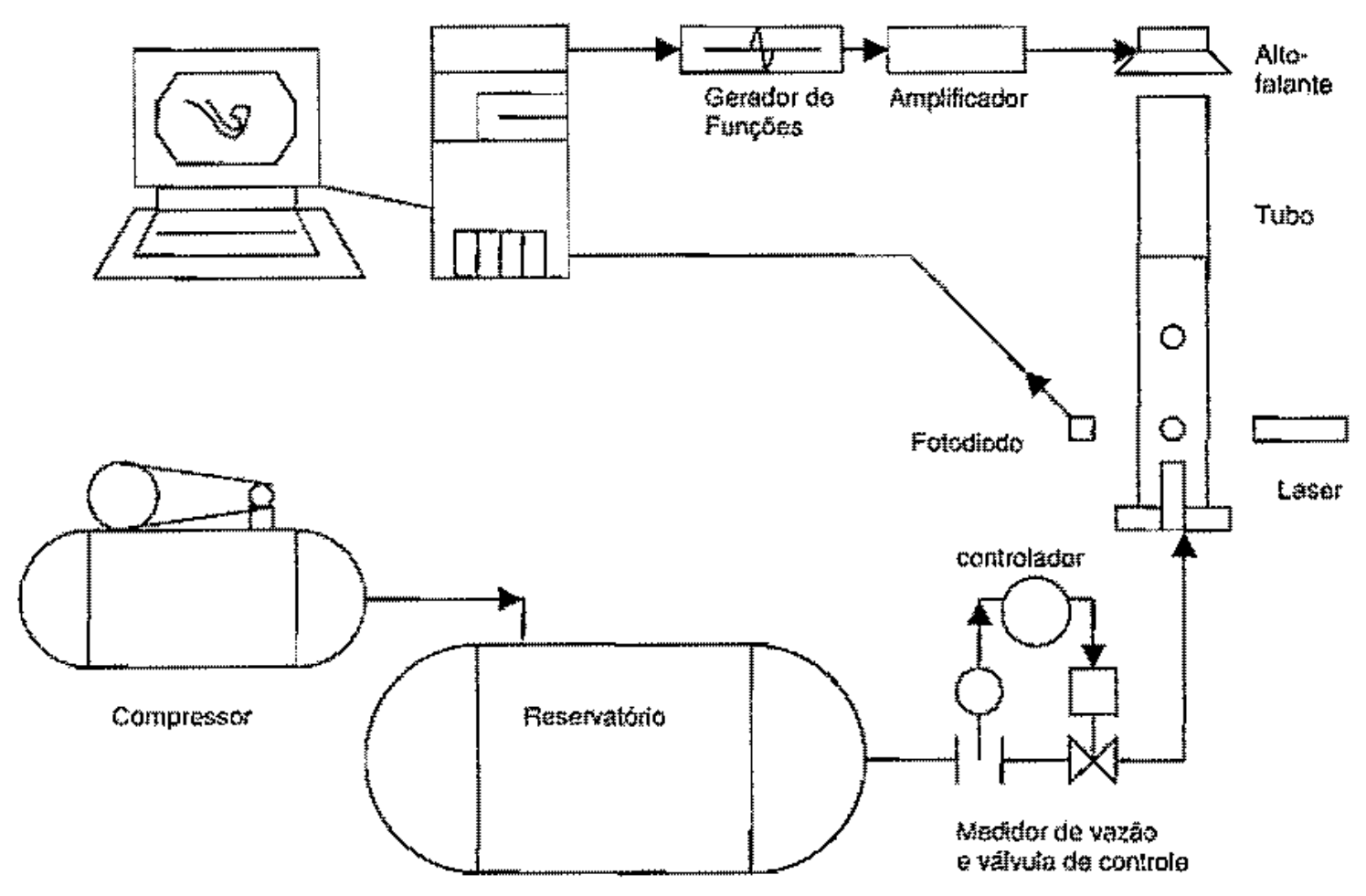

Figura 3.1 Dingrama geral do aparate experiniental do ubo borbuliador 
Na Fig. 3.2, podemos ver o tubo borbulhador, que foi construido com tubo de acrilico transparente de diâmetro intemo de $10,5 \mathrm{~cm}$ e $70 \mathrm{~cm}$ de altura. Na base estăo fixados o bico borbulhador e um termopar para monitorar a temperatura do liquido. A entrada e saida do líquĩdo ocorrem através de duas válvulas do tipo esfera.

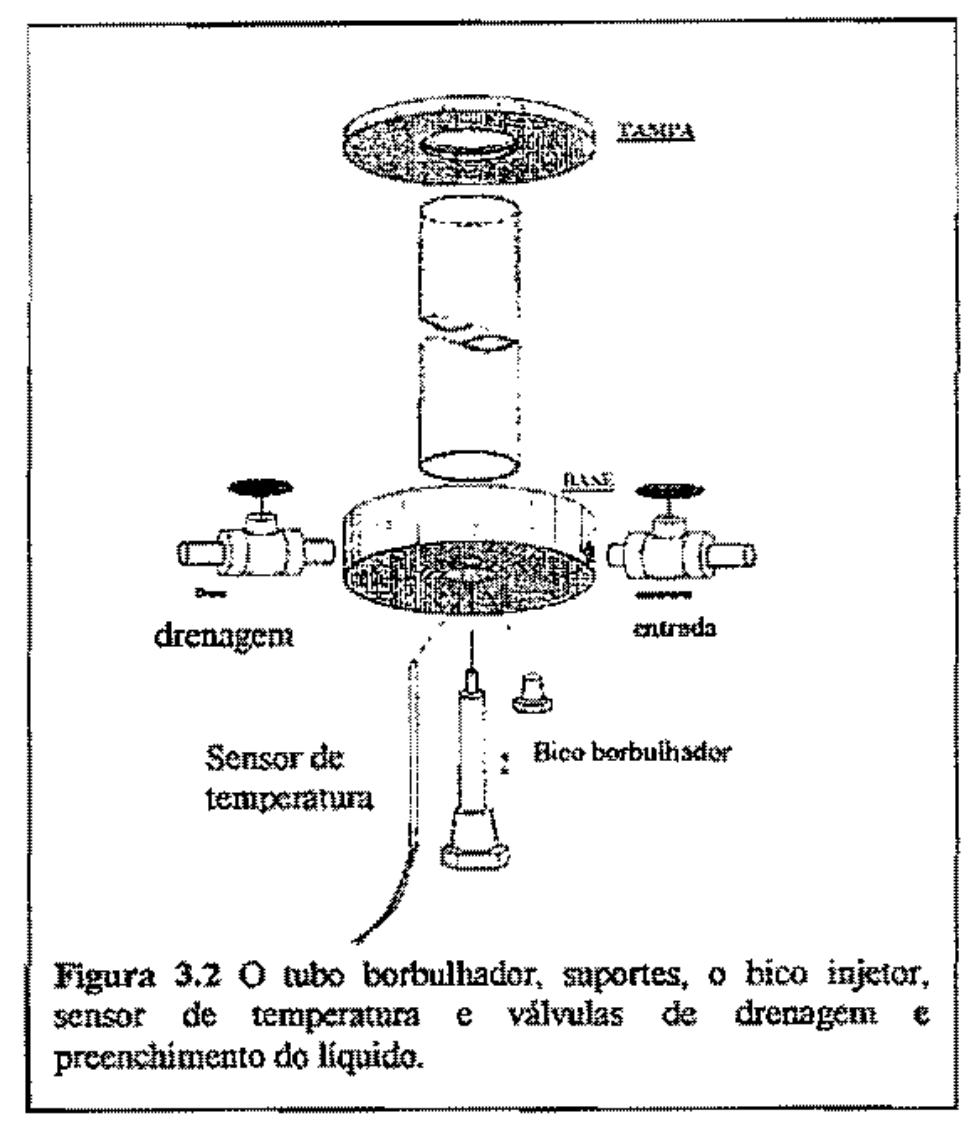

Este arranjo permite $O$ preenchimento do tubo e o ser esvaziamento através das vảivulas nas laterais da base. Todo o conjunto é preso ao suporte através de quatro parafusos na base $e$ quatro parafusos na tampa. Um sistema de iluminaçẵo constituido de uma lâmpada fluorescente e uma placa difusora de luz foi colocada atrás do tubo borbulhador, para obtermos imagens das bolhas utilizando uma câmará de vídeo VHS.

O tubo esta montado em uma bancada sobre quatro blocos de espuma para amortecer vibraçős externas.

\subsection{Sistema de aquisiçāo}

O sistema de deteção consiste de um laser He-Ne e um fotodiodo. Quando uma bolka atravessa o feixe laser, induz no fotodiodo um sinal analógico, e um pulso é enviado a uma placa contadora de tempo inserida em um microcomputador. $O$ inicio e o fim do desvio do feixe laser induzidos pela passagem de ama bolha, criam o sinal de entrada da placa atravtes de pulsos de tensäo TTL gerados pelo fotodiodo. Na Fig. 3.3 temos o gráfico que mostra o sinal $\delta t_{n}$, devido a passagern de uma bolha, e sinal $t_{n}$ relativo ao tempo entre bolhas. Assim um par de dados constituido do tempo entre as bolhas e o tempo de passagem da bolha coletado pelo computador. $O$ intervalo de tempo total entre a n-ésima e a (n+1)-ésima gota $T_{n}$ que a soma destes dos dois intervalos de tempo. 


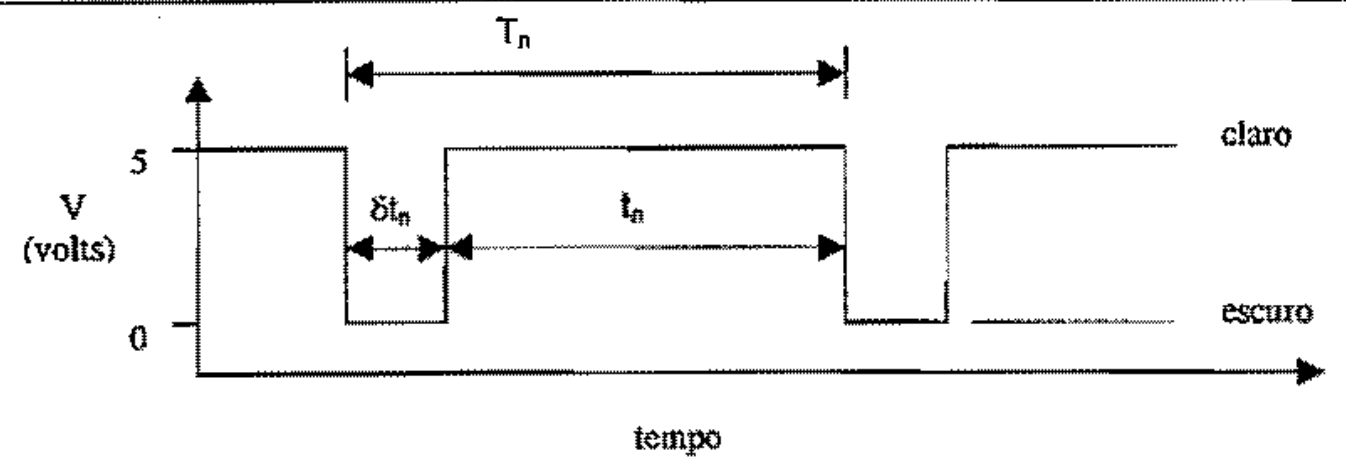

Figura 3.3 Sinal gerado pelo fotodiodo e indurito na placa contadora de tempo pela passagen tas bolhas que desviam o feixe laser. O feixe esta positionado -5 mun acima da extrentidade do bico soprador.

O sinal de vazäo obtido pelo medidor de vazäo e convertido em um sinal proporcional de tensäs em milivolts digitilizado em um osciloscópio digital Tektronix, depois e transferido para o computador através de uma interface General Pupose Interface Bocti (GPIB).

\subsection{Medidor de yazão}

O medidor de vazäo utilizado é o modelo GFM47, fabricado pela AALBORG Instruments \& Controls. Neste equipamento o fluxo do ar entra em um transdutor de vazäo, e dentro dele uma pequena parte do fluxo do ar é separada por um sensor do tipo wabo capilar de aço inoxidável. O restante do ar flui através de um condutor de fluxo primário. A geometria do tubo primátio e do tubo sensor foi projetada de modo a garantí um fluxo laminar en cada ramo. De acordo com os princípios da Fluidodinâmica as vazôes do ar nos dois condutores são proporcionais entre sì. Deste modo a vazăo medida no tabo sensor é diretamente proporcional à vazäo total atraves do transdutor.

Para obter a varia no tubo sensor, é feito um aquecimento do fluxo em duas partes do tubo sensor através de resistências sensoras de precisão. $O$ calor é transferido através de uma parede fina para o ar. $O$ ar aquecido é levado pelo fluxo desde um aquecedor a jusante, ate um aquecedor montante do tubo sensor. 0 sinal elétrico de uma resistência dependente de temperatura diferencial é detectada atraves de um sircuito eletrônico de controle. $\mathrm{O}$ gradiente de temperatura medido no sensor linearmente proporcional à vazão atrayếs to sensor. 
O valor da vazão mostrado diretamente em um indicador digital, simultaneamente em dois sinais elétricos, um de tensäo proporcional ao valor da vazão entre 0 e $5 \mathrm{~V}$, e outro de corrente proporcional à vazăo entre 4 e $20 \mathrm{~mA}$.

\subsection{Controlador de vazão}

$O$ controlador de vazão é da marca BTC, modelo BTC-2220, é um controlador do tipo proporcional, integral e diferencial (PID). Ele recebe o sinal de corrente do medidor de vazão (4-20 mA), com módulo de saída linear (OM92-3), com a tensão de saida variando entre 0 e $10 \mathrm{~V}$, com uma impedância de saída de $500 \mathrm{k} \Omega$. Devido a alta impedẫncia de saida, um circuito amplifícador de corrente toi adaptado na saida do controlador, para gue ele pudesse enviar o sinal de controle para a válvila solenóide, como esta mostrado na Fig. 3.4.

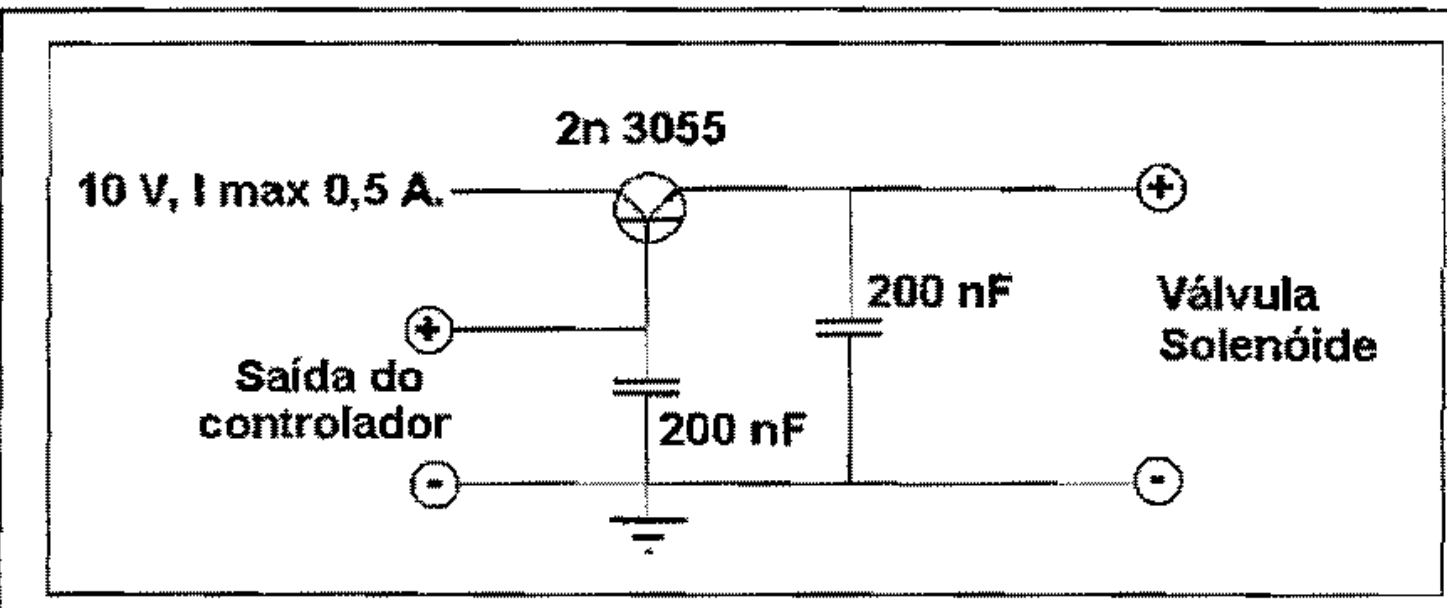

Figura 3,4 O Circuito que amplifica o sinal do controlador para a vâlyula

O controlador possui dois modos de operação. No primeiro modo, ele mantém uma vazăo fixa preestabelecida. No segundo modo, o controlador aumenta ou diminui a yazão linearmente entre dois valores distintos, com uma velocidade preestabelecida pelo usuário. 


\subsection{Válvula solenóide proporcional}

O fabricante da válvula utilizada no experimento do tubo borbulhador é AALBORG Instruments \& Controls, o o seu modelo é o PSV-5. Basicamente a vălvula é uma bobina que posiciona o atuador da válvula de moto contínuo, variando a vazão suavemente. A valvula solenóide proporcional foi projetada para responder a um sinal de tensão continua de entrada, entre 0 e 30 volts, para regular proporeionalmente ao sinal de tensão ofluxo de líquidos gases. Por medida de segurança as válvulas são normalmente fechadas quando desernegizadas. Na Fig 3,4 temos um diagrama desta văinula.

Devido á corrente na bobina da válvula, o corpo da mesma sofre um pequeno aquecimento, que é dissipado por aletas de aluminio colocadas na vălvula.

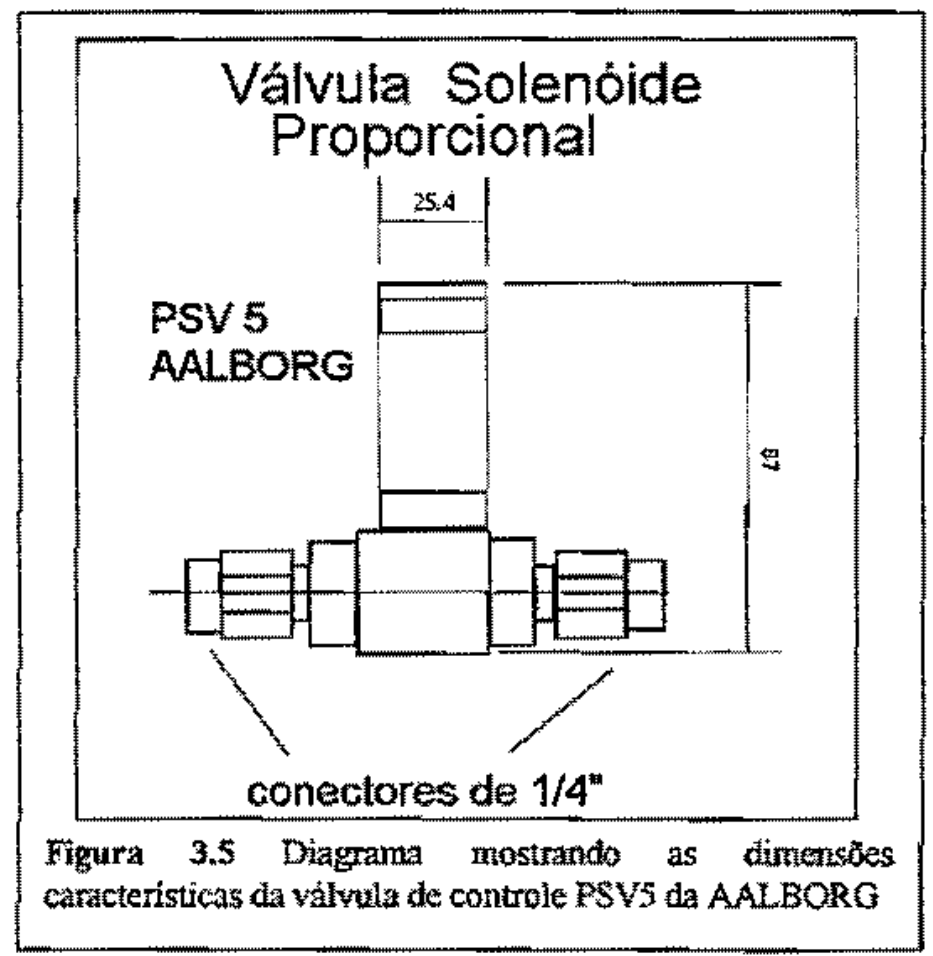




\section{3,6. $\mathrm{O}$ bico borbulhador}

Na Fig. 3,6 , vemos o conjunto de agulhas e o cilindro de uma seringa hipodérmica que foram utilizados como bicos sopradores no experimento do tubo borbulhador. As bolhas săo formadas diretamente no cilindro da seringa ou nas agulhas hipodẻmicas que são colocadas na seringa que está ligada ao sistema de alimentação de ar.

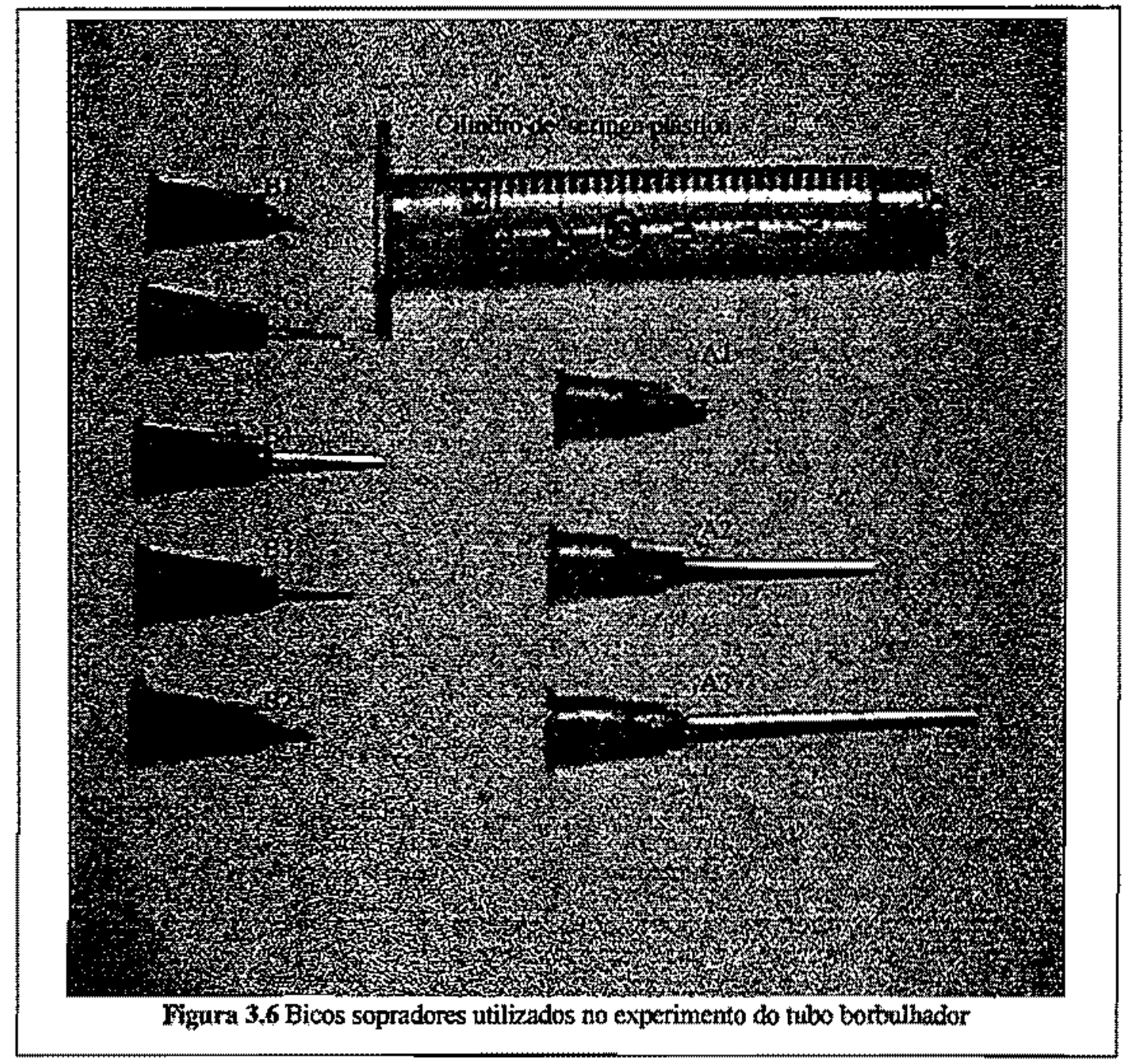

Na tabela 3.1, temos as dimensões dos bicos mostrados na Fig. 3.6. Para verificarmos os efeitos do comprimento das agulhas, utilizamos agulhas com o mesmo diâmetro, mas que foram cortadas em comprimentos diferentes com uma serra diamante, como para as agulhas do grupo $\mathrm{A}$ e $\mathrm{B}$. A seringa e algumas agulhas possuem dois valores na coluna relacionada com o diàmetro, 0 primeiro valor corresponde ao 


\begin{tabular}{|c|c|c|}
\hline Bico & $\begin{array}{l}\text { Diânetro (mm) } \\
\text { Interno/externo }\end{array}$ & Comprimento(mm) \\
\hline Seringa Plastica & $0,8 / 1,3$ & 2 \\
\hline Al & $0,72 / 1,28$ & 2 \\
\hline $\mathrm{A}^{2}$ & $0,72 / 1,28$ & 24,6 \\
\hline $\mathrm{A} 3$ & $0,72 / 1,28$ & 37.7 \\
\hline BI & 0,72 & 2 \\
\hline $\mathrm{B2}$ & 0,72 & 14,5 \\
\hline $\mathrm{B3}$ & 0,72 & 10,2 \\
\hline $\mathrm{B4}$ & 0,72 & 5,1 \\
\hline $\mathrm{Cl}$ & 0.5 & 2 \\
\hline
\end{tabular}

Tabela 3.1 Dimensóes da seringa e das agulhas utilizadas como bicos sopradores no experimento do tubo borbulhador.

diametro interno e o segundo valor estă relacionado com o diâmetro externo. Para as demais agulhas temos apenas um valor corresponde apenas ao diầmetro extemo.

\section{7. $\mathrm{O}$ sistema pneumático}

O objetivo do sistema pneumătico é fornecer o ar numa vazão estabilizada para ser soprado no liquido viscoso. $O$ ar é comprimido por um compressor com um reservatório de 75 litros, no qual um pressostato foi calibrado para manter o ar na faixa de pressão entre 70 e 100 psi (libra por polegada quadrada). A pressão do ar é reduzida para $60 \mathrm{psi}$ em um segundo reservatório de 200 litros, através de uma valivula reguladora de pressão. Uma segunda reguladora, próxima do bico soprador, reduz a pressão do ar para 10 psi e a vazão controlada pelo conjunto controlador, formado pelo medidor de vazăo, controlador e válvula solenóide. Deste modo una vazão estável chega atë o bico borbulhador.

\subsection{O sistema sonoro}

A onda sonora gerada no topo do tubo por um alto-falante de bobina móvel. 0 sinal elétrico para o alto-falante é gerado num gerador de funç̋es Tektronix modelo AFG 320 e amplificado em um amplificador de audio Aiwa $O$ gerador de funçôes 
possui uma placa GPIB que permite o controle de todas as suas funçöes através do microcomputador.

A equação de onda [Fletcher e Rossing, 1991] dentro do tubo em coordenadas cilindricas é:

$$
\frac{1}{r} \frac{\partial}{\partial x}\left(r \frac{\partial p}{\partial}\right)+\frac{1}{r^{2}}\left(\frac{\partial^{2} p}{\partial \phi^{2}}\right)+\frac{\partial^{2} p}{\partial x^{2}}=\frac{1}{v^{2}} \frac{\partial^{2} p}{\partial^{2}}
$$

onde $p$ é a onda de pressão na direçăo $x$ e $v_{s}$ é velocidade do som no ar. A solução desta equaçă丶

$$
p_{m n}(r, \varphi, x)=p_{\text {som }}^{\mathrm{zos}}(m \varphi) f_{m}\left(\frac{m q_{m n} r}{a}\right) \exp \left[\hat{\imath}\left(-k_{m m} x+\omega t\right)\right]
$$

onde $J_{m}$ é uma função de Bessel e $q_{m m}$ é definido pela condição de contorno $\partial p / \partial r=0$ e $r$ $=a\left(a\right.$ é o raio do tubo), thal que a derivada $f_{m}^{\prime}\left(\pi q_{\mathrm{man}}\right)$ é zero. Se considerarmos em primeira aproximaçăo 0 tubo borbulhador como um tubo com uma extremidade

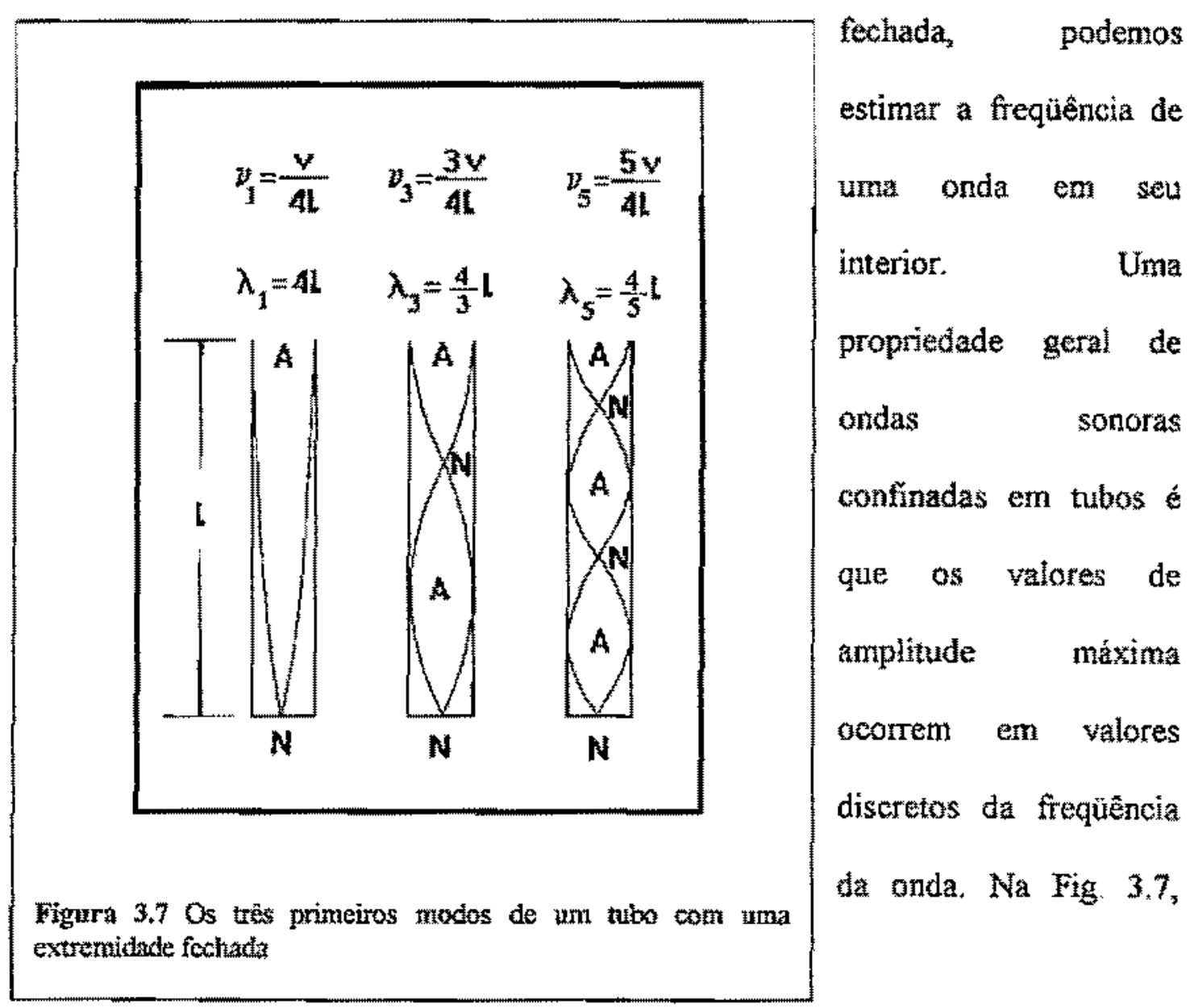


podemos ver os três primeiros modos de um tubo com a extremidade inferior fechada.

A distância do centro do tubo as linhas finas desenhadas dentro deste representa a amplitude de deslocamento da onda em cada ponto. $N$. A designam as posiçoses dos nodos antinodos de deslocamento. As freqüuncias $y_{n}$ de ressonância do tubo săo tadas por:

$$
v_{n}=(2 k+1) \frac{v_{s}}{4 !}
$$

onde $l$ o comprimento do tubo e $k=0,1,2,3, \ldots$, q que nos fornece apenas os harmônicos impares.

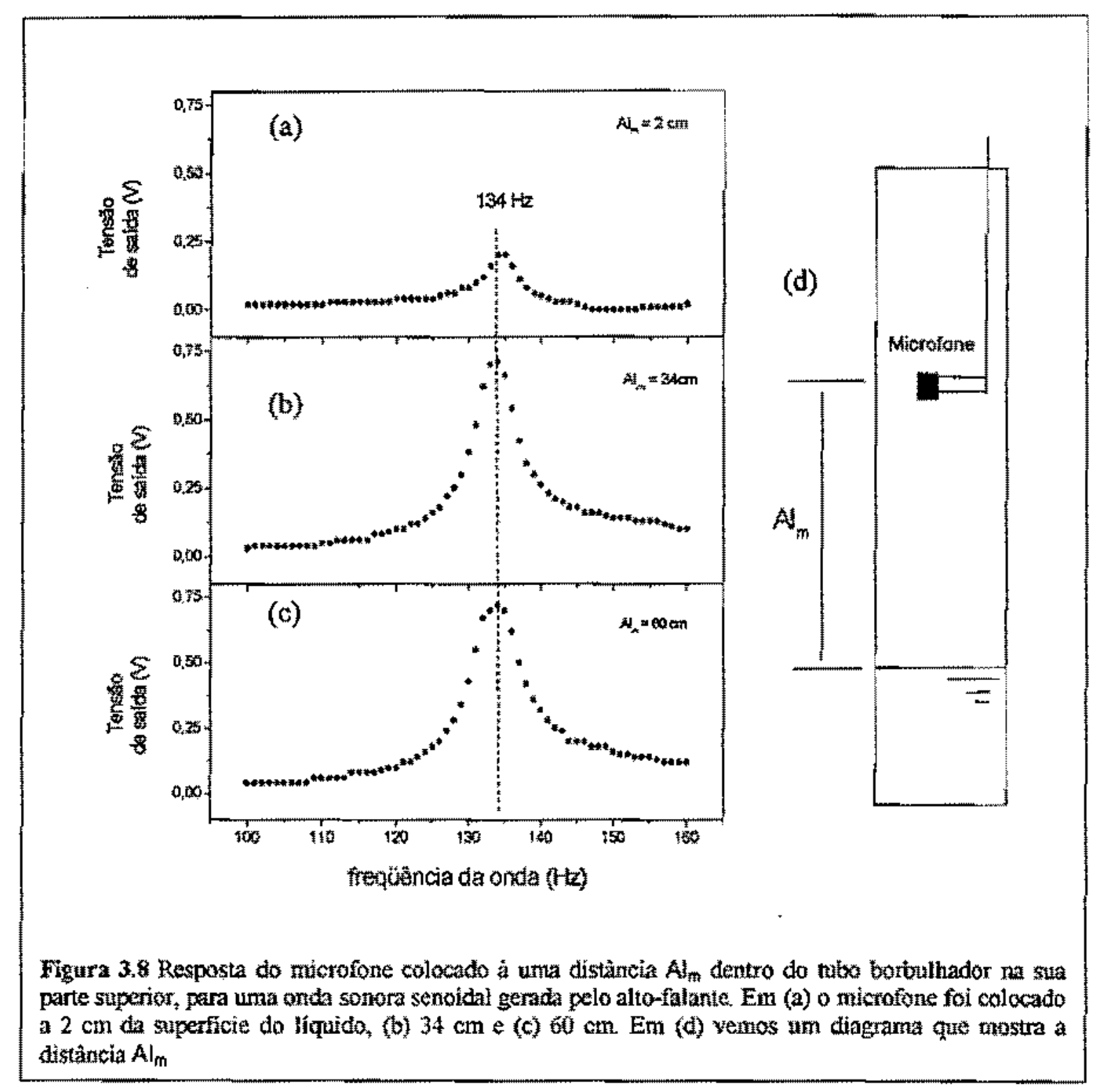


Fô verificada a frequêtencia de ressonância do tubo borbulhador, obtendo um sinal proporcional ao deslocamento da onda sonora, colocando um microfone dentro do tubo. A distüncia entre o microfone a superficie do líguido é $A l_{\mathrm{m}} . \mathrm{O}$ sinal obtido pelo microfone, colocado em três alturas distintas dentro do tubo borbulhador, está mostrado na Fig. 3.8 , onde temos os valores obtidos para as aituras de $2 \mathrm{~cm}, 34 \mathrm{~cm}$ e $60 \mathrm{~cm}$ em relação ao nivel do liquido, com um comprimento de coluna de ar total de $60 \mathrm{~cm}$. Variando a frequência da onda entre $100 \mathrm{~Hz}$ e $160 \mathrm{~Hz}$, obteve-se que a frequêtencia de ressonância do tubo ś de aproximadamente $134 \mathrm{~Hz}$. O sinal do microfone tem a mesma forma que o sinal senoidal injetado no aito-falante.

Depois de determinada a frequêtncia de ressonância do tubo nas condiçốes do parágrafo anterior, obtivemos o sinal do microfone colocado m vários pontos do tubo, para os três primeiros ...armônicos 134,402 e 670 Hz, como está mostrado na Fig. 3,9, de modo a verifficar experimentalmente as posiçôes dos nodos e antinodos de deslocamento. Na Fig. 3.9, podemos ver que a tensão não se anula na origem, portanto a onda não forma um nodo exatamente na superficie do liquido para os três harmônicos, mas parte da onda refrata no liquido.

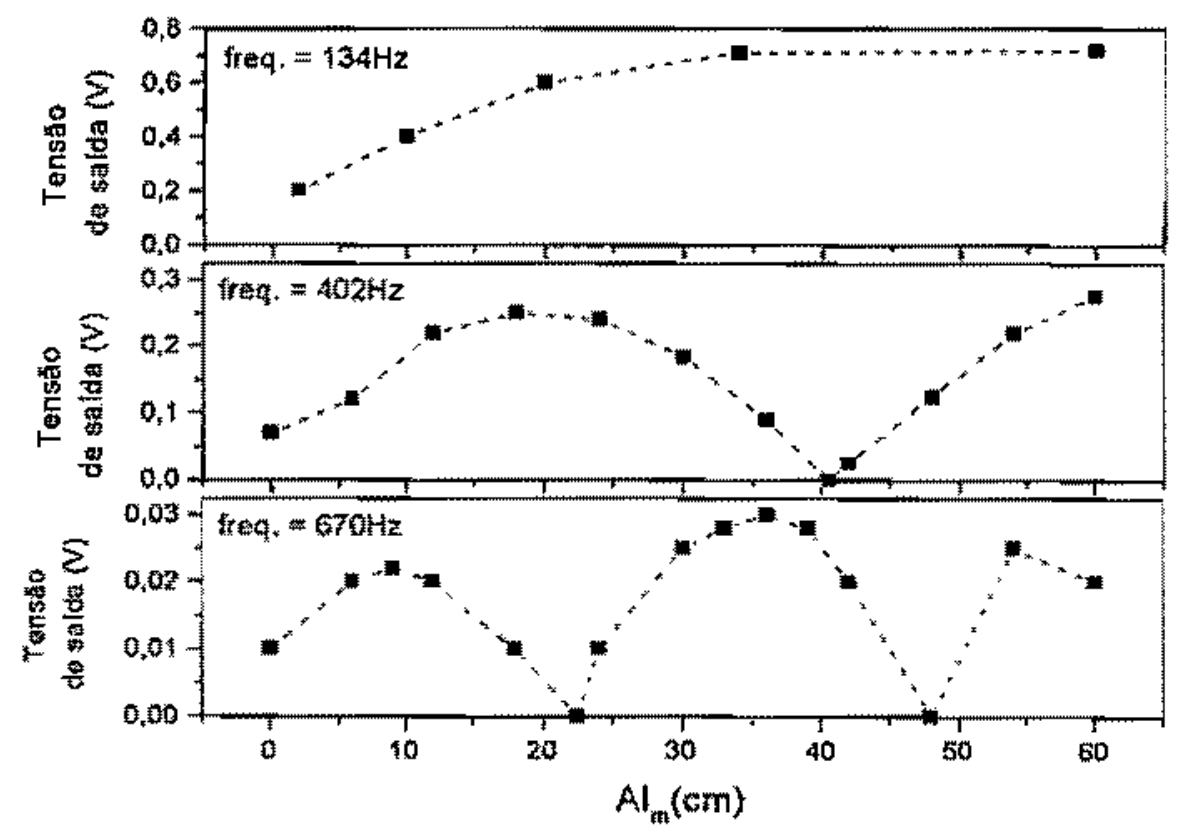

Figura 3.9 Nodos e antinotios đentro do tubo para os trés primeiros hambinicos medidos em

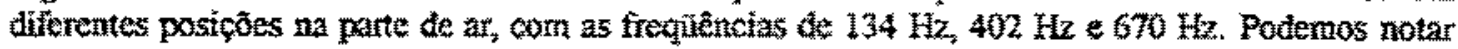
nos trës grăficos que a onda sonon nầ forma exataments um nodo na superficie to liquido. 


\subsection{0 líquido}

O liquido utilizado foi preparado em soluçōes utilizando-se diferentes concentrações de água e glicerina.

A tensăo superficial fol obtida através do mêtodo do tensiômetro de anel [Ueta e Tabacniks, 1989], que consiste em se deterninar a força para se elevar um anei delgado do líquido e relacionando-a com a tensăo superficial, numa temperatura de $25^{\circ} \mathrm{C} \cdot \mathrm{Na}$ tabela 3.2 temos a tensão superficial de alguns liquidos comuns obtidos com este método. Para as diferentes concentrações de glicerina obtivemos os valores da Fig. 3.10.

\begin{tabular}{|c|c|}
\hline Láquido & Tensão superficial (dina/cm) \\
\hline Água destilada & 72 \\
\hline Agua de tomeira & 66 \\
\hline Oleo 20W-50 (Mobil) & 35 \\
\hline Glicerina & 58 \\
\hline Alcool hidratado & 30 \\
\hline Agua com detergente & 36 \\
\hline Detergente & 23 \\
\hline Cafè (soluçăo) & 42 \\
\hline
\end{tabular}

Tabela 3.2 Tensäo superficial de alguns líquidos comuns medidos pelo método do tensiónuetro do anel.

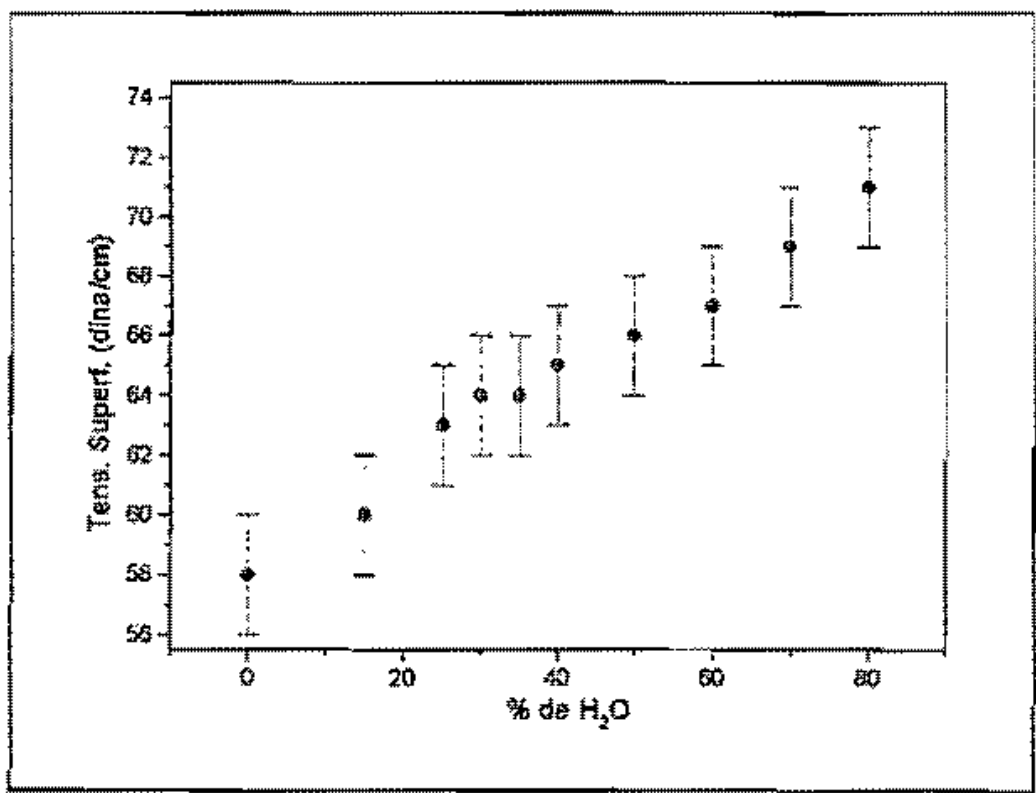

Figura $\mathbf{3 . 1 0}$

Ternsto

superficial

medida com 0

método do

tensionnetro do

ancl para

diferentes

concentraçătes

de água e

flicerina. 
A viscosidade das soluções de água e glicerina foi estimada através do método de Stokes [Ueta Tabacniks, 1989 ] e a viscosidade varia como a função exponencial mostruda na Fig. 3.11 para $25^{\circ} \mathrm{C}$. Para os valores da viscosidade da agua pura e da glicerina para diferentes temperaturas fol consultada uma tabela de viscosidades [Perry e Clinton, 1972; Weast e Selby, 1996].

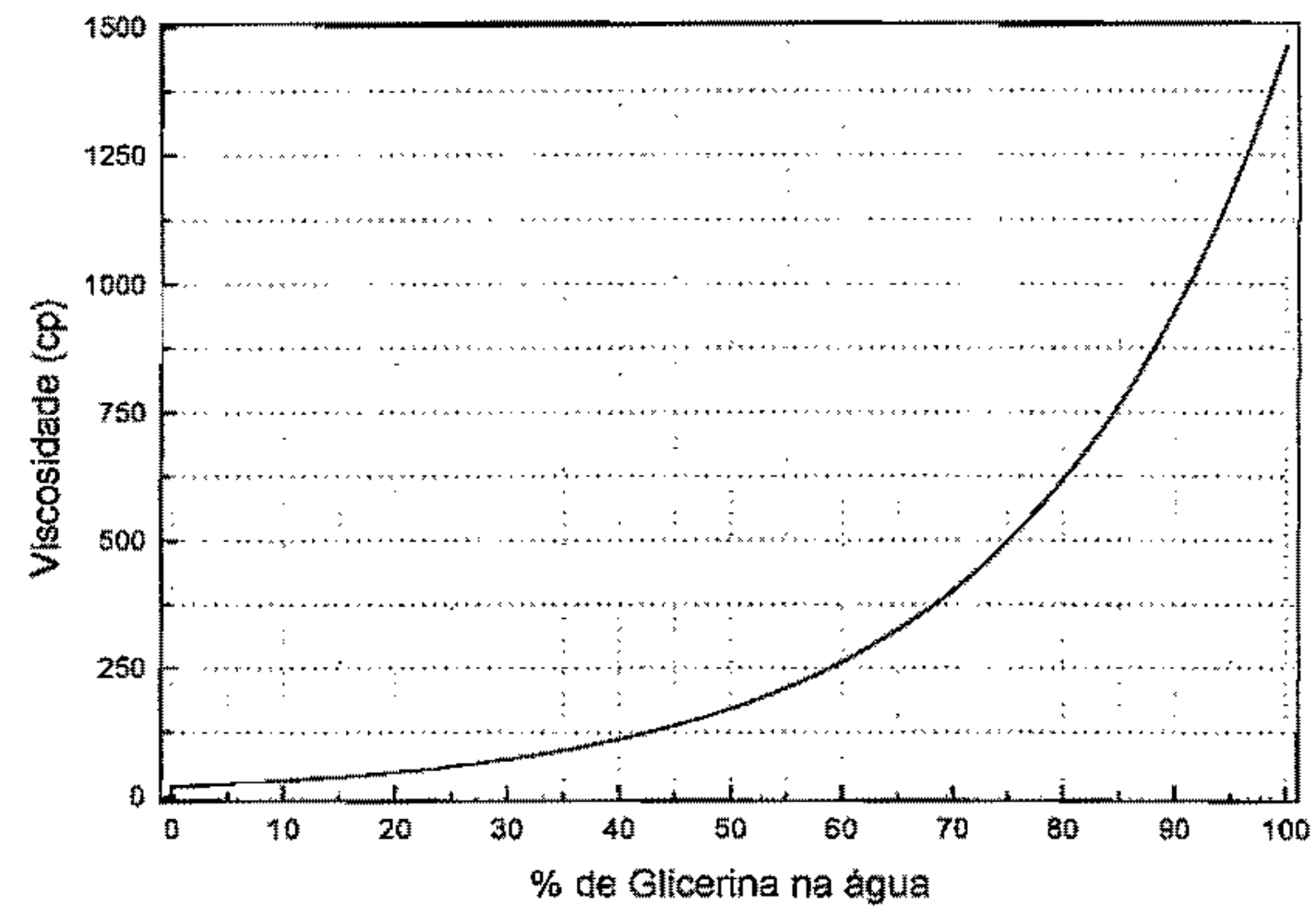

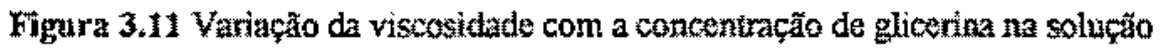

\subsection{Imagens}

Algumas imagens foram obtidas para esclarecer alguns aspectos da formação das bothas. As imagens da formação das bolhas foram feitas através de uma câmera VHS. Para iluminar o tubo borbulhador, utilizou-se a tenica de iluminação traseira, com uma placa translucida para difundír a luz proveniente de uma lâmpada fluorescente, e o tubo borbulhador fot colocado entre a placa difusora de luz a câmera. As imagens obtidas foram digitalizadas e armazenadas. 


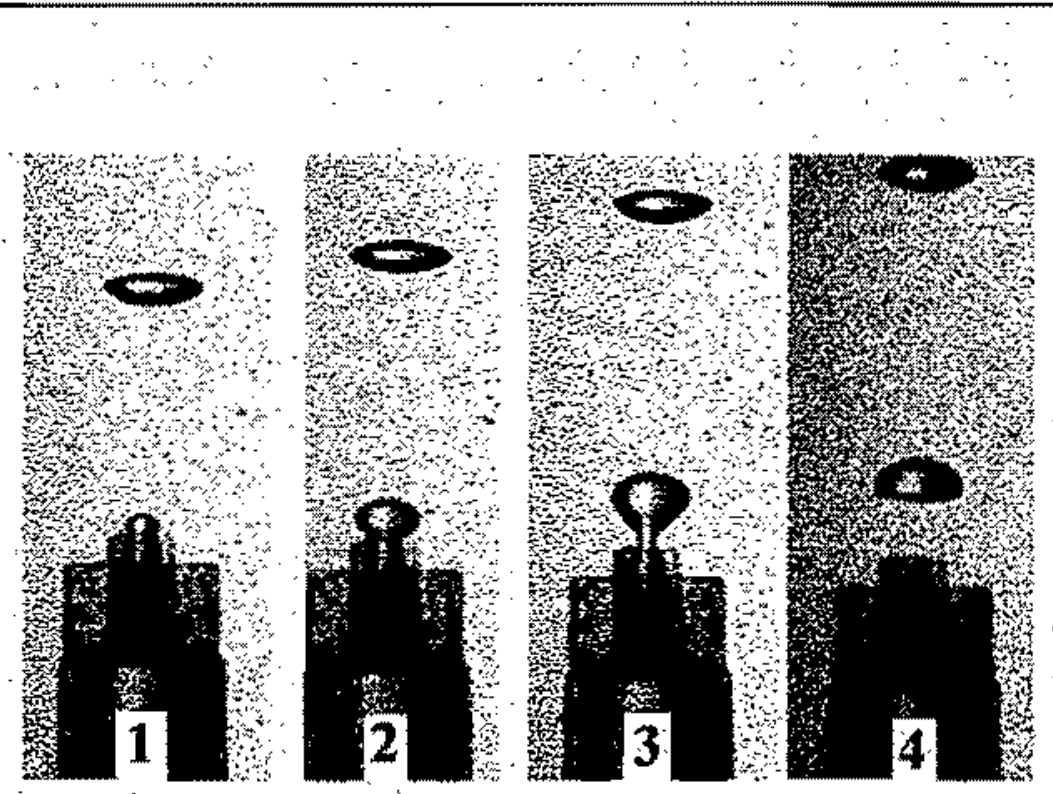

Figura 3.12 Imagens obtidas a partir do experinento do tabo botbalhador. Em (1) vemos uma bolla se formando junto a seringa, enquato a bolha anterior emerge no liquido, (2) a bolha aumenta de volume,

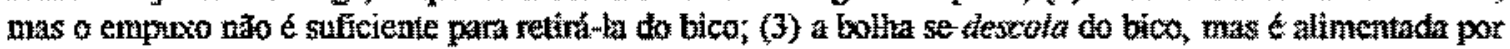

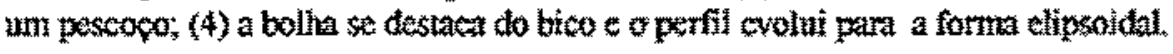

Na Fig. 3.12 temos a cvoluça de uma bolha se formando junto ao bico soprador, numa solução viscosa de ảgua com glicerina, em quatro instantes distintos, $\mathrm{A}$ forma final das bolhas depende de vários fatores, entre eles o seu volume, $\mathrm{e}$ isto pode ser observado nas cinco imagens da Fíg. 3.13.

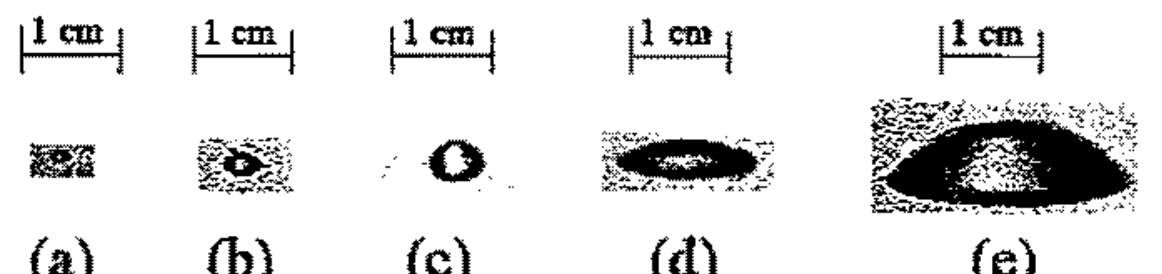

Figura 3,13 Excmplo do perfil das bothas em relacăo ao seu tamanho 


\subsection{O Experimento da Torneira Gotejante}

O experimento da tomeira gotejante foi uma das primeiras tentativas de se criar um sistema com o propósito de se observar o Caos deterministico. Este experimento possui um extenso material produzido pelo LFNL, que pode ser encontrado na forma de dissertaçes de mestrado e teses de doutorado [da Rocha, 1995; da Silva, 1996, Tufaile, 1996; Gonçalves, 1996; Pinto, 1999$]$.

O experimento consiste basicamente de um bico gotejador que a alimentado por um grande reservatorio, como pode ser visto no diagrama do aparato experimental da Fig. 3.14. O tempo associado para cada gota é medido do mesmo modo que o descrito na seză 3.3 para o tempo entre as bolhas, mas para o experimento da tomeira gotejante, o feixe laser está posicionado $\sim 9 \mathrm{~cm}$ abaixo do bico.

Nós controlamos a taxa de gotejamento $\left(f_{\text {gor }}=<1 / T\right)$ mantendo o nivel do reservatório intermediário constante e selecionando a frequência de gotejamento atraves da abertura da válvula acionada por um motor de passo controlada por um microcomputador. Para uma dada taxa de gotejamento, nós construímos os mapas de primeiro retomo.

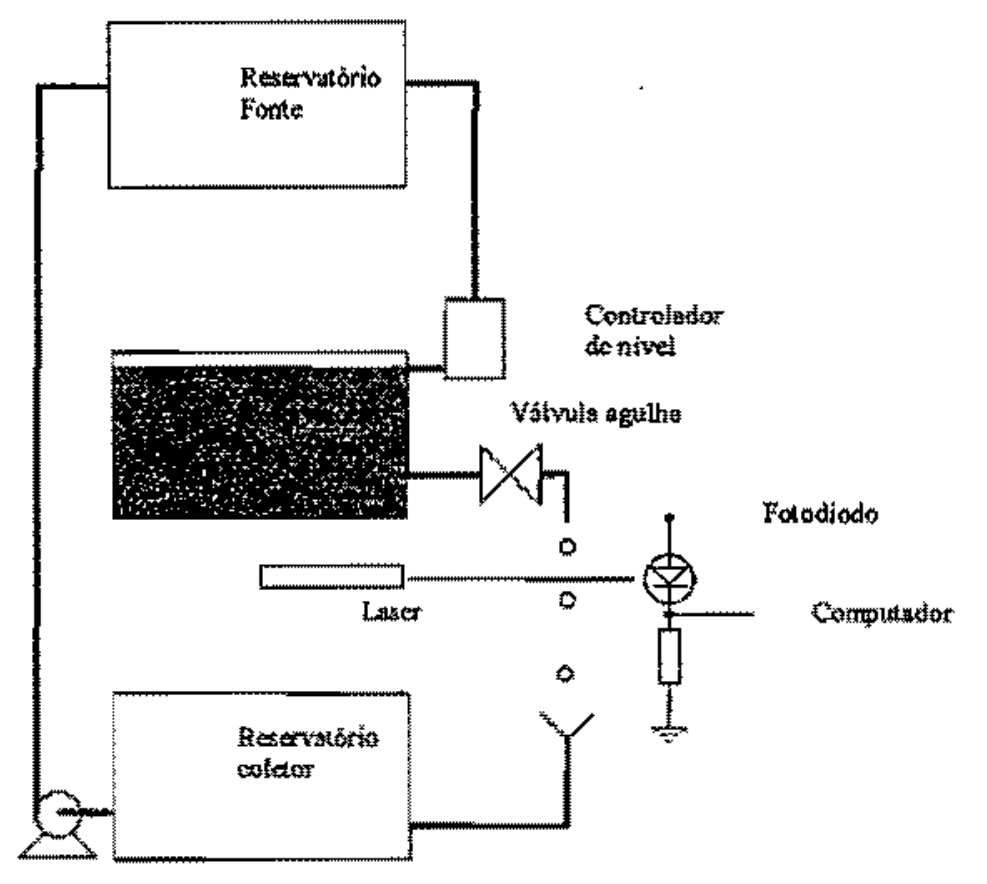

Figura 3.14 Diagrama do experinteuto da torneira gotejante 


\section{Resultados e Análise}

A formaçăo das bolhas ê frequentemente inaginada como o experimento da torneira gotcjante invertido. Esta analogia é fraca e para podermos verificá-la, estudaremos inicialmente a formaça de gotas e depois estudaremos a formaça das bolhas.

\subsection{A torneira gotejante}

As equaçōes diferenciais de primeira ordem, para a tomeira gotejante, propostas no modelo de Shaw [Shaw, 1984], com as modificaçoes de D'Innocenzo a Renna [D'Innocenzo e Remna, 1996] são:

$$
\begin{aligned}
& d x / d t=v, \\
& d(M v) / d t=M g-k x-b v, \\
& d M / d t=Q .
\end{aligned}
$$

onde $x$ é a coordenada do centro de massa da gota $Q$ é o fluxo de água. A tensão superficial eo atrito entre a agua a tomeira säo dados pela constante de mola $b$ e por $b$, respectivamente. Una gota $\Delta M$, se desprende do bico com velocidade $v_{*}$, com o fator de reduçãa z quando o centro de massa alcança o limiar $x_{s}$

$$
\Delta M=C M M_{c} v_{c}
$$

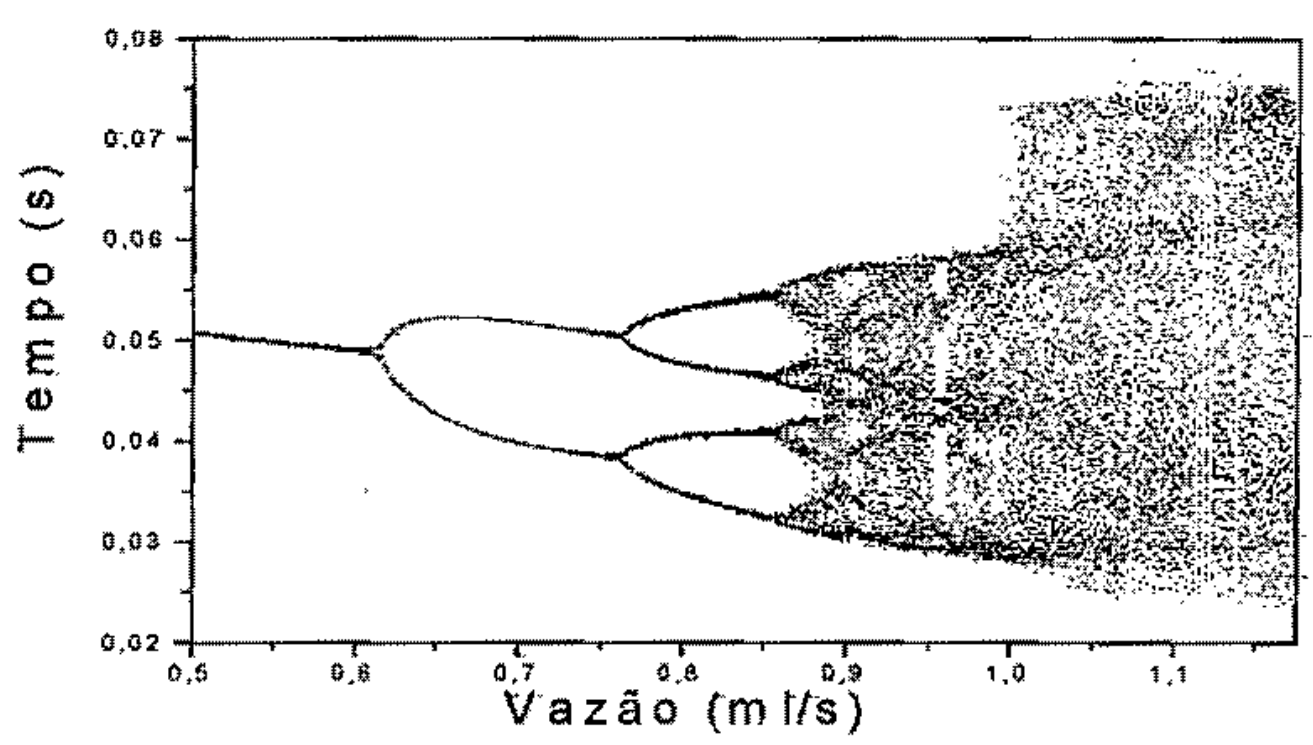

Figura 4.1 Série temporal obtida com o modelo da torneira gotejante variando-se a vazäo $Q . k=475$ dina $/ \mathrm{cm}, \mathrm{g}=580 \mathrm{~cm} / \mathrm{s}, \mathrm{b}=1 \mathrm{~g} / \mathrm{s}, \mathrm{x}_{\mathrm{p}}=0,14 \mathrm{~cm}, \alpha=0,19 \mathrm{~s} / \mathrm{m}$. 
Na Figg. 4.1 mostramos uma série temporal obtida a partir do modelo das equaçöes $(4,1)$, com os parametros $k=475 \mathrm{dina} / \mathrm{cm}, g=980 \mathrm{~cm} / \mathrm{s}, b=1,0 \mathrm{~g} / \mathrm{s}, x_{c}=0,14 \mathrm{~cm} \mathrm{e}$ $\alpha=0.19 \mathrm{~s} / \mathrm{m}$. Na integraçăo do modelo foi utilizado um integrador Runge-Kutta de

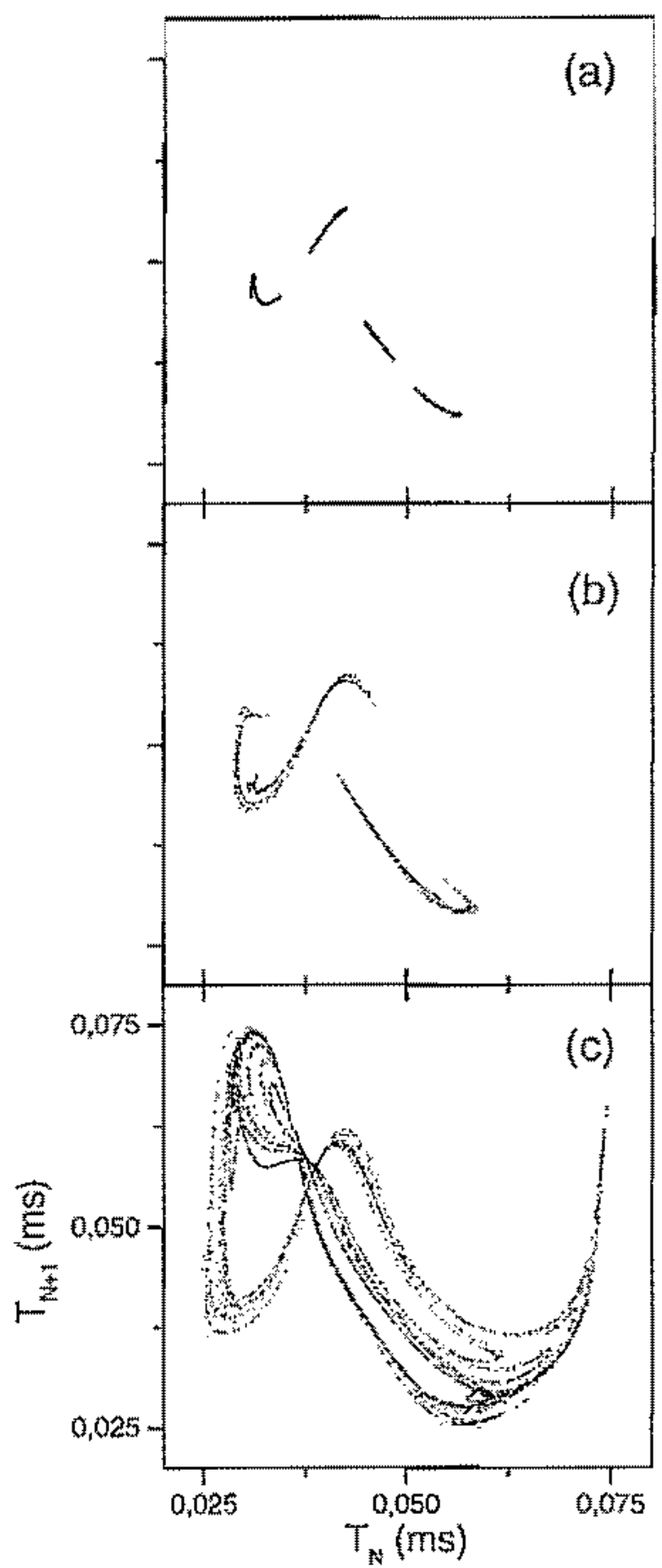

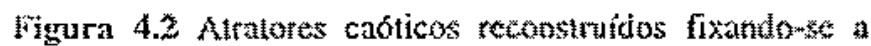
vazäo ern três valores distintos de vazäo $Q$. A dimensüo de Kaplatu-Yorke $\mathrm{D}_{\mathrm{kY}}$ fol catculada para cada um destes almatorts:

(a) $\mathrm{D}_{\mathrm{K} Y}=1,2(1) ;$ (b) $\mathrm{D}_{\mathrm{K}}=1,39(1) ;$ (c) $\mathrm{D}_{\mathrm{KY}}=1,73(2)$, quarta ordem, com passo de integração de $10^{-6}$ e condiçōes iniciats $x(0)=0.0 \mathrm{~cm}$ \& $y(0)=0.1$ $\mathrm{cm} / \mathrm{s}$. Nesta sêtie temos uma sequiência de duplicações de período para $0,5<Q<0,87 \mathrm{mil} / \mathrm{s}$, caos e janelas periódicas para $Q$ acima de $0,87 \mathrm{ml} / \mathrm{s}$, e un alargamento abutupto do atrator próximo de $Q=1,02 \mathrm{ml} / \mathrm{s}$.

Na Fig. 4.2 vemos três atratores para três diferentes valores de vazzẫo $Q$ do modelo. Para calda um destes atratores foi calculado os expoentes de Lyapunoy e sua respectiva dimensāo de Lyapunov, que os catacterizaram como caóticos devido a existencia de expoentes de Lyapunoy positivos. Na Fig. 4.2(a) temos um atrator formado por quatro bandas caóticas, com vazão $Q=$ $0,885 \mathrm{~m} / \mathrm{s}$. Para uma vazäo maior de $0.95 \mathrm{~m} / \mathrm{s}$, Fig. $4.2(\mathrm{~b})$, temos um atrator caótico com duas bandas caóticas. Na Fig. 4.2(c) um atrator caótico mis "largo" apos a crise, para $Q=1,05 \mathrm{ml} / \mathrm{s}$ 

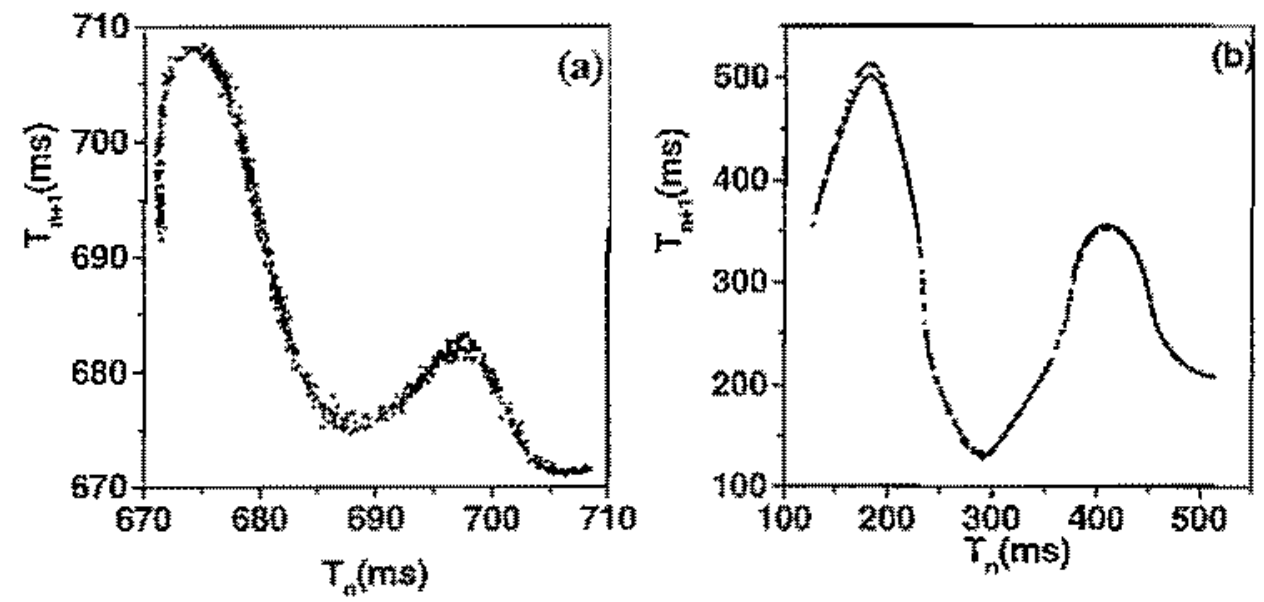

Figura 4.3 (a) dados experimentais para uma freqüềncia đo gotejamento de 1,46 gotas/s. (b) atrator wbtido com o modelo con de oscilador com relaxação com uma freqüerencia de 3,15 gotas/s.

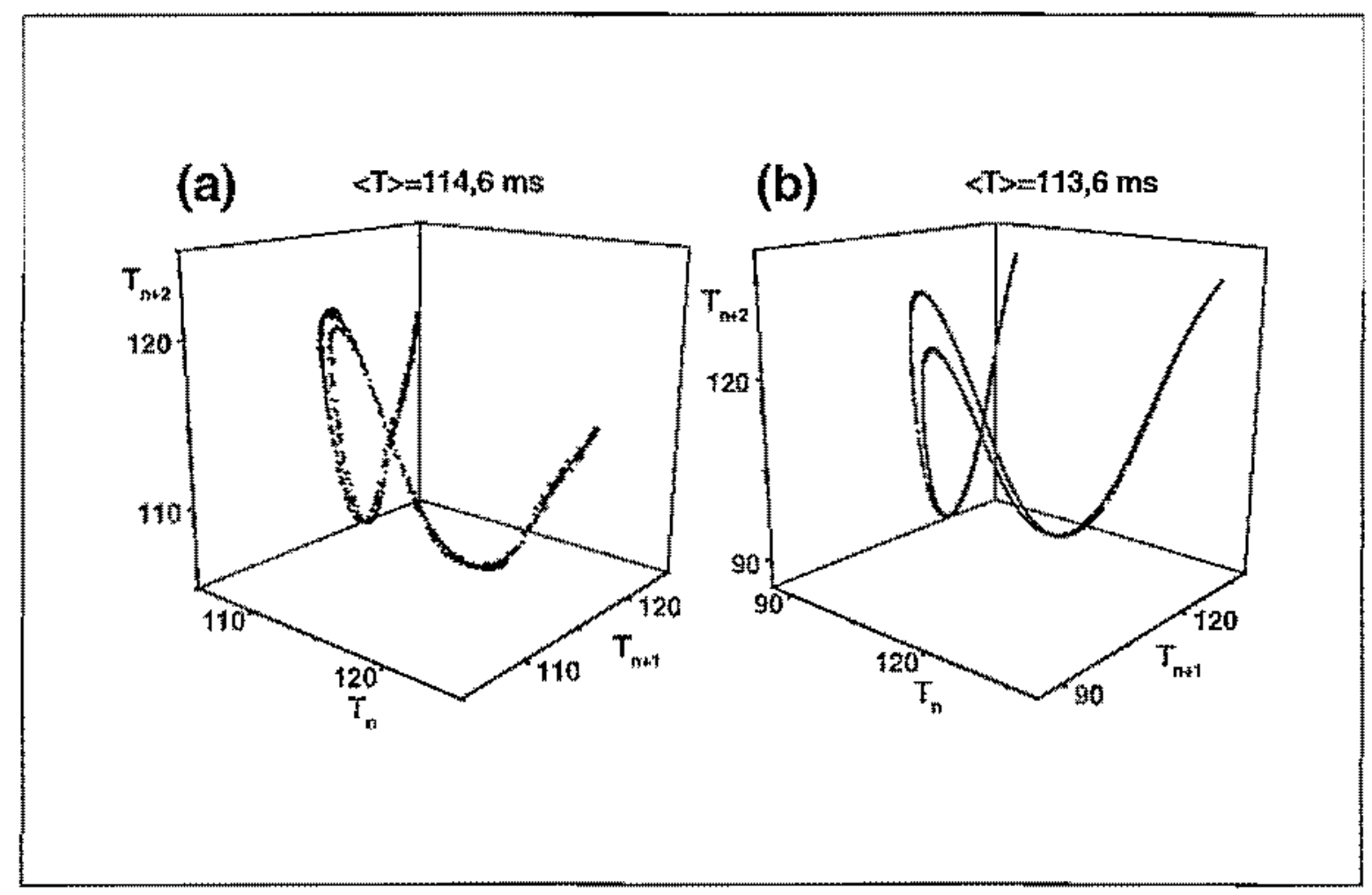

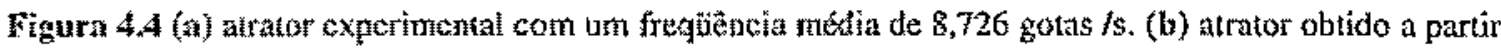
ta simulaçăo com uma frẹülència média de $8,80 \mathrm{gotas} / \mathrm{s}$. 
Fizemos duas comparacones entre os dados experimentais e modelo. [Tufatle et al, 1990, Apendice 1]. Na Fig. 4.3(a) está mostrado o mapa de primeiro retorno experimental mantendo-se constante o nível do reservatório intermediário, com uma freqüência de gotejamento de 1,46 gotas/s, com o bico de vidro. Uma estimativa para os valores experimentais é dada por: $k=365 \mathrm{dina} / \mathrm{cm}_{2} x_{\varepsilon} \sim 0,6 \mathrm{~cm}_{*}$ e $Q$ no intervalo $0,12-0,15$

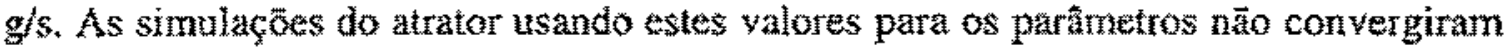
para vátios valores de $\alpha$ e $b$. Desta forma outro conjunto de valores fol procurado para a reproduçăo do atrator experimental. Os valores escolhidos foram $k=475 \mathrm{dina} / \mathrm{cm}, x_{t}=$ $1,3 \mathrm{~cm}, Q=0,15 \mathrm{~g} / \mathrm{s}, \alpha=0,2 \mathrm{~s} / \mathrm{cm}, e b=10 \mathrm{~s}^{4}$, como está mostrado na Fig. $4.3(\mathrm{~b})$, com uma frequiencia de gotejamento de $3,15 \mathrm{gotas} / \mathrm{s}$,

Na Fig. 4.4(a) esta mostrado um atrator reconstrúdo em um mapa tridimensional: $T_{n+z}$ Ys. $T_{n+1}$ Ys. $T_{n}$, com a frequência de gotejamento de 8,726 gotas/s. O perfil do atrator foi simulado com os parâmetros com os seguintes parâmetros: $Q=0,141 \mathrm{~g} / \mathrm{s}, x_{i}=0,251 \mathrm{~cm}, \alpha=0,51 \mathrm{~s} / \mathrm{cm}, b=0,943 \mathrm{~s}^{-1}$, e $k=120$ dina $/ \mathrm{cm}$, como está mostrado na Fig. $4.4(\mathrm{~b})$. A frequência média de gotejamento è te 8,80 gotas/s, proxima do valor experimental. Os dois atratores da Fig. 4.4 apresentam expoentes de Lyapunov positivos e dimentates de Kaplan-Yorke $1,0 \pm 0,1$ (atrator experimental) e $1,1 \pm 0,1$ (modelo),

Outros atratores obtidos a partir de mapas criados baseados neste modelo podem ser encontrados na literatura [Rema, 1999], assim como comparaçoes entre atratores experimentais e simulados na mesma regiāo de vazöos das Figs. 4.3 e 4.4 [D'Innocenzo e Renna, 1997]. Em todas estas referencias o modelo apresenta problcmas quardo os valores escolhidos para os parânetros sāo os mesmos do experimento, que normalmente çusam divergência das soluçōes durante a integraçâo. Uma possível causa destes probiemas é fato de que a gota não se rompe exatamente sempre na mesma posiçẵo, mas em alturas diferentes com relação no bico. Conclumos que este modelo apresenta ctracteristicas qualitativas interessantes, mas que nāo pode ser utilizado para comparaçọes quantitativas com a experiência. Modflicaçoes neste modelo estâo sendo feitas por Fuchikami [Fuchikami at al., 1999], que compara este modelo com outro modelo mais elaborado, que utiliza por princípio físico a minimização da energia com relação a perfil da gota que cresce junto ao bico. O modelo de Fuchikami utiliza uma descriçăa Lagrangeana para calcular numericamente a evoluçăo da formaçăo da gota. 


\subsection{Dinâmica das bolhas}

Veremos nesta seçăo os diferentes regimes de borbulhamento causados pelo aumento da vazâo do ar, e como podemos esclarecer as transiçôes destes regimes através de alguns modelos.

\subsubsection{Formaçāo quase-estấtica}

Devido à complexidade do processo da formação de bolhas, os modelos existentes são adequados apenas em casos particulares [Clift et al., 1978]. Para uma bolha se formando em condiçōes quase-estáticas, o equilibrio de forças na bolha é dado por:

$$
f_{s}=f_{a}
$$

onde $f_{\mathrm{g}}$ e a for orifício do tipo bico circular, a equação $(4,3)$ tem a forma:

$$
m g=2 R_{b} \pi \sigma
$$

onde $m$ é a massa do liquido deslocado pelo volume da bolha, $g$ é acelerą̧äo da gravidade, $R$ e o raio do bico soprador e $\sigma$ é a tensão superficial entre $o$ ar eo líquido.

Tomando um bico com $R_{b}=0,4 \mathrm{~mm}$, e criando-se uma bolha de ar na água nas condições quase-estáticas, quando a tensão superficial do sistema é igual a $0,07 \mathrm{~N} / \mathrm{m}$ e $g$ é igual a $9,8 \mathrm{~m} / \mathrm{s}$, teremos uma massa de liquido deslocado de:

$$
m=1,8.10^{-3} \mathrm{~kg} \text {. }
$$

Como temos a densidade da água igual a $1 \mathrm{~g} / \mathrm{cm}^{3}$, o volume máximo da bolha será dado por:

$$
V=\frac{m}{\rho_{1}}=18 m m^{3} .
$$

Se considerarmos uma esfera de volume equivalente, teremos um raio para a bolha, $r_{b}$ :

$$
r_{b} \cong 1,6 \mathrm{~mm} .
$$

Podemos também estimar a pressâo do ar dentro de uma bolha através da relaçăo:

$$
p_{2}-p_{1}=\frac{2 \sigma}{r_{b}} .
$$

Se a interface não é esférica, mas possui como raios principais de curvatura $r_{a}$ e $r_{b}$, então a equação (4.8) terá a forma: 


$$
p_{2}-p_{1}=2 \sigma\left(\frac{1}{r_{b}}+\frac{1}{r_{b}}\right) .
$$

As diferenças de pressão đas equaçôes (4.8) e (4.9) fornece-nos a pressão laplactana devido a tensäo superfictal[Clift et al, 1978$]$.

Para uma bolha com o raio de $1,6 \mathrm{~mm}$, como calculado na equação (4.7), a diferença de pressấo entre o ar dentro da bolha e a água é

$$
p_{2}-p_{1}=175 P a \text {. }
$$

Para uma bolha a $5 \mathrm{~cm}$ da superficie teremos $p_{j}=500 \mathrm{~Pa}$, então, de acordo com a equaçàio (4.10), a pressẩo dentro da bolha será de $675 \mathrm{~Pa}$, ou seja, a presstăo dentro da bolha é equivalente a uma coluna de água de $67,5 \mathrm{~mm}$.

Esta análise só é válida para sistemas em equilibrio, fora do equilibrio outros métodos de análise sẩo empregados serão discutidos na próxima seção.

\subsubsection{Formação de bolhas con vazão constante}

Podemos obter um modelo para baixas vazoes, fazendo algumas suposições sobre a geometria da bolha [Davidson Schüler, 1960]. $O$ modelo segue as seguintes consideraçōes:

1. A bolha é esférica durante sua formactăo.

2. Não há circulaçăo do líquido ao redor da boha que está se formando, de tal modo que o líquido está em repouso quando a bolha comega a se formar.

3. O movimento de uma bolha não afetado pela presença de uma bolha acima ela

4. A bolha está a todo instante movendo-se na velocidade de Stokes apropriada para o seu tamanho.

5. Quando a bolha atinge o raio máximo $R$ ela se destaca.

Considerando o movimento de uma bolha que se forma em um ponto longe das paredes de um reservatorio infinito nas condiçôs acima, a velocidade do centro da bolha, $v_{2}$ no tempo $t$ após o começo da sua formaçẫo, será dada pela velocidade de Stokes:

$$
v=\frac{2 r^{2} g}{9 v}
$$

onde $\nu$ é a viscosidade cinemática do liquido, dada pela razão entre a viscosidade e a densidade do liquido. Além disso, se $Q$ e o fluxo do găs, então o volume da bolha $V$ é 


$$
Y=Q=\frac{4 m^{3}}{3}
$$

Deste modo, definindo $x$ como a distância entre o centro da bolha e o ponto de suprimento do gás, obtemos a equaçăo que define o movimento do centro da bolha, atraves do seu raio $r$, como uma função de $Q$ e $t$, dados pela equação $(4,12)$. Substituindo $r$ na equaçäo da velocidade de Stokes:

$$
v=\frac{2 g}{5 v}\left(\frac{3 Q}{4 \pi}\right)^{2 / 3} t^{2 / 3}
$$

e integrando a equação (4.11) em relaçäo a nós obtemos o deslocamento do centro da bolha em fungẫo do tempo:

$$
x=\frac{2 g}{15 v}\left(\frac{3 Q}{4 \pi}\right)^{3 / 3} t^{3 / t}
$$

A bolha irá se destacar quando $x=R$, o raio máximo da bolha, com o tempo para a formaçẩo completa da bolha $T$ obtido a partír da equação (4.14):

$$
T=\left(\frac{15 v R}{2 g}\right)^{3 /}\left(\frac{4 \pi}{30}\right)^{3 / 2},
$$

que nos dả uma relaça hipetbolica entre o tempo $r$ da formaça da bolha e a vazno $Q$, como mostrado no gráfico da Fig. 4.5. Com isto obtemos que a relação entre a frequência de borbulhamento $F_{b}=(1 / T)$ e a vazão volumétrica do ar $Q$ é:

$$
F_{b} \propto Q^{0,4}
$$

Este e um modelo razoável para baixas vazőes, pois explica de modo simples as principais caracteristicas da variaçăo da frequêtencia do borbulhamento com a vazăo do ar. Entretanto, as cinco condições para formą̧ăo das bolhas no início desta seção não são rigidamente observadas, isto faz a equação (4.16) ter um caráter principalmente qualitativo. O trabalho de Ponter e Surati [Ponter e Surati, 1997] faz um estudo comparativo entre vários trabalhos que investigam a emissão de bolhas a partir de orificios submersos, e apontam como principal causa da discrepância entre os diferentes resultados experimentais, a influência da superficte do bico soprador e a falta de padronizaçăo da geometria do equipamento. Mesmo com as discrepanciáas, 0 comportamento hiperbolico com as bolhas se formando sequencialmente observado quando se aumenta vazäo [Sullivan at at., 1964]. No nosso trabalho soprando ar diretamente na seringa, para vazós acima de $200 \mathrm{~m} / \mathrm{min}$ ocorrem bifurcaçóes no tempo entre bolhas, e isto e o tema da próxima seçấo. 


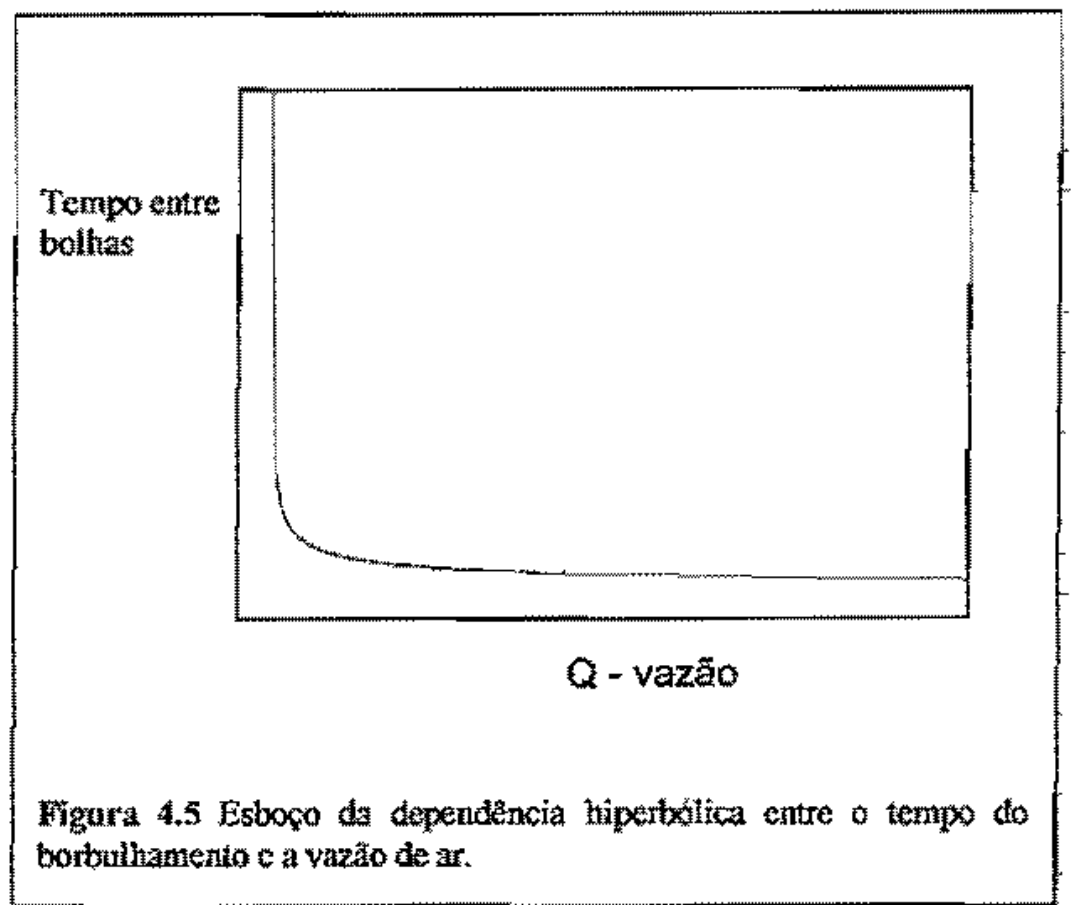

\section{2,3. Bifurcações}

Dependendo principalmente da geometria to bico soprador, para vazões acima de um determinado valor ocorre uma transição de um regime de borbuhamento igualmente espaçado no tempo, para um regime

no qual as bolhas se forman com dois tempos distintos e emergem aos pares, formando um dubleto [Davidson e Schuler, 1960; Marmur e Rubin, 1975; Miyhara ef al., 1983; Tritton e Egdell, 1993; Mitoni et al, 1995; Kyriaides $z$ al., 1997]. Este fato pode ser atribuido à transferêneia de momento do gâs, pois, uma parte do líquido fica agregada à superficie da bolha, formando uma casca esférica líquida, que é chamada de massa viriual $\beta$ [Davidson e Schüler, 1960; Miyhara et at., 1983] reduzindo o empuxo da bolha para 11/16. Além disso, nós podemos fazer um modelo simplificado para a formaçã⿰ das bolhas. Se considerarmos a presença de uma força restauradora de coeficiente $k$ devido à tensão superficial, usando as consideraçōes 1,4 e 5 da seção 4.2 .2 e considerando que existe uma força dissipativa na formaçăo da bolha (que é proporcional à velocidade, $b v$ ). Utilizando a segunda lei de Newton chegarnos as equaçōes tiferenciais de primeira ordem:

$$
\begin{aligned}
& \frac{d x}{d t}=*, \\
& \frac{d(M N)}{d t}=(M g-k x-b v) \\
& \frac{d M}{d t}=Q
\end{aligned}
$$

onde $x$ é a posiçăo do centro da bolha, $M$ é a massa de líquido destocada pela bolha $\left(M=V_{0}\right)$. Além destas equaçỏes, uma quarta equaçăo define quando a bolha deve se destacar. No momento que a la atinge o ponto crítico $x_{c_{y}}$ a bolha se desprende do bico soprador com a massa: 


$$
\Delta M=\alpha M_{c} \mathrm{Y}_{e},
$$

$\operatorname{com} M_{c}$ e $v_{c}$ sendo a massa e a velocidade no ponto de rompimento $x_{c}$, respectivamente. A constante de proporcionalidade de massa é $\alpha$. $O$ diagrama do modelo pode ser visto na nig. $^{4} .6$.

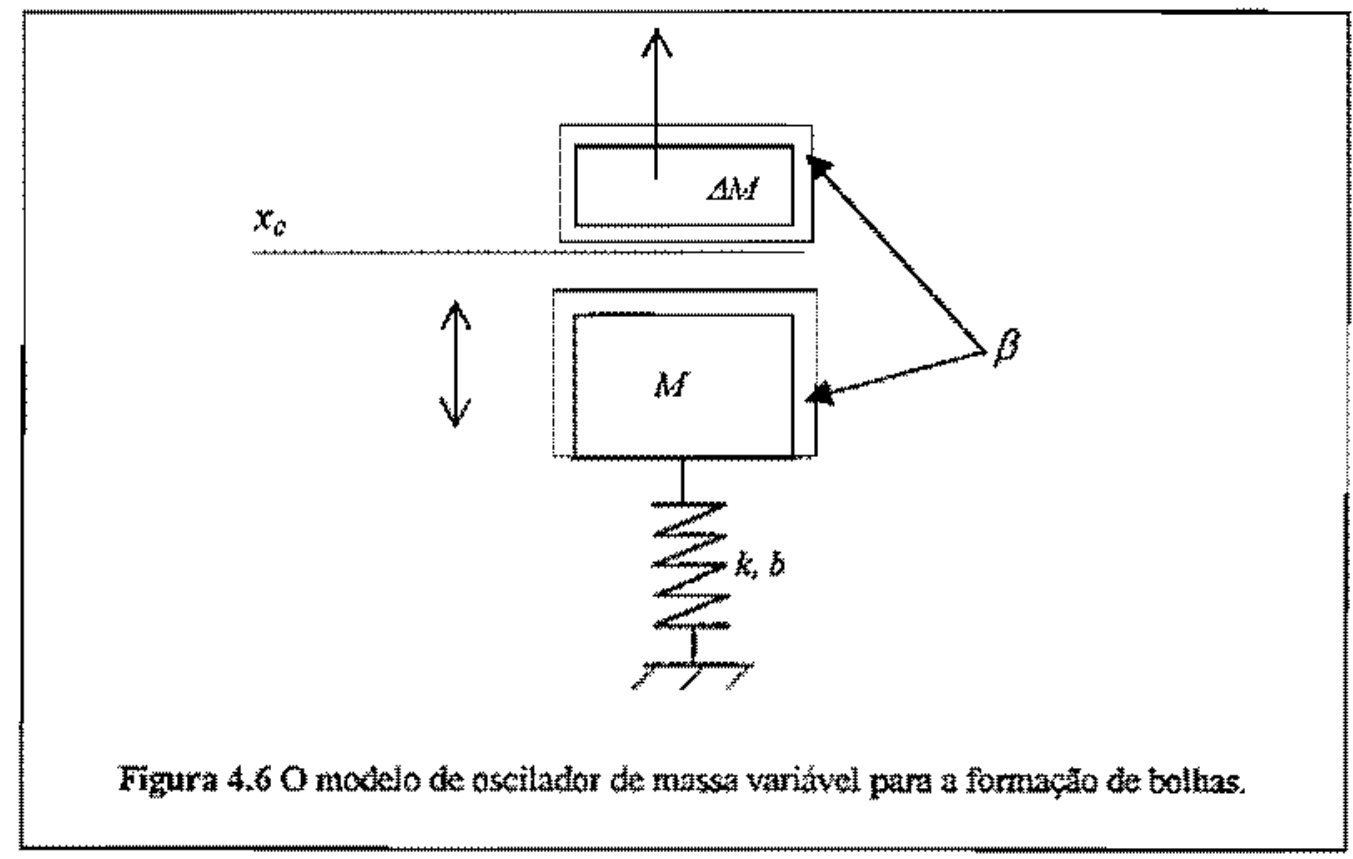


Estas equaçôs foram inspiradas em equaçōes do mesmo tipo para o experimento da torneira gotejante [Tufaile et $a l_{k}$, 1999, Apêndicel] mostradas na seçâo 4.1. Shaw [Shaw, 1984] propos o primeiro modelo para a torneira gotejante inspirado nas idéias de Rayleigh $O$ modelo foi atualizado por Sánches-Oriz e Salas-Brito [Sănches-Ortiz e Salas-Brito, 1995a; Sánches-Ortiz e Salas-Brito, 1995b] e independentemente por D'Imoncenzo e Renna $\left[D^{3}\right.$ Innoncenzo e Renna, 1996], que, através da mudança do mecanismo de rompimento, mostraram uma vasta gama de comportamento cab́tico usando o modalo, e o quanto ele pode ser comparado com dados experimentais. E importante salientar que, apesar da enorme simplificação que se faz quando se reduz um sistema fluido com muitos graus de liberdade para um modelo unidimensional, existem muitos resultados que podem ser compreendidos usando o modelo de oscilador de massa variável, como bifureaçôes, comportamento caótico e janelas periódicas. Seguindo esta linha, Kiyono e Fuchikami trabalham na construçăo de modelos de osctiador de massa variável, utitzando resultados obtidos a partir de seu modelo hidrodinâmico [Kyono e Fuchikami, 1999].

Na Fig. 4.7 vemos espaços de fase para a formação de bolhas para diferentes vazöes, numa sequêtncia que evolui desde o periodo 1 até o comportamento caótico. Para a vazäo de $1,0 \mathrm{~m} / \mathrm{s}$ obtivemos um ciclo límite, com a velocidade crescendo, atingindo um valor maximo e depois diminuindo retomando próximo ao vaior inicial. Neste instante ocorre o rompimento e a proxima bolha inicia o ciclo com a mesma posição da bolha anterior, deste modo o sistema retoma abruptamente ao ponto inicial $(x \rightarrow 0,1 \mathrm{~cm}$ e $\times 1,4 \mathrm{~cm} / \mathrm{s})$. Para a vazäo de $1,8 \mathrm{ml} / \mathrm{s}$ o sistema atinge o ponto de rompimento com duas condiçoses te rompimento distintas, a primeira com uma velocidade ascendente e uma segunda com uma velocidade descendente. Para $2,0 \mathrm{ml} / \mathrm{s}$ temos uma outra duplicą̧ăo de periodo, levando a um período quatro, e finalmente para uma yazăo de $2,15 \mathrm{ml} / \mathrm{s}$ yemos o espaço de fase do comportamento caótico.

A série temporal deste modelo está na Fig. 4.8, e mostra as variações da dínâmica cam a variaçäo da vazăo, na faxa de vazăo $0,8<Q<2,2 \mathrm{ml} / \mathrm{s}$. Para uma vazão por volta de $1,55 \mathrm{ml} / \mathrm{s}$ ocorre uma duplicaçã̃o de periodo. Para $1,97 \mathrm{~m} / \mathrm{s}$ uma descontinuidade na sénie, seguida de novas duplicaçốes a caos. 

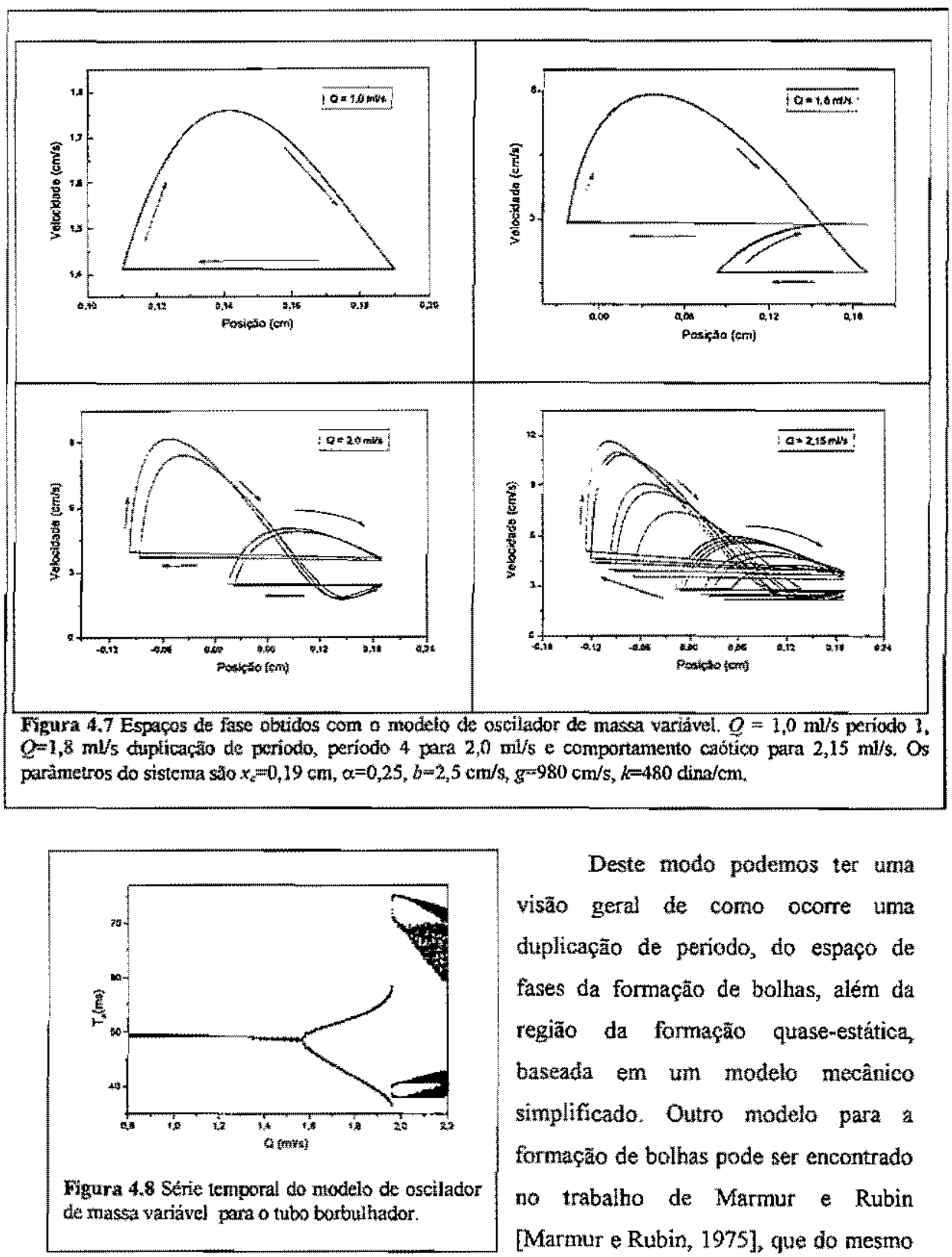

Deste modo podemos ter uma visão geral de como ocorre uma duplicação de periodo, do espaço de fases da formaçấo de bolhas, além da região da formação quase-estatica, baseata em um modelo mecânico simplificado. Outro modelo para a formação de bolhas pode ser encontrado no trabalho de Marmur e Rubin [Marmur e Rubin, 1975], que do mesmo modo que Fuchikami [Fuchikam: et al., 1998], utiliza o formalismo Lagrangeano. 


\subsubsection{Veias liquidas}

Verificamos experimentalmente a ocorrência da agregação de liquido junto à bolha, que causa a reduçăo do empuxo sobre a bolha. Utilizando um sistema de três fases (ar, agua o oleo), observamos a formaçäo de veias liquidas. Uma veia líquida ocorre quando temos um canal de água dentro do óleo, que sustentado pela emergência das bolhas, como pode ser visto no diagrama da Fig. 4.9. Na literatura existem classificaçöes para padrôes de lluxos de duas fases como o padrấo de borbulhamento, padrão de jateamento e padräo anular [Sharpe, 1994]. O primeiro caso, borbulhamento, é o caso tratado neste trabalho; o padräo de jateamento [Ruzicka, 1997] ocorre quando o gass possui velocidades maiores do que a do borbulhamento e é espargìdo dentro do líquido; o terceiro caso, o padrăo anular, ocorre para velocidades ainda maiores do gás, que passa pelo centro do liquido, formando um tubo gasoso, com goticulas do liquido subindo pelo centro junto com o gats. Devido a propriedades viscoelásticas do óleo, diferença de cor entre o óleo a a água, e a refraçẫo do sistema água-ar, podemos ver a formação desse padrão anulat, a veia liquida, num sistema de três fases, ar, água e óleo, e deste modo verificar o arrasto da água junto com as bọlhas.

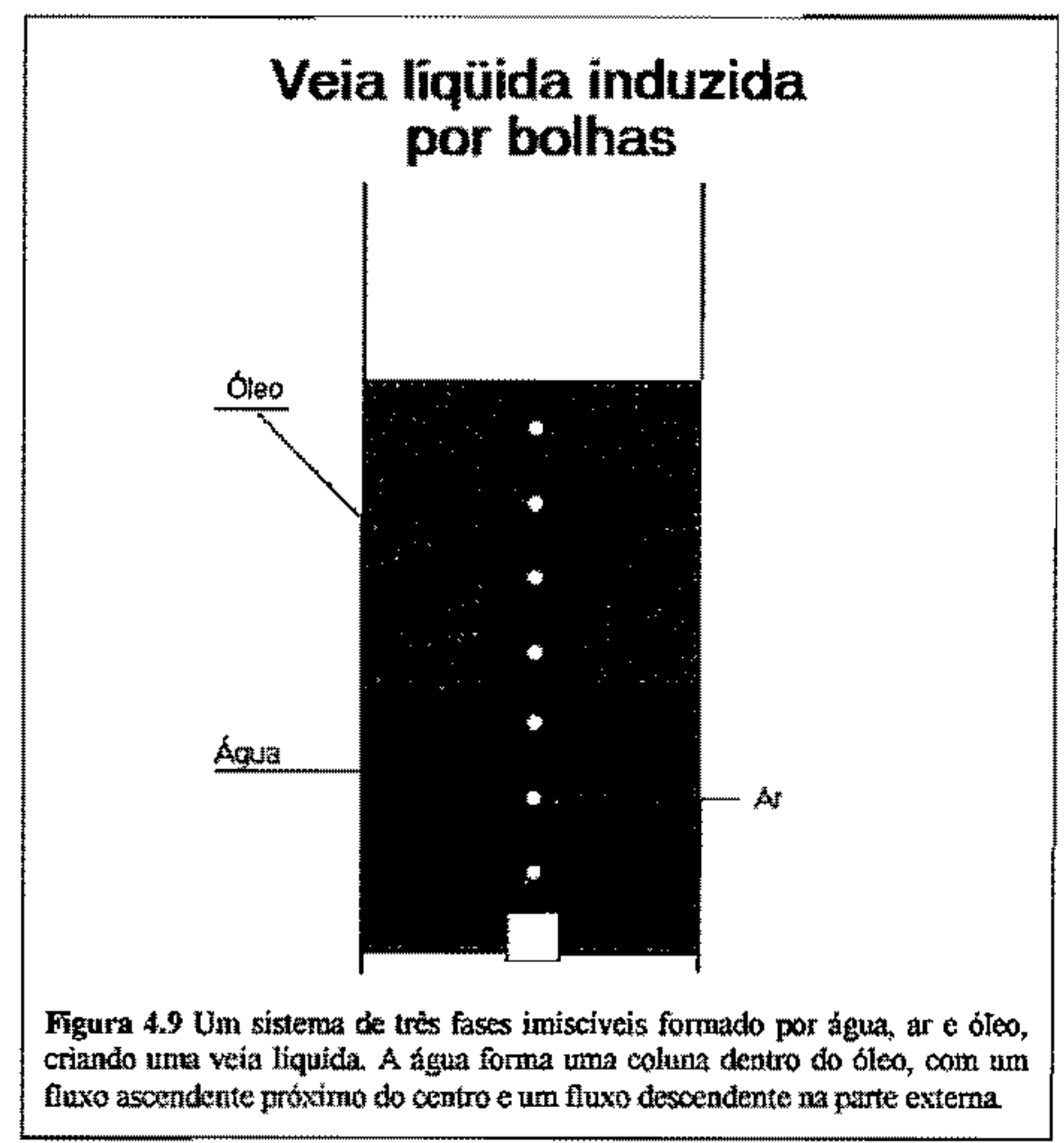


O liquido que envolve a bolha deve ter a mesma velocidade da superficie da bolha, formando uma casca esferica de líquido. A casca esfêtrica de água acompanha a bolha até o ponto em que ela atinge a superficie do sistema liquido, a partir deste ponto, este volume de agua é afastado lateralmente e inicia a descida para a base da coluna. Na Fig 4,10, podemos ver uma imagem obtida no $\mathrm{LFNL}$ de uma veia liquida.

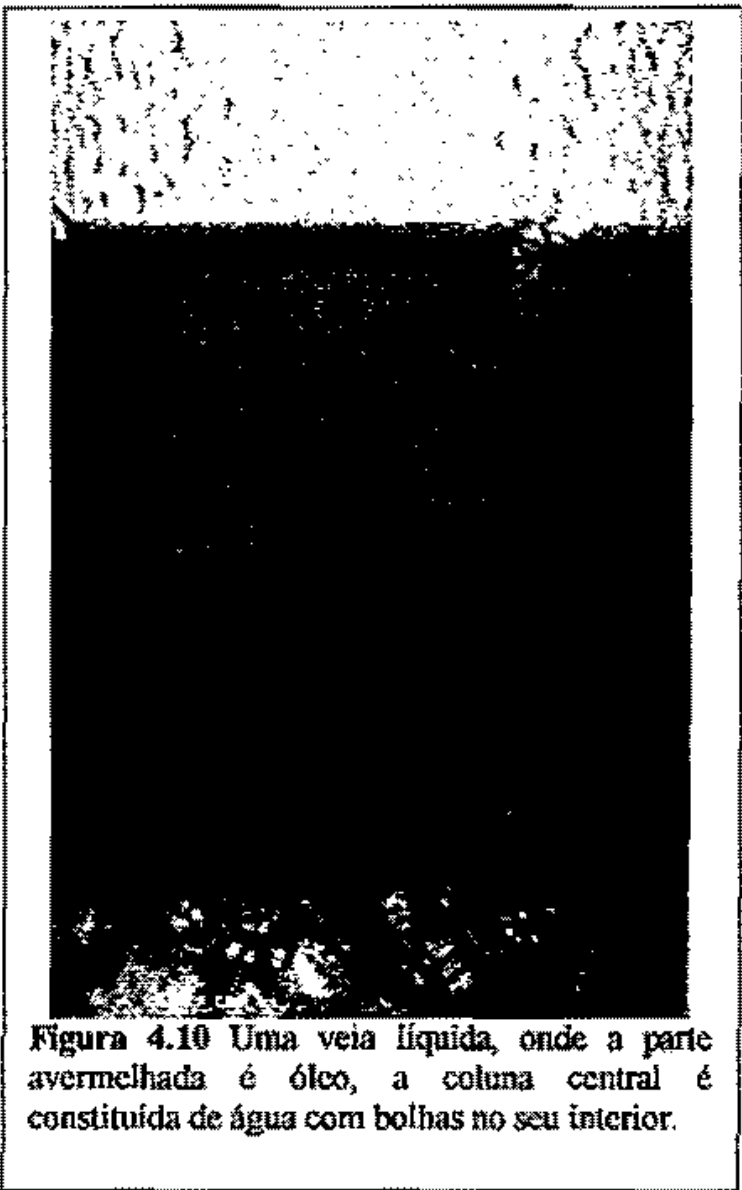

A existência da massa de liquido agregada junto à bolha mostra que, a experiềncia do tubo botbulhador nầo o experimento da torneira gotejante invertido.
Se aumentarmos a vazẫo de $\operatorname{ar}$, inicialmente ocorre uma acumulaçäo de agura sobre o óleo, que depois se precipita, na forma de uma bolsa de ägua, como podemos ver na sequêtencia de imagens da Fig. 4.11. Deste modo o fator de massa agregada, $\beta$ das equą̧öes $(4.17)$ e uma das principais diferenças entre os modelos de oscilador para bolhas e gotas.
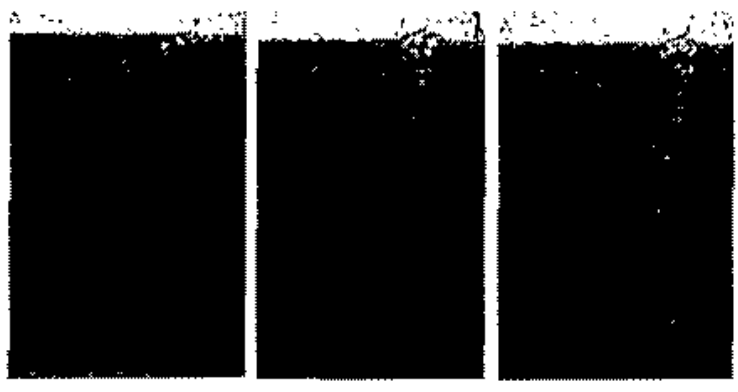

Tgura 4.11 Aumbentando-se a frequetencta de bolhas, a agua se acumula no topo da coluna (a), a núbuulo de

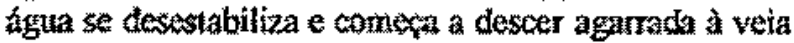

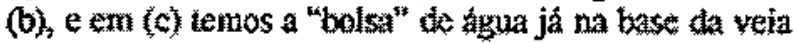
liqulidata. 


\subsubsection{A estabilidade de dois fluidos sobrepostos}

O problema físico fundamental na formação de bolhas em liquidos è a superposição de dois fluidos de densidades muito diferentes. O estudo de instabilidades hidrodinâmicas aborda tal problema, além de outras instabilidades que também são tratadas de um ponto de vista matemático muito interessante, no livro Hydrodynamic and Hybomagnetic stablity, de Chandrasekhar [Chandrasekhar, 1981]; onde foram estudadas as soluçotes das equaçōes hidrodinâmicas para doís casos nos quais ocorre a

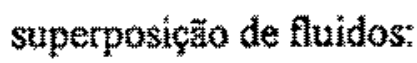

a) A instabilidade de Rayleigh-Toylor, que trata da instabilidade da interface plana entre dois filutios;

b) A instabilidade de Kelvin-Helmholtz, que surge quando camadas diferentes de fluidos heterogêneos estratificados estão em movimento horizontal relativo.

Os problemas de instabilidade hidrodinâmica envolvem o reconhecimento de fluxos estáveis e instáveis, que são obtidos para determinados valores dos parâmetros que governam o sistema. Como exemplos temos o número de Rayleigh, para a convecção de calor num fluido entre duas pacas, uma acima e outra abaixo do fluido; ou o numero de Taylor para o comportamento do fluido entre dois cilindros coaxiais girantes. Restringindo-se à instabilidade de Rayleigh-Taylor, temos um arranjo com dois fluidos de densidade uniforme, um com a densidade $p$ sob outro com densidade $\rho_{2,}$ sendo que $p_{2}$ e maior que $\rho_{l}$ num campo gravitacional $g$. A superficie horizontal que separa os dois fluidos tem a tensão superficial $c$. Este sistema possui um número de onda crítico $k_{e_{x}}$ para as oscilações entre os fluidos, dado por:

$$
k_{\mathrm{r}}=\sqrt{\left(p_{2}-p_{1}\right) g(\sigma}
$$

Os sistemas com números de onda no intervalo $0<k<k_{\text {a }}$ são instáveis; quando $k>k_{k *}$ temos um estado marginal ou limite. De um modo geral, a tensäo superficial estabiliza arranjos potencialmente instáveis. Levando em conta que a unidade de medida de $k_{c}$ $1 / \mathrm{m}$, obtemos um número puro, conhecido como número de Rayleigh-Taylor, RT, que determina a estabilidade do sistema de fluidos sobrepostos:

$$
R T=\frac{g^{2} \Delta \rho}{\sigma}
$$

onde l é um comprimento característico do sistema. Este número está relacionado diretamente com o uúmero de Eôtvös (Eo) [Clift et al., 1978] para partículas, gotas e bolhas, dado por: 

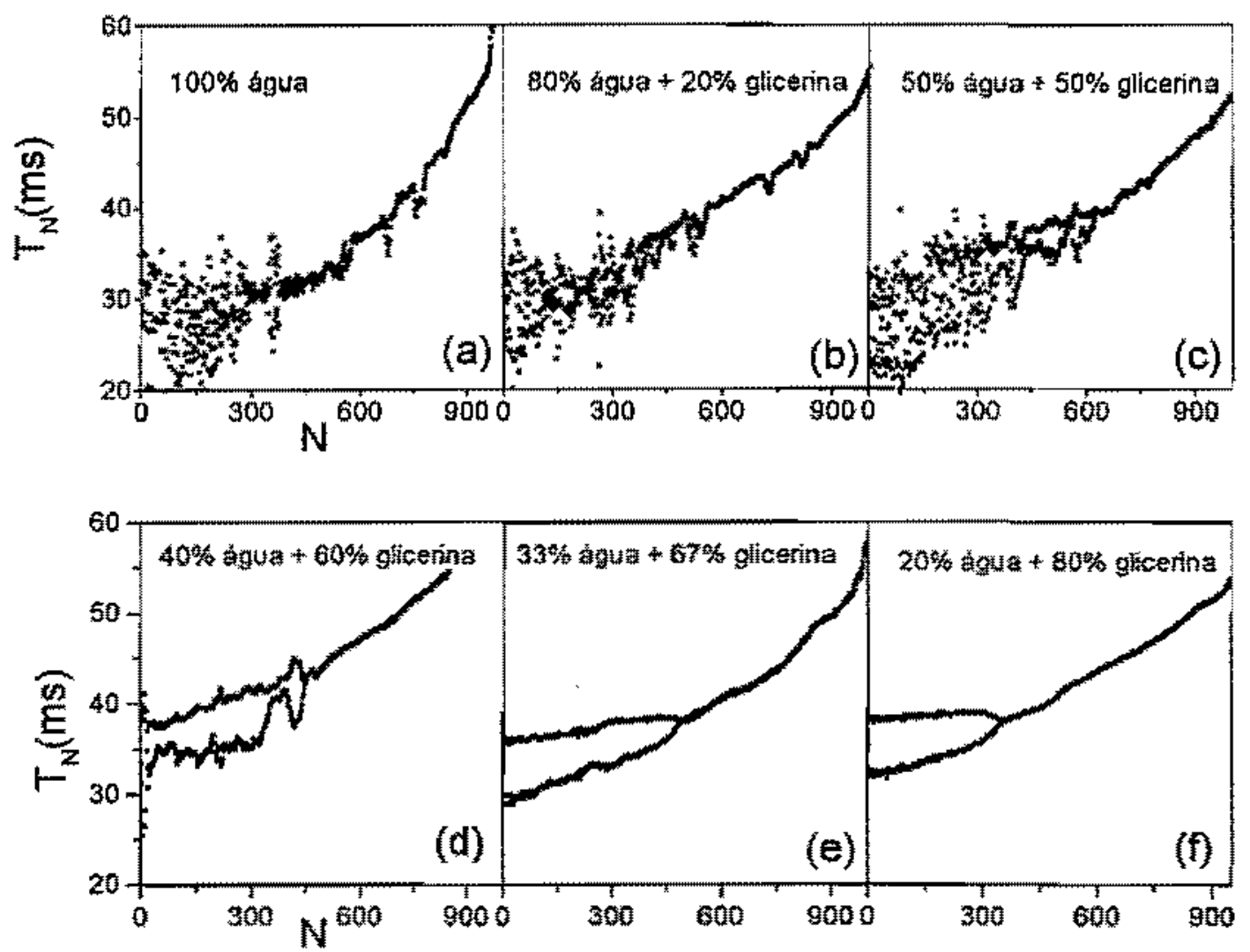

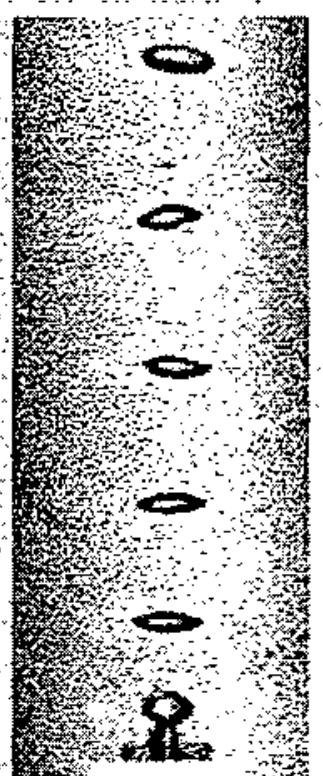

(g)

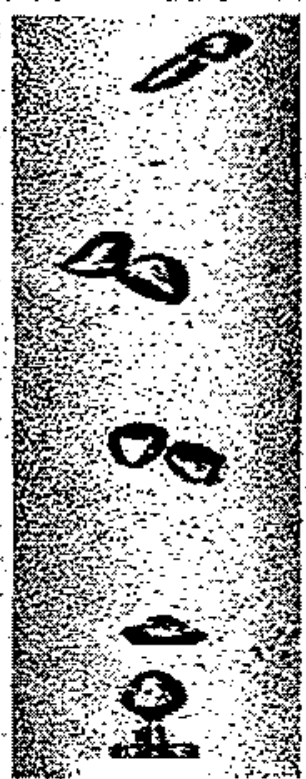

(h)
Figura 4.12 Graficos da transiçầ do regime do borbultamento, diminuindo-se a vazăo do ar, 0 ammento da yiscosidade catusa uma definição da chupticaço de perído no experimento do tubo bortbulhador, como pode ser visto nos gráficos mostrados de (a) ate (f). A duplicaçato de parícto tanbém é visfivel espacialmente, como estả mostrado en (g) que temos - periodo I com as bolhas se elevaudo igualmente espacadas, c en (h) onde temos o periodo 2, vemos a formacão dos dubletor de bollhas $(33 \%$ água $+67 \%$ glicerina). 


$$
E o=\frac{g d_{c}^{2} \Delta \rho}{\sigma}
$$

onde $d_{*}$ e o diâmetro de uma esfera de volume $V$ equivalente, $d_{\mathrm{s}}=(6 \mathrm{~V} / \pi)^{1 / 3}$, da particula, gota, ou bolha, obtido pela média de seus raios principais.

Medimos o numero Eo juntamente com o número de Reynolds, Re, das bolhas [Clift et al., 1978], $(\operatorname{Re}=u d, \rho / \mu$, onde $u$ é a velocidade da formaçã da bolha, $\mu$ é a viscosidade, e $\rho$ é a densidade do liquido). Quando o sistema passa do regime de periodo 1 para uma bifurcaçăo ou alargamento abrupto do tempo entre bolhas,

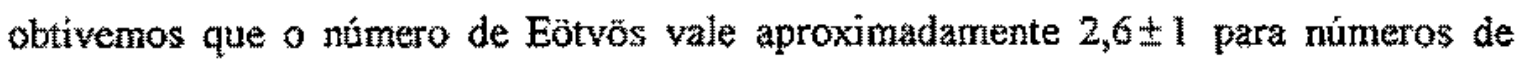
Reynolds entre 200 e 1500 . Este resultado foi verificado para todos os bicos utilizados neste trabalho.

\subsubsection{Instabilidade da superficie da bolha}

Utilizando algumas concentraçöes diferentes de glicerina e o bico de seringa, verificamos, no experimento do tubo borbuhador, que os tempos entre bolhas ocorrem em período 1 para baixas vazōes (0 a $100 \mathrm{~m} / \mathrm{min})$ e que para faixas maiores de vazão, os tempos entre bolhas ocorrem dentro de uma faixa de valores para baixas concentraçôes de glicerina, ou em dois valores de tempo, caracterizando um periodo 2 para concentraçöes maiores que $50 \%$, como pode ser visto na Fig. 4.12. Podemos ver que com o aumento da viscosidade do liquido, os ramos que ocorrem no periodo 1 , assim como os ramos do periodo 2 ficam com valores mais estáveis. Segundo Mittoni [Mittoni et al., 1993] o aunnento da viscosidade através da glicerina produz atratores mais estruturados e reprodutiveis, pois o aumento da viscosidade aumenta também a estabilidade do envelope da bolha e atenua a circulação do liquido próximo do bico. Este fato pode ser visto nas imagens da Fig. 4.13 , onde temos um conjunto de imagens antes (a) e depois (b) da duplicą̧⿸丆o para a água, e duplicação de periodo para a glicerina (c, d). Deste modo a viscosidade suprime instabilidades que podem levar à variaçôes no tempo de formação da bolba.

A instabilitade na formaçẩo devido à baixa viscosidade pode ser vista na Fig. 4.14 , onde temos uma comparação entre a água e a soluçăo com $80 \%$ de glicerina e $20 \%$ de água. Na Fig. 4.14(a) temos o mapa de primeiro retorno com 10.000 pontos, para o 
bico de seringa, com uma altura de coluna de $3 \mathrm{~cm}$ e una yazão de ar mantida constante $\mathrm{em} 50 \mathrm{ml} / \mathrm{min}$.

Este regime de borbulhamento corresponde a um periodo I para água com os pontos se espalhando num intervalo entre $75,92,5 \mathrm{~ms}$ a $\mathrm{Fig}, 4,14(\mathrm{~A})$, vemos o histograma correspondente à frequêtrcia de visitaça dos tempos entre bolhas, com um valor mẻdio de 87 ms. Para o liquido com $80 \%$ de glicenina e $20 \%$ de água, temos o atrator da Fig. $4.14(\mathrm{~b})$, com as demais condiçoes semelhantes ao caso anterior, tambem com 10.000 tempos entre bolhas e mig, 4. 14(B) temos o histograma para este atrator. Os pontos neste atrator estâo entre $82,7 \notin 83,5$ ms, muto mats concentrados do que 0 caso anterior.

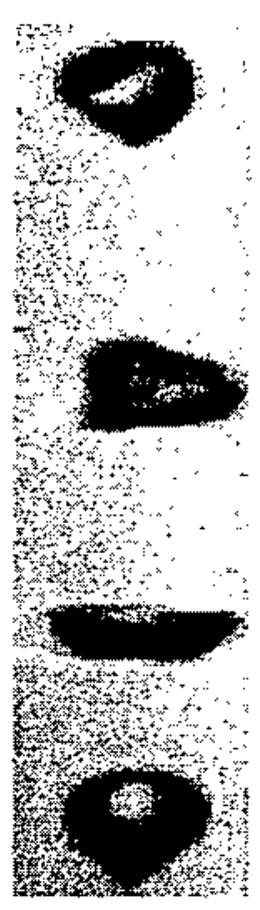

(a)

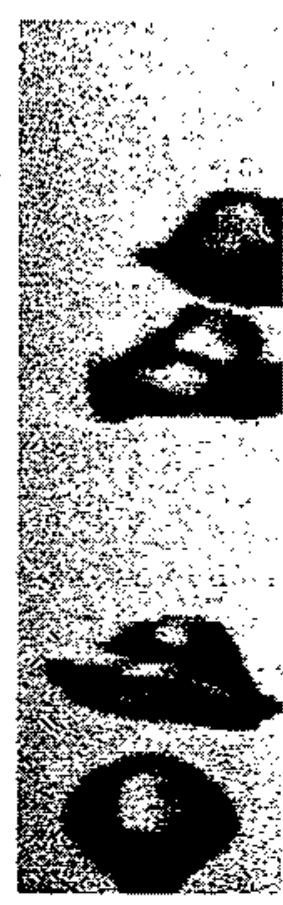

(b)

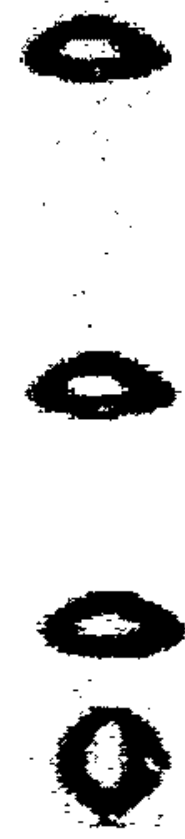

(c)
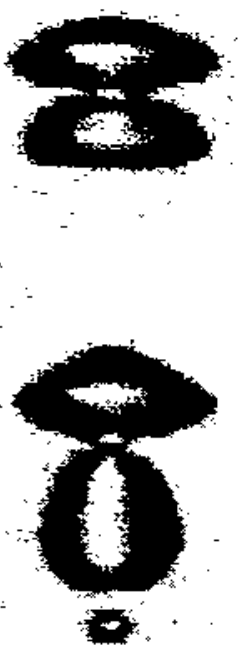

(d)

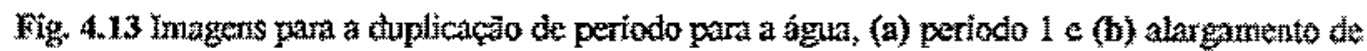
periodo, 10 liqudo visco50 $20 \%$ agua $+80 \%$ glicerina com periodo 1 em (c) pentodo 2 en (d). Nestas ünagens podemos notar que a superficie das bolhas emergentes salo mais estáteis para o líquido mais viscoso do que para a água. 

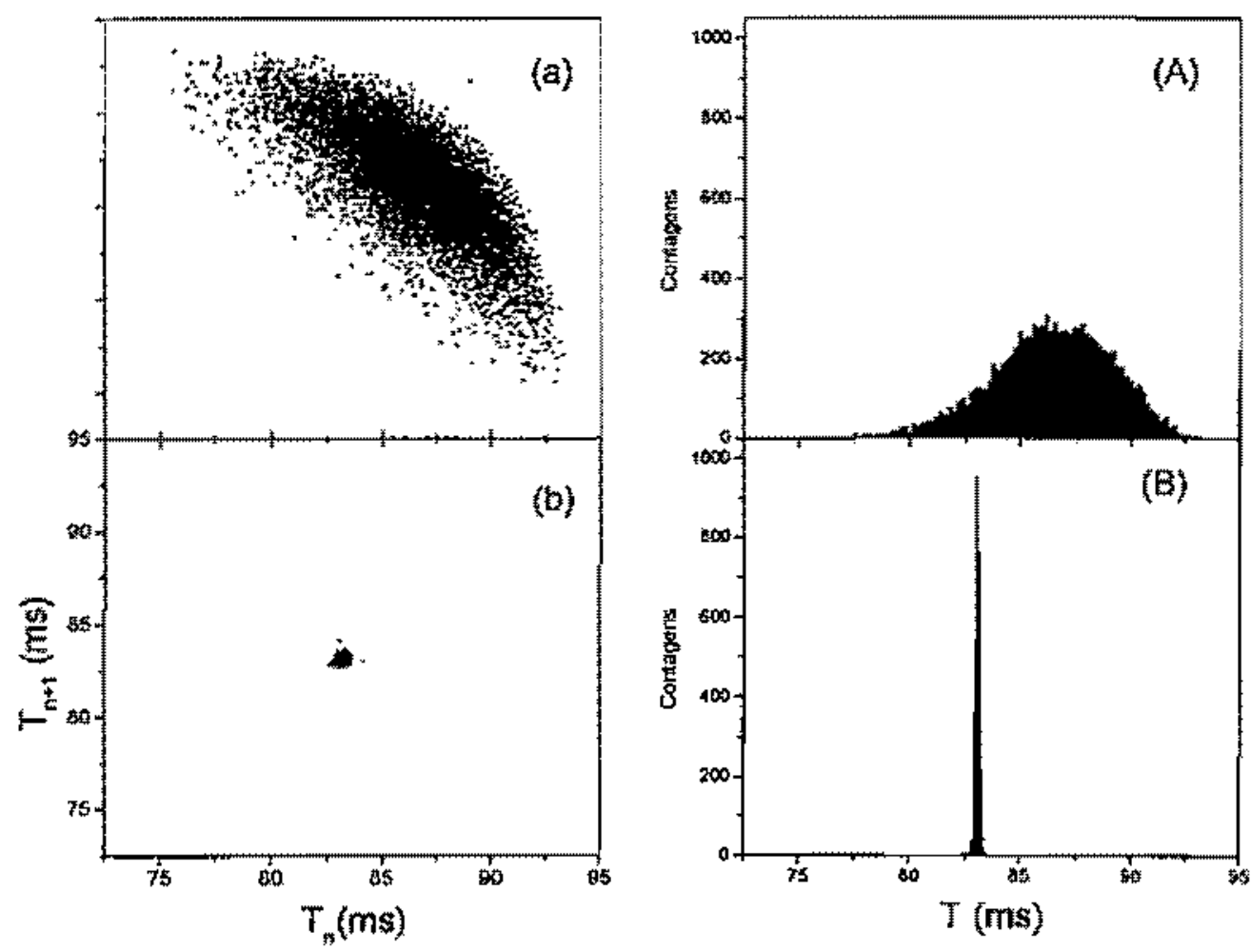

Figura 4.14 Mapas de primeiro relomo (a) para água $e$ em (b) para solução $80 \%$ glicerina e $20 \%$ aga. Em (A) lemos - histograma para os 10.010 tempos obtidos para a agua em (B) o mesmo para $\odot$ línido mais viscoso. A baixa viscosidade da fgua iorna - sinal muito mais integular, como pode ser comparado em 500 pontos da série (c) da água e (C) da soluçäo viscosa.

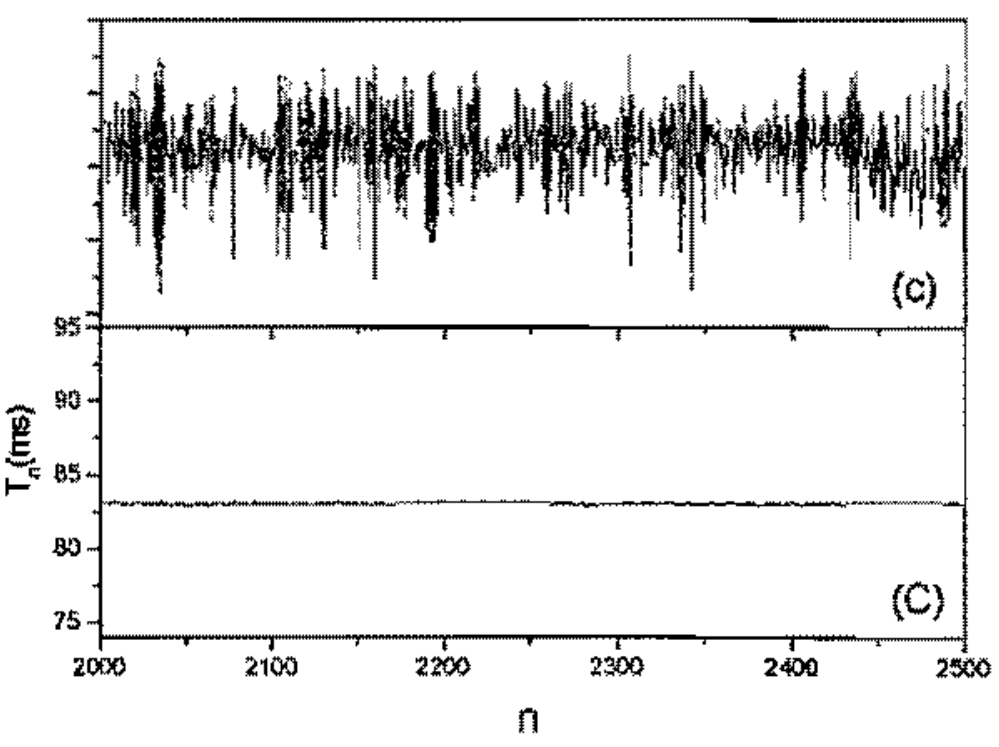




\subsubsection{Freqüuência de borbulhamento}

A frequêtencia das bolhas dada pela equaça 4.16 tem uma validade limitada pelas condiçós geométricas e dinâmicas ja citadas anteriormente. Fazendo outras medidas com diferentes alturas de coluna, observamos uma variação na freqüểincia de borbulhamento. Basicamente o aumento da altura da cohna liquida causa a diminuiçäo da frequêtncia de borbulhamento para a mesma vazão. Na Fig. 4.15 é apresentada a frequência de borbulhamento em função do logaritmo da vazäo, com o sistema predominantemente emitindo bolhas em periodo 1 , onde se utilizou a soluçäo $80 \%$ de glicerina $20 \%$ água, o bico de seringa e três alturas da coluna liquida: $5 \mathrm{~cm}, 12 \mathrm{~cm}$ e 26 cn. Fazendo um ajuste linear para calcular os expoentes da frequência de

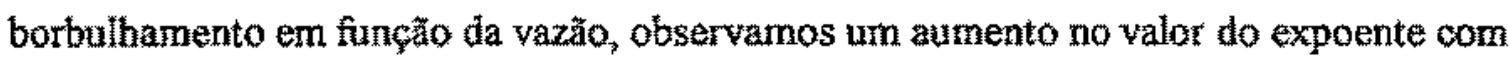
o aumento da altura da coluna, simultaneamente a diminuição do coeficiente linear do ajuste. Deste modo a frequiência em bolhas diminui com o aumento da altura da coluna, mas temos um aumento na sua inclinação com a vazäo volumétrica. $O$ mesmo efeito ocorre com um liquido menos viscoso ( $66 \%$ glicerina e $34 \%$ agua) mostrado na Fig. 4.16. Podemos ter uma variaçẫo ainda maior, quando usamos o bico $\mathrm{Al}$, isto diminuimos o orfficio do bico borbulhador, como esta mostrado na Fig. 4.17, com a soluçăo $80 \%$ glicerina $20 \%$ água, com altura de coluna de $3 \mathrm{~cm}$ acima do bico.

Existem alguns fatores que podem causar estes efeitos. Ruzicka que estudou experimentalmente a transiçazo intermitente entre os regimes de borbulhamento de jateamento em um sistema água enitrogênio, mediu a velocidade da circulaçăo do liquido com um anemồmetro Dantec e observou que a circulaç冖̆o do líquido aumenta com a altura da coluna [Ruzicka at al., 1997]. Para a construção do modelo da equação (4.16), a segunda condiçăo è que não haja circulaçăo do liquido próximo do bico e deste modo o aumento da coluna poderia afastar o sistema das condiçōes de validade da lej de frequência de borbulhamento.

Outros autores Davidson et al. 1960; Marmur e Rubin, 1976; Clift et al., 1978] afirmam que a diminuição do diâmetro do bico afeta a freqüencia de borbulhamento, causando o emparelhamento das bolhas (duplicaço de periodo) devido ao aumento do número de capacitância $N_{c}$ dado por:

$$
N_{*}=\frac{4 V_{s}\left(\rho_{2}-\rho_{s}\right)}{\pi d_{a}^{2} P}
$$




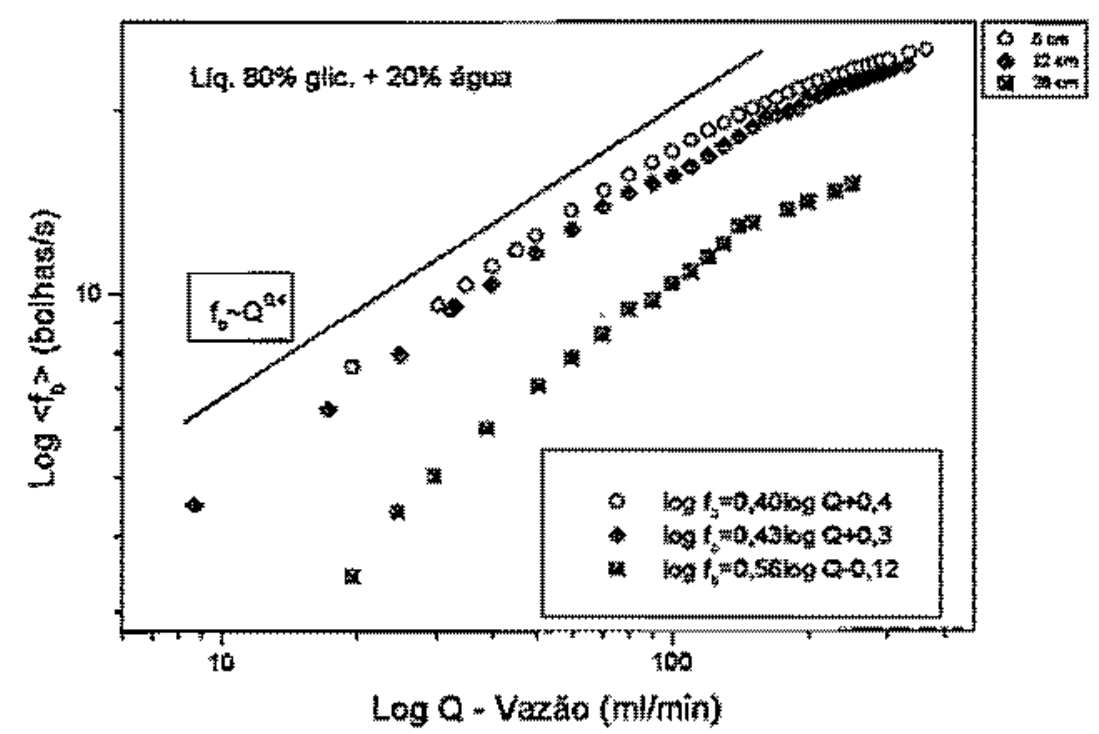

Figura 4.15 Freqüêneia de borbulhamento em funçăo da vazẩo e altura da coluna líquida

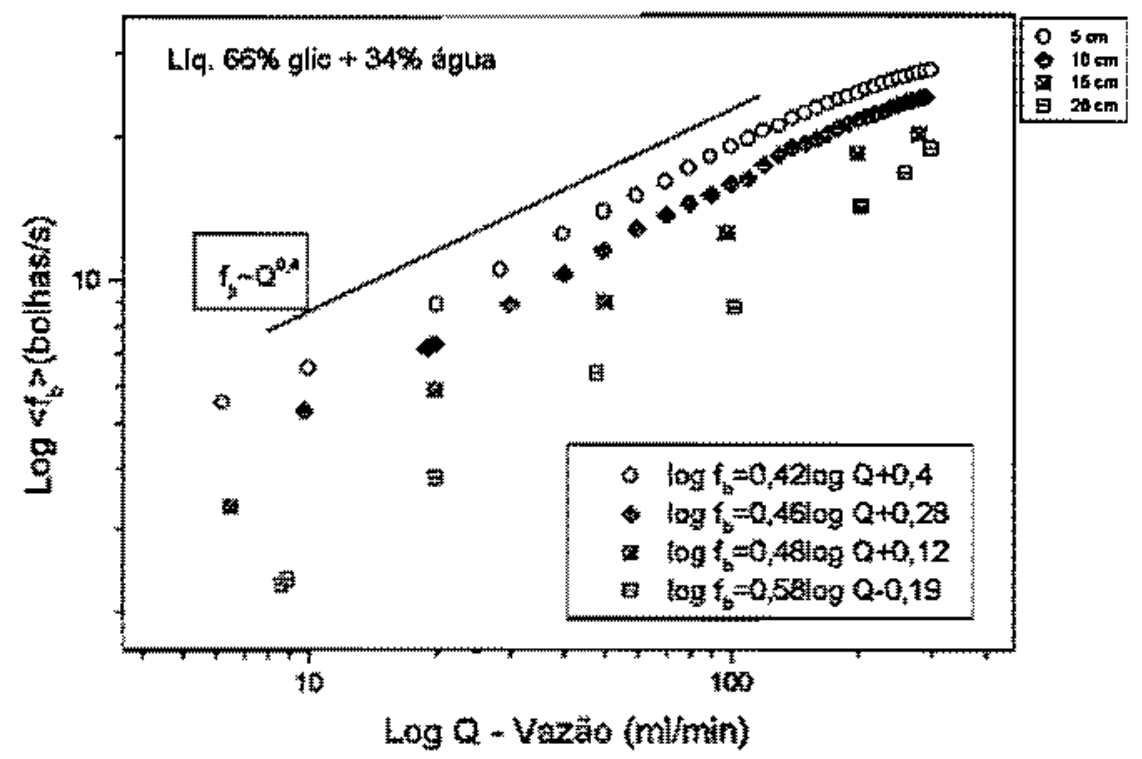

Figura 4.16 o mesmo que a figura anterior, porém com um liçuido menos viscoso 


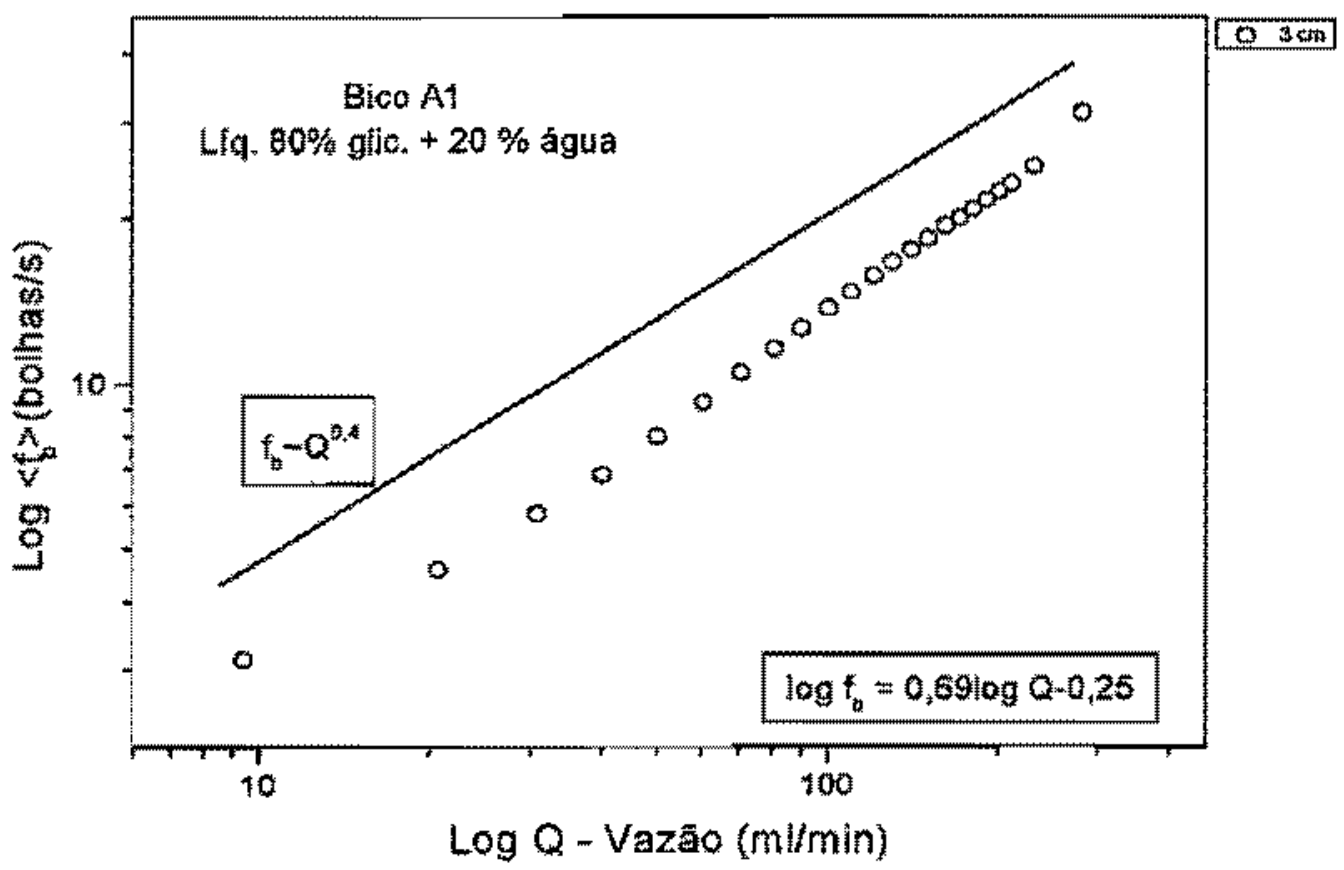

Figura 4.17 O mesmo liquido que foi utilizado para os dados da Fig. 4.16, mas agora com o bico Al e uma altura de coluna acima do bico de $3 \mathrm{~cm}$.

onde $V_{c}$ é o volume da câmara que contém o ar entre a válvula de controle de vazão e o bico, $\rho_{i}$ e $\rho_{g}$ são as densidades do líquido e do gás (ar) respectivamente, $d_{o}$ é o diâmetro do onficio (bico) e $P$ a pressão absoluta na bolha.

Segundo Marmur e Rubin, orificios grandes $\left(d_{6}-1 \mathrm{~mm}\right)$ implicam em báxa resistência ao fluxo do gás entre a cämara a bolhn devido $\mathrm{a}$ isto, a bolha $\mathrm{e}$ cầmara funcionam como um sistama unitário para $\mathrm{o}$ ar. Jả com orificios menores, 0 número de capacitância aumenta e a velocidade do ar no bico aumenta, causando pequenas variaçōes de pressão na cămara, que causam diferentes tempos de formaçăo para as bolhas.

Além destes fatores, a temperatura ê um parämetro fundamental a ser monitorado. Todas as medidas anteriores foram realizadas a $24^{\circ} \mathrm{C}$. 


\subsubsection{Duplicações de período}

Com uma soluçăo de quatro partes de glicerina e uma parte de água, e usando a seringa plástica como bico, obtivemos a série temporal da Fig. 4.18, que mostra a clássica sequiuencia de duplicação de período para o sistema do tubo borbulhador. Nesta figura temos uma diminuição gradual da vazão de ar através do bico, com uma evolução desde a regiazo caótica (a), passando por comportamento de borbulhamento de periodo 2 na parte (b), que passa a um periodo 4 na região (c), que passa para um novo comportamento de peniodo 2, região (d), seguido por uma regiăo de formação de bolhas em periodol na regitão (e). $\mathrm{Na}$ Fig. 4.19(e), apresentamos uma imagem das bolhas se formando periodicamente uma a uma, e na Fig. 4.19(d) é mostrado o comportamento de periodo 2 , sem o efeito de coalescencia entre as bolhas. Na Fig. $4.19(\mathrm{c})$ temos a irnagem para o periodo 4 , enquanto que na Fig. 4.19(b) temos um periodo 2 devido à coalescência de pares de bolhas, que anteriormente formavam o periodo 4 . Finalmente, na Fig. 4.19(a), temos a inagem das bolhas em regime catotico.

\subsubsection{Salto e coalescência}

Obtivemos uma serric temporal diferente com o mesmo aparato anterior, mas utilizando o bico A3, un captlar metálico longo, deixando a pressão do reservatớno diminuir naturaimente através do borbulhamento. Esta série temporal é mostrada na Fig. 4.20. O sistema está evoluindo em um movimento de periodo 2, região (a) na Fig. 4.20 , onde a diferença entre os dois ramos do atrator é de $5,5 \mathrm{~ms}$. A medida que a vazäo do ar diminu, ocorre un encolbimento abrupto do atrator para outro periodo 2 , onde a diferença entre os ramos passa o ser $1 \mathrm{~ms}$, mostrando um salto na dinâmica da formação de bolhas, na regix̃o (b) da Fig. 4.20. Depois disto, o sistema evolui para um periodo 1 , mostrado na região (c). Na Fig. 4.21 estão lustrados cada perfil de borbulhamento nas trềs regiöes. Na Fig. 4.21(a) temos duas imagens que mostram a formação de uma grande bolha em dois estagios. No primeiro estágio a bolha se forma com o tempo do ramo superior do periodo 2 da strie temporal da Fig. $4.20(-25 \mathrm{~ms})$. Logo que esta bolha se destaca, uma segunda bolha é criada, durante a sua formaça esta segunda bolha toca a bolha anterior e fluxo de ar ascendente soprado dentro ta bolha em formação vence a tensão superficial, fazendo a coalescência do par que alimentado 


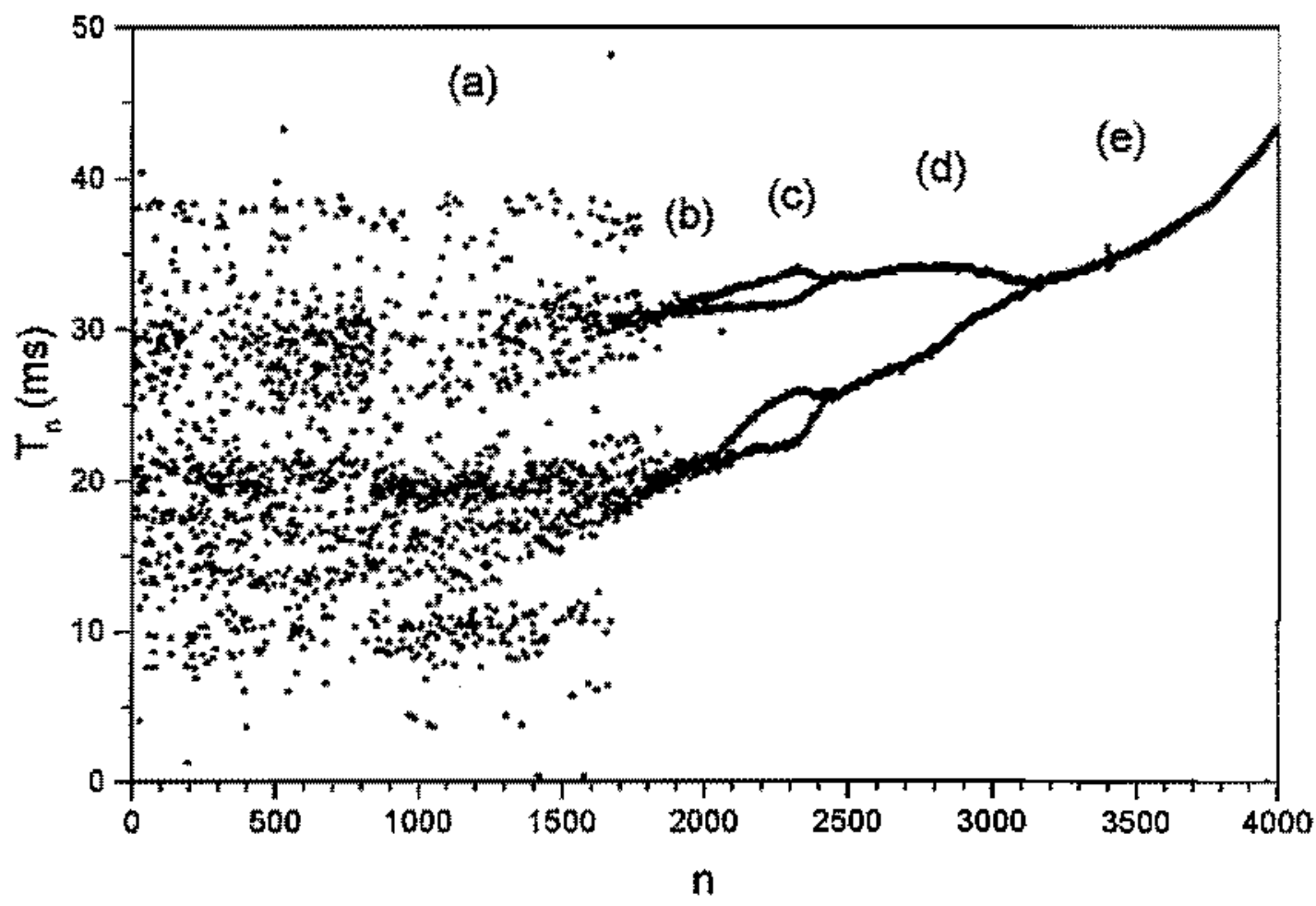

Figura 4.18 Série temporal a partir do comportamento caśtico até o periodo $1, T_{n}$ e o tempo entre bolhas e n ê a ordem da bolha colctada.

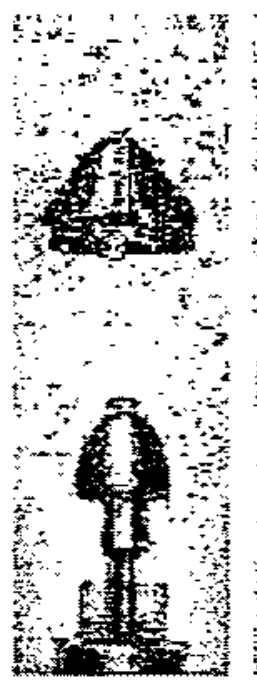

(a)

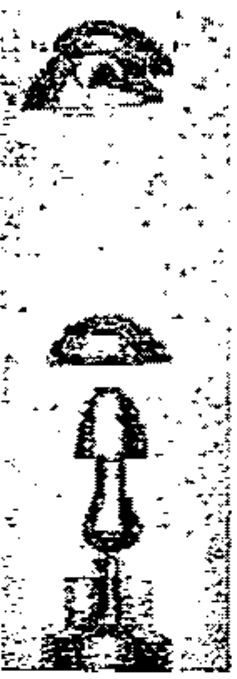

(b)

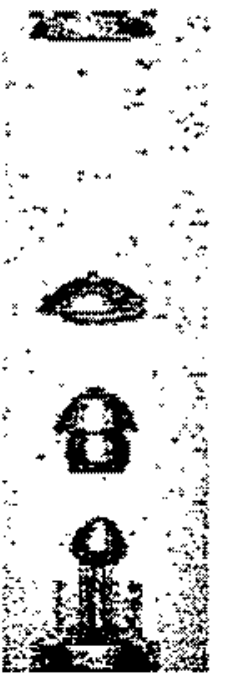

(c)

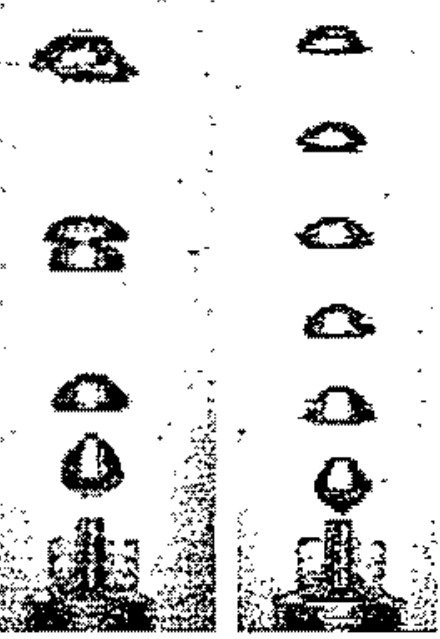

(d)

(e)

Figura 4.19 Pertil das bolhas enitidas en cada um dos regimes mostrados na série da Fig. 5.15. Em (a) vemos o comportamento cabtico, (b) pericdo 2 com coalescência, (c) periocio 4, (d) periodo 2 e em (e) periodo (1).

pelo bico soprador e se torna uma única grande bolha. Corn a diminuição da vazão de $a r$, o toque entre as bolhas deixa de ocorrer $r_{2} \mathrm{o}$ atrator diminui abruptamente. 


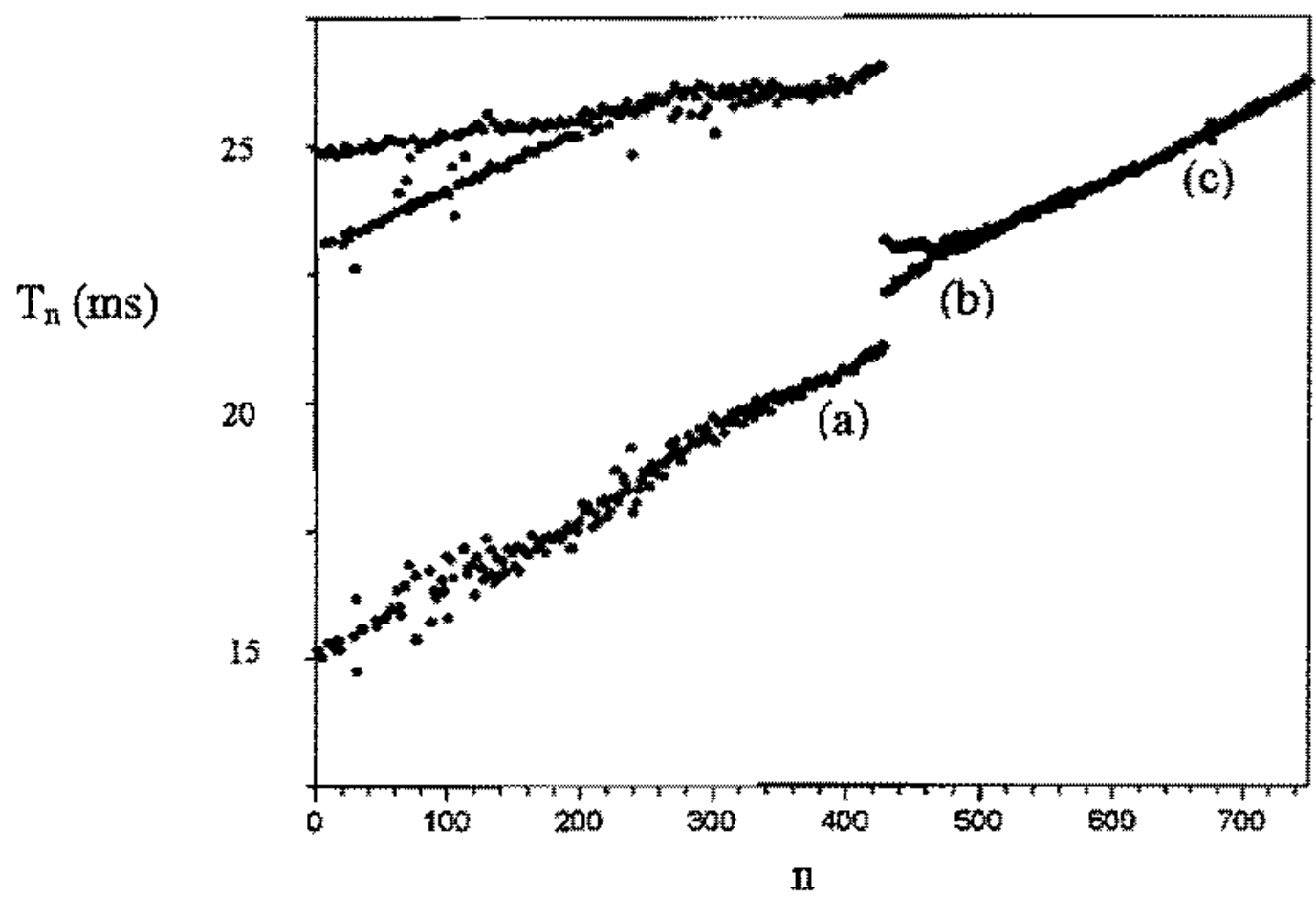

Figura 4.20 Série temporal mostrando um salto na dinâmica da formaçăo das bxithas, o periodo 2 se contral abruptamente en um periodo 2, dininuindo o periodo do borbulhamento.

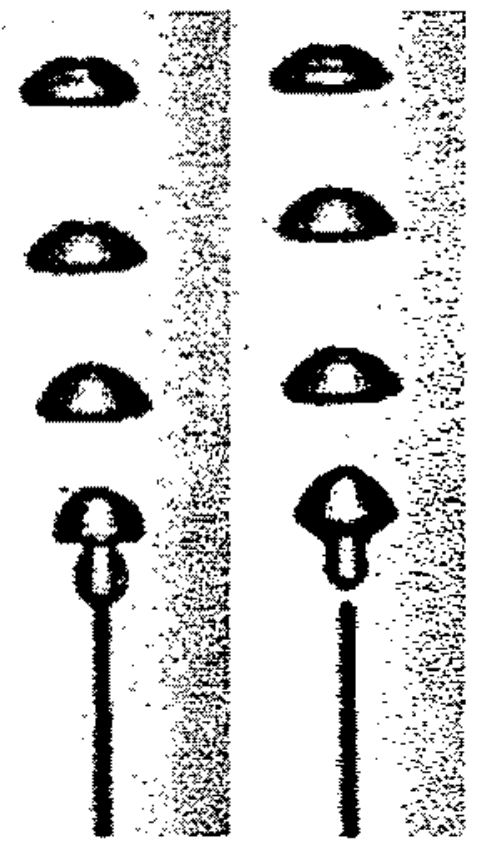

(a)

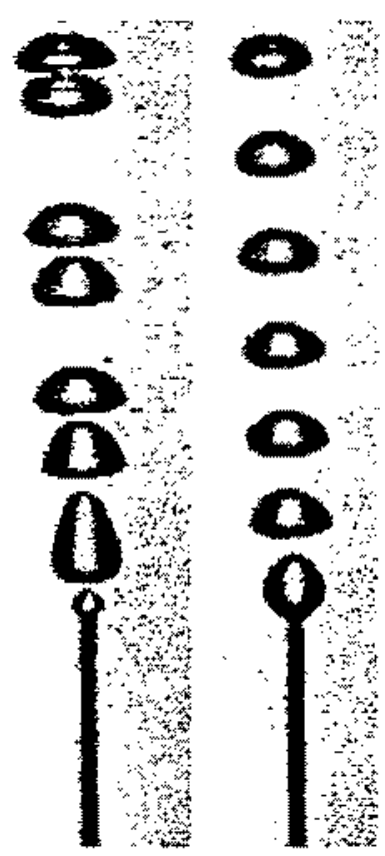

(b)

(c)

Figura 4.21 Imagens das belhas: (a) antes do salto, onde pxienos ver as bolhas se tocando e coalescenda, (b) o periodo 2 após o salto, onde as bolhas stíc enuitidas aos pares sem coalescência $t$ (c) 0 periodo 1. 
Uma mudança abrupta de comportamento nos sistemas fisicos pode ser explicada através de mapas com descontinuidades, como foi proposto por de Sousa Vieira et al. [Souza Vieira et al, 1987]. Para estudar assimetrias e descontinuidades eles utitizaram o mapa:

$$
x_{n+1}=f\left(x_{n}\right)=\left\{\begin{array}{l}
1-\varepsilon_{1}-a_{1}\left|x_{n}\right|^{z} \text { se } x_{n}>0, \\
1-\left(\varepsilon_{1}+\varepsilon_{3}\right) \text { se } x_{n}=0_{n} \\
1-\varepsilon_{2}-a_{2}\left|x_{n}\right|^{22} \text { se } x_{n}<0,
\end{array}\right.
$$

onde $\Sigma_{1}<\Sigma_{2}$ săo os coeficientes de descontinuidade, $z_{i}$ e $z_{2}$ săo os expoentes de assimetria, $a_{1}$ e $a_{2}$ säo os paràmetros de controle do mapa
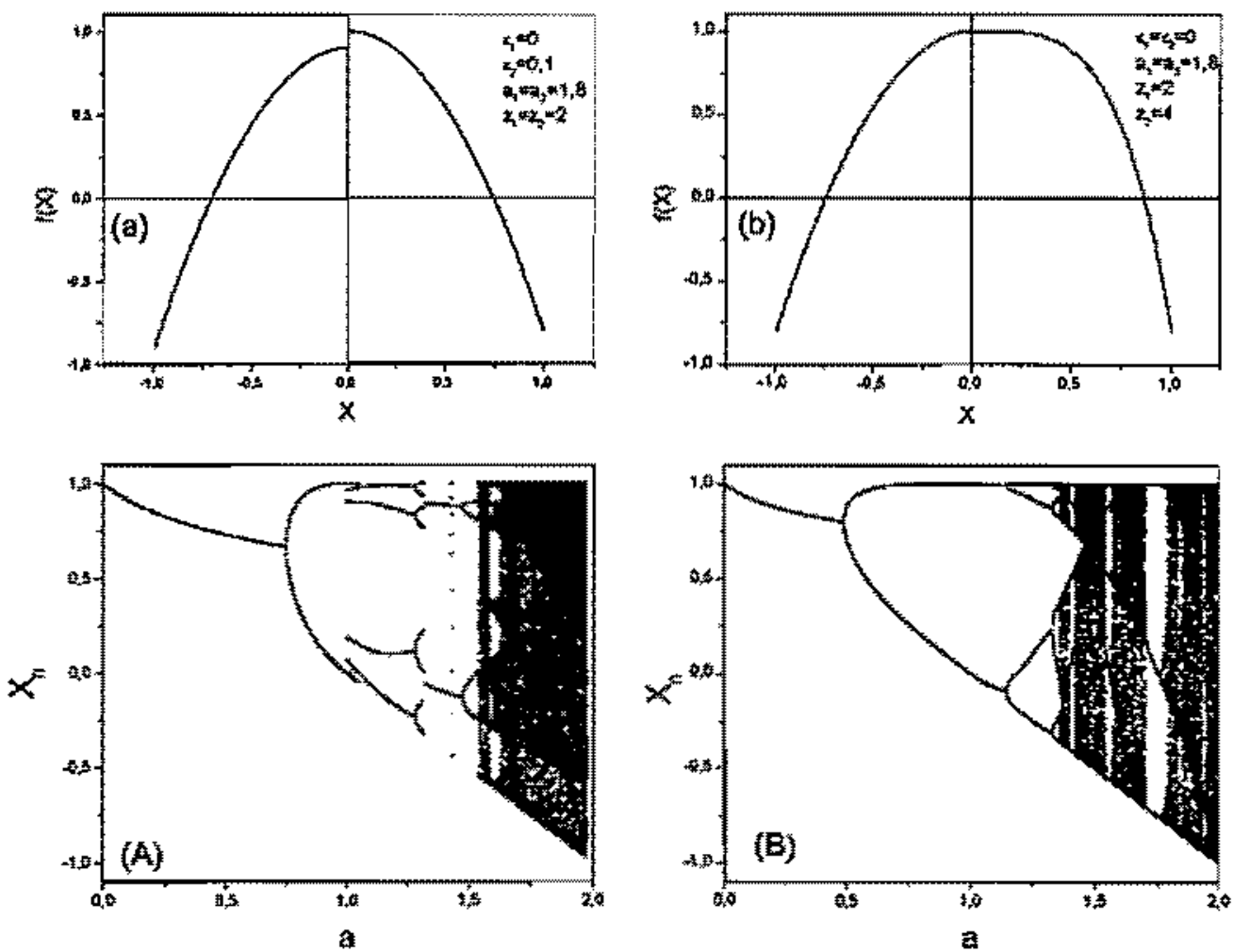

Figura 4.22 Dois exemplos de mapes assimetricos. (a) 0 mapa descontínuo das equaçôes 4.22 e 0 \% valores de cada parămetro, em (A) tcmos o su diagrama de bifurcaçőes. Em (b) os paràmetros do mapa contínuo em (B) o respectivo diagrama de bifurcaçōes. 
Outro caso onde ocone descontinuidades é atraves do modelo de mapas combinados em série [Tufaile, 1996, Tufalle et al., 1999], no qual os sistemas interagem altemadamente. Este modelo pode ser exemplificado com os mapas unidimensionais:

$$
\begin{aligned}
& x_{n+1}=f\left(\xi, y_{n}\right)_{n} \\
& y_{n+3}=g\left(\xi, x_{n+1}\right),
\end{aligned}
$$

cuja combinaçă é a uniāo dos resultados dos dois mapas:

$$
S_{n}=f \cup g
$$

Se considerarmos o mapa logistico com o parâmetro de controle $p_{x y}$ :

$$
\begin{aligned}
& z_{k+1}=p_{x y} z_{n}\left(1-z_{n}\right), \text { com } \\
& p_{x y}=\frac{\left[1+(-1)^{n+1} \mid p_{x}+\left[1+(-1)^{n}\right] p_{y}\right.}{2} .
\end{aligned}
$$

A recorência $z_{n}$ pode ser rescrita em dois subsistemas independentes, associados com a paridade te $n$

$$
\begin{aligned}
& x_{n+2}=16 p_{x} p_{y} x_{n}\left(1-x_{n}\right)\left[1-4 p_{y} x_{n}\left(1-x_{n}\right)\right] \\
& y_{n+2}=16 p_{x} p_{y} y_{n}\left(1-y_{n}\right)\left[1-4 p_{x} y_{n}\left(1-y_{n}\right)\right]
\end{aligned}
$$

Além disso os parâmetros $p_{*} \in p_{y}$ podem ser simultaneamente funç̧̋̈es de um parâmetro $\xi$, que acopla o sistema. Devido à propriedade da fomaçäo de bolhas de diminuição do tempo em função do parâmetro de controle, pode-se utilizar uma tunçă̧o convexa do tipo:

$$
z_{n+1}=z_{n}^{2}-a
$$

e fazer a combinação em sétie deste mapa, com o parâmetro de controle assumindo dois valores para $a>0,8$

$$
\begin{aligned}
& a_{x}=a_{3} \\
& a_{y}=a+0,1
\end{aligned}
$$

O diagrama de bifurçaçă desta combinaçấo está mostrado na Fig 4.23 .

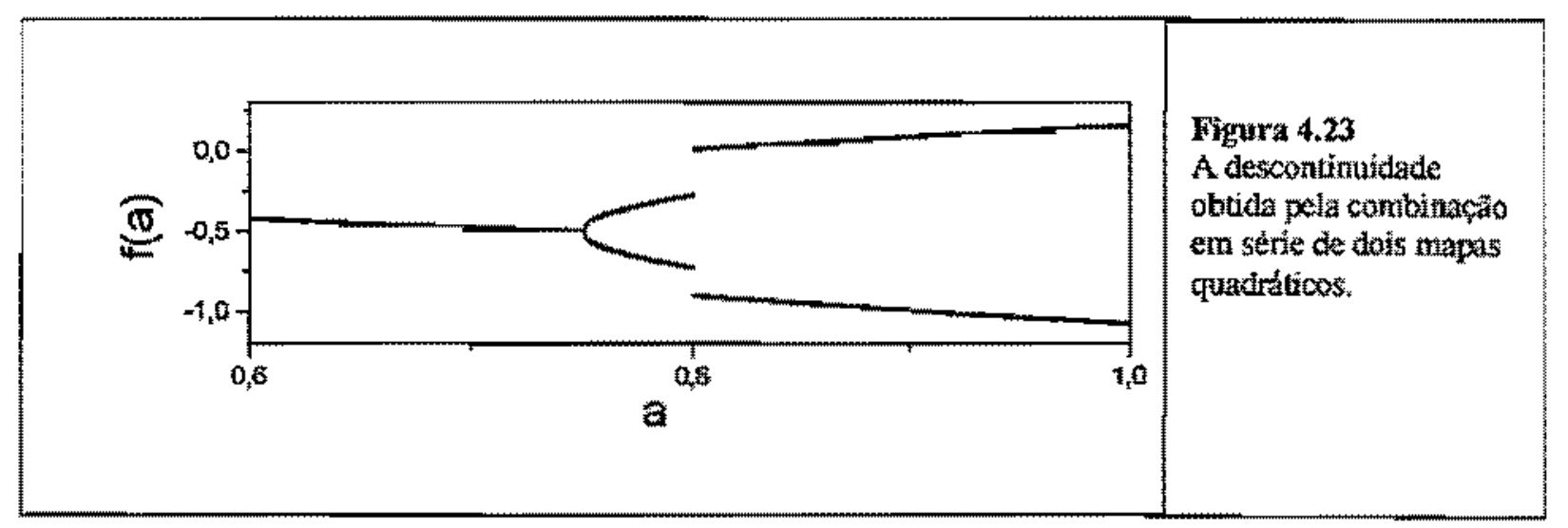


Interpretando o salto sob o ponto de vista dos mapas combinados em série, podemos considerar que antes do salto, logo após a duplicaçäo de periodo as duas bolhas săo formadas através da mesma functa de formagăo. Quando ocorre o toque, a primeira bolha do par possui uma funcẫo de formaçầo distinta da segunda bolha, pois, a segunda bolha coalesce durante sua formação com a primeira, e o bico soprador passa a encher o conjunto con quase o dobro do volume uma bolha.

Outro tipo de combinação de mapas é a combinaçăo paralela de doís mapas $f\left(x_{n}\right)$ e $g\left(y_{n}\right)$ que resultam no mapa combinado $S_{B}$ :

$$
\begin{aligned}
& x_{n+1}=x_{2}-p_{x}(\xi)_{2} \quad y_{n+1}=y_{n}^{*}-p_{y}(\xi), \\
& \xi_{n}=x_{n}+y_{n},
\end{aligned}
$$

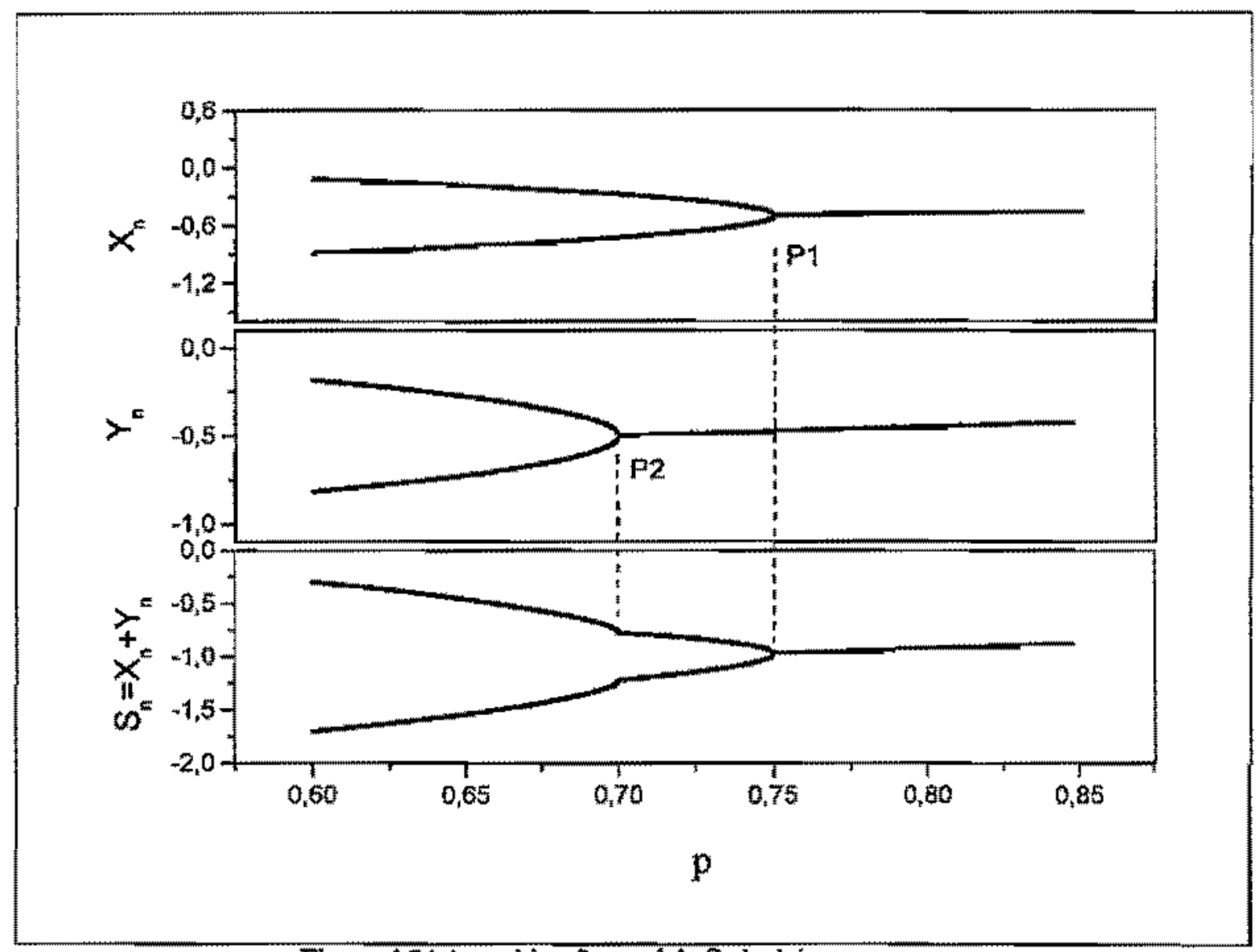

Figura 4.24 A combinação paraleia $S_{n}$ de dois mapas

onde $p_{x}(\xi)$ e py $(\xi)$ são parâmetros de controle em funçăo de um parâmetro cornum $\xi$, com cada mapa sendo iterado separadamente. Na Fig. 4.24 temos dois mapas bifurcando inversamente para diferentes valores do parâmetro de controle $p_{s}$ enquanto que a sua combinaçăo paralela possui uma bifurcação fip do mapa da variável $x_{n}$ no 
ponto $P 1$ e que equivale a uma alteração no período dois do mapa $S_{n}$, no ponto $\mathrm{P} 2$ devido à segunda bifurcaçäo flip do mapa $\mathrm{y}_{\mathbf{n}}$.

A serie da Fig 4.25(a) foi obtida utilizando-se o bico $\mathrm{Al}$, o mais curto dos bicos da série A. Nesta tigura podemos ver que o salto foi minimizado. Na Fig. 4.25(b) apresentamos a simulaçâo correspondente, na qual utilizamos dois mapas combinados em série.
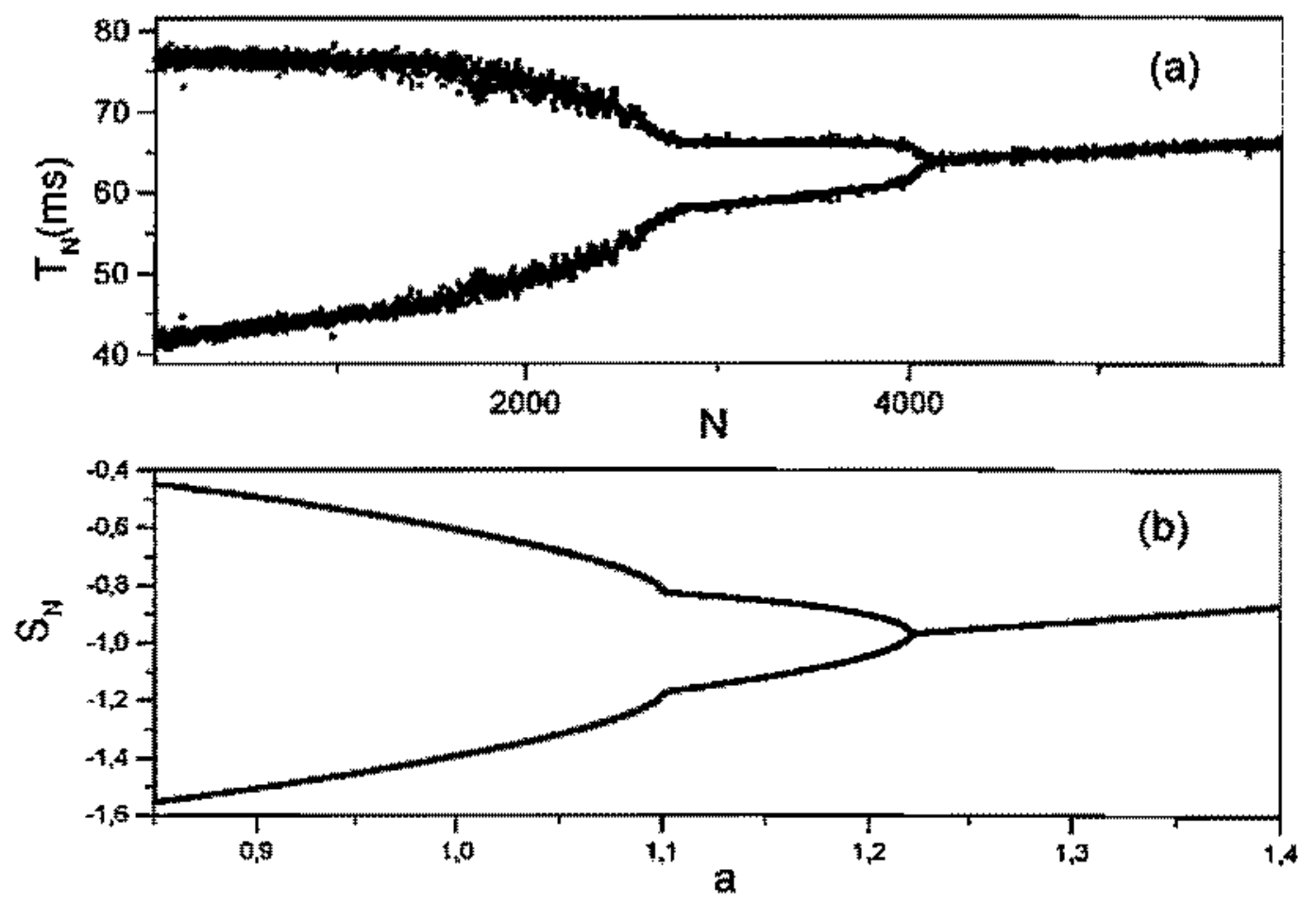

Figura 4.25 Em (a) podemos ver uma série temporal obtida com a diminuiço da vazăo com o bico $\mathrm{Al}$ e uma solução viscosa $80 \%$ glicerina e $20 \%$ água. En (b) a combinaçăo paralela de dois mapas. A bifurcaça fip que ocorre no mapa $y_{n}$ quando levada à combinacäo paralela $S_{N}$, causa a diminuiça do período 2. 


\subsubsection{Antibolhas}

Uma casca aproximadamente esferica de ar dentro de um liquido forma o que foi chamado por J. E. Connett de cambolha, segundo C. L. Stong [Stong, 1974]. Na Fig. 4.26 está esquematizadia uma antibolha.

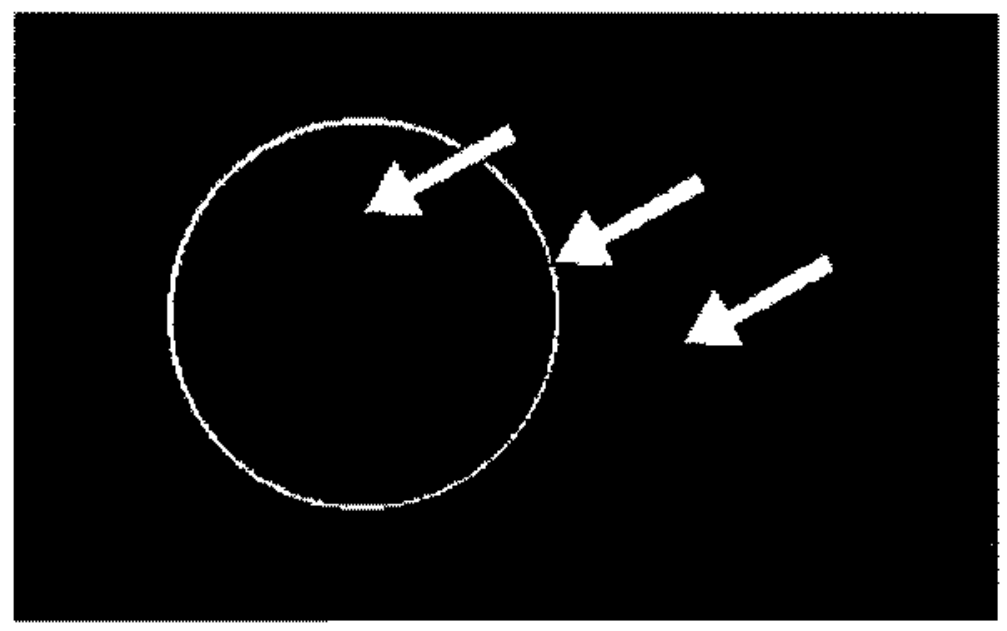

Figura 4.26 Una antibolla é una gota de un liquido envolvida por uma fina carnada de ar dentro do liquido.

Como o seu interior e preenchido pelo o mesmo liquido da parte externa, as antibolhas săo ligeiramente mais leves que o fluido à sua volta, mas são mais pesadas que as bolhas. Deste modo correntes proximas a antibolha podem deslocá-la facilmente, superando a seu empuxo. Quando a casca esférica se desestabiliza, a antibolha colapsa em uma pequena bolha de ar esférica, que emerge no liquido. $O$ tempo de existência de uma antibolha antes de sua desetabilização em uma pequena bolha de ar pode chegar a orden de minutos.

No experimento do tubo borbulhador, ocorre tanbém a formaçăo de antibolhas, para determinados regimes da formação de bolhas. As antibolhas seguem as correntes do líquido dentro do tubo, em movimentos ascendente descendente. Na Fig. 4.27 podemos ver antibolhas ao redor de bolhas sendo sopradas no bico borbulhador. para o líquido utilizado ( 2 partes de glicerina para 1 de agua), a ocorrência de antibolhas acontece a partir do estágio onde aparece a coalescência do par de bolhas, chamato de periodo 2 antes do salto, da Fig, 4.21(a), A formaçăo das antibolhas e precedida pela formação de goticulas. A formaçäo de goticulas esta esquematizada na Fig 4.28 , onde vemos em (a), que parte do liquido em movimento ascendente forma posteriormente um capilar em (b), e uma goticula se desprende. Nas imagens da Fig. 4.28, podemos ver 
akgumas imagens que mostram a formaçäo de goticulas dentro da bolha, assim como invaginą̧ões que podem levar a criaçăo de antibolhas.

Assim como as bolhas, as antibothas desviam o féxe laser podem ser detectadas. Verificamos isto colocando o sistema no regime de formação de antibolhas, que corresponde a um periodo 4 para as bolhas, mostrado no mapa de retorno da Fig. 4.29(a). O seu espectro de potências está na Fig. 4.29(b). As antibolhas se deslocavam dentro do nubo borbulhador seguindo as correntes internas do fluido, com deslocamentos preferencialmente descendente proximo à parede do tubo ascendente e acelerado proximo do bico soprador. A quantidade de antibolhas dentro do tubo era aproximadamente 30 o féxe laser foi colocado num ponto en que as bolhas nāo passavarn por ele, num ponto $2 \mathrm{~cm}$ acima do bico e $2 \mathrm{~cm}$ deslocado do eixo do tubo, como o ponto Pl da Fig, 4.27 . Nesta região apenas as antibolhas passavam pelo feixe laser e nós obtivemos os dados mostrados no mapa de retorno da Fig. 4.29(c). Nestes dados são apresentados 500 pontos correspondendo a 50 minutos de aquisiçăo, com intervalos de tempo entre 17 milissegundos até 85 segundos.

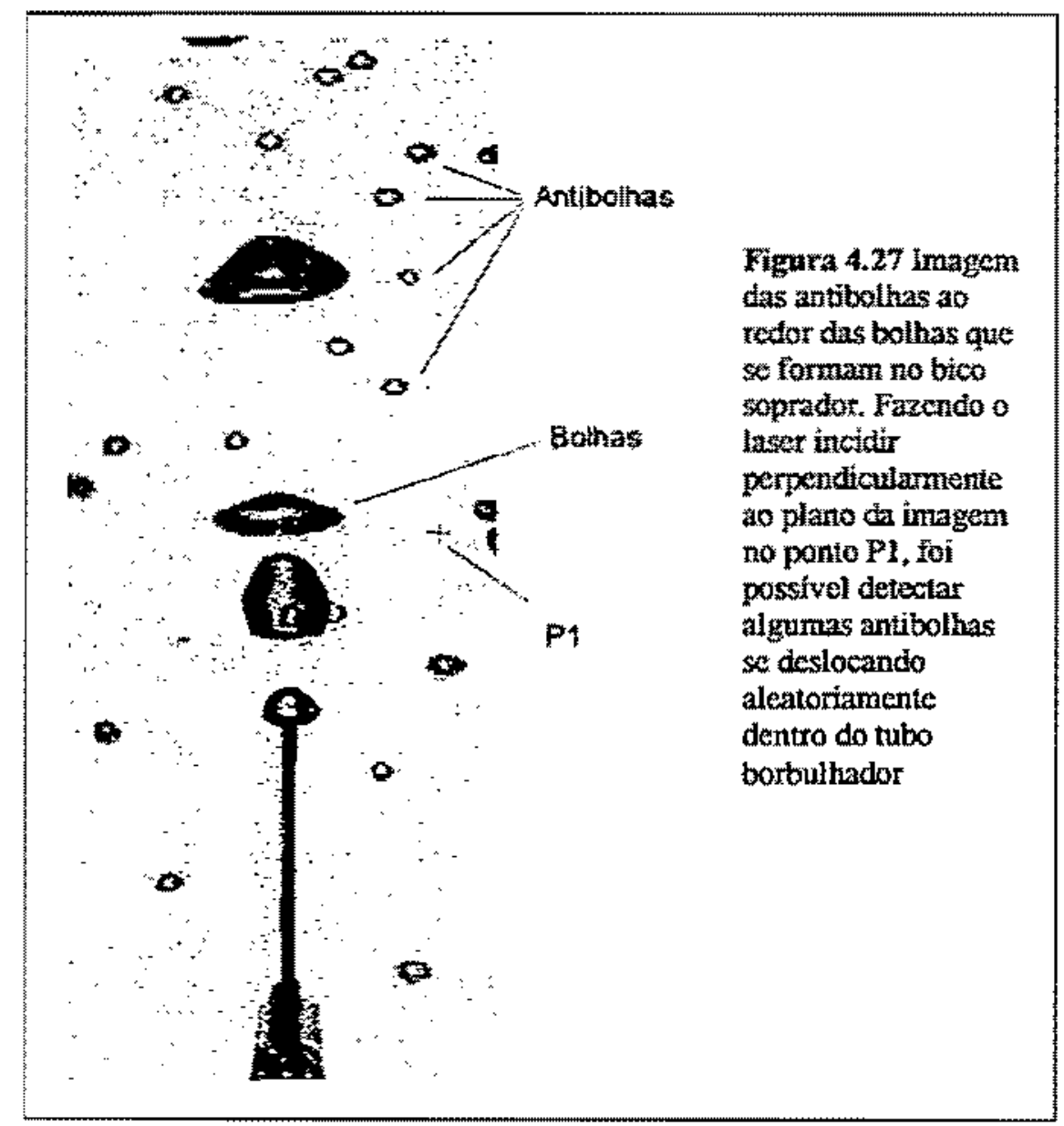




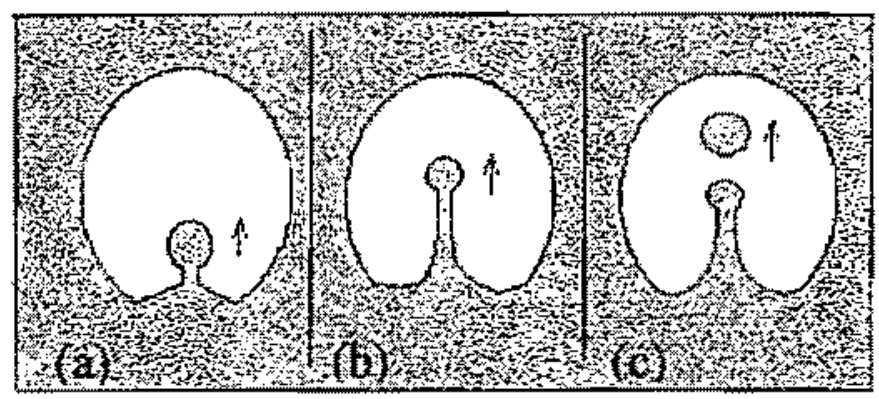

(d)

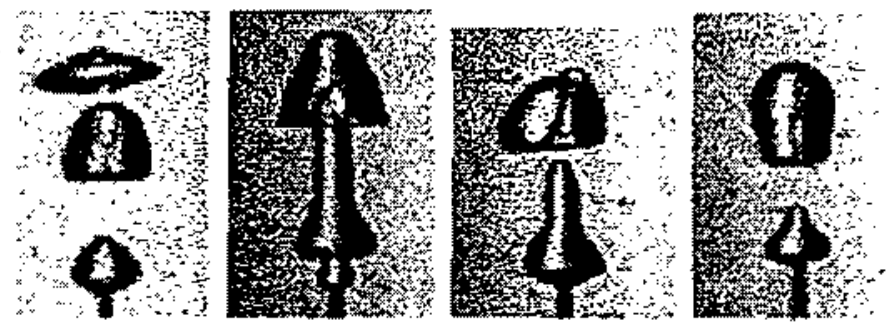

Figura 4.28 Formação de goticulas exquematizada em (a), (b) e (c). (d) Nas imagens podemos ver padróes semethantes nas bolhas.
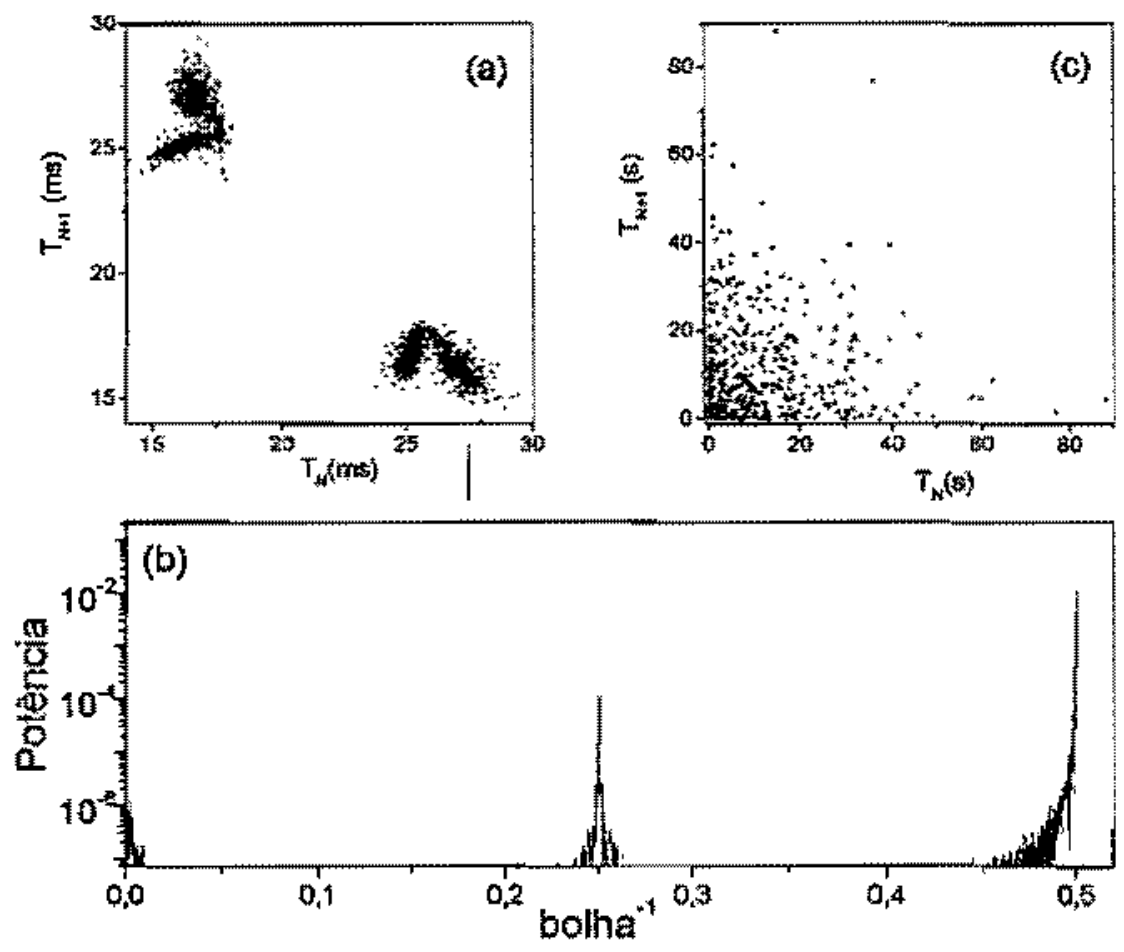

Bigura 4.29 (a) Mapa de prineiro reforno to periodo 4 , e em (b) o sea espectro de potencias, O mapa de ratomo en (c) foi obtido com a sistema nas mesmas condiços da formatato das antibolhas, mas posicionando o feixe laser e o fotodiodo de ntodo a detectar as antibolhas que passavam pelo ponto PI da Fig. 4.27. 


\subsection{A onda sonora e as bolhas}

Os efeitos de uma perturbação externa, a onda sonora, na formação das bolhas, sẫo apresentados e analisatios neste capítulo. O problema das bolhas perturbadas por ondas sonoras apresenta desafios muito interessantes do ponto de vista matemático, coma relação a proposição das equaçōes que controlam o sistema e suas condiçôes de contorno, pois, além de um sistema de duas fases, com uma das fases compressível, temos a açĩo de uma onda sonora. Do ponto de vista experimental, o tubo borbulhador possui uma geometria que falitita a utilização da onda sonora, devido à propriedade de confinamento de ondas sonoras em tubos.

Existem trabalhos que envolvem a ação de ondas sonoras em bolhas ou gotas já formadias [Marston, 1980], ou quando bothas ou cavidades säo criadas dentro de um liquido devido a uma onda sonora de alta intensidade[Lauterbom, 1986; Prosperetti, 1986], a chamada cavitaça actistica. Hia ainda um caso, conhecido como cavitação transiente, no qual a temperatura no interior da bolha atinge milhares de graus $e$ pressâto chega milhares de atmosferas. Nestas condiçöes ocorre o fenômeno conhecido como sonohminescencia, que é a eniskăo de luz por bolhas en um liquido excitado por ondas sonoras [Putterman, 1995; Moran at al, 2000]. As frequêencias das ondas sonoras envolvidas com cavitação são da ordem de centenas de $\mathrm{kHz}$. Nestes trabalhos também se estuda como o campo sonoro emitido pelas bolhas, devido aos efeitos da cavitação, afeta as próprias bolhas. Neste capitulo veremos condições mais clössicks de interação entre bolhas e ondas sonoras do que as que ocorrem na sonoluminescềncta. Aqui, neste capitulo, a bolha afetadia pela onda sonora durante a sua formaçăo no bico soprador, com frequêtendias da onda sonora variando no intervalo entre dezenas e centenas de hertz. O tamanho das bolhas estudadas é da ordem de centímetros, o que permitiu registrar suas imagens através de uma câmara VHS cornum. Veremos também como o sistema onda sonora -- bolhas nos levou ao estudo do mapa do circulo bidimensional, onde temos um oscilador sofrendo impulsos periódicos de uma força externa. 


\subsubsection{A formação de bolhas perturbadas pelas ondas sonoras}

Nesta seçăo verzmos os resultados que mostran a mudança do tempo entre as bolhas para una onda sonora de frequência fixa valores de amplitude crescentes [Tufatle e Sartorell, 2000a, Apêndice 2].

Mantendo fixa a vazäo do ar através á válvula controladora e utilizando a solução de $66 \%$ de glicerina e $34 \%$ de ăgua, nós mudamos a dinâmica da formaçấo de bolhas aplicando ondas sonoras sintonizadas na fregütência fundamental da colunz de ar acima do liquido (138 $\mathrm{Hz}$ ).

Na Fig, 4.30 mostramos os mapas de primeiro retomo em funçầ da amplitude da onda sonora, em regime de vazão constante. Estäo em destaque no canto superior esquerdo de cada gráfico a amplitude do sinal senoidal e a frequiência média das bolhas. O sistema é colocado inicialmente borbulhando em periodo 1 , com uma freqüência em bothas $f_{t}$ de 11,282 bolhas $/ s_{2}$ como esta mostrado na Fig. 4.30(a). Aplicando a onda sonora, o ponto fixo perde sua estabilidade e um ciclo limite aparese, como pode ser visto na Fig. 4.30(b) 4.30 (c), com um pequeno aumento da taxa de borbulhamento médio.

Na Fig. 4.30(c), o ciclo limite perde sua estabilidade e um ponto fixo, próximo de $(87 \mathrm{~ms}, 87 \mathrm{~ms})$, visitado intermitentemente. Este ponto fixo foi determinado através de um histograma do gráfico de $T_{n}$. As transformadas de Fourier dos dados relacionados ás Figs. 4.30(d-g) mostram um periodo 2 rutudoso. Mostramos na Fig. 4.31, o espectro de Fourier dos dados do atrator da Fig. 4.30(f). Neste espectro, vemos um grante pico em 0,5 , o que corresponde ao períndo 2 .

Isto mostra que está ocorrendo uma bifurcação flip em função da amplitude da onda sonora. Em uma bifurcạăo Iip, $_{\text {, }}$ existe um ponto fixo instável entre os dois pontos fixos estáveis. Nossos dados mostram que a vizinhança do ponto médio entre os dois pontos fixos é visitada devido ao ruído, e consequentemente, nossos dados săa adequados para se aplicar a técnica de transformaçäo de ponto fixo desenvolvida por So et al. [So et al., 1996] para se encontrar órbitas periódicas instaveis em séries de eventos. 

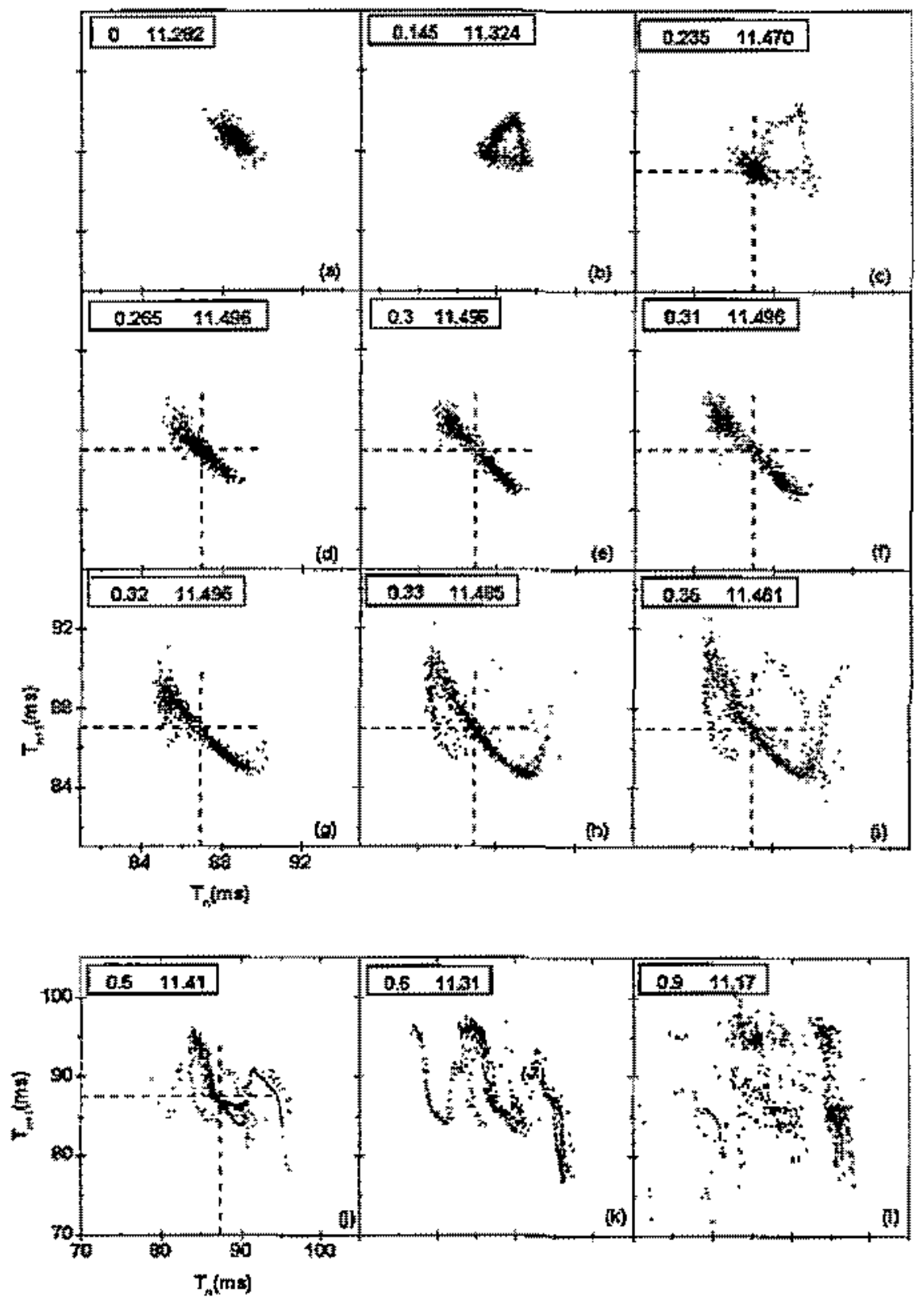

Figura 4.30 Mapas de retorno do experimento do tubs borbulhador. Em cada gráfico temos, no canto superior esquerdo, o vator da tensão aplicada no alto-falante e o valor đa freqüuência de borbulkamento média. O liquidido utilizado é uma soluçăe de $66 \%$ glicurita e $34 \%$ água, e as bollhas foram sopradas diretamerite na seringa plastica. 


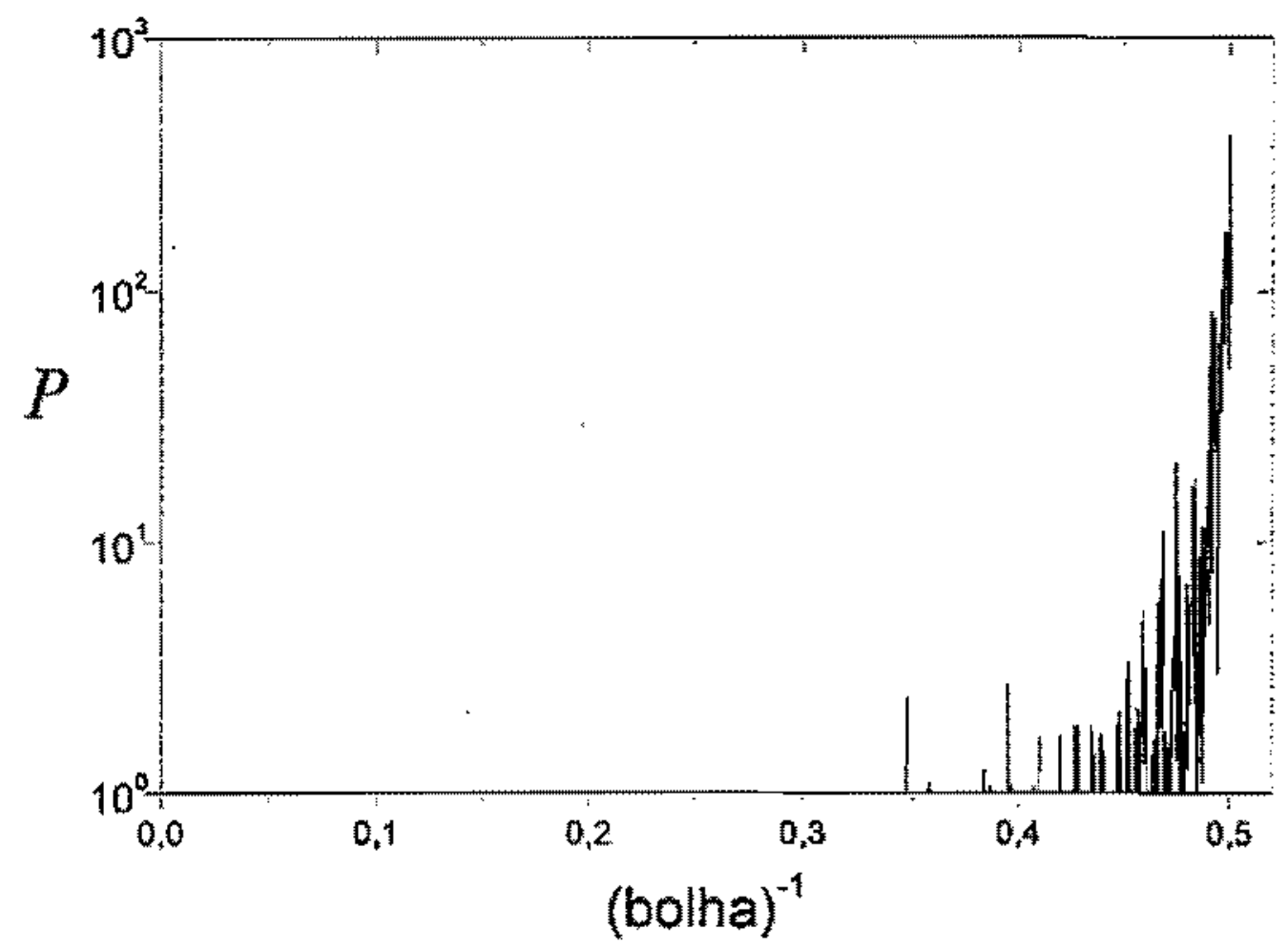

Figura 4,31 Espectro de Fourier dos dados da Fig $4,30($ indicando a existểncia de um periodo 2 ruidoso.

Um exemplo dos nossos resultados está mostrado na Fig 4.32(a), onde está representado o histograrna para o cálculo do ponto fixo usando os dados mostrados na Fig. 4.30(h), Para uma melhor visualização da posição da órbita periódica instável, um gráfico de intensidade para os mesmos dados é mostrado na Fig.4.32(b). O maior pico define um períoto 1 instável em $(86,99 \mathrm{~ms} ; 86,99 \mathrm{~ms})$, próximo do ponto fixo estável mostrado na Fig. 4.30(c).

Aumentando ainda mais a amplitude, nós observamos o aparecimento da região caótica, com as características da dinâmica de extiramento e dobra, como está mostrado nas Figs. 4.30(h-i), e com pequena mudança na frequiència média de borbuthamento. Os atratores na regiâo caótica foram caracterizados pelo expoente de Lyapunov dominante [Elner et al., 1992], e estes expoentes podem ser vistos na Fig. 4.33. 


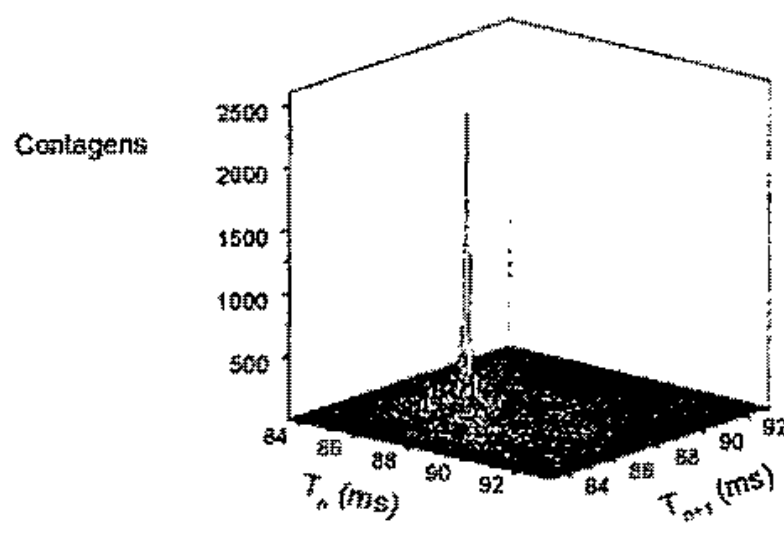

(a)

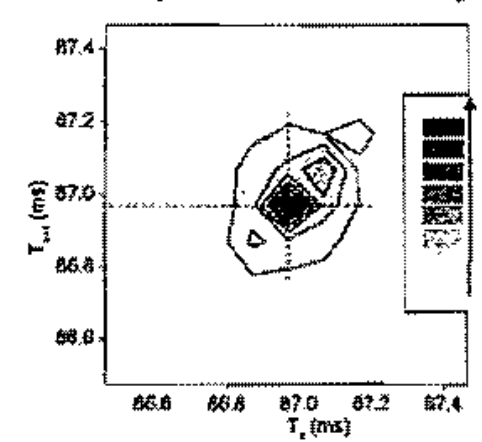

(b)

Contagens

Figura 4.32 Histograma para a determinação da brbita geriódica instảvel (a) e gráfico ce contomo para os mesmos (adatas (b), localizando o ponto fixo instátivel um pouco abaixo de $87 \mathrm{~ms}$.

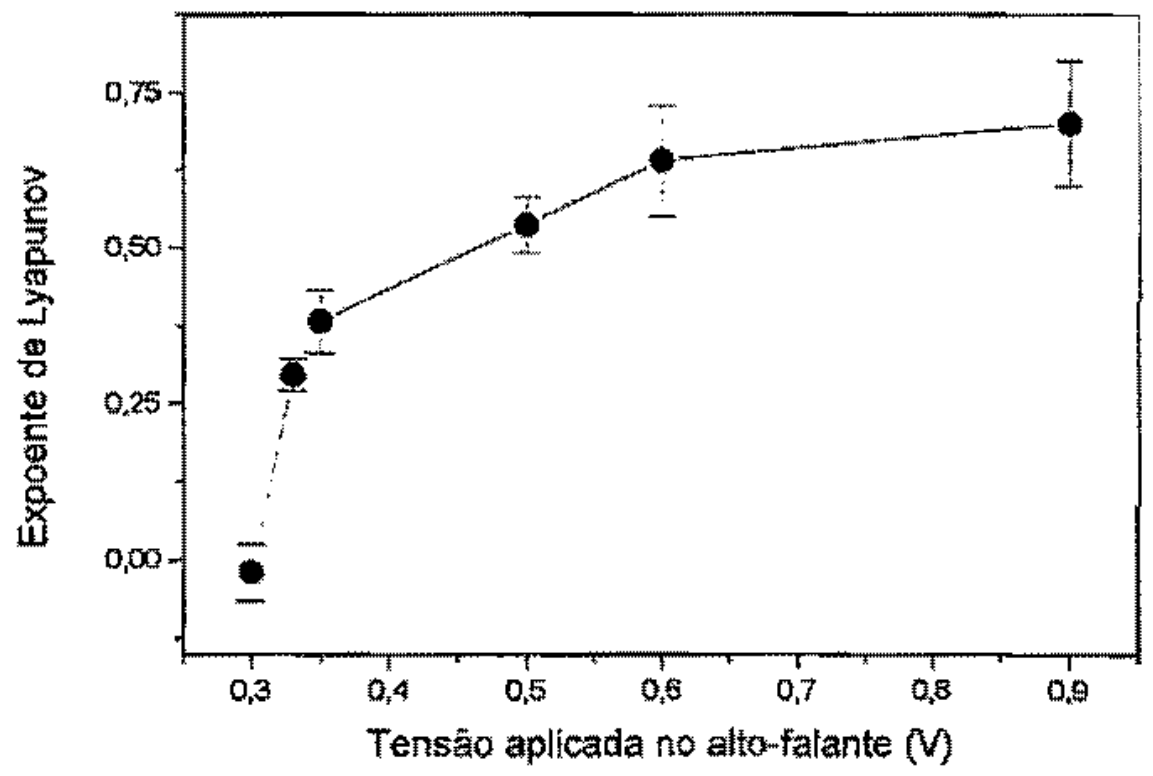

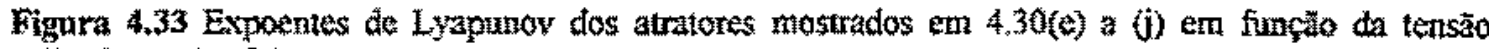
aplicada no alto-falante. 
Continuando a aumentar a amplitude da onda sonora com incrementos maiores do que antes, nots obtivemos os atratores mostrados na Fig. 4.34. Na Fig. 4.34(m) a taxa de botbulhamento média é de 20,5 bolhas/s para uma onda sonora gerada com uma tensão de $3.14 \mathrm{~V}$ no alto-falante. A posição $\sim(7,25 \mathrm{~ms} ; 7,25 \mathrm{~ms})$ é visitada com um comportamento intermitente. O tempo de visitaçă aumenta quando a amplitude do som aumenta, até que o ponto $-(7,25 \mathrm{~ms} ; 7,25 \mathrm{~ms})$ torna-se um ponto fixo estivel, como mostrado na Fig. 4.34(n). Nesta situaçăo, a frequênchia média de bortbulhamento $F_{b}=137,97 \pm 9$ bolihas/s tem o mesmo valor da frequência da onda sonora. Na Fig. 4.35 podemos ver a diferença entre as imagens das bolhas para o primeito ponto fixo dos dados mostrados na Fig. $4.34(a)$, e ponto fixo na ressonância do atrator da Fig. $4.34(n)$

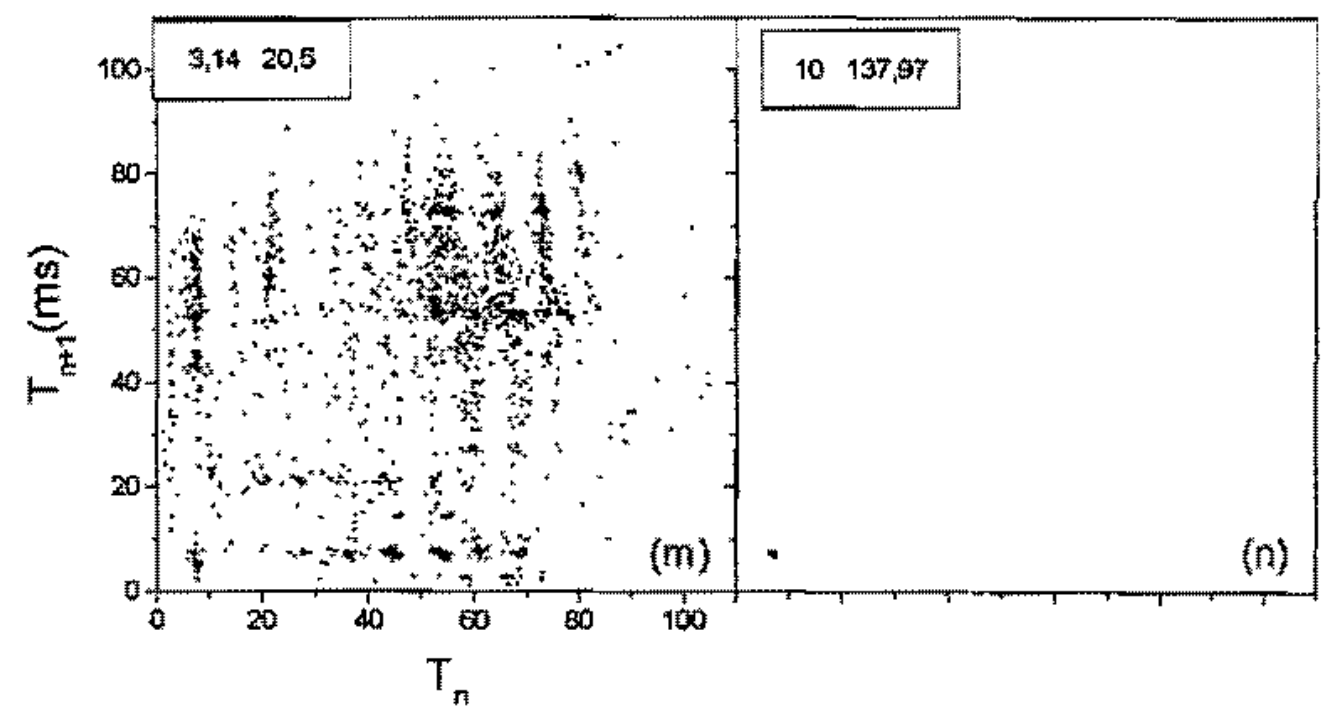

Figura $4.34(\mathrm{~m}) \mathrm{O}$ ponto $-(7,25 \mathrm{~ms}, 7,25 \mathrm{~ms})$ visitudo em un comportamento intermitente com os outros pontos espalhados pelo espaco de fases. Ena (n) a formacito das bolhas sincroniza-se com a trequêracia furdanental do tubo, e temos apenas o ponto- $(7.25 \mathrm{~ms} ; 7,25 \mathrm{~ms})$. 


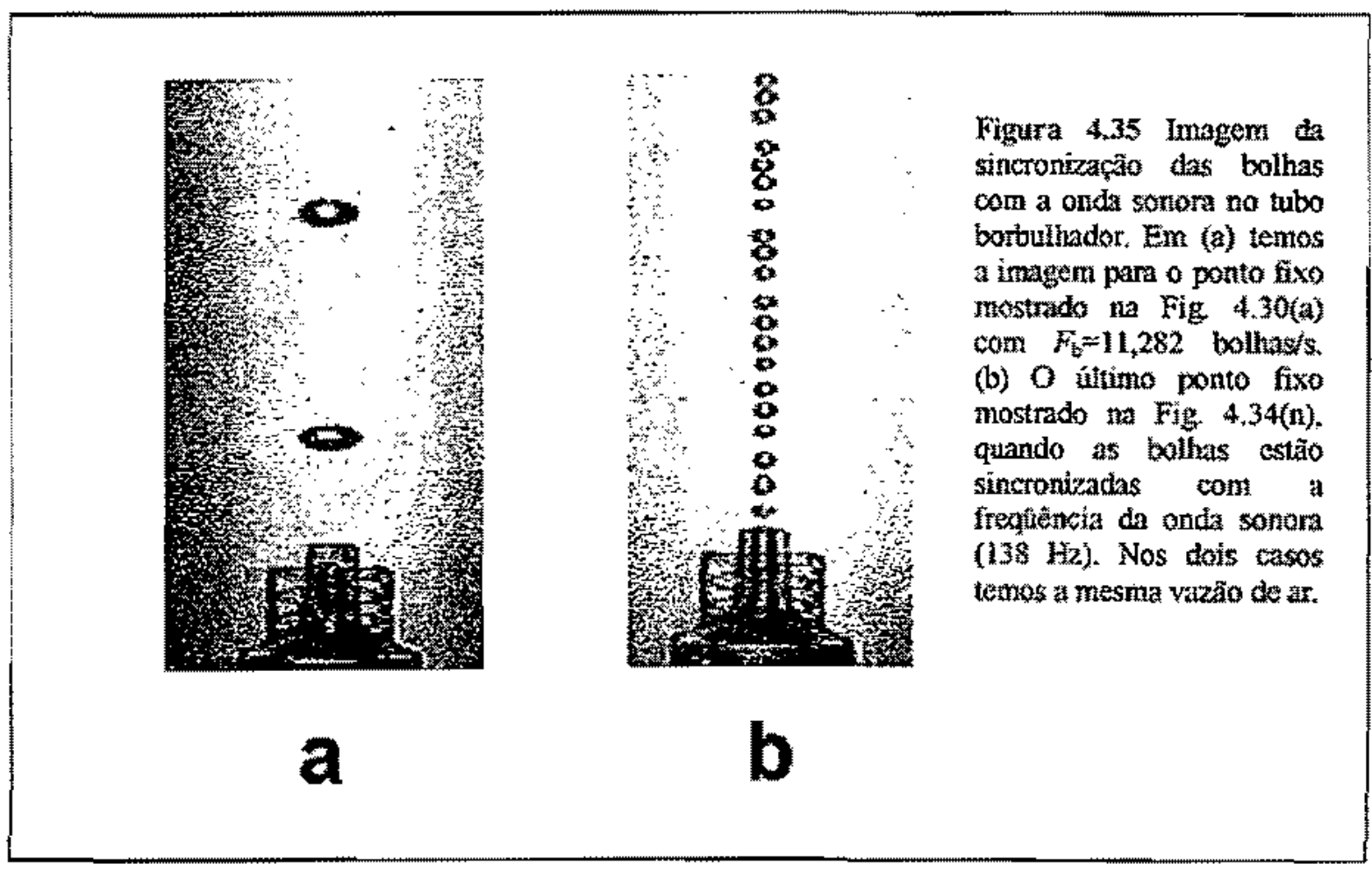

\subsubsection{Atratores do tipo Hénon}

Os resultados da seção 4.3 .1 nos mostraram uma grande evoluçăo da dinâmica da formação das bolhas com o aumento da tensăo aplicada no alto-falante. A regiano da dinâmica que apresenta a bifurcação flp̀, seguida por atratores caóticos, é semelhante aos sistemas dinâmicos que apresentam propriedades de estiramento e dobra, como o mapa de Hénon discutido na seça 2.7. Por este motivo veremos a comparaçăo entre atratores experimentais nessa regizo e o mapa de Hénon na tentativa de compreender a

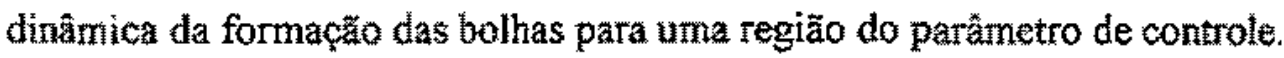

De modo a reduzir o ruido nos dados utilizamos uma soluçăo mais viscosa, $80 \%$ glicerina e 20 \% água, e utilizamos o bico A2. Para termos uma variação mais fina do parâmetro de controle, alteramos o fator de amplificação do gerador de funçóes, cujo sinal alimenta o aito-falante. A vazăo de ar e a frequência da onda sonora foram mantidas constantes, en $-36,6$ bolhas/s e $150 \mathrm{~Hz}$, respectivamente. Nós alteramos a dinâmica da formaçào das bolhas, aumentando a tensão no aito-falante como mostrado 
pelo diagrama de bifurcação na Fig. 4.36, num regime de vazão constante. Nesta figura vemos uma duplicação de período ocorrendo ao redor de $2,0 \mathrm{~V}$, com as bolhas sendo emitidas aos pares até aproximadamente $3,0 \mathrm{~V}$, quando um periodo 4 ruidoso aparece. Após isto, duas bandas caóticas aparecem. Para $-3,5 \mathrm{~V}$ as duas bandas caóticas se encontram e se sobrepöen, com o aparecimento de um atrator caótico maior.

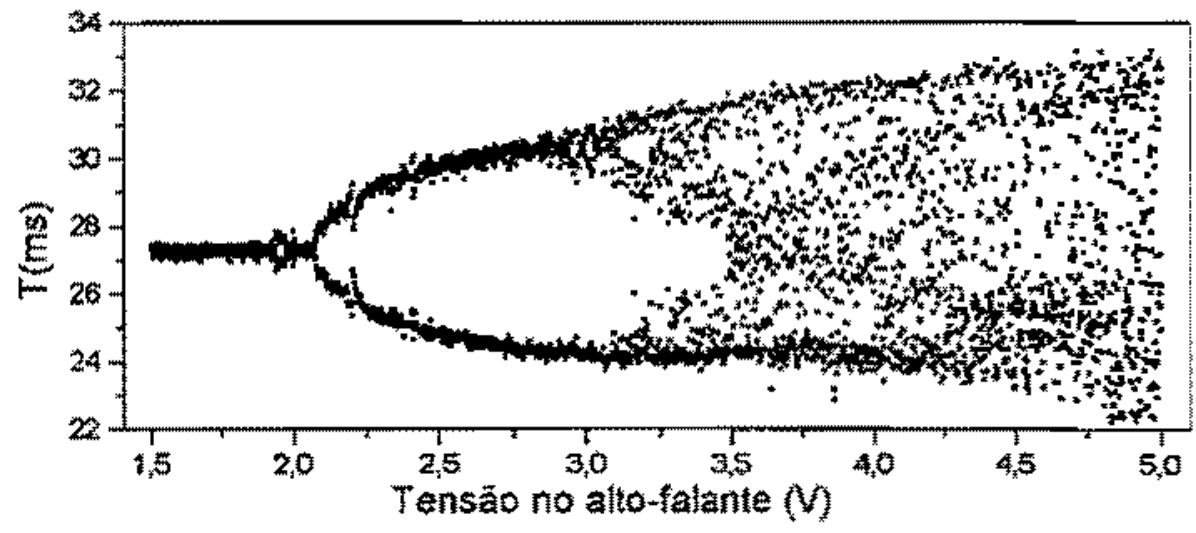

Figura 436 Duplicaça de periodo em funçã amplitude da onda sonora A frequência da onda sonota e $150 \mathrm{~Hz}$ e a frequetencia de borbulhamento inicial o por volta de 37 bolhasts.

Para realizar a caracterização métrica e topológica da dinâmica da formação de bolhas sob a ação da onda sonora, nós coletamos seis séries de eventos, fixando a tensão em seis valores distintos, cujos mapas de retomo $\left(T_{n+1}\right.$ vs. $\left.T_{n}\right)$ säo mostrados na Fig. 4.37 .

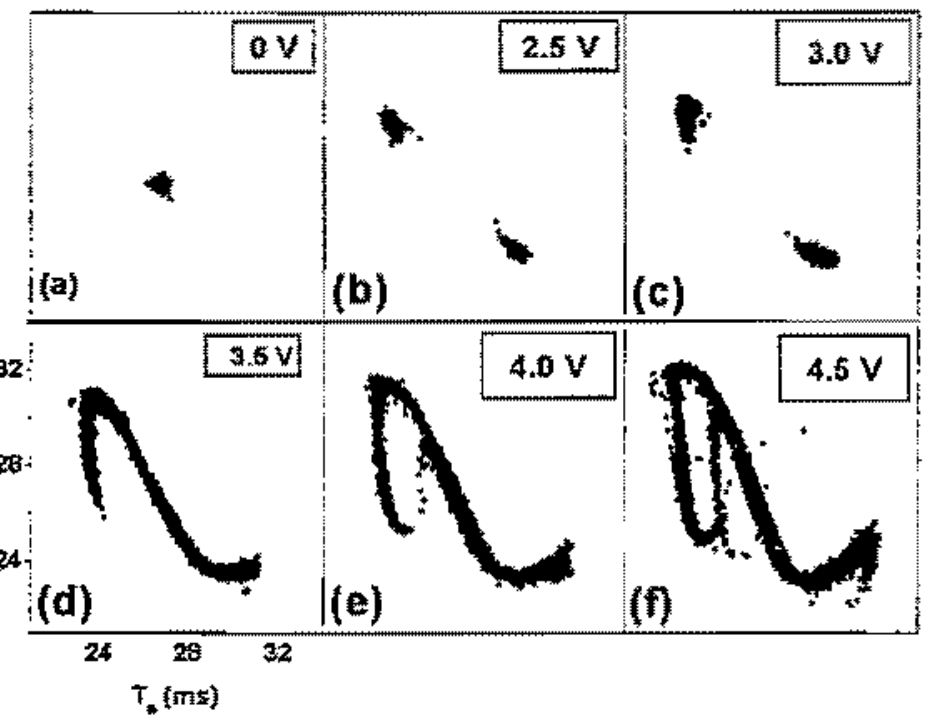

IItgura $4.37 \mathrm{Uma}$ surutucia de atratores reconstruídos mostrando unu rota para o Caos através de duplicaçón dic periods. O valor en volts corresponnie à tensăo manticia constante no altow falante durante a obtençäo do atrator. 


\subsubsection{A. Caracterização métrìca}

Os atratores caóticos reconstnuidos, Figs. 4.37 (d) até $4,37(\mathrm{f})$, form taracterizados atravès dos expoentes de Lyapunov, pela dimensä̀ de Kaplan-Yorke, além da dimensão de Informação, obtidos pelo pacote de programas TISEAN [Hegger et al, 1999]. A conjectura de Kaplan-Yorke [Argyris et al, 1994], que relaciona a dimensão de Informaçäo a a dimensäo de Kaplan-Yorke (equação (2.11)), mostra que elas se igualam para atratores do tipo Hénon. As dimensôes foram obtidas para as tensôes de $3,5 \mathrm{~V}, 4,0 \mathrm{~V}$ e 4,5 V, como esta mostrado na tabela 4.1. As dimensões de Informação e Kaplan Yorke coincidem para os três atratores caóticos.

\begin{tabular}{|c|c|c|c|c|}
\hline Figura nimero & Tenato & $\begin{array}{l}\text { Espxitro de } \\
\text { Lyapunoy }\end{array}$ & $\begin{array}{l}\text { Dimensuo de } \\
\text { Kaplan-Yorke }\end{array}$ & $\begin{array}{l}\text { Dimens } x_{0} \text { ds } \\
\text { Informacto }\end{array}$ \\
\hline $3(d)$ & 3,5 & $+0,11 ;-0,8$ & $1,15(1)$ & $1,3(3)$ \\
\hline $3(\mathrm{c})$ & 4,0 & $\neq 0,12 ;-0,6$ & $1,23(1)$ & $1.4(3)$ \\
\hline \multirow[t]{4}{*}{30} & 4,5 & $+0,2=0,3-0,9$ & $1,68(1)$ & $1.8(3)$ \\
\hline & $\begin{array}{c}\text { Atrator de Hénon } \\
a_{1}^{*} b\end{array}$ & & & \\
\hline & 1,$55 ; 0,1$ & $+0,38 ;-2,38$ & 1.16 & $1,16(9)$ \\
\hline & 1,$4 ; 0,3$ & $+0,42 ;-1,62$ & 1,17 & $1,19(9)$ \\
\hline
\end{tabular}

Tabela 4.1 Expoentes de Lyapunov e äimensoses dos atratores caúticos experimentais e de dois pares de valores do mapa de Hénon.

Cada um dos dois primeiros atratores catticos possui espectro de Lyapunov com um expoente positivo e o outro negativo, enquanto que o ultimo atrator, Fig. $4.37(f)$, possui um expoente positivo e dois expoentes negativos. Na tabela 4.1 säo apresentados os resultados para mapa de Hénon, mostrado na equaçâo (2.12), para dois conjuntos de valores dos purâmetros $(a, b)$, e os atratores experimentais reconstruidos.

Os valores das dimensôes dos atratores para amplitudes de $3,5 \mathrm{~V}$ e $4,0 \mathrm{~V}$ săo próximos dos valores das dimensões do mapa de Hénon, stugerindo que eles podem ter dinâmica similar. $O$ atrator zeconstruido para $4,5 \mathrm{~V}$ mostrado na Fig. $4.37(\mathrm{f}$, tem a forma semelhante aos dois outros atratores anterior Entretanto, comparando-se as dimensões deste atrator com as dimensôes dos atratores das Figs, $4.37(\mathrm{~d})$ e 4.37 (c), venos que o valor da sua dimensão de Informação é maior que a dimensão dos dois outros atratores experimentais, assim como dos valores de dimentẫo para o mapa de Hénon, como pode ser 
visto na tabela 4.1. Junto com o fato de que o atrator da Fig. 4.37(f) tem três componentes no espectro de Lyapunov, a dimensão de Informaça proxima de dois é uma indicação que este atrator nẫo pode ser totalmente desdobrado em duas dimensöes.

\subsubsection{B. Caracterizaçẵo topológica}

Para o mapa de Hénon, com os parâmetros $a=1,55$ e $b=0,1$, utillzando a equação (2.12) para calcular a posição dos pontos fixos para a variavel $x$ do mapa de Hénon, encontra-se que o ponto fixo $x^{*}$ está localizado em aproximadamente 0,56 . Este ponto corresponde a um dos pontos de cruzamento da linha diagonal pontilhada com o atrator reconstruido $X_{n+1}$ is. $X_{n}$, como pode ser visto na Fig. $4.38(\mathrm{a})$. Neste atrator o ponto fixo possui dois autovalores, dados pela equação $(2.14), \lambda_{1}=0,06 \pm \lambda_{2}=-1,79$, que caracterizam este ponto fixo como um ponto de sela. A variedade estável é tangente à direção do autovetor contraente relacionado ao autovalor positivo $\lambda_{1}$, menor do que 1, e a variedade instavel é tangente ao autovetor de estiramento relacionado com o autovetor $\lambda_{2}$, com valor absoluto maior do que 1. Isto estabelece que o ponto fixo é uma sela flip [Alligood et al., 1997 .

Na Fig. 4.38(a) podemos ver também um exemplo da evolução dos pontos no atrator, através da altemância dos pontos ao longo đa direçẫo instável, atẻ a trajetória alcançar as extremidades do atrator. Partindo de uma região próxima do ponto de sela do atrator de Hénon, nós vemos os pontos fmpareścínioiais acina da linha diagonal pontithada $(1,3,5$ e 7$)$, a os pontos pares abaixo desta linha $(2,4$ e 6$)$, caracterizando a variedade instável. Nos mapas de primeiro retomo experimentais, mostrados nas Figs. 4.37(d), (e) e (f), nós dividimos o atrator em duas partes com una linha diagonal para determinar os pontos que cruzam com o atrator. Ocorreu o comportamento de altemância da trajetónia para os três casos, do mesmo modo que o observado no atrator de Hénon, como está exemplificado na Fig. $4.38($ b) para o atrator obtido com uma tensão no alto-falante de 4,0 V. Do mesmo modo que no atrator de Hénon, nós começamos num ponto próximo da interseçăo do atrator com a linha diagonal $\left(\mathrm{T}_{\mathrm{N}}=\mathrm{T}_{\mathrm{N}+1}\right.$ aproximadamente igual a $27 \mathrm{~ms}$ ), com as extremidades do atrator sendo visitadas pela órbita. Deste modo, devido as semalhanças de evoluçẵo dos atratores experimentais com a evoluçño do atrator de Hénon, 
nós podemos inferir a existência de um ponto de sela flip nos atratores experimentais, mesmo para o caso da tensäo de controle de $4,5 V$, cujo espectro de Lyapunov tem três componentes e dimensẫo próxima de dois.
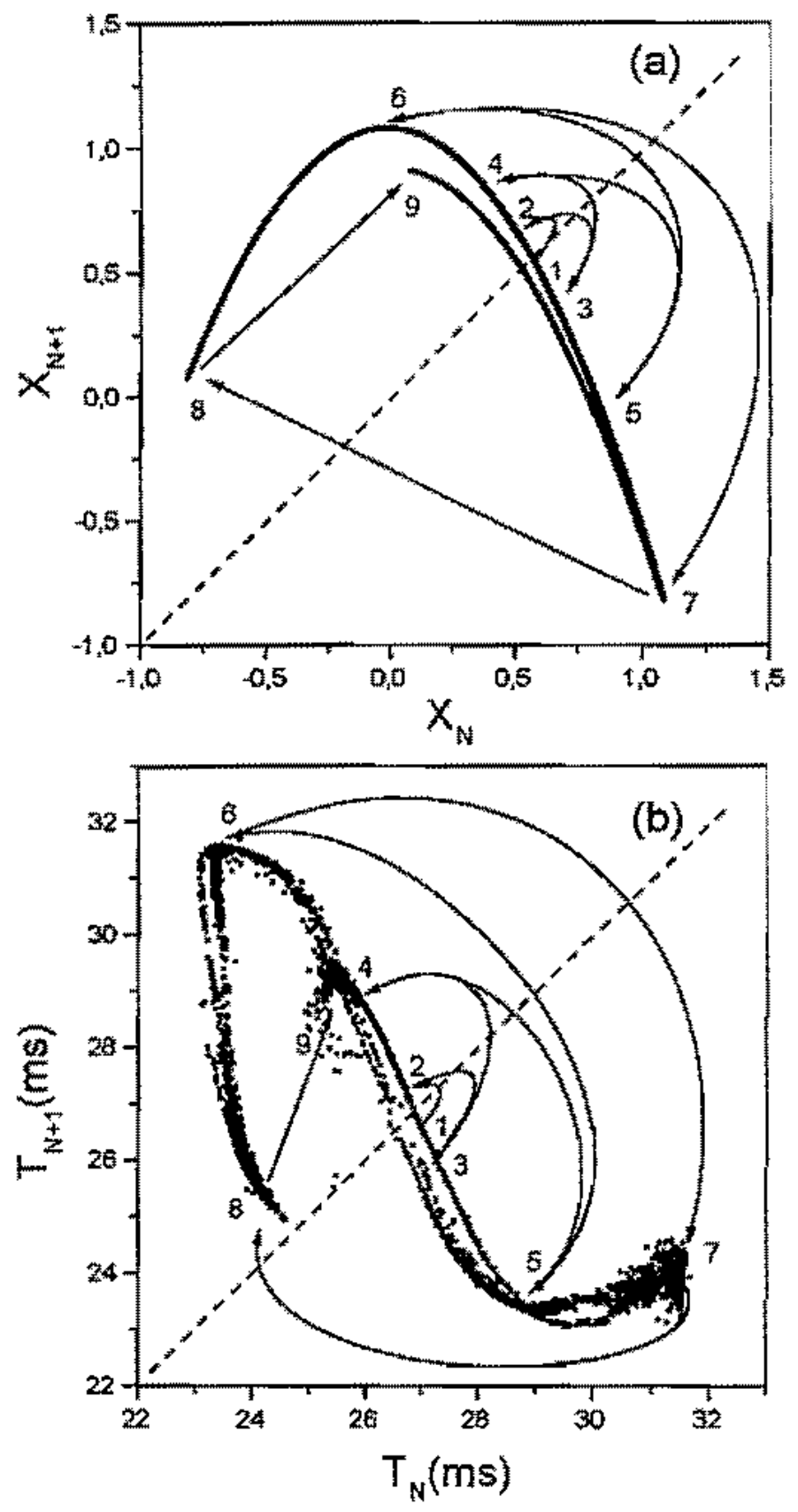

Figura 4.38 (a) Vemos ao lado a trajetónia sobre nove pontos do atrator ctu Henon para exeringlificia o comportumento de um ponto de sela fip, localizada próxima do ponto 1 $\left(x^{*}=0,56\right)$

(b) O nesme comportamento de um ponto fixo tipo sela flip pode ser observado para o atrator experimental, com os pottos pares niciais $(2,4$ e 6$)$ acima da diagonal, es pontos impares iniciais $(1,3,5$, 7$)$ abaixo. 


\subsubsection{Plano simbólico}

Como os planos simbôlicos são representaçōes graficas da dinâmica t uma poterosa ferramenta para semparar sistemas dinâmicos, nós aplicamos a técnica de dinâmica simbólica para os atratores mostrados nas Figs 4,37 (d) até $4.37(\mathrm{f}$ ), assint somo no atrator de Hénon $(a=1,55$ e $b=0,1)$ para podermos comparar as semelhanças e diférenças entre eles. Definimos as partiçôes $L(R)$ através da linha tracejada. Na Fig. 4.39(a) mostramos o atrator de Hénon para $a=1.55$ e $b=0.1 \mathrm{com}$ a sua respectiva partição, que separa a regrầo formada por uma linha (L), da regiâo com uma dobra $(\mathrm{R})$ que contém o ponto fixo instável. $O$ plano simbólico $\alpha \beta$ deste atrator está mostrado na Fig. 4,39(A). Nas Frgs, 4.40(b) até 4.40(d) temos os atratores experimentais, cujas particöes são as linhas tracejadas, que separam uma região com um ramo (L), de uma regiẫo com dobra $(\mathrm{R})$. Os respectivos planos simbólicos $\alpha \beta$ estão mostrados nas Figs $4.40(B)$, (C) e (D).

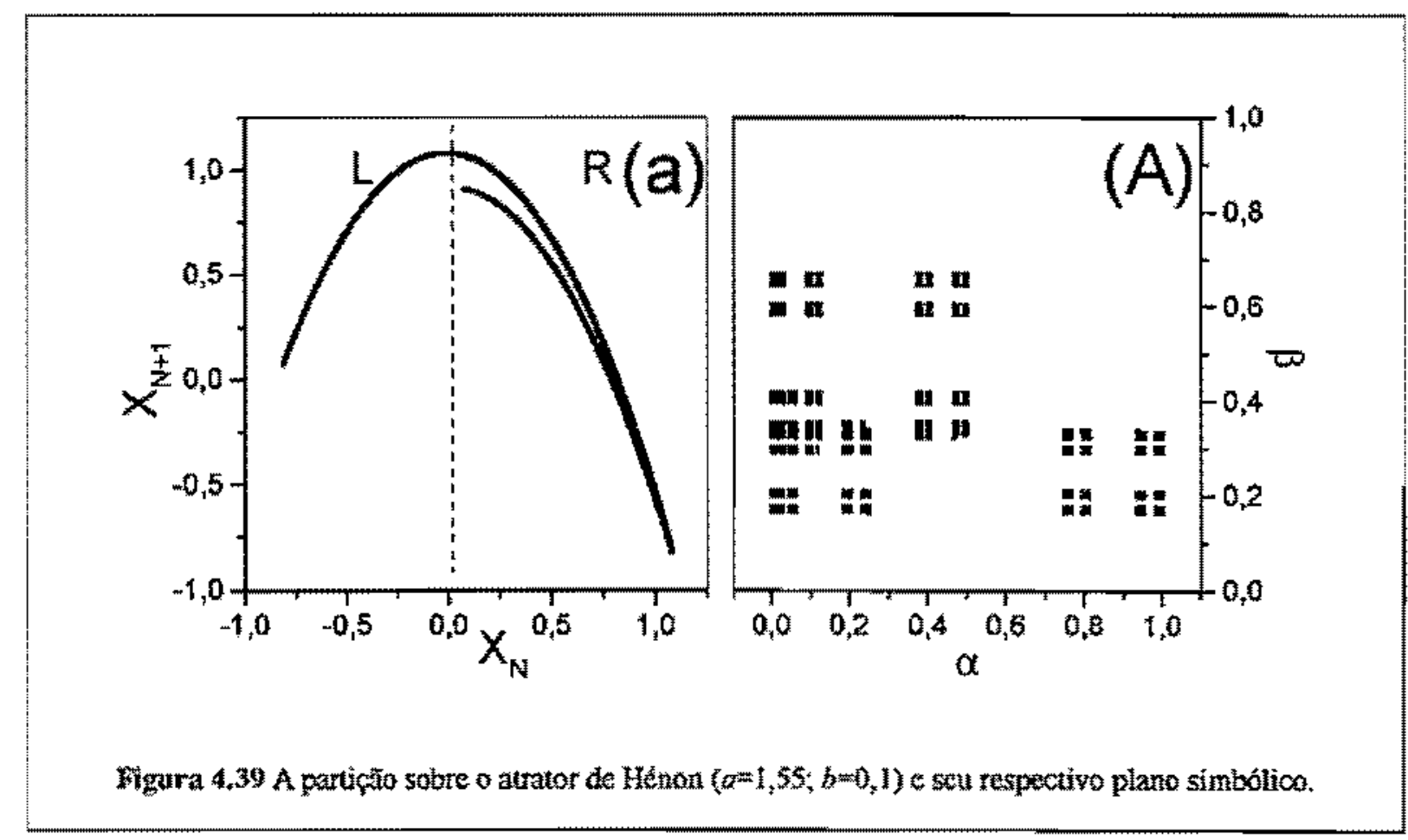

Comparando-se a Fig. 4.39(A) com as Figs, 4.40(B), (C) e (D) percebe-se o padrỗo de cada plano simbólico é semelhante ao plano simbólico do mapa de Hénon. A maior 
semelhanga ocorre entre o atrator de Henon e o atrator experimental com a tensäo de controle de $3,5 \mathrm{~V}$ da Fig. $4.40(\mathrm{~B})$, cujo plano simbólico possui as mesmas regióos permitida e proibida. Para valores maiores de amplitude da onda sonora, algumas zonas deixam de ser proibidas, veorrendo uma invasão nestas regiōes, como por exemplo $\alpha=0,8$ e $\beta=0,4$ nt Fig, 4.40(D), mostrando que a formaçăo de bolhas está se afastando da dinatuica do tipo Hênon, e ficando muito semelhante ao plano simbolico do mapa do círculo, como pode ser visto na comparação entre a Fig. $4.40(\mathrm{C})$ e a Fig. $2.12(\mathrm{~A})$.

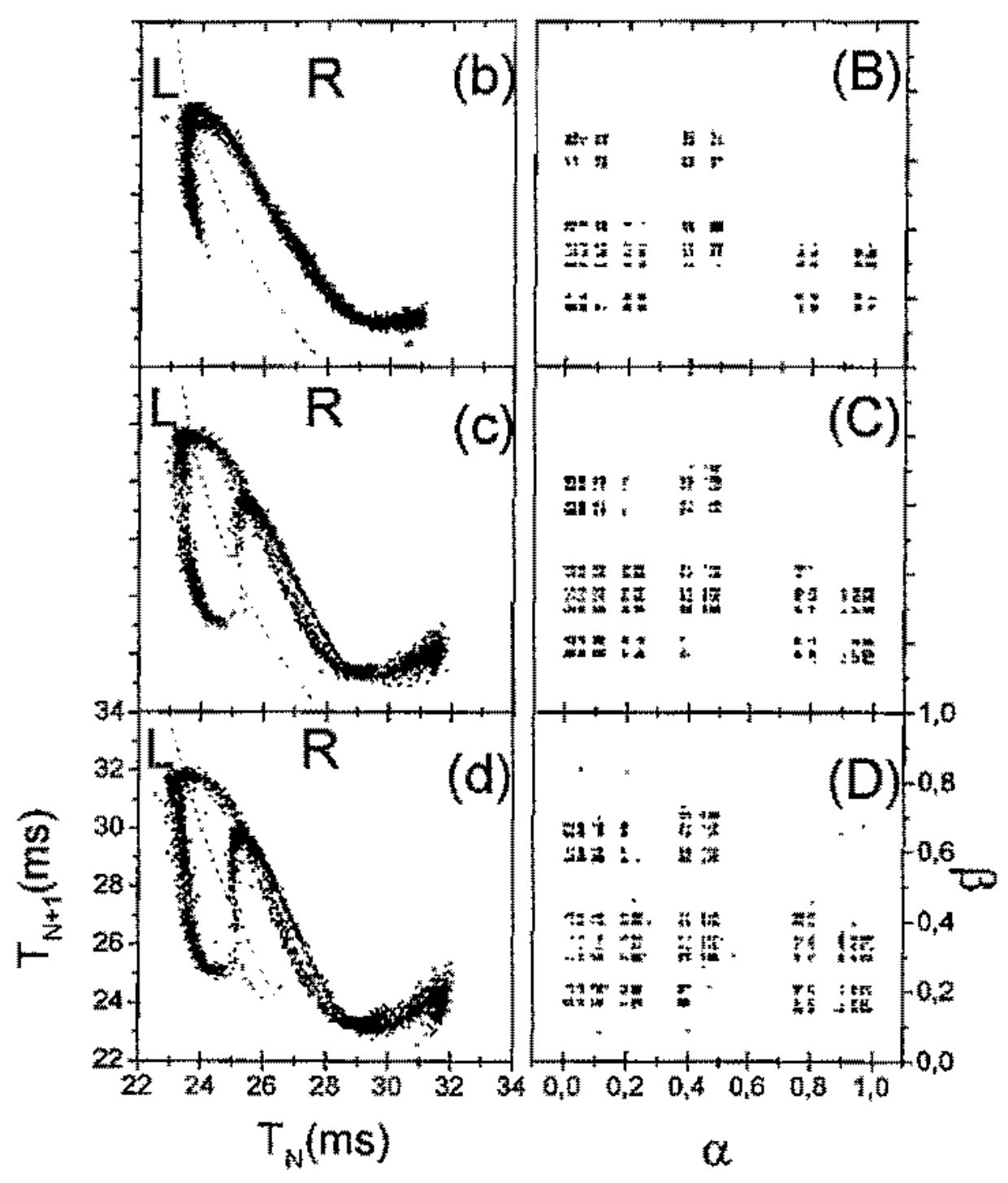

Figura 4.40 Mapas de retomo experimentais com partiçoes e respectivos planos sinulólicos. 


\subsection{Oscilações forçadas}

Mapeamentos bidimensionais, como o mapa de Hénon, normalmente são usados como seções de Poincaré de osciladores forçados [Thompson e Stewart, 1986]. Se considerarmos a existência de um movimento oscilatório na formação de bolhas, e a onda sonora como uma força periódica extema, podemos compreender o sistema bolhas/onda sonora como um oscilador forçado, como

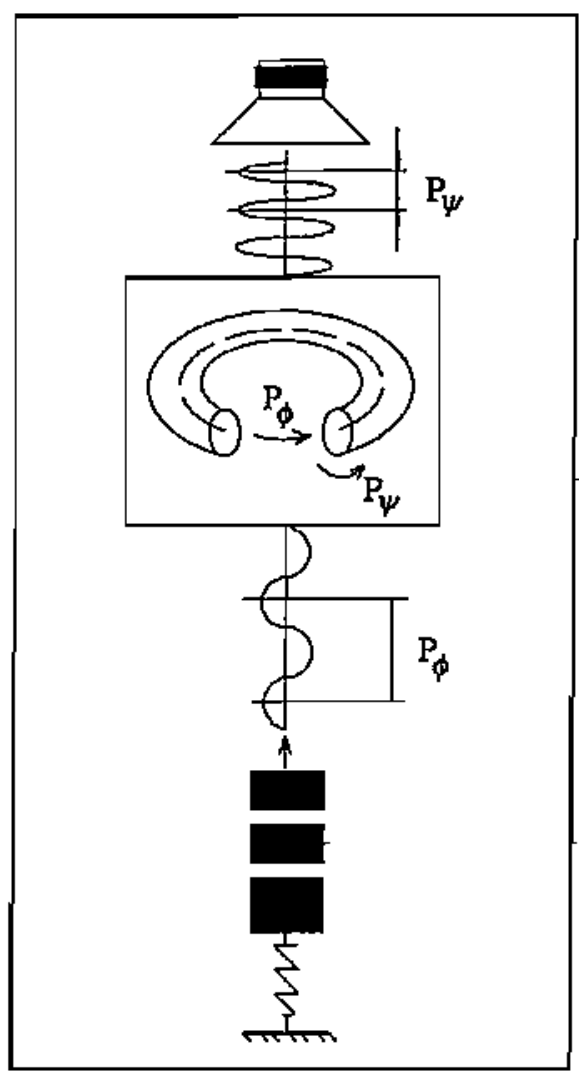

Figura 4.41 Representação esquemática do sistema bolhas/onda sonora como um oscilador forçado, onde $P_{\phi}$ é o período de oscilaçăo associado às bolhas e $P_{\psi}$ é o período da onda sonora. está diagramado na Fig. 4.41.

Deste modo podemos interpretar os mapas de primeiro retorno observados experimentalmente como seções de Poincaré de um oscilador forçado. Outro sistema dinâmico que representa um oscilador forçado é o mapa bidimensional do círculo, discutido na seção 2.9:

$$
\begin{aligned}
& \theta_{n+1}=\theta_{n}+\Omega-\frac{K}{2 \pi} \operatorname{sen} 2 \pi \theta_{n}+b r_{n}, \quad(\bmod 1) \\
& r_{n+1}=b r_{n}-\frac{K}{2 \pi} \operatorname{sen} 2 \pi \theta_{n}
\end{aligned}
$$

As duas freqüências envolvidas no experimento cuja razão nos dá $\Omega$, para o tubo borbulhador, são a freqüência da onda sonora e a frequência de borbulhamento. $O$ tempo entre bolhas está relacionado com a variável $r_{n}$ do mapa. O parâmetro $K$ está relacionado com o experimento com a tensão que é aplicada no alto-falante. Para explorarmos a região inicial do mapa do círculo, diminuímos o fator de amplificação do sinal do gerador de funções para o alto-falante. Utilizamos o líquido $80 \%$ glicerina e $20 \%$ água e o bico A2. 
Na Fig. 4.42(a) temos os dados obtidos para um valor de $\Omega_{\mathrm{Ex}}=3,7$, na Fig. 4.42 (b) o resultado da simulacäo utilizando o mapa do pirculo com $b=-0,1$. Os dados mostram que com o aumento da amplitude da onda sonora o ponto fixo inicial da lugar a um ciclo limite, cujo raio aumenta de maneira aproximadamente linear ate a tens V. Após este valor de tensâo uma janela periódica ocorre e o sistema entra numa regiăo caótica, para valores de tensâo entre $5,4 \mathrm{~V}$ e 8,7 V. A regiăo caótica é substituida por um travamento frequência de períado 1 .
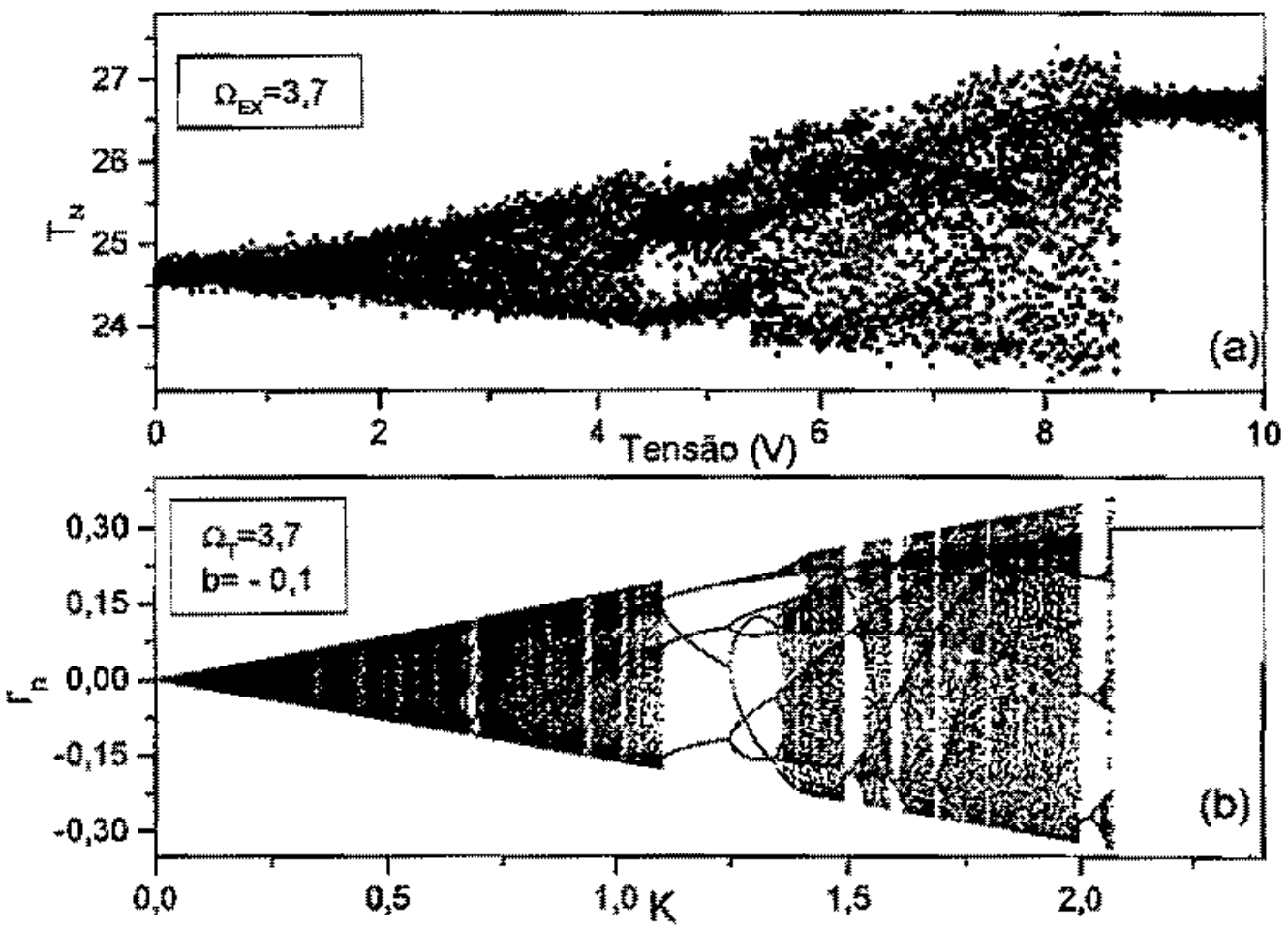

Figura 4.42 Em (a) vemos os dados obtidos com o experiniento do tubo borbulltador, com a razão entre a frequência da onda sonora e a frecutência de borbulhamento igual a 3,7. Em (b) simulaçăo com o mapa do circulo bidimensional.

A comparaçâo com o mapa do circulo da Fig. 4.42(b) mostra as mesmas caracteristicas. O rutio experimental tem a tendência de mascarar as janelas periódicas, mas a jancla periodica central é bem visivel nos dois casos.

Diminuindo a frequência de borbulhamento e repetindo o aumento da amplitude a partir do zero, temos os dados da Fig. $4.43(\mathrm{a})$, com um valor de $\Omega_{\mathrm{Ex}}=4,27$. Na Fig. 4,43(b) 
a simulação com o mesmo valor de $\Omega$ eb=-0,1. Esta regiảo triangular inicial, para baixas amplitudes da onda sonora e para estes valores de $\Omega_{\mathrm{Ex}}$, é uma rota para o Caos via quaseperiodicidade.

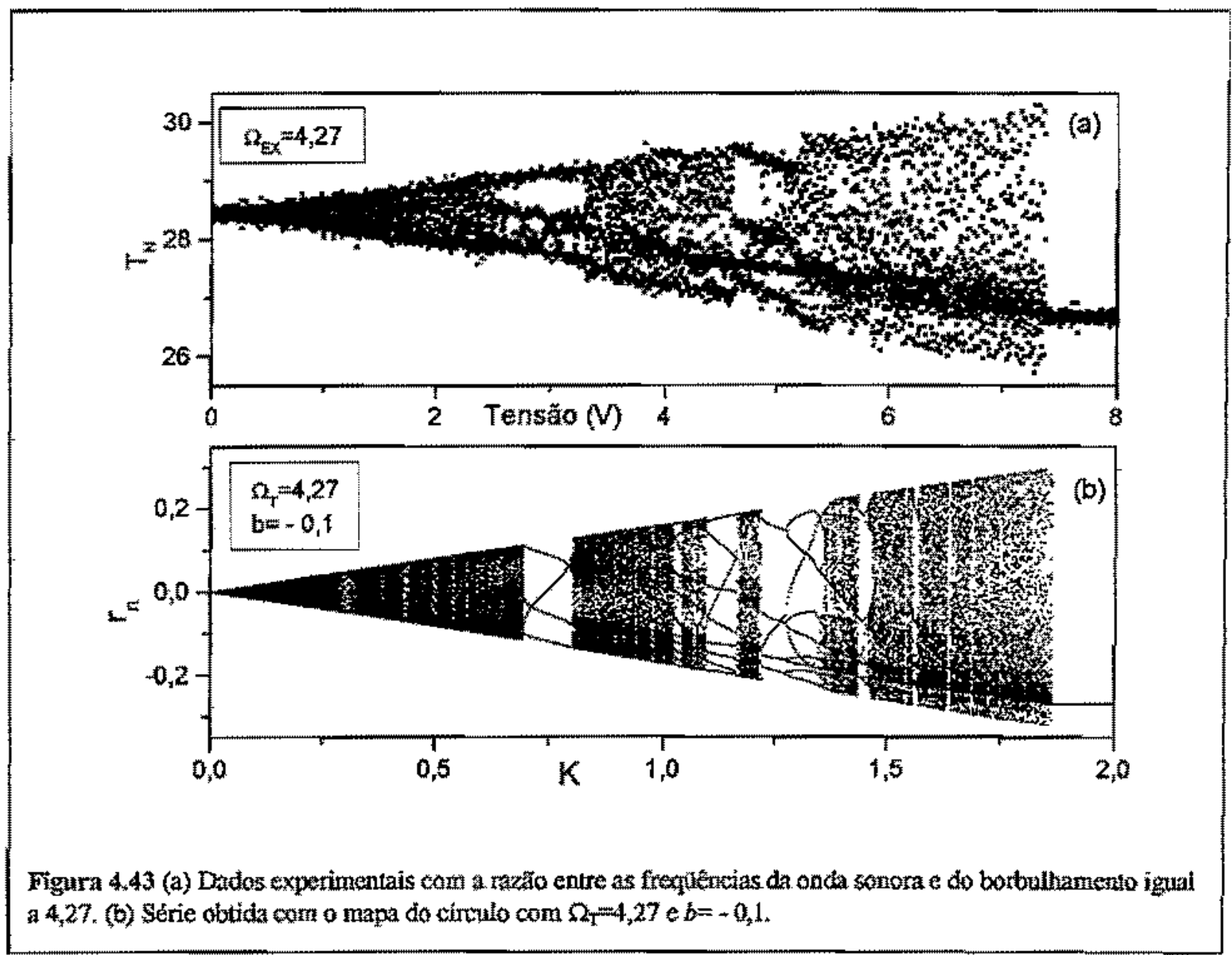

\subsubsection{Comportamento geral}

Agora veremos o travamento em periodo 1 após a região quasemperiódica triangular, seguida de duplicaça de periodo e Caos.

Para obter a série temporal, nós escolhemos um ponto fixo sem a onda sonora, com a taxa de borbulhamento $F_{b}=1 / T_{0}$ onde $T_{0}$ to tempo médio entre bolhas sucessivas, e apos isto, nós aumentamos a amplitude $A$ do som continuamente. 

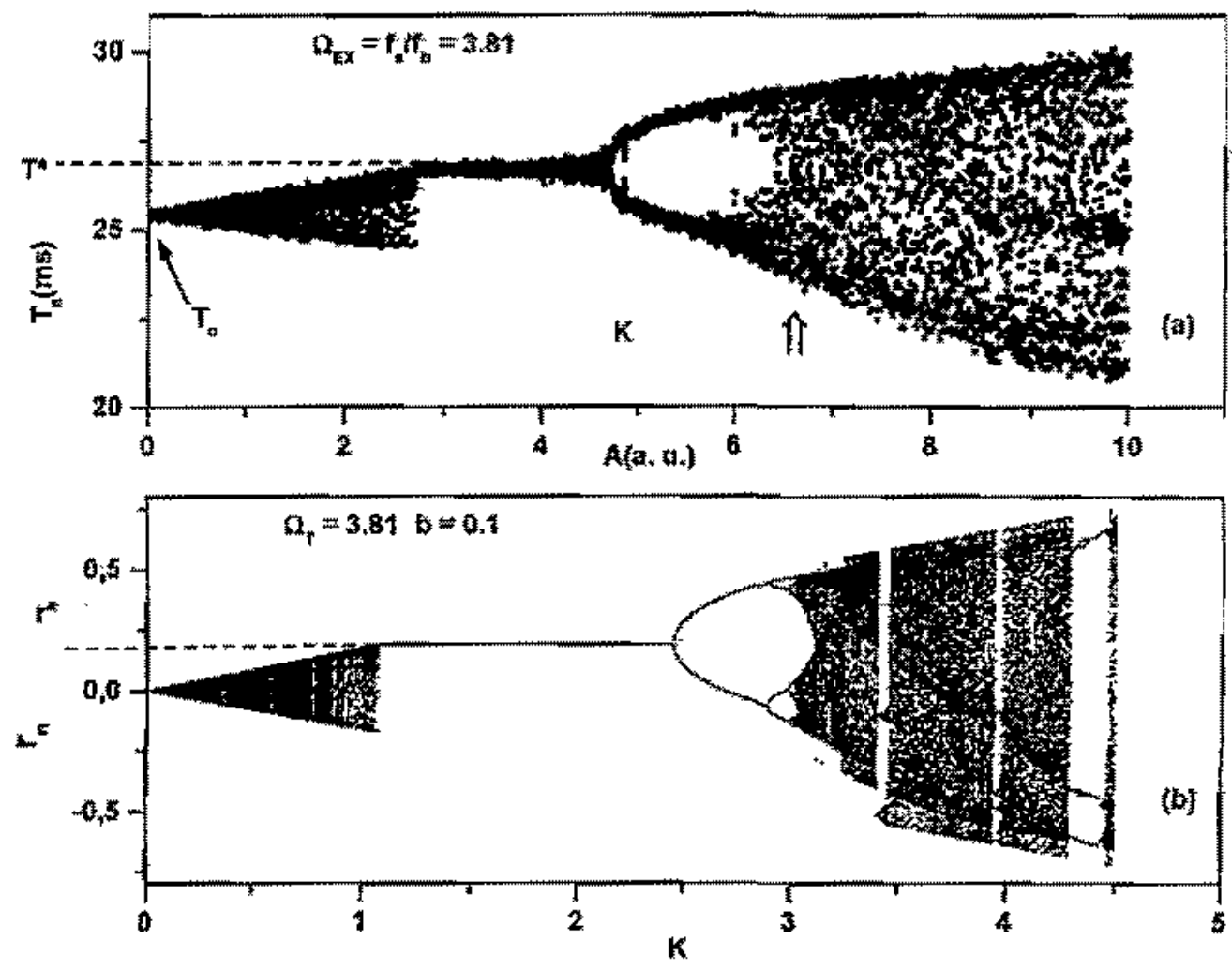

Figura 4.44 (a) Diagrama de bifurcaça experimental, O ponto fixo experimental $T^{*}$ conresponde a 26,7 mis, (b) diagranat obtido com o mata do circulo, com $z^{*}=0,19$.

Na Fig. 4.44(a), pode ser vista a série experimental, $T_{n}$ vs. $A$, para uma taxa de borbulhamento de $F_{5}=39,37$ bolhas/s e $\Omega_{\mathrm{Ex}}=F_{y} / F_{b}=3,81$. Na Fig. $4.44(\mathrm{~b})$ temos o diagrama de bifurcaçăo do mapa do círculo, $r_{n} 4 s . K$, calculado com $b=0,1$ e o mesmo valor de razão de freqüências $\Omega_{\mathrm{T}}=3,81$.

Temos algumas similaridades entre os dois diagramas. Partindo de $K=0$ e $A=0$, cada ponto fixo perde sta estabilidade quando aumentamos o respectivo parâmetro de controle, $\mathrm{e}$ ocorre uma região quase-periódica. Os pontos fixos, $T^{*}$ e $r^{*}$ tornam-3e estaveis para $A$ por volta de 2,7 e $K$ aproximadamente jgual a $1,07.0$ ponto fixo $T^{*}\left(r^{*}\right)$ é estáyel até $A \cong 4,7(K$ $=2,44)$, quando inicia-se uma cascata de duplicaçōes de periodo. Deve ser notado que as posiçôtes destes pontos fixos estâo na regiato superior da banda triangular $\left(r^{*}>0\right.$ e $\left.T^{*}>T_{0}\right)$. 
As propriedades dos diagramas süo facilmente explicadas, se analisarmos as propriedades do mapa do circulo. Segundo as equaçós $(2.28)$, o ponto fixo ${ }^{*}$ após a regiäo quase-periotica no mapa do circulo é dado por:

$$
r^{*}=\left\{\begin{array}{l}
-\Omega(\bmod 1) \text { se } \Omega(\bmod 1)<0,5 ; \\
1-\Omega(\bmod 1) \text { se } \Omega(\bmod 1)>0,5
\end{array}\right.
$$

No atrator experimental, o ponto fixo r $^{*}$ ocorre quando a região quase-periódica atinge uma frequêtencia de borbulhamento igual a um submuttiplo da frequểncia da onda sonora de $150 \mathrm{~Hz}$ :

$$
\mathrm{T}^{*}=4 / 150 \equiv 26,7 \mathrm{~ms},
$$

onde o número 4 e inteiro mais próximo do valor de $\Omega_{\mathrm{Ex}}=3,81$. Este fenômeno é conhecido com travamento sub-harmônico (subhamonic entrainment) [Hayashi, 1985] e ocorre em um oscilador forçado quando a razão entre a freqüência da força extema e a frequiência natural do oscilador está na vizinhanęa de um inteiro diferente de 1.
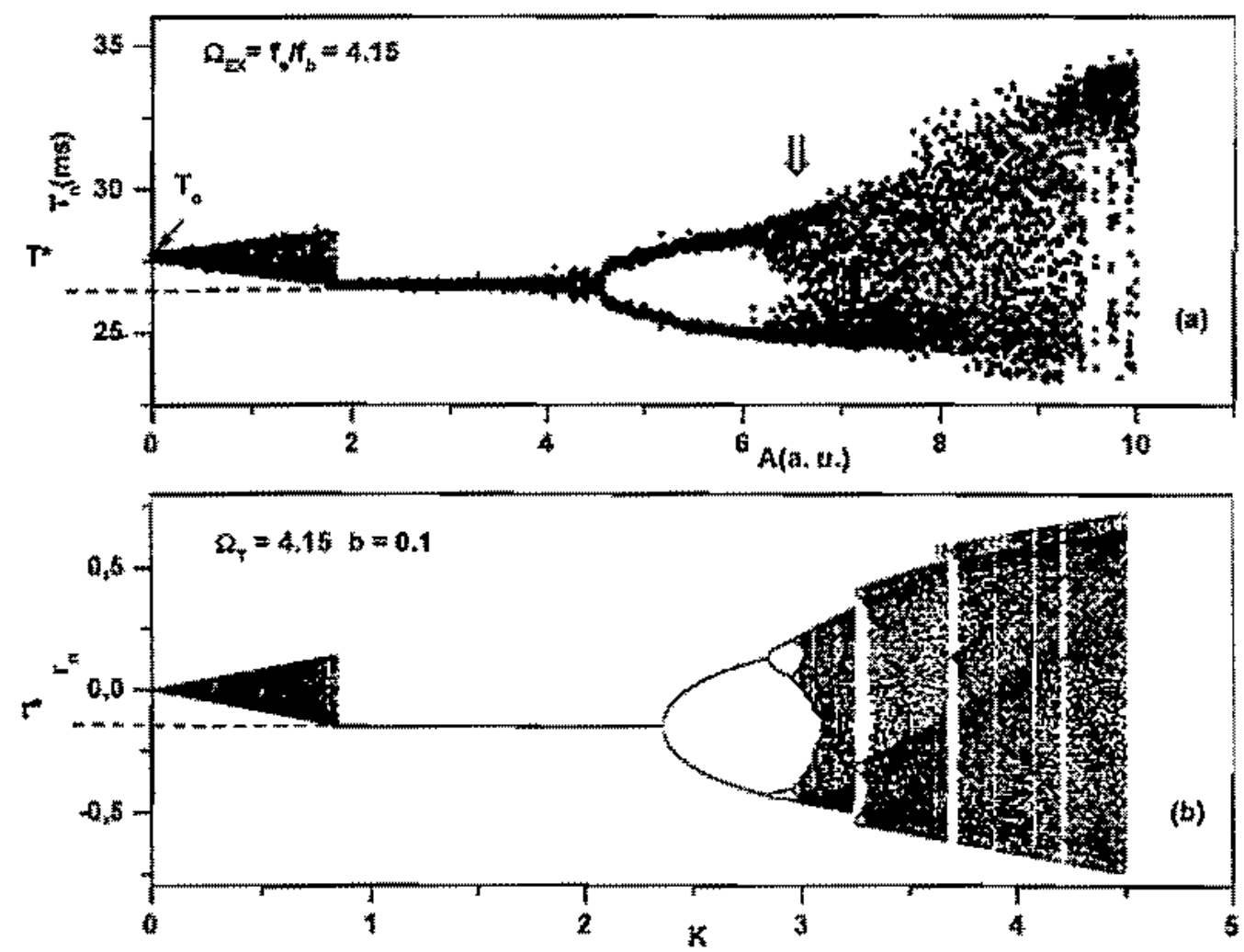

Figura 4.45 (a) Diagrama de bifurcaçăo experimental con $\mathrm{T}_{0}-27,7$ ms. $O$ ponto fixo experimental $\mathrm{T} *$ conresponde a $26,7 \mathrm{~ms}$, (b) diagrama totido com o nutpa do circulo, com $r^{*}=-0,15$. 
Com outra frequểncia de borbuhamento, $F_{\mathrm{B}}=36,14$ bolhas/s, mas com a mesma freqüência da onda sonora de $150 \mathrm{~Hz}$, obtivemos o diagrama experimental que está mostrado na Fig 4,45(a) com $\Omega_{\mathrm{Ex}}=4,15$. Podemos notar as mesmas similaridades descritas anteriormente, como o travamento sub-harmônico do borbulhamento dado pela equação (4.32), porém o ponto fixo experimental $\left(T^{*}<T_{0}\right)$ está agora no limite inferior da região quase-periódica triangular. Na Fig. $4.45(\mathrm{~b})$, temos o diagrama de bifurcaçấo do mapa do circulo com $\Omega_{\Upsilon}=4,15 \Leftrightarrow b=0,1$. O ponto fixo $T^{*}\left(r^{*}\right)$ tornamse instável em $A$ aproximadamente igual a $4,5(K \cong 2,36)$.

Nós podemos dividir a evolução do borbuhamento em duas regiọes: uma regizãa inicial, relacionada com o comportamento quase-periódico $(A \leq 2,5)$ e a rota de duplicação de periodo $(A \approx 4)$.

Para valores inteíros de $\Omega_{\mathrm{T}}$, não observamos a região quasêterióticá. Ajustando a

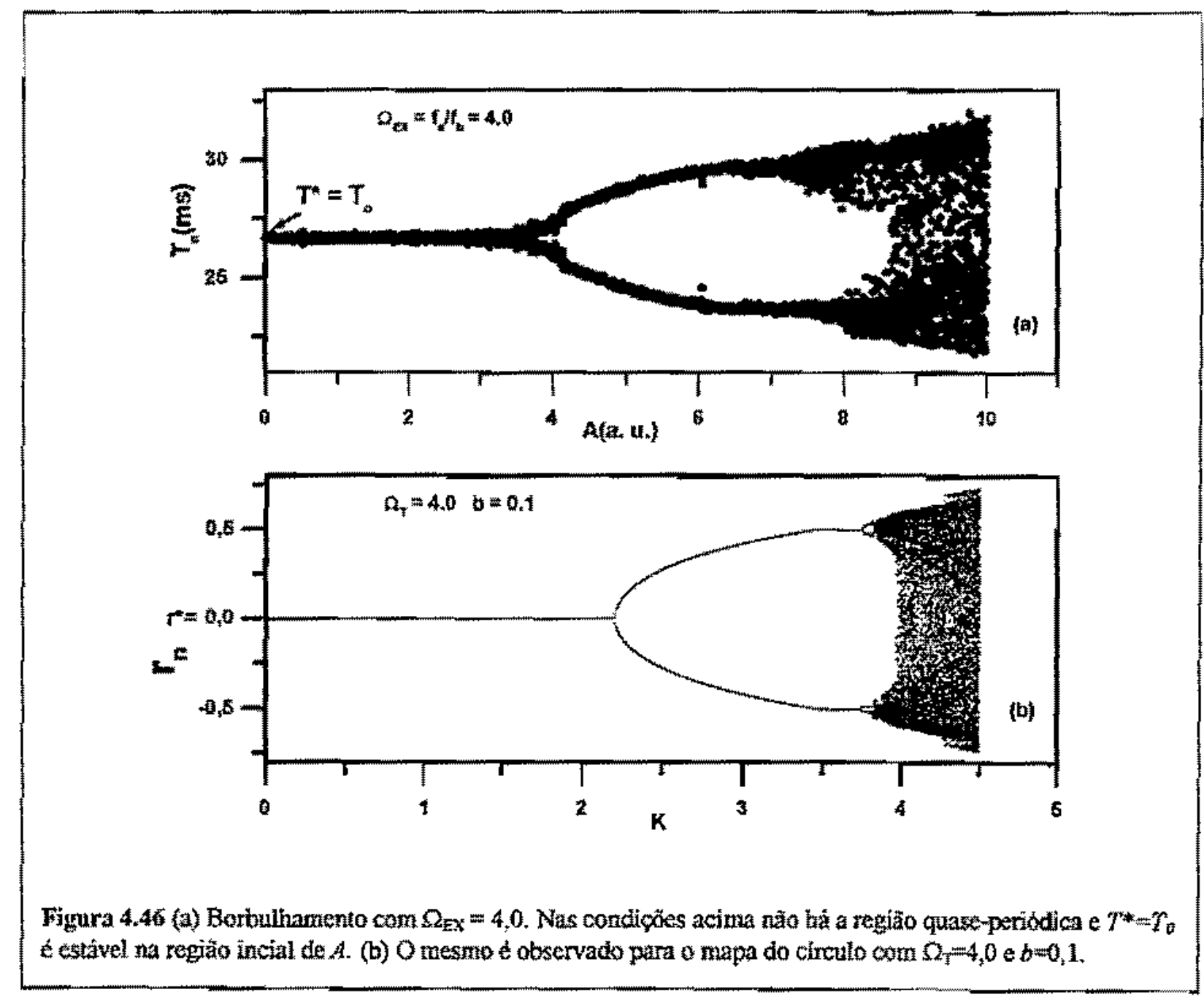


frequência de borbuthamento para 37,5 bolhas/s, tal que $\Omega_{\mathrm{EX}}=4,0$, não ocorre a região quase-periodica, como pode ser visto nos dois diagramas da Fig. 4.46. O ponto fixo $T * T_{0}$ $\left(r^{*}=0\right)$ é estável até $A^{*}$ aproximadamente ígual a $3,7\left(K^{*} \cong 2,2\right)$ e o sistema evolui diretamente para a cascata de duplicaçós de periodo.

Na Fig. 4.47, temos algumas linguas de Amold para o mapa do circulo unidimensional $(b=0)$ como uma aproximaçäo do nipa do círculo bidimensional com $b= \pm 0,1$. Para um valor de $\Omega$ (mod 1) diferente de 0,0 sistema inicialmente evolui na região quase-periódica, mostrato pelas setas pontilhadas, ate que o sistema alcança o ponto fixo estável, dado pelos círculos cheios. Mesmo para os casos dos dados mostrados nas Figs. 4.42 e 4.43 , podemos ver quando o sistema atinge as regibes das linguas de Amold relativas ao pertodo 4 , marcado pelas pequenas linhas horizontais pontilhadas. Para $\Omega=0$, 0 sistema percorte a regino inicial de $K$ no periodo 1 relativo ao número de rotação $W=01$.

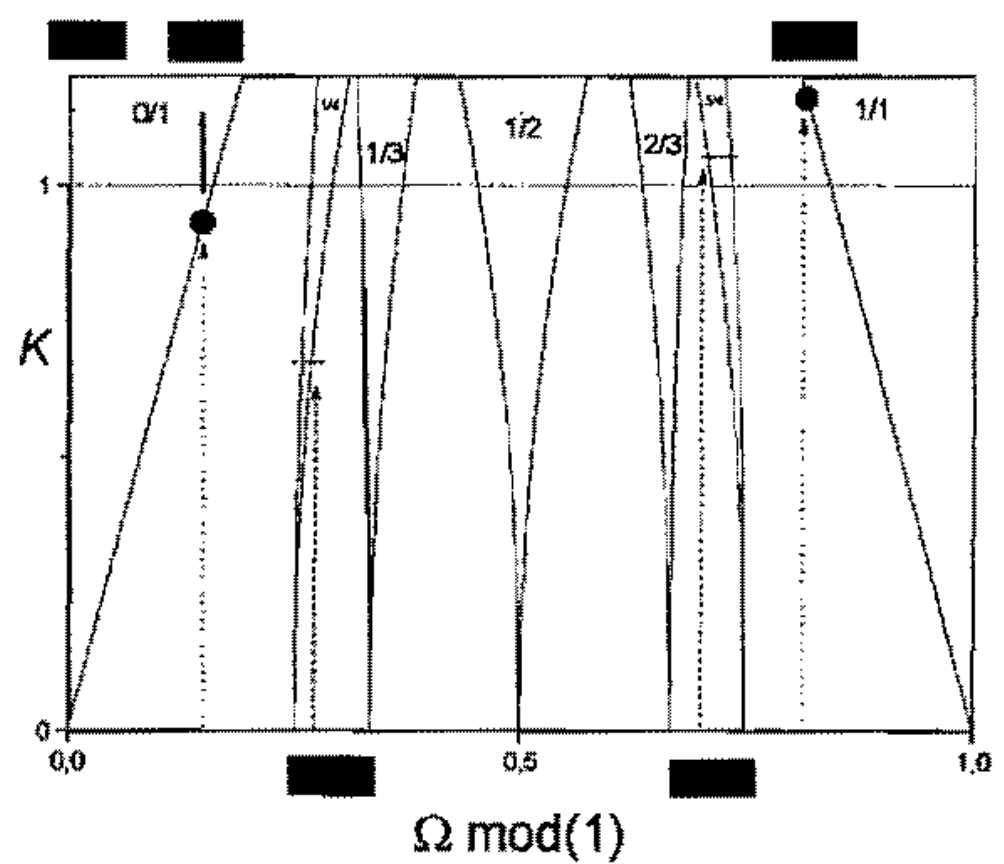

Figura 4.47 As sete linguas de Amold mäs largas com seus respectivos numeros de rotaço. Os números enire paréntese coloridos no topo e na base correspondem aos nứmeros das figuras mostradas neste comitulo. 


\section{4,4.2. Comparação dos atratores}

Os atratores caóticos do tipo Hénon, que aparecem no mapa do círculo, sofrem uma rotactio ao redor do ponto do ponto de sela flip, como pode ser visto nas comparações entre atratores experimentais reconstruidos das Figs $4.48(\mathrm{~A})$ e $4.48(\mathrm{C})$, e entre os atratores obtidos numericamente das Figs. 4.48(a), (b) e (c). Usaremos o termo saxofone, que foi utilizado por R. Shaw [Shaw, 1984] para atratores obtidos no experimento da tomeira gotejante, para designar os atratores das Figs. 4.48(a)-(A). Experimentalmente e numericamente, as condiçôs de orientaçăo dos atratores saxofone säo as seguintes:

$$
\begin{gathered}
\Omega(\bmod 1)>0,5 \text { formato de saxofone, } \\
\Omega(\bmod 1)<0,5 \text { formato de saxofone invertido. }
\end{gathered}
$$

Quando a parte fracionária de $\Omega$ se anula temos a formação de um atrator do tipo duplo gancho, como esta mostrado na Fig. 4.48(b) e 4.48(B). Como foi discutido na seçấo 4,3.2.2, todos os atratores experimentais apresentam um ponto de sela flip, que estä localizado na interseça de cada linha diagonal com cada atrator das Figs, 4.48. Em todos as casos, este ponto de sela substituiu o ponto fixo estável, $T^{*}$, do travamento subharmônico (equação 4.32). Por isso, no atrator experimental o ponto de sela flip, $T_{\beta}$ calculado do mesmo modo que o ponto fixo estável $T *$;

$$
T_{f}=4 / 150 \cong 26,7 \mathrm{~ms}
$$

onde o número 4 e o inteiro mais próximo do valores das razóes de frequềncias $\Omega_{\mathrm{Ex}}(3,81$, $4,0$ e 4,15$)$, com a frequência da onda sonora sendo de $150 \mathrm{~Hz}$. Para os atratores obtidos

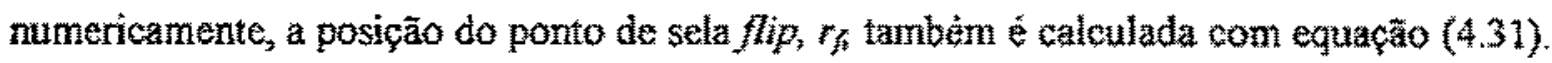
Em particular, os três pontos de sela fip dos atratores mostrado nas Figs. 4.48 sac:

$$
\begin{aligned}
& r_{f}(A)=0,19 \\
& r_{f}(B)=0,0 \\
& r_{f}(C)=-0,15
\end{aligned}
$$



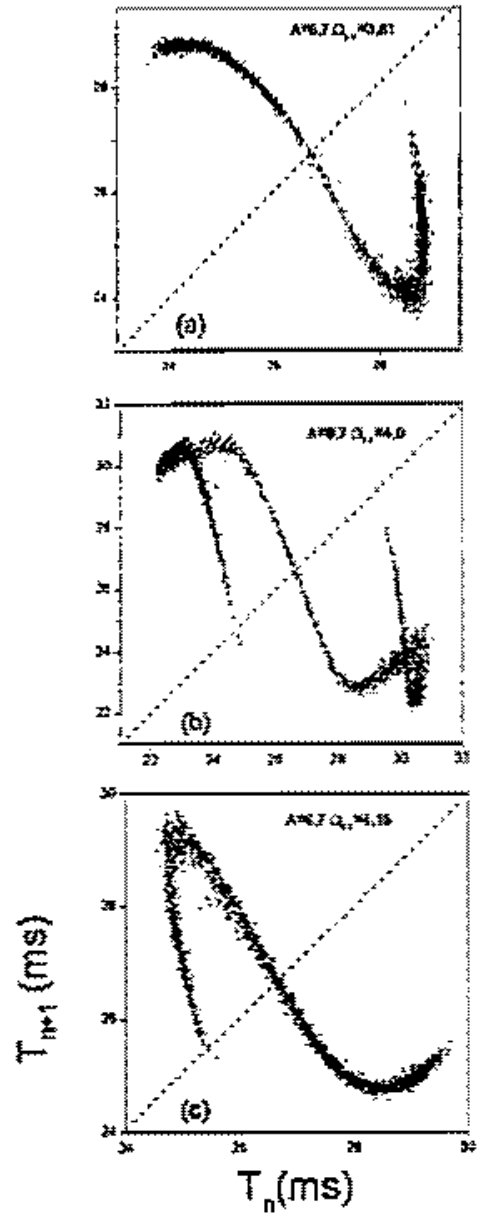
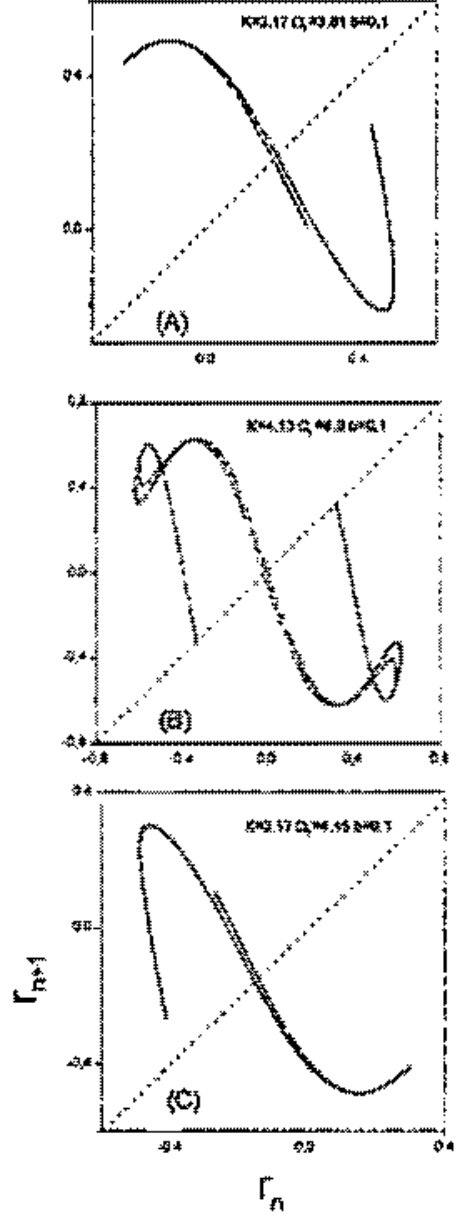

Figura 4.48 (a) $\mathrm{O}$ atrutor saxofone obido com o experimento do tubo borbulhador no ponto indicado por una seta na serrie mostrada na Fig. 4.44(a). (A) A simulaça com o mapa do circulo.

(b) Atrator experimental do tipo gancho atzblo, obtido nas mesmas condiçồes indicadas pela seia sobre a setrie da Fig. 4.46(a) (B) Afrator obtido con o mapa do circulo.

(c) Rotaçẫo do atrator experimenial, obtido no ponto indicado pela seta na série ta Fig 4.45(a). (C) A mesma rotaçăo na simulaçẫo feita com o malapa do circulo.

Quando a parte fracionária de $\Omega_{\mathrm{Ex}}$ vale 0,5, aumentando-se a amplitude, temos também o ponto fixo de período 1 que se torna instável, surge um periodo quatro e depois disso surge urn atrator caótico com a forma de uma crzz, que está mostrado na Fig. 4.49.

Além disso, outros mais atratores experimentais mais complexos também podem ser simulados com o mapa do circulo, como

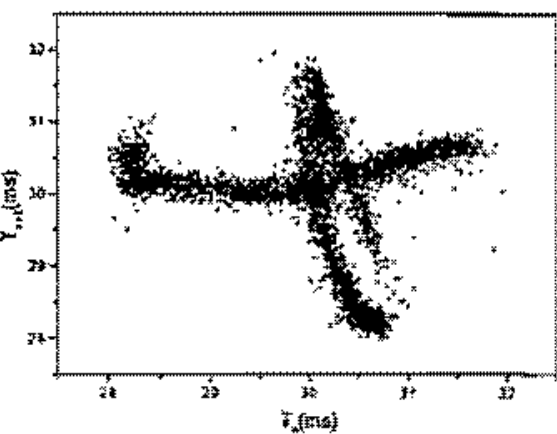

Figura 4.49 Atrator cabitico obtido com $\Omega \mathrm{x}$ igual a 0,5 , pode ser visto na Fig $4,50(a)$, onde temos uma freqüência de borbuhamento de 8 bolhas $/ \mathrm{s}$, 
com una frequêencia da onda sonora de $150 \mathrm{~Hz}$. A simulaçăo com o mapa do círculo, como estấ mostrada na Fig. 4.50 (b), foi feita com $\Omega_{\mathrm{T}}=18,85, b=0,1$ e $K=8,3$.
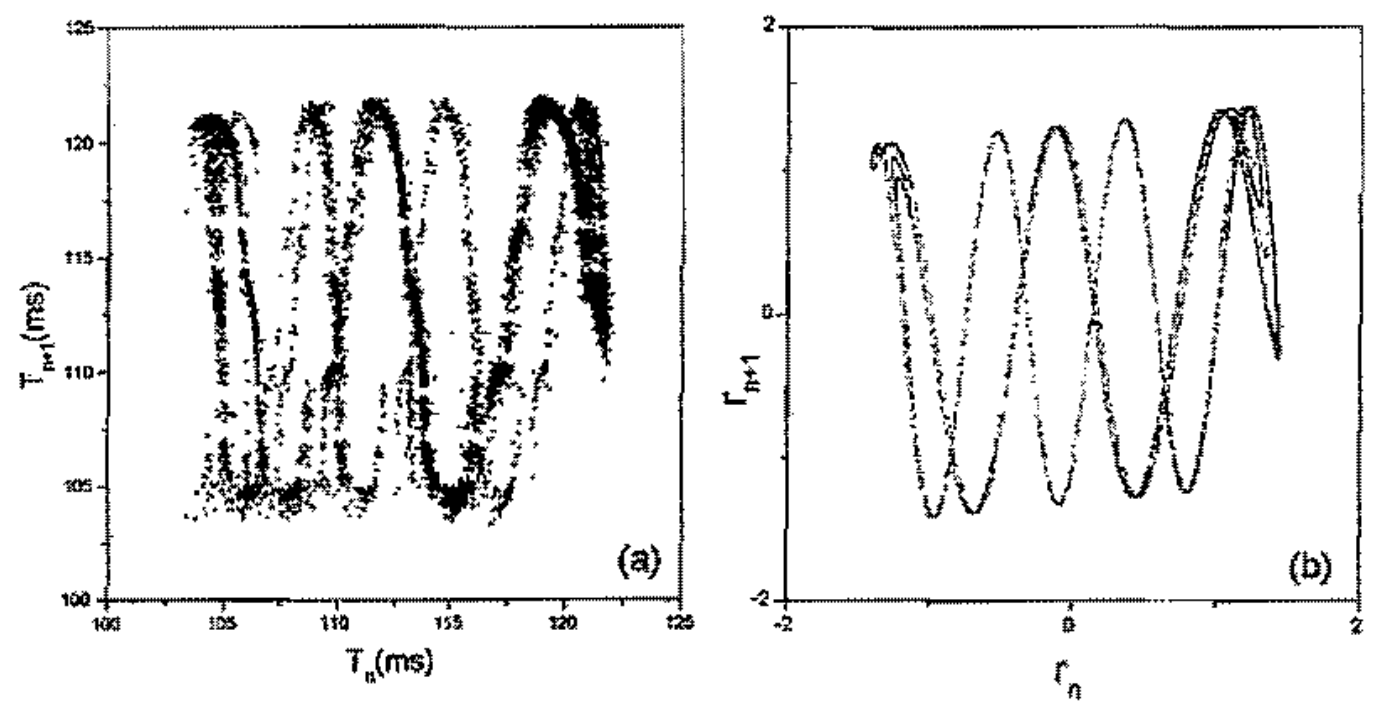

Figura 4.50 Atrator experincntal en (a) $\Omega_{\mathrm{ex}}=18,75, b=0,1$. Eni (b) a simulaça conn o mapa do circulo, $\Omega_{\uparrow}=18,85, b=0,1 \notin K=8,3$.

\subsubsection{Modulação do Parâmetro de Controle}

Quando utilizamos a Teoria do Caos para analisar resultados experimentais, uma das mais dificeis tarefas é associar os parâmetros experimentais aos parâmetros dos modelos existentes, como o mapa logistico, ou o sistema de equaçōes de Rössler e outras equações dos sistemas cáticos. Algumas vezes, o paràmetro de controle escolhido é modulado por uma função que não permite a observação direta dos sistemas caóticos clássicos através da variável de medida [Tufaile, 1996]. Isto acontece no experimento do tubo borbulhador, caso utilizemos, por exemplo, a vazão do ar como parâmetro de controle, como estả mostrado na Fig. 4.51, onde utilizamos a soluçăo de $66 \%$ glicerina e $34 \%$ água e o bico de seringa. A vazăo do ar, o parâmetro de controle, está relacionado de uma forma hiperbólica com o tempo de borbulhamento, a variável de medida, representada pela linha 
pontilhada. Quando

sintonizamos uma onda sonora no sistema com uma frequência de $126 \mathrm{~Hz}$ toma amplitude constante, ocorre uma composiçăo entre funçäo hiperbolica o to mapa do circulo. Os tempos associados aos patamares, $\mathrm{T}_{p}$ são bem definidos e podem ser calculados com a equaçăo (4.36). Os patamares se alargam com o aumento da vazão e o valor do tempo

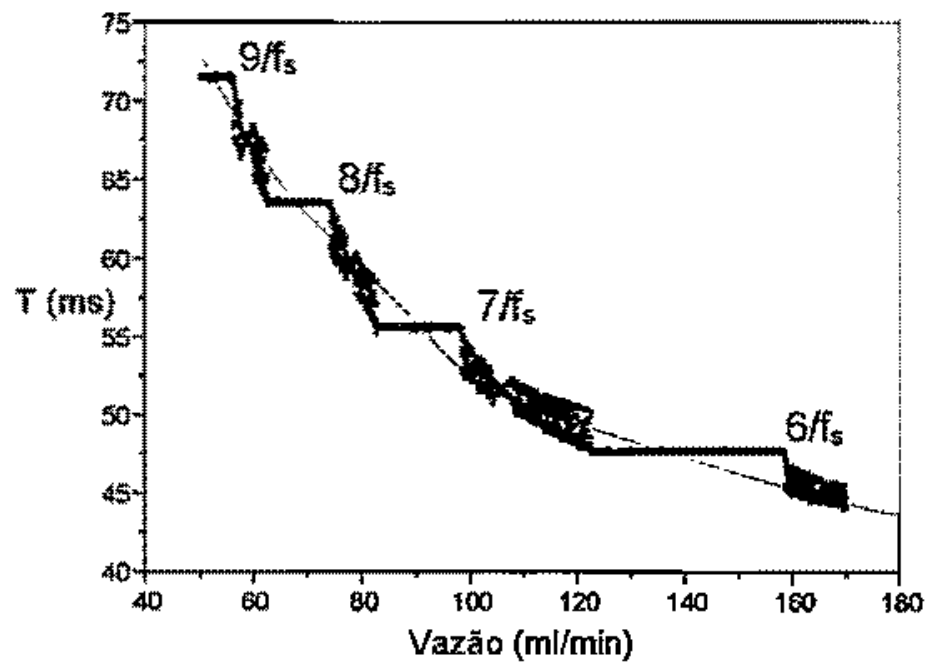

Figura 4.51 A composiçăo de urna funcăo hiperbólica de borbulhamento com o mana do cirmilo, as fracöes ao lado de cada patamar däo o valor do tempo do ponto fixo, $T_{\mathfrak{p}}$, devido ao trayantento sulı̈harmônico

associado a cada um deles é calculado através dos travamentos sub-harmônicos :

$$
T_{p}=j / t_{s}
$$

onde j é o inteiro mais proximo da razão entre a freqüûncia da onda sonora e a frequêencia de borbulhamento.

Outra situação na qual ocorre a modulaçăo do parâmetro de controle é quando

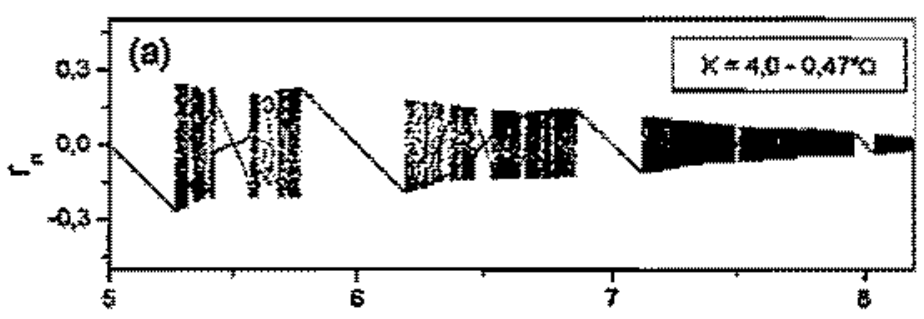

Figura 4.52 (a) Composiçẵo do mapa do circulo com uma funçù linear decrescente. 0 parä̉metro de acoplamento

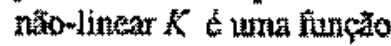
decrescente do valor de $\Omega$

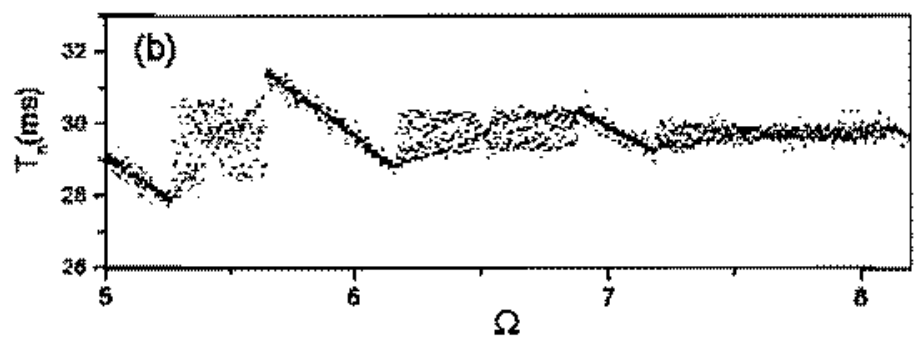

(b) Dados do tempo de borbulhaunento em função de $\Omega$. A variaçäo de $\Omega$ é oblida mantendo os demais gartumetros constuntes e aumentando linearmente a frequência da onda sonora. 
variamos a freqüência da onda sonor:, mantendo constante a sua amplitude. Medindo o tempo de borbulhamento obtivemos os dados da Fig. 4.51(b) do tempo de borbulhamento contra a razão entre as frequèncias $\Omega$, para uma freguência de borbulhamento inicial de 33 bolhass.s. Devido às propriedades da acústica do tubo, a variação da frequetencia da onda sonora afeta simultaneamente a amplitude da onda. Isto pode ser simuiado com o mapa do circulo, com $b=0,1$, supondo que o parâmetro de acoplamento näo-linear, $K$, do mapa do vî̉culo seja una funçăo linear decrescente com relaçăo à razăo de freqüências $\Omega$ que, na Fig. 4.52(a), è o parâmetro de controle:

$$
K(\Omega)=4,0-0,47 \Omega
$$

Os patamares da Fig. 4.51, assim como as linhas diagonais da Fig. 4.52(a) correspondem a composições da frequêtências de borbulhamento da onda sonora quue levam o sistema dinämico nas regiōes de língua de Arnold com nưmero de rotaçăo $W$ igual a 1. 


\section{Conclusôes}

Constuímos o aparato do tubo borbulhador e observamos que o principal aspecto da formaçầo de bolhas em líquidos viscosos é que este sistema é equivalente a un oscilador vão-linear. Esta afirmação foi baseada inicialmente nos intervalos de tempo da formaçẫo das bolhas no experimento do tubo borbulhador, quando a vazão de ar aumenta, e na comparação deste experimento com o experimento da tomeira gotejante. A comparaçẫo dos dados experimentais da formagăo das bolhas influenciadas pela onda sonora com os resultados teóricos do mapa bidimensional do circulo, confirmou que o borbulhamento stá associado a um movimento oscilatónio. Na comparaça do sistema bolhas/onda sonora e o mapa do círculo, o ponto mais

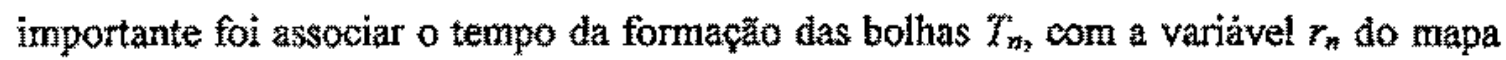
do círculo.

A interpretaçầo da oscilaçăo na formaçăo das bolhas pode ser feita observandose o deslocamento do liquido. Durante a subida da bolha no llquido, este e afastado para dar passagem à bolha, até que a bolha passe o liquido volta a preencher o espaco que antes era ocupado pela bolha. Este processo se repete e assim temos o comportamento oscilatório. Entâo podemos entender o movimento do líquido induzido pela passagem da bolha como um oscilador näo-linear. O sistema de deteçä̌o mede apenas valores máximos deste comportamento oscilatónio, por isso temos as seç̧es de Poincaré do borbulhamento e não curvas contínuas do espaço de fases.

A duplicaçato de período, que ocorre quando variamos a vazâo, foi a primeira observação que indicou que uma abordagem utilizando a Teoria do Caos seria um método possivel para a compreznsâo do fenômeno da formaçăo das bolhas. Mesmo assim, uma abordagem utilizando os conceitos da Mecânica dos Fluidos foi feita e, com este ponto de vista, observamos que a duplicaçäo de período som a vazäo está associada com a instabilidade de Rayleigh-Taylor, que representa a instabilidade da interface de dois fuidos que não se misturam. A duplicação de periodo só ev evidente em fluidos viscosos, pois, em líquidos pouco vìscosos como a água, a dinâmica observada vại diretamente do comportamento regular, para um comportamento irregular. Verificamos que a instabilidade da superficie da bolha nos fluidos com baixa viscosidade é a resposta

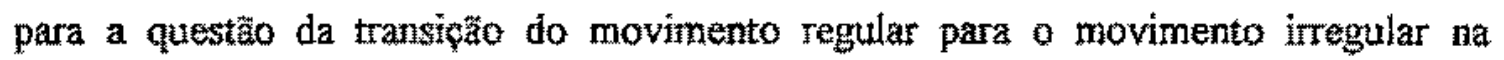
formaçăo das bolhas. Esta instabilidade é catısada pela interaçăo entre as bolhas que se elevam dentro do liquido e a bolha que estä se formando junto ao bico. Em flutidos 
viscosos e com baixas vazỏes do ar, o deslocamento das bolhas que estão emergindo năo afeta a bolha que está se formando, pois nầo ha uma perturbaçāo significativa criàa pela circulação do líquido e esta circulaçăo permanece laminar junto ao bico. Porém, para vazöes mais elevadas, mesmos nos líquidos viscosos, teremos todo o conjunto das bolhas emergentes e da bolha que esta se fomando interagindo, pois, as perturbaços na circulaça do liquido se propagam em todas as direçes dentro do tubo borbulhador. Deste modo a formaça das bolhas apresenta uma dependência tanto do tempo, quanto das condiçôs de contorno. Neste sspecto, o experimento do tubo borbulhador é diferente do experimento da torneira gotejante, pois o deslocamento das gotas que estäo caindo năo ten efeito significativo na gota que cresce junto ao bico.

Utilizando diferentes tipos de bicos, verificamos algumas das influências da geometria do bico na formação das bolhas. Emulamos as séries temporais através da combinaçäo de mapas. Isto permitiu o desenvolvimento de idéias para tentar entender e explicar os fenômenos observatos, como alargamentos suaves a abruptos nos tempos entre as bolhas. A combinaçäo de mapas ja havia sido utilizada no experimento da torneira gotejante, o que mostra a sua importăncia como ferramenta na compreensa de sistemas catiticos.

Do mesmo modo, as simulapões com modelo unidimensional massa-mola, permitiram melhorar a nossa interpretação dos dados tanto da torneira gotejante, quanto do tubo borbulhador. $O$ modelo nấo é adequado para observaçōes quantitativas, mas pode ser usado para a obtençẫo de resultados qualitativos. Durante a verificaçẫo da hipótese do fator de massa agregada, $\beta$, do modelo massa-mola para a formaçăo das bolhas, encontramos as estruturas das veias líquidas, que sấo colunas de agua dentro do óleo sustentadas pela subida de bolhas de ar.

Além disso, durante a realiząẫo da experiência, foram encontradas algumas das condições que fazem o aparecimento de antibolhas, que são gotas envolvidas por uma fina camada de ar dentro do liquido e que ficam aprisionadas na circulaçăo dentro do liquido.

Verificamos as condtç̧os de validade para a relaçåo entre a frequêência da formaça das bolhas c a vazto do ar, para um modelo simplificado que estabelece uma frequência para a formação das bolhas proporcional à vazăo elevada a 0,4 .

Atrayés da associaçăo com o mapa do circulo, verificamos algumas similaridades entre o mapa e o experimento, como por exemplo, a comparacăo da variaçăo da fazăo entre as frequêtncias da onda sonora e do borbuhamento, $\Omega$ Ex, com a 
variaça do parämetro $\Omega_{\mathrm{T}}$ do mapa, assim como fizemos a comparaçăo entre as formas dos atratores reconstruidos. Deste modo encontramos algumas rotas para o Caos, quando e ceita a variagăo da amplitude da onda sonora. A formaça das bolhas pode evoluir inicialmente atraves da rota de quase-periodicidade quando amplitude do som e aumentada linearmente, que pode ser reconhecida no inicio das sĕries temporais devido a sua forma trangular, para alguns valores da razäo entre as freqülencias, $\Omega_{\mathrm{Ex}}$. Outra rota observada foi a rota de duplicaçăo de período com a formaça de atratores do tipo-Hěnonon, devido aos processos de estiramento e dobra.

A dinâmica do mapa do círculo ainda permitiu interpretar o comportamento mais global da existencia de patamares no tempo da formaçâa das bolhas nas séries temporais, sujeitas a uma onda sonora de freqüência ben definida. Os patamares ocorrem quando a frequência do borbulhamento está próximo a um submúltiplo da frequẻneia da onda sonora, o que caracteriza um travamento sub-harmônico. 0 travamento sub-harmónico ocorre quanđơ a frequência de um oscillador fica travada em um stubmúltiplo da frequência de uma força externa aplicada. 0 caso limite da

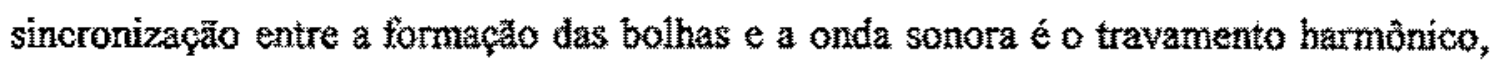
quando as bolhas se formam com a mesma frequência da onda sonora. 


\section{Referências}

Argyris, J, Faust, $\mathrm{G}$, e Haase, M. (1994): An Exploration of Chaos, North-Holland, Amsterdam.

Alligood, K. T., Sauer, T. D. Yorke J. A. (1997): Choos - an intraduction to dymamical systems, Springer, New York.

Bai-lin, H. (1989): Elementary symbalic dynomics and Chaos in Dissipative Systems, World Scientiffic, Singapura.

Bertelsen, P., Ellegaard, C., Guhr, T., Oxborrow, M. e Schaadt, K. (1999): Measurement of Parametric Correlations in Spectra of Resonating Quartz Blocks, Phys. Rev. Lett. 83, $2171-2174$.

Chandrasekhar, S. (1981), Hydrodynamic and Hydromagnetic Stability, Dover, New York.

Clift, R., Grace, J. R. Weber, M. E. (1978): Bubbles, Drops, and Particles, Academic Press, New York.

Collet, P. e Eckmann, J. (1980). Lerated maps on the imterval as dymamical systens, Birkhäuser, New York.

Davidson, J. F. e Schuler, B. O. G. (1960): Bubble formation at an orfice in a viscous liquid, Trans. Inst. Chem. Eng. 38, 144-154.

D'Innocenzo A Renna, L. (1996): Dripping Fautet, Int. J. Theor. Phys, 35, 941-973.

D'Innocenzo A, e Renna, L. (1997): Modeling lecty faucet dynamics, Phys. Rev. E 55 , 677606787.

Eliner, S., Nychka, D. W. Gallant A. R (1992): LENNS, a program to estimate the dominant Lyopthov exponent of noisy nonlinear systems from time series data (Institute of Statistics Mimeo Series n. 2235 (BMA series n. 39), Statistics Departmont, North Carolina State University, Raleigh.

Femat, $\mathrm{R}$, Alvarez-Ramirez e Soria, A, (1998): Chaotic fow structure in a vertical bubble column, Phys. Let. A 248,67-79.

Finney, C. E. A, (2000); Bibliography of chaos \& mbbling, htpil/www chaos.engr.utk. edu/bibBubbling. html

Fletcher, N. H. e Rossing, T. D. (1991): The Physics of Mnsical Instruments, Springer, New York.

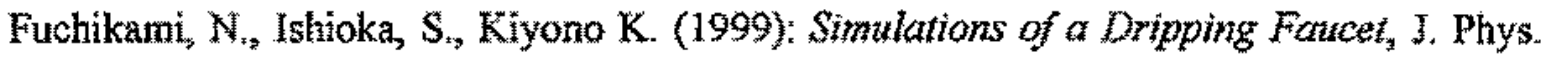
Soc. Jpn. 68, 1185-1196. 
Gonçalves, W. M. (1996): A experiencia da Tomeira Gotejante, Tese de doutorado, TFUSP.

Gonfalves, W. M., Pinto, R. D., Sartorelli, J, C. e de Oliveira, M. J. (1998): Inferring statiscal complexity in the dripping fucet experimen, Physica A 257,385-389.

Grebogi, C., Oth, E. e Yorke, J. A.(1982): Chaotic atractors in crisis, Phys. Rev. Lett 48, $1507-1510$.

Hayashy, C. (1985): Nonlinear Oscilations in Physical Systems, p. 285, Princeton University Press, Princeton.

Hegger, R, Kantz, H. Schreiber, T. (1999): Pratical implementation of nonlinear time series methods: The TISEAN package, Chaos $9,413-435$.

Jackson, E. A. (1995); Perspectives of nonlmear anamics, Cambridge University, Cambridge.

Kaneko, K. (1992): Overview of coupled mop lattices, Chaos 2, 279.

Kiyono, K. e Fuchikami, N. (1999): Dripping Foucet Dynamics Clarified by am Improved Mass-Spring Model, I. Phys. Soc. Jpn. 68, 3259-3270.

Kyriakides, N. K., Kastrinakis, E. G., Nychas, S. G. C Coulas, A. (1997): Bubbling from Nozales Submerged in Water: Tramsitions Between Bubbling Regimes, Can. J. Chem. Eng. $75,684-691$.

Lauterborn, W. (1986): Acoustic Turbulence em Fronters in Physical Acoustics, p. 124 144, North-Holland, Amsterdam

Li, H. Z, Mouline, $\Psi$, Choplin, L. Midoux, N.(1997): Chaotic butble coalescence in non-newtonikn fluids, Int. I. Multiphase Flow 23, 713-723.

Li, T. Y. e Yorke, J. A. (1975): Period 3 implies chaos, Am. Math. Month. 82, 985-992.

Lorenz, E. N. (1980): Attactor sets and quasi-geostrophic equilibrium, J. Atmos. Sci. 37, $1685 \mathrm{~m} 1699$.

Mañe, R. (1981): On the dimension of compact invariant set of certain non-linear maps, em Dynamieal Systems and Turbulence, ed. D. A. Rand L. S. Young, Springer, Berlim.

Marmur, A e Rubin, E. (1975): A theoretical model for bubble formation at an orifice submorged in an inviscial liquid, Chem. Eng. Sci. 31, 453-463. 
Marston, P. L. (1980): Shape ascillation and static deformation of drops and bubbles driven by modutated radiation stresses-7heory, J. Acoust. Soc. Am 67, 15-26.

Martien, P., Pope, S. C., Scott, P. L. Shaw, R. S. (1985): The chootic behovior of a leaky fauce, Phys. Lett. A 110,399-404.

Mitoni L. J., Schwartz, M. P, E La Nauze, R. J. (1995): Deterministic chaos in the gas inlet pressure of gas-liqutd bubbling systems, Phys. Fiuids 7, 891-893.

Moran, M. J., Haigh, R. E., Lowry M. E. e Sweider, D. R. (2000): Obsenations of Singtem Pulse Sonoluminestence, htp:/www-phys.linl.gov/N_Divisonolum/sonolum_paper.html.

Myyahara, T., Hagh, N., Takahashi, T. (1983): Bubble formation from an orfice at high gas flow rales, Int. Chem. Eng. 23, 524-531.

Nguyen, K., Daw, C. S, Cheng, M., Bruns, D. D., Finney, C. E. A. Kennel, M. B. (1906); Spatio-temporal atnamics in a train of rising bubbles, Chem. Eng. J. 64, 191-197.

Packard, N. H. Crutchfield, J. P., Farmer, I. D. Shaw, R. S. (1980): Geometry from a time series, Phys. Rev. Lett 45, 712-716.

Perry $_{s}$ R. H. e Clinton C. H. (1972); Chemical Engineers' Handbook, MeCraw-Hill, New York.

Pinto, R D. (1999): Comportamento Complexo na Experiencta da Torneira Gotejante, Tese de Doutorado, IFUSP.

Pinto, R. D, e Sartorelli, J. C. (2000): Homocline tongency and chaotic attrator disappearance in a dripping foucet experiment, Phys, Rev, E 61, 342-347.

Prosperetti, A (1986): Physics of Aconstic Cavitation em Frontiers in Physicat Acoustics, p. 145-188, North-Holland, Amsterdam

Ponter, A. B. e Surati, A. 1. (1997): Bubble Emissions from Submerged Orifices - A critucal Review, Chem. Eng. Technol. 20,85-89.

Putterman, S. J. (1995): Sonoluminescence; Sownd into light, Sci. Am., Fevereiro, 33-37

Rapp, P. E., Bashore, T. R., Zimmermean, 1. D., Martinerie, J. M., Abano, A. M. e Mees, A. 1. (1990): Dymamical Characterization of Brain Electrical Activity, em The Ubiquity of Chaos, AAAS, Washington, D.C.

Renna, L. (1959, A discrete map for dripping faucet dynamics, Phys. Let. A 261, 162-168.

da Rocha, M. S. (1995): Determinzçäo da evoluçấo temporal da formaça de gotos, Dissertacazo de mestrado, IFUSP.

Rössler, O. E. (1977): Symergetics: a workshop, Haken, H., Springer, Berlim, 174m183. 
Ruzicka, M. C., Drahos, I., Zahradnik, I. e Thomas, N. H. (1997): Intermitrent mansition from bubbling to jetting regime in gas-liquid two phase flows, Int. J. Multiphase Flow 23, $671-682$

Sanches-Ortiz, G. I e \$alas-Brito A. L. (1995a): Strange attractor in a relcoation oscillator model for the dripping foucet, Phys. Let. A 203, 300.

Sánches-Ortiz, G. I. e Salas-Brito A. L. (1995b): Chaos in a variable mass relcaxation oscillator model for the leaky tap, Physica $\mathrm{D} 89,151$.

Sartorelli, J. C., Gonçalves, W. M. e Pinto, R D. (1994): Crisis and intermittence in a leaky-fauce experiment, Phys. Rev. E 49, 3963-3975.

Schemelcher, $P_{-}$, Diakonos, $F$. K. (1998): A general approach to the finding of unstabie pertodic orbits in chaotic dynamical systems, Phys. Rev. E 57, 2739.

Sharpe, G. J. (1994): Solving Problems in Fluid Dynamics, p. 203, Longman, Essex.

Shaw, R. (1984): The dripping faucet as a model chootic system, Aerial Press: Santa Cruz.

da Silva, J, G. M (1996): Caracterizaçäo da Dinânica da Formaţö̌o de Gotas, Dissertaçăo de mestrado, FUSP.

So, R., Ot, E, Schiff, S. F., Kaplan, D. T, Sauer, T. e Grebogi, C. (1996): Detecting unstable periodtc orbits in chatic experimental data, Phys. Rev. Lett 76,47054708 .

Sotomayor, J. (1979): Lições de equaçäes diferenciais ordinárias, Projeto Euclides, Rio de faneiro.

de Souza Vieira, M. C., Lazo, E. e Tsallis, C. (1987) New road to chaos, Phys. Rev. A 35 , 945-948.

Stong, C. L. (1974): The amatert scientist, Sci. Am, Abril, 116-121.

Sulivan, S. L., Hardy, B. W, e Holland, C. D. (1964): Fommation of Air Bubbles at Orifices Submerged Beneath Linuids, A. I. Ch. E. Journal 10, 848-854.

Takens, $F$. (1981): Detecting strange attractors in turbulence em Dynamical Systems and Turbulence, ed. D. A. Rand e L. S. Young, Springer, Berlim.

Thompson, I. M. T. e Stewart, H. B. (1986): Nonlinear Dynamics and Chaos, Geometrical Methods for Engineers and Scientists, p. 162 , John Wiey and Sons, Chichester.

Trition, D. J., Egdell, C. (1993): Chaotic buhhimg, Phys. Fluids A 5, 503-505.

Tufaile, A. (1996) Mapas combinados o experimento da tomeira gotejante, Dissertação de mestrado, IFUSP. 
Tufaile, A, Pinto, R D., Gonçalves, W. M. e Sartorelli, J. C. (1999): Simulations in a dripping faucet experiment, Phys. Let. A 255, 58-64, (Apêndice 1).

Tufaile, A. e Sartorelli, J. C., (2000a): Chaotic behavior in bubble formation dynamics, Physica A, 275, 336-346, (Apêndice 2).

Tufaile, A. e Sartorelli, J. C. (2000b): Hénon-like attractor in air bubble formation, Phys. Let. A, 275, 211-217, (Apêndice 3).

Ueta, N. e Tabacniks, M.H. (1994): Laboratório de Física para Ciências Biológicas, IFUSP.

Viana, R. L. (2000): Introdução às Redes de Mapas Acoplados-Modelos para o estudo de Caos Espaço-Temporal, Notas de Aula, IFUSP.

Weast, R.C., Selby, S. M. (1996): Handbook of Chemistry and Physics, p. F33-F42, The Chemical Rubber, Cleveland.

Willeboordse, F. (1992): Time-delayed map as a model for open fluid flow, Chaos 2, 423426.

Wolf, A., Swift, J. B., Swinney, H. L. e Vastano, J. A. (1985): Determining Lyapunov exponents from a time series, Physica D 16, 285-317. 


\section{Apêndice 1}

Simulations in a dripping faucet experiment

A. Tufaile, R.D. Pinto, W.M. Gonçalves e J.C. Sartorelli

Physics Letters A 255 (1999) 58-64 


\title{
Simulations in a dripping faucet experiment
}

\author{
A. Tufaile, R.D. Pinto, W.M. Gonçaives, J.C. Sartorelii ${ }^{1}$

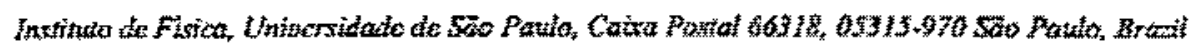

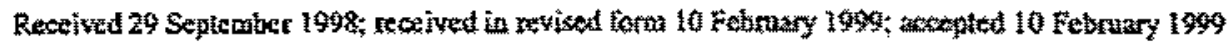

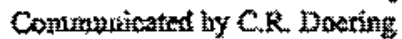

\begin{abstract}
Abstruat
The profiles of two experimental attractors were simulated by using a simple onceditnensional spring-mass modol. Some peculiar behavions observed in experimental bifurcation diggrams (in shon ranges of drighing rate yariation) wene crnulated by combining two quadratic maps (a kind of coupling) in two different ways parallel combination wib non-interactaks rasps; and series combination with strongly interacting maps. The choice of each kind of combination was suggesced by the own characteristics of esch experimental bifuncation diagram. to 1999 Elseviex Science B.V. All righs resured.
\end{abstract}

EASS: $05.45 .+b$

\section{Introduction}

The leaky faucet dynumits has been used as a pardidigm of a chaotie system $[1,2]$ sinee the sugyzs:tion made by Rössier [3] in 1977 that the formation of water drops in a tap nipple conld show chaotic behavior, what was later confirmed by Shaw and Martien et al. [4,5]. Period doubling was obstrved by Martien al al. [4,5], Yépez al, [6], Calualun et al. [7], Wu and Schelly [8,9] Dreyer al. [10] Sarm torelli et al. [11]. Tengent intermitiencies are rem ported in Refs. $[7,11]$ quasimpriodicity and boutud ary crisis in Ref: [11] and a Hopf bifurcation in Refs. $[12,13]$. Othez studies alout the formation of drops or droplets of water can be found in Refic [14-23]

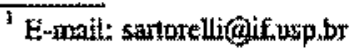

Shaw and collaborators supposed that the water column hanging in a nippie faucet should oscillate as a mass-sping system, with the mass increasing linw early until it roches a critical point, when a drop is ejosted, imposing the initial conditions on the remaning water column. This model was modified by Sánches-Ortiz and Salas-Brito [24] supposing that the muss of the ejected drop must depend on the curreat value of the column mass. $D^{\prime \prime}$ la* nocenzo and Rerna [25] have also carried ont their calculations assuming that the remaining water colunin shape can be eitber a sphere or a material point.

Inspired by an Ising-like model to find the water drop profle hanging in a vertical wall, Oliveira and Penna [26] stutlied the dynamies of the drop formatton applying Monte Cardo techniques. Pexna to al. [27] showed that the time deluys betwen successive drops display long-range anticorrelations character" ized by the same exponents of the heartbeat-tom heartbeat intervals of healthy subjects [28]. 
Nune if these modtels are adequate to explain all the behaviors otserved in the range from -0 up to $\sim 40 \mathrm{drops} / \mathrm{s}$. In this paper we present two simulations of experimental attractors which are the best emulations yet obtained by the one-dimensional spring-mas motel. It is also presented two experimental bifurcation diagrams, in short ranges of dripm ping rule, with new peculiar behaviors never seen before. Inspired by the behavior of each experitnental diagram, we did a kind of simple coupling of maps [29-32] by combtaing two quadratic maps to emulate these experimental bifurcations. Two ways of combination are propesed. In the first catse, two non-interacting quadratic maps are added (parallel combination), while in the second ont, two strungly interacting logistic musp (stries combination) are combined in a feedback way.

\section{Experimental apparatus}

The measurements were done with the fauck attached lo a large reservoir, see Refs. $[11,21]$ for details. The time delays between successive drops are measured with a time counter circtitry, whth resolution of $1 \mu s$, inserted in a PC slot. The input signals are voltage pulses, induced in a resistor, defined by the beginning (ending) of the scattering of a laser beam focused on a phuto-transistor (in seritss with the resistor) when the drop starts (ends) to cross the laser bearn. The width of the pulse is the time interval $t_{n}$ (where $n$ is the drop number), and the time delay between two puises is the crossing time $\left(\delta l_{n}\right)$, of a drop through the laser beam, so that the total time interval is $T_{n}=t_{n}+\delta t_{n}$.

We can setup the drop rate $(f=1 /\langle T\rangle)$ in two ways: (a) by feeding back the water neservoir to ketp the height $h$ of the water level and selecting the drop rate by opening (closing) a needle valve driven by a step motor which is controlled by a microcomputer.

For a given drop rate we have constructed first return maps $T_{n+1}$ vs $r_{n}$ (b) by fixing the opening of the needle yalve, turaing of the water supply, letting the water level decresse naturally, and so the tiripping rate. Therefors, the control parraneter, the height F of the water level, varies as $h \approx h_{0}-n \delta V / A$, whens $8 Y / A=2 \times 10^{-3} \mathrm{~mm}_{3} h_{0}$ is the initial height. $8 V$ the mean volume of the drops, and $A$ is the area of the water reservoir surface. In this case, bifurcation diagrams $T_{n}$ v $n$ were constructed. We
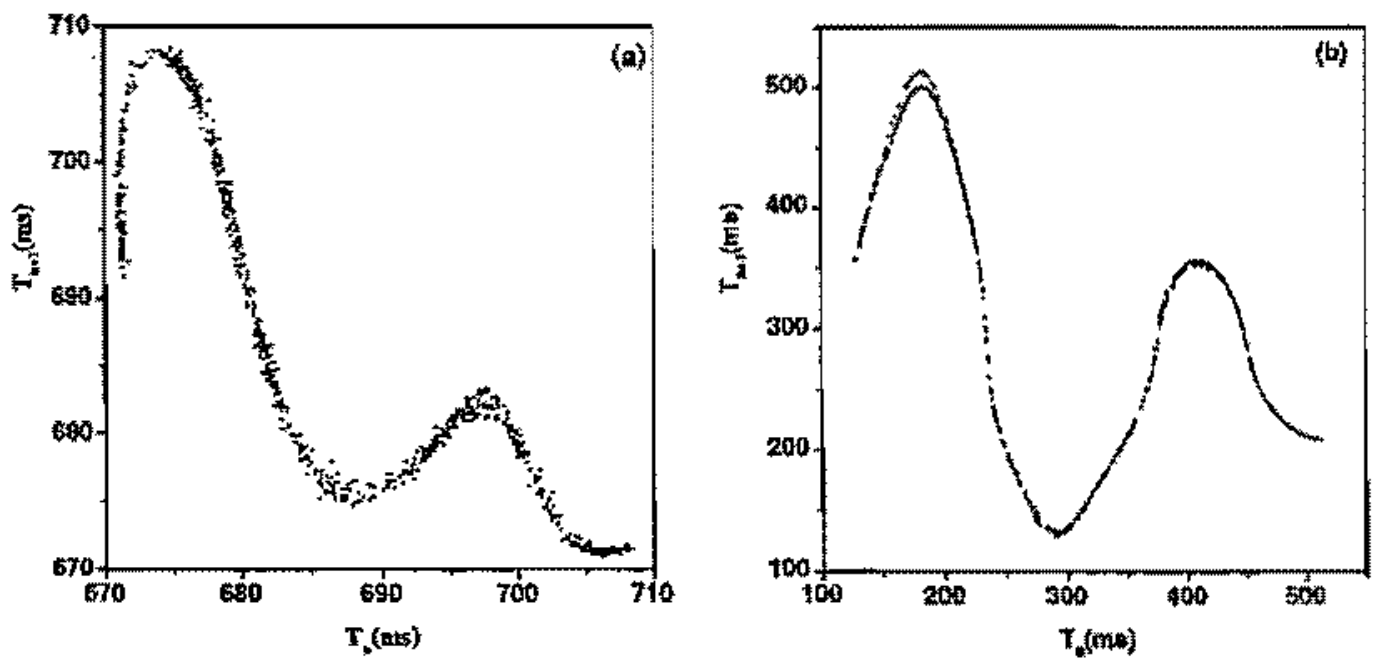

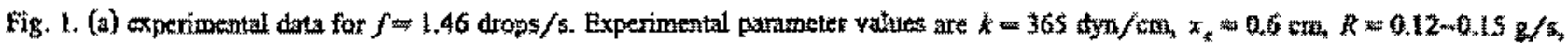

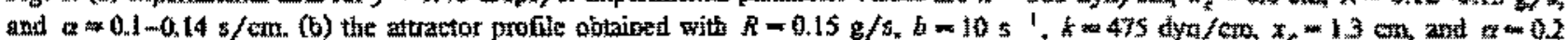

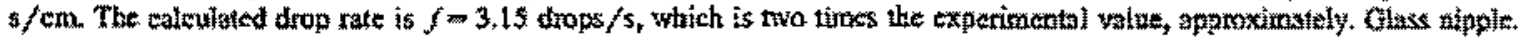




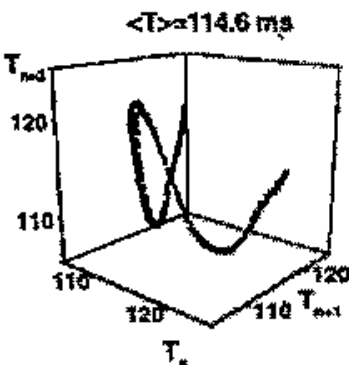

(t)

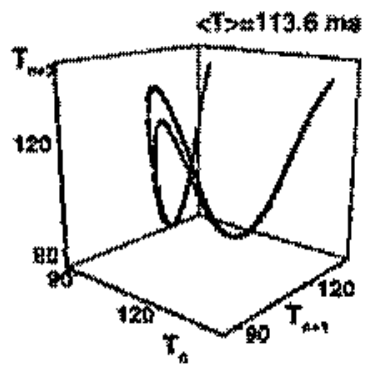

(b)

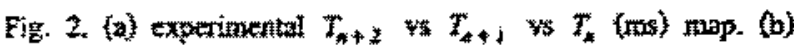

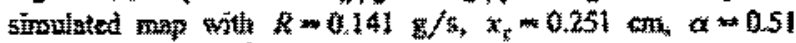

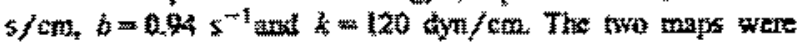
construted foro he sume angie af vision. The calcribted drop

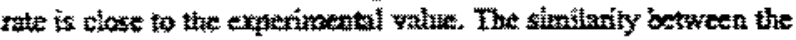

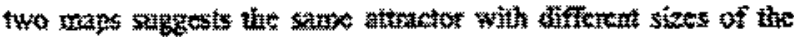

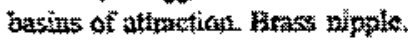

have used one glass uipple and other one of brass, with both having the same internal fiameter.

\section{Results}

\subsection{Mass-spring model}

Following D'Innocenzo and Renna [25] notation, the set of antonomous differential equations for the mass-spring model is $[4,5]$

$$
\frac{d x}{d t}=n ; \frac{d(M v)}{d}=M g-k x-b v, \frac{d M}{d t}=R,
$$

where $x$ is the cootdinate of the center of mass of the hanging water, and $R$ the flow rate.

The surface tension and friction between the waw ter and the fauce are respectively represented by the spring constant $k$ and by $b$. A drop with mass

$$
\Delta M=\alpha M_{c} u_{\varepsilon x}
$$

is shot when the center of mass $x$ exceeds a threst old $x_{k}$ where $M_{\mathrm{r}}$ and $v_{\mathrm{c}}$ are respectively the hang-
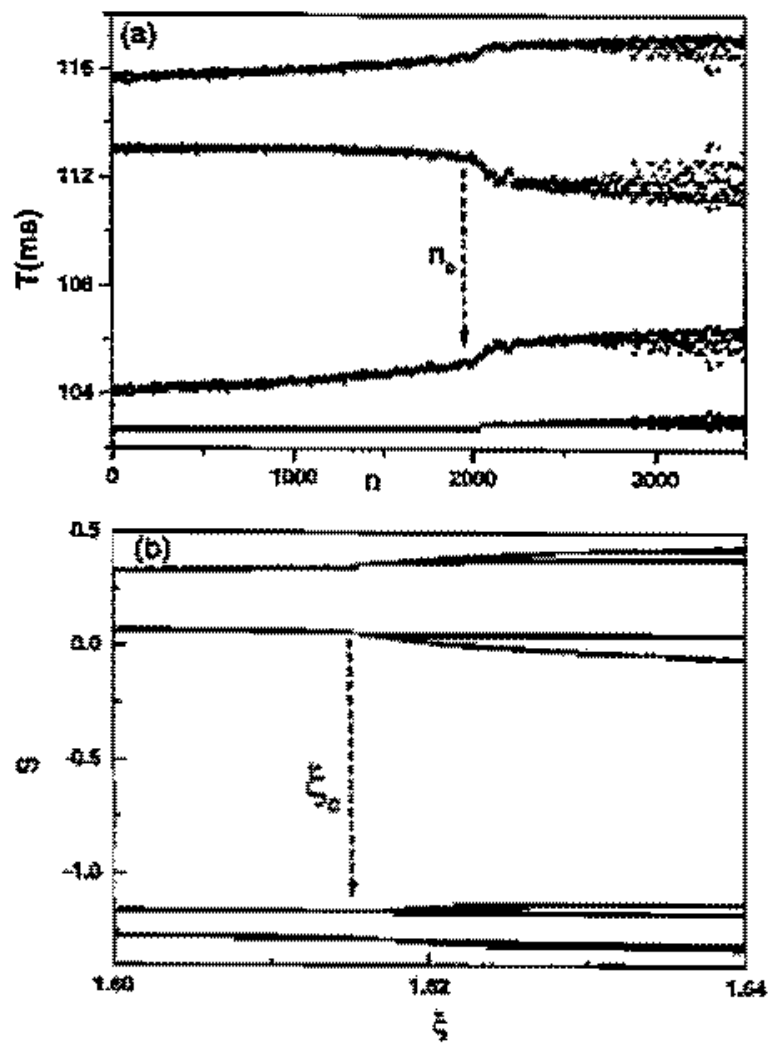

Fig. 3n (a) experimental bifurstion diagram, with the frop rate ranging fromt $\sim 9.18$ down to $\sim 9.13$ trops $/ 5$. (b) paraliel combinastion of two nonimteracting logistic maps with $p_{2}(\xi)-\xi+\frac{b}{5}$ and $p_{y}(\xi)-p_{x}(\xi)-0.115$. Brass nippie.

ing water and the speed at the threshold point, $z=980 \mathrm{~cm} / \mathrm{s}^{2}$, and $\alpha$ is a parameter.

For the remaining water, D'Innocenzo and Renna proposed two models: (PS) the point-sphere one, the orop is spherical of radus $r$ and the woter residue is a point situsated af $x_{0}=x_{s}-r A M / M_{k}$; (TS) twon sphere model, the drop is spierical of radius $r$ and the water tesidute is aphere of radius $r^{3}=13\left(M_{r}-\right.$ $\Delta M) /(4 \pi p)]^{z / 3}$ centered at $x_{0}=x_{t}-(r+$ $r) \Delta M / M$. Thetefore the simulations require the adjustratent of five pasameters $\left(k_{3}, x_{k}, R, \alpha\right.$ and $\left.b\right)$ but. with an unknown dependence berween them.

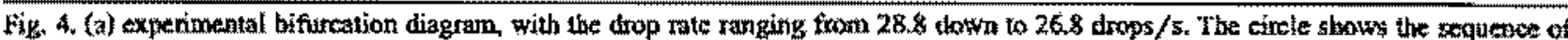

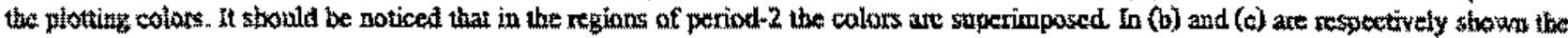

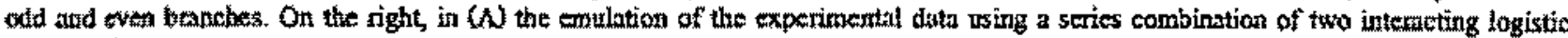

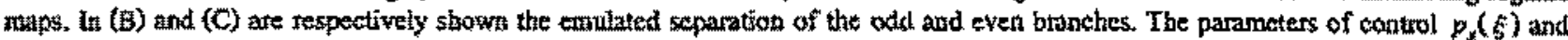

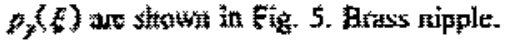




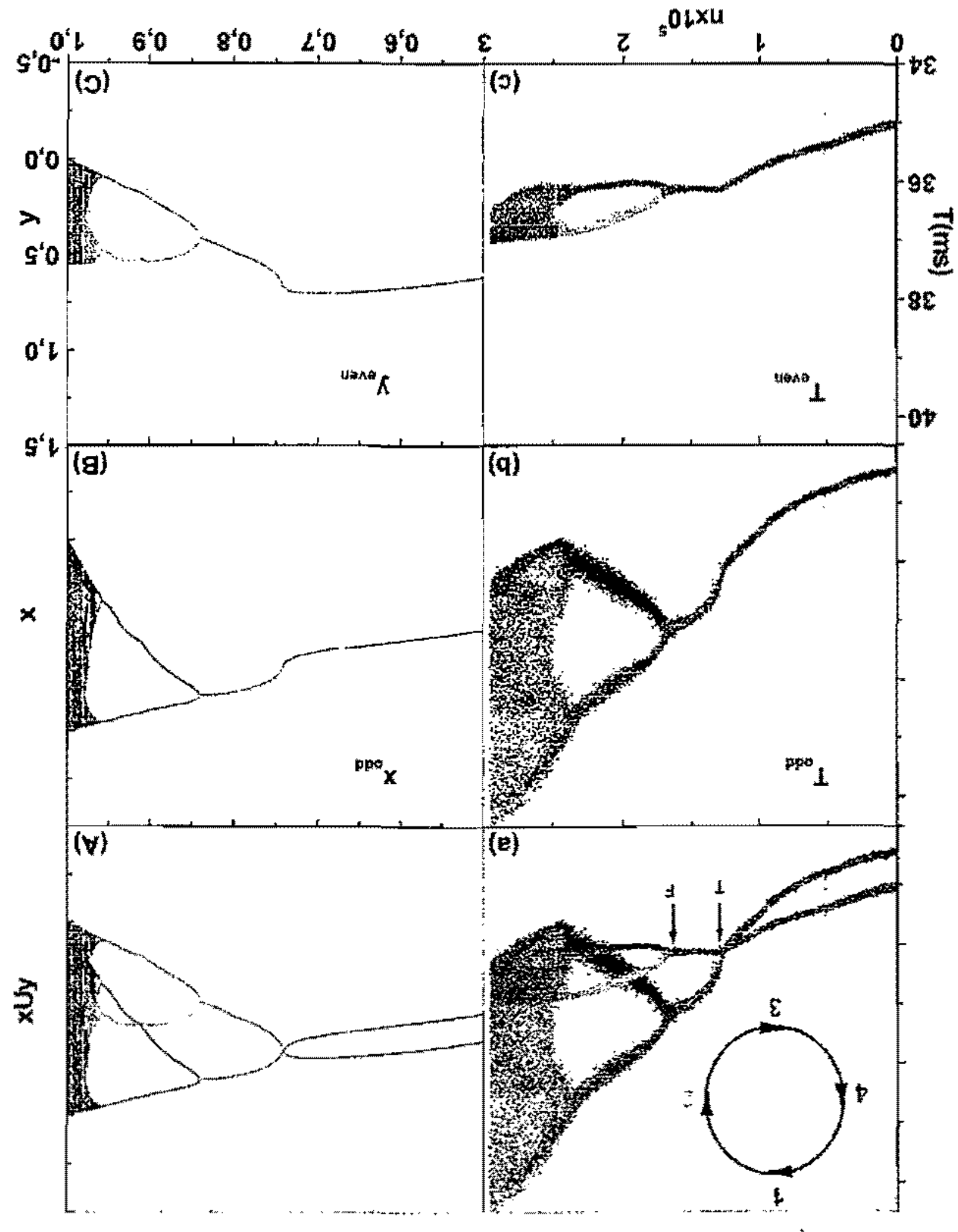


In Fig. 1(a) is shown the experimental first neturn map obtained by keeping fixed the water level hoight, at $f=1.46$ trops $/ s$ (glass nipple). An experimental estimation for the parameter values are [21] $z=365$ tyn $/ \mathrm{cm}, x_{\mathrm{z}} \approx 0.6 \mathrm{~cm}, R \approx 0.12-0.15 \mathrm{~g} / \mathrm{s}$. The simulations of the attractor using these paraneter values bitl not converge for wide ranges of $a$ and $b$ values. We could wnulate the attractor profile, tsing the PS model, by adjusting all the parameter values. The emulation, with $k=475 \mathrm{dyn} / \mathrm{cm}_{1}, x_{\mathrm{c}}=1.3 \mathrm{~cm}, R$ $0.15 \mathrm{~g} / \mathrm{s}, \alpha=0.2 \mathrm{~s} / \mathrm{cm}$, and $b=10 \mathrm{~s}^{-1}$, is shown in Fig. $1(b)$, but the mean drop rate obtained $(f=$ 3.15 arrops $/ s$ ) is about two times the exprimental value.

In Fig. 2(a) is shown an attractor reconstructed in a three-dimensional map $T_{n+2}$ is $T_{n+1}$ 蟆 $T_{n}$, at $f=8.726$ drops/s. The attractor ptofile was simulated by the PS model with the patameter values: $R=0.141 \mathrm{~g} / \mathrm{s}, x_{\mathrm{s}}=0.251 \mathrm{~cm}, \alpha=0.51 \mathrm{~s} / \mathrm{cm}, b=$ $0.94 \mathrm{~s}^{-1}$, and $k=120 \mathrm{dyn} / \mathrm{cm}$, as shown in Fig. 2(b). Despite the fact that these values are quite different from the experimental ones, we obtained, by coincidence, a drop rate of $f=8.80$ drops $/ \mathrm{s}$, close to the experimental value. The similarty between the two maps suggests that we have the same attractor while the different time scales point out to different sizes of the basins of attractions, with approximately the same mean time $\{T\}$.

We could at find in the literature better simulatons of dripping fauce atcractors than the examples above. This rodel is not enough to explain all the details of the experimental data, but it can be useful to give a first sight (or the general properties) of the drop formation dynamics [4] since the classical by* drodynamical models are too complicated to obtain large time series.

We observed some pecullar behaviors in the experimental bifurcation diagrans, and we attempted to construct empirical models to emulate such behaviors in a simple way, looking for relations beween two quadratic mants.

\subsection{Combined mops}

\subsubsection{Parallel combination}

In Fig. 3(a) is shown an experimental bifurcation diagram, $T_{n}$ vs $n$, which was obtained by letting the water level go down naturally, and the dripping rate ranging from -9.18 down to $-9,13$ drops/s. Below $n_{\mathrm{f}}$, as the water level height goes down, the dymanical system evolves in a period four move ment. When the system reaches the critical point $n_{c}$ (or $h_{c}$ ) the initial four stable fixed points are teplaced by new four fixed points.

We simulated this peculiar change of fixed points by adding two non-interacting quadratic maps (parallel combination), so the giabal map $S$ is given by

$x_{n+1}=x_{n}^{2}-p_{x}(\xi), \quad y_{n+1}=y_{n}^{2}-p_{y}(\xi)$,

$\mathfrak{S}_{n}=\frac{x_{n}+y_{n}}{2}$

where $p_{x}(\xi)$ and $p_{y}(\xi)$ are the control parameters as functions of a common parameter $\xi$, and each map is iterated separately ? We observed that the choice of $p_{x}(\xi)=\xi-1 / 4, p_{y}(\xi)=p_{x}(\xi)-0.115$, $\xi \in(1.6,1.64)$, can emulate the experimental change of the fixed points as shown in Fig. 3(b). The transition point, $\xi_{\mathrm{c}}=1.615$, corresponds to the second flip bifurcation in the $y$ map and a period-4 movement in the $x$ map, bat the global map $s$ corresponds to a four fixed points until the next flip bifircation which occurs in the $x$ unap at $\xi=1.618$.

Different from an interior crisis [33] in which occurs a sudden clunge in the size of the attractor, in Fig. 3(a) we have a smooti tnereasing in the size of the period 4 attractor. Regarding the oscillatory character of the funging water, these two period- 4 behaviors suggests that we bave the same oscillation mode below and above $\left(n_{c}\right)$, but with a little difference between their boundary condlitions.

\subsubsection{Series combination}

For a higher drop rate another experimental bifurcation diagran was observed, with the driphing rate ranging from 28.8 down to 26.8 drops/s. In Fig. 4(a) is shown the bifurcation diagram, $T_{n}$ vs $n_{k}$ botained by plotting the points altenutely in black $(n=1,5,9 \ldots)$, in green $(n=2,6,10, \ldots)$, in red $(n$ $=3,7,11, \ldots)$, and in blue $(n=4,8,12, \ldots)$.

Initally, the system evolves in a period-2 attractor watil the branches red + black and green + blue col-

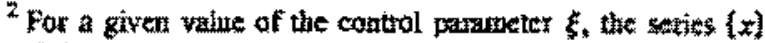

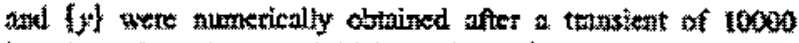

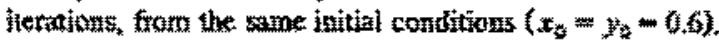




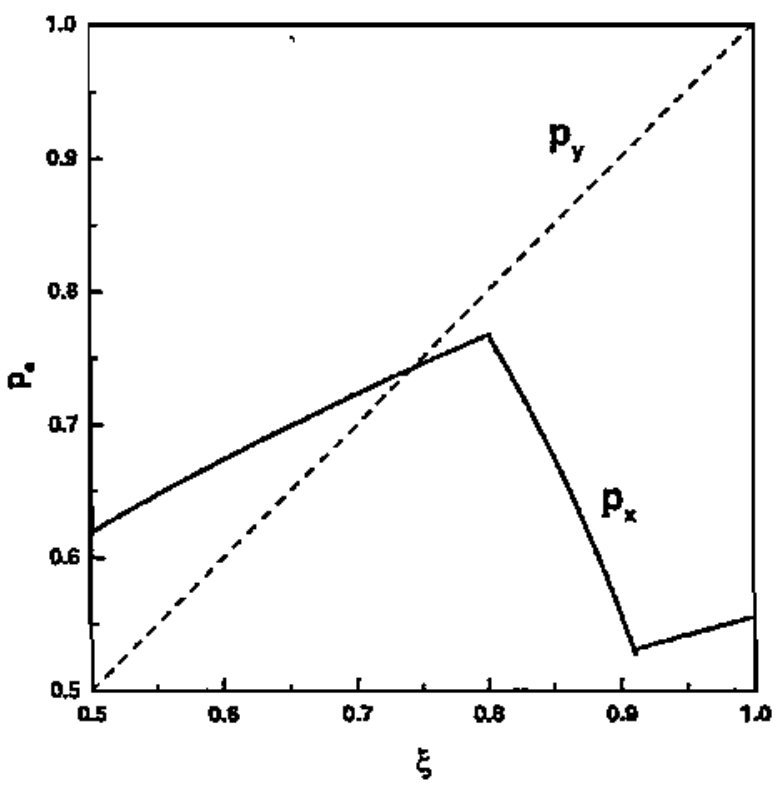

Fig. 5. $p_{x}$ (cuntinuous line) and $p_{y}$ (bashed line) as functions of E.

lapses at point $T$. After that, the system continues to evolve in a period- 2 movement, but showing inversion of phases (see the colors exchange) until point $F$, where another bifurcation occurs on each branch. Therefore, this diagram can be split in an odd diagram (black + red) as shown in Fig. 4(b), and in an even diagram (green + blue) as shown in Fig. 4(c). The skeleton of each branch is preserved even in the regions of superposition of the branches, as in the chaotic region $\left(n \geq 2.5 \times 10^{5}\right.$ and $\xi \geq 0.97$ in Fig. 4). The branches in Fig. 4(b) and 4(c) have sirailar behavior and structures (common bifurcation points and chrotic regions), but different sizes.

The similarity between each branch and the logistic map suggests that this peculiar behavior could be interpreted by the combination of two strongly interacting logistic maps (series combination) as to say, the feedback of one logistic map into another one

$x_{n+1}=4 p_{x}(\xi) y_{n}\left(1-y_{n}\right)$, odd branch,

$y_{n+1}=4 p_{y}(\xi) x_{n}\left(1-x_{n}\right)$, even branch,

where $p_{x}(\xi)$ and $p_{y}(\xi)$ are the control parameter functions. The choice of $p_{x}(\xi)$ and $p_{y}(\xi)$ shown in Fig. 5 leads to a reasonable emulation of the experimental diagram, as shown in Fig. 4(A), (B) and (C).
Considering that each branch is visited alternately, and associating each branch to an oscillating mode of the water column, it seems that the initial conditions imposed by one drop to the next one switches from one oscillating mode to another one.Therefore, the combined maps models can give us a first sight about some local behaviors of the experimental diagram.

\section{Conclusions}

We could reproduce the profile of some attractors by using the one-dimensional mass-spring model. The parameters values obtained by this model are not realistic due to the drastic simplification of the water drop formation dynamics.

To interpret some peculiar behaviors observed locally in bifurcation diagrams we proposed the empirical model of combined maps. With the parallel combination we could emulate the peculiar replacing of four fixed points by four new ones. The feedback of one quadratic map into another one, in the series combination, allowed us to realize the collapse of branches and their further separation, as well as the preservation of the skeleton of each branch in the chaotic region.

\section{Acknowledgements}

This work was partially financed by the Brazilian agencies FAPESP, CNPq, and FINEP.

\section{References}

[1] F.C. Moon, Chsotic Vibrations, Wiley, New York, 1987.

[2] KT. Alligood, T.D. Sauet, J.A. Yorke, Chaos: An Introduction to Dynanical Systems, Springer-Veriag, New York, 1997.

[3] O.E. Rösslet, Synergetics: A Workshop, Springer-Vedag, Berlin 1977.

[4] $R$ Shaw, The dripping faucet as a model chaotic system, Aerial Press, Santa Cruz, 1984.

[5] P. Martien, S.C. Pope, P.L. Scoth, R.S. Shaw, Phys. Lett. A 110 (1985) 399. 
[6] H.N.N. Yépez, ALS. Brito, C.A. Vargas, L.A. Vicente, Ens. J. Tuys. $10(1989)$ 99.

11) R.F. Cakalan, H. Leifte-tter, O.D. Calutan, Comp. Phys. Jnily/August, 1990, p. 368 .

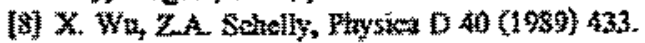

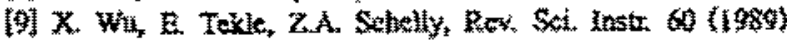
$377 \%$

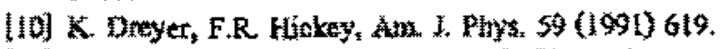

[11] J.E. Sartorelli, WM. Gongatres, R.D. Piato, Phys. Roy. 49 (1994) 3963.

\{12\} R.D. Pinto, W.M. Gonçalves, J.C. Sartorelli, M.J. de Oliveira, Dhys. Rev. E 52 (1995) 6892.

[13] 3.G.M. do Siva, 1.C. Sartertill, W.M. Gongaives, R.D. Pinto, Dhy let $\mathrm{A} 226$ (1997) 269 .

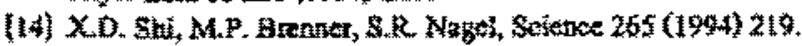

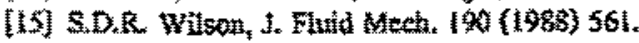

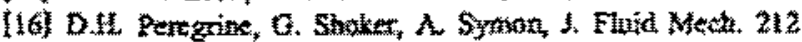
(1990) 25.

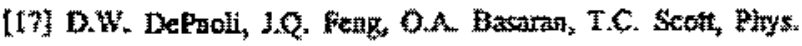
Finids 7 (1995) 1181 .

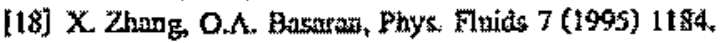

[19] A Laverón-Siravilla, JM. Perales, Phys. Finids 7 (1995) 1204.

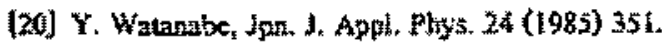

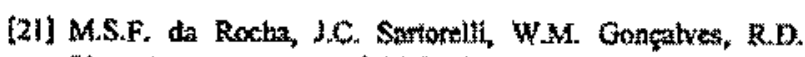
Pinto, Phys. RcV, E $\$ 4(1996) 2378$.

[22] 1. Austin, Phys. Lott. A 155 (1991) 148.

[23] 4.A. Fonde, 1. Procóplo, J.C. Sartorelli, J. App Phys 80 (1996) 6021.

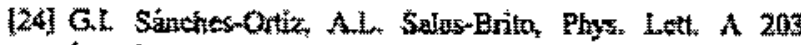

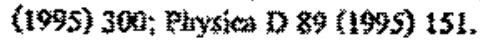

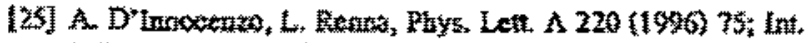

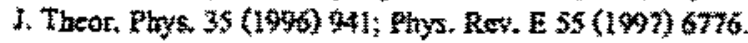

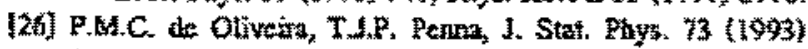

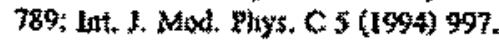

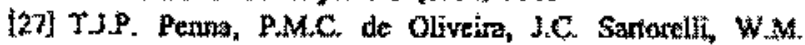
Goncalves, R.D. Finto, Plyys. Rev, E 52 (1995) R2168.

[28] H.E. Stanley, S.V. Buldyrev A.L. Goldeberger, Z.D. Goldeberges, S. Havlin, R.N. Mantegar, S.M. Ossadnik, C.X. Reng, ㄱ. Sirmons, Poysiea A 205 (1994) 214.

[29] K. Kancks, Progr. Theat. Phys. 69 (1983) 1427; Pregr.

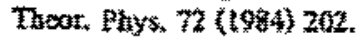

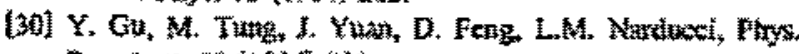
Rev. Leti 52 (1984) tot.

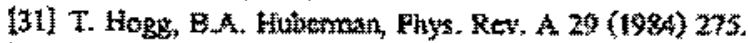

132) LA Buninowich, piysise D \&6 (1995) 248.

[33] C. Grebogi, E. Oth, JA, Yatke, Phys. Rey. Lett. 48 (1982) 1507; Physica D 7 (1983) 181. 


\title{
Apêndice 2
}

Chaotic behavior in bubble formation dynamics

\author{
A. Tufaile e J.C. Sartorelli \\ Physica A 275 (2000) 336-346
}




\title{
Chaotic behavior in bubble formation dynamics
}

\author{
A. Tufaile, J.C. Sartorelli* \\ Instituto de Física, Universidade de Säo Paulo, Caixa Postal 66318, 05315-970 Säo Paulo, SP, Brazil
}

Received 25 June 1999; revised 19 August 1999

\begin{abstract}
We constructed an experimental apparatus to study the dynamics of the formation of air bubbles in a submerged nozzle in a water/glycerin solution inside a cylindrical tube. The delay time between successive bubbles was measured with a laser-photodiode system. It was observed bifurcations, chaotic behavior, and sudden changes in a periodic regime as a function of the decreasing air pressure in a reservoir. We also observed dynamical effects by applying a sound wave tuned to the fundamental frequency of the air column above the solution. As a function of the sound wave amplitude, we obtained a limit cycle, a flip bifurcation, chaotic behavior, and the synchronization of the bubbling with sound wave frequency. We related some of the different dynamical behaviors to coalescent effects and bubble sizes. (C) 2000 Elsevier Science B.V. All rights reserved.
\end{abstract}

PACS: 05.45.+b

Keywords: Chaos; Bubble dynamics; Unstable periodic orbit; Synchronization

\section{Introduction}

The formation of gas bubbles in a nozzle submerged in a liquid column has been studied by Davidson and Schüler [1], Buyevich and Webbon [2], and Kyriakides ct al. [3]. A critical review about the experimental and theoretical results is presented by Ponter and Surati in Ref. [4]. Results of simulations of the motion of gas bubbles in a liquid are presented by Krishna and van Baten in Ref. [5]. The bubbling dynamics presents some features that resemble chaotic systems [6-8]. Triton and Edgell [7] observed some attractors by detecting the bubble passage by a transducer (hot-film anemometer) placed close to the nozzle.

The aim of this paper is to report the existence of dynamical properties of bubble formation with non-invasive techniques, and report the effects of a sound wave on the

- Corresponding author.

E-mail address: sartorelli@if.usp.br (J.C. Sartorelli)

0378-4371/00/ -see front matter (c) 2000 Elsevier Science B.V. All rights reserved.

PII : $S 0378-4371(99) 00440-9$ 


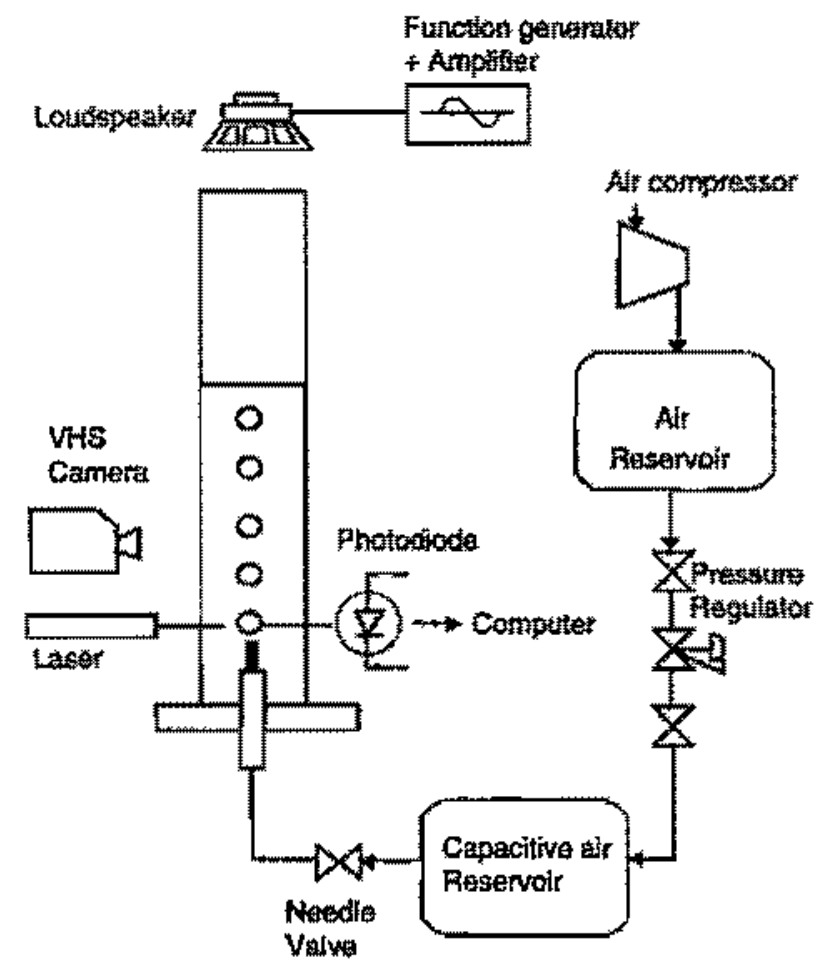

Fig. 1. Diaguram of tic experimental uppomatus.

bubble formation dynamics. The delay time between successive bubbles was measured by using the same techniques as in the dripping faucet experiments [9]. Besides a route to chaos via period doubling, we related some pecultar behaviors observed in bifurcation diagrams to the coalescent eflects (for a bubble penetrating into another just above the nozzle, and forming a single--larger bubble; or when one bubble touches the previous one forming a doublet).

\section{The bobble gon apparafus}

The experimental apparatus consists of a glass tube partially filled with a viscous solution (water tglycerol), as schematically shown in Fig. 1 . The air bubbles are fomed blowing air through a nozzle at the bottom of the tube. The air is supplied by an air compressor whose reservoir is connected to another one (a capacitive reservoir) through a pressure reducer. The detection system is the same as in the dripping faucet experiment [9]. A horizontal He-Ne laser beam, focused in a photodiode, is placed a little above the norzle. The input signals are voltage pulses, induced in a resistor, defined by the begining (ending) of the scattering of a laser beam focused on the photodiode (in series with the resistor) when the bubble starts (ends) to cross the laser beam. The delay time betwen successive bubbles was measured with a time counter circuitry inserted in a $\mathrm{PC}$ slot (time resolution $=1 \mu \mathrm{s}$ ). The width of the pulse is the 
time interval $l_{n}$ (where $n$ is the bubble number), and the delay time between two pulseg is the crossing time $\left(\delta t_{n}\right)$, of a bubble through the laser beam, so that the total time interval is $T_{n}=t_{n}+\delta t_{n}$. We can setup the bubble rate $(f=1 /(T))$ in two ways: (a) by hixing the opening of the needle valve, tarning off the air supply to the capacitive reservoir, and letting the air pressure to dectease naturally, so the bubtling rate. In this case, we have analyzed the data constructing bifurcation diagrams $\left(w_{n}\right.$ is. $n$ ), that are functions of the air pressure decreasing; (b) by kecping fix the air pressure in the capacitive reservoir and selecting the bubble rate by opening (closing) the needle valve, In this case, for a given bubbling rate we have constnicted first return maps $T_{n+1}$ vs. $T_{n}$. We also studied the changing of the bubbles formation dyamics with a sound wave tuned to the fundamental frequency of the sir column above the solution. The sound waves are generated by a loudspeaker, placed at the top of the tube (see Fig. 1), which is driven by an arbitrary function generator. The sound wave amplitude was used as a control parameter.

We also recorded the butble formation with a VHS camera to llinstrate how the profiles of the bubbles are in different dynamical behaviors.

\section{Results and discussion}

\subsection{Air pressute as a control parameter}

Using a solution of four parts of glycerol and one part of water, and a plastic hypodernic syringe, without the metallic needle, as a nozzle, a bifurcation diagram was obtained letting the air pressure in the capasitive reservoir go down naturally with the bubbling, as shown in Fig. 2. The diagram shows the evolution from a chaotic behavior in region (a) to a periodic window. The periodic behavior starts with a period-2, region (b), thereafter a bifurcation occurs giving rise to a period 4 , region (c), which again evolves to another period-2, region (d), followed by a period-1 movement region (e) In Fig. 3 the illustrations of the bubbles profile in ach region, as labled above are shown. In Fig. 3(e), the bubbles are formed without the coalescent effect; in the period-2 behavior shown in Fig. 3(d) there is no collescence near the nozzle, but a little fsr above it; in Fig. 3(c), the coalescence occurs close to the nozzle, but bubbles do not touch each other, and a period 4 is observed; in Fig. 3(b) two successive bubbles coalesce completely giving rise to a large single bubble in a period-2 behavior; and in Fig. 3(a) the coalescent effet in the chaotic region.

A different bifurcation diagram was obtained, in the same way as above, using a long metallic hypodernic needle as a nozzle, as shown in Fig. 4. The system is cvolving in a period-2 movement, region (a) in the Fig. 4 , with an atractors sizz $\approx\left|T_{n+1}-T_{n}\right| \sim 5.5$ wrs. As the air pressure in the capacitive reservoir goes down, suddenly a shortening of the period-2 occurs, and a new period-2 starts with the attractors size $\approx\left|T_{n+1}-T_{n}\right| \sim 1$ $\mathrm{ms}$, region (b) in the Fig. 4. Thereafter, the system evolves to a period-1 movenent. Illustrations of the bubbles profife, obtained in each region described in Fig. 4 , are 


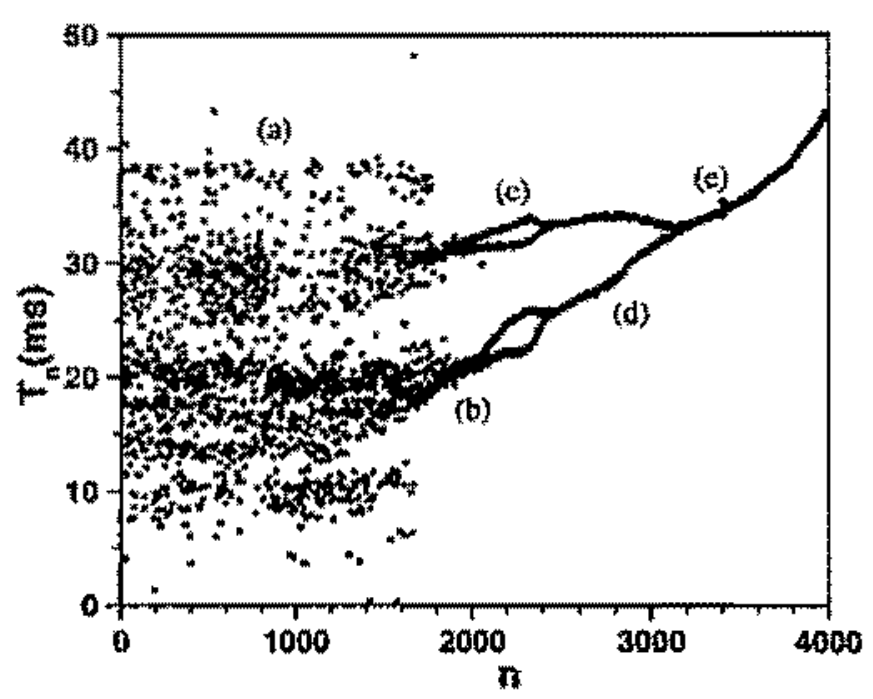

Fig. 2. Bifurcation diagram obtained with the air pressure decteasing in the cerpacitive rescrovoir. Region

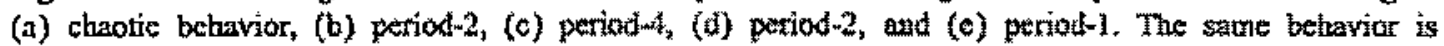
obtained by increasing the air pressure. Hypodermite syringe sarzale.

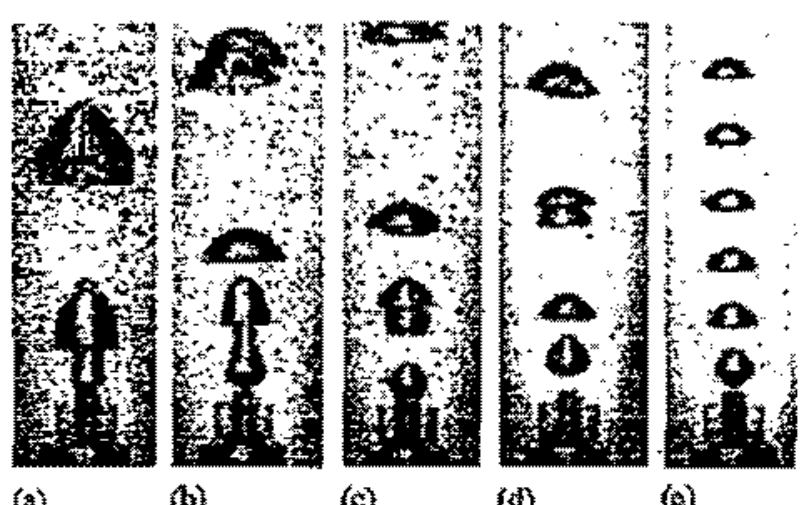

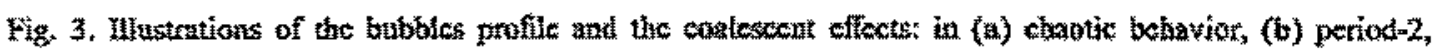

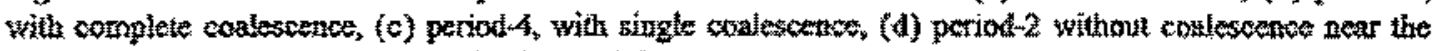

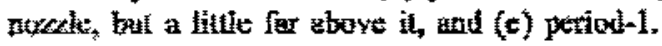

stown in Fig. 5. The shotening of the size of the attractor is accomplished by the shortening of the size of the bubbles, as it is shown in Fig $5(\mathrm{a})$ and (b). In the larger peried-2 region, close to the nozzle, two bubbles coalesce completely forming a large single bubble, as described in Refs. $[1,3]$.

\subsection{Sotnd wave amplitude as a control parameter}

By keeping fixed the air pressure in the capacitive reservoir, we clxanged the bubble dynamics formation by applying sound waves tuned to the tundamental frequency, $f_{s}=138 \mathrm{~Hz}$, of the air column above the liquid sohution (two parts of glycerol/one part of water). 


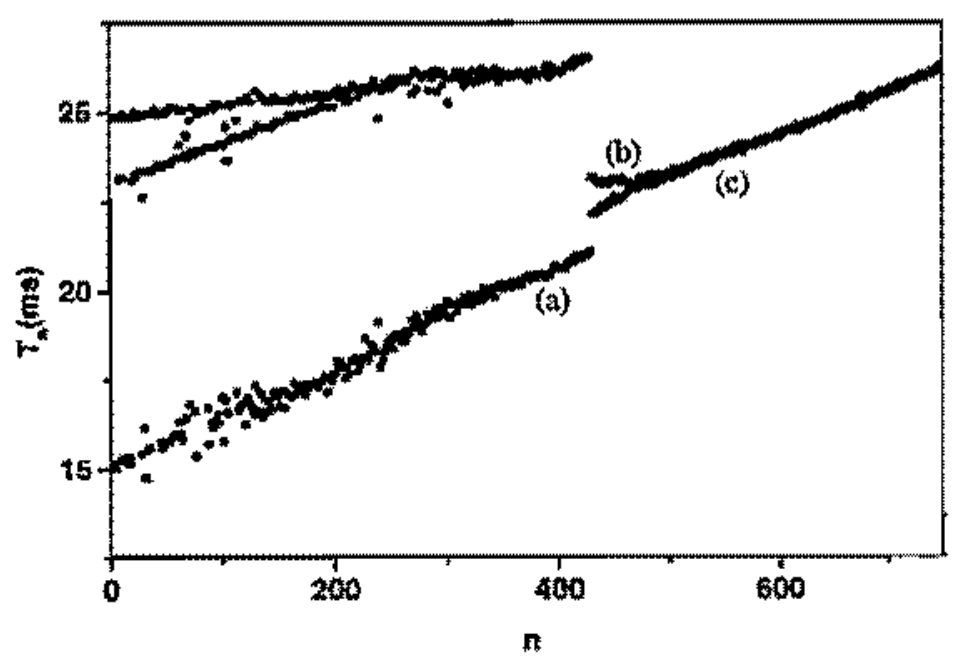

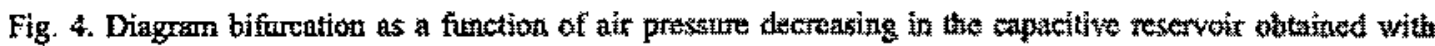
a melallic needis. Around the region (a) the movement is the large pertod-2 the to the coxalesckat affect, around the region (b) is shown a shorer period-2, and in the region (c) is shown a fact point.

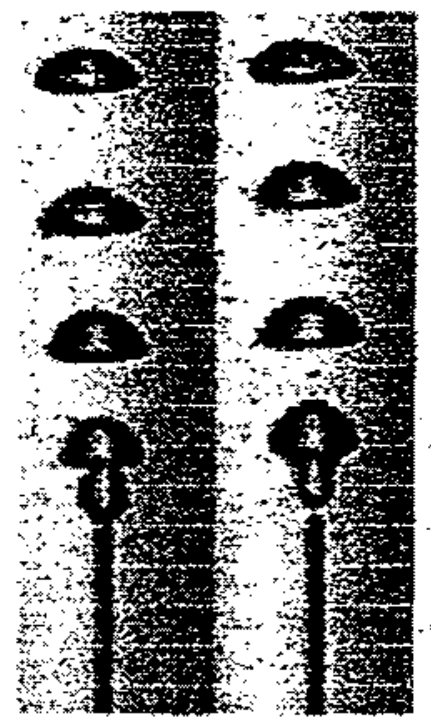

(a)

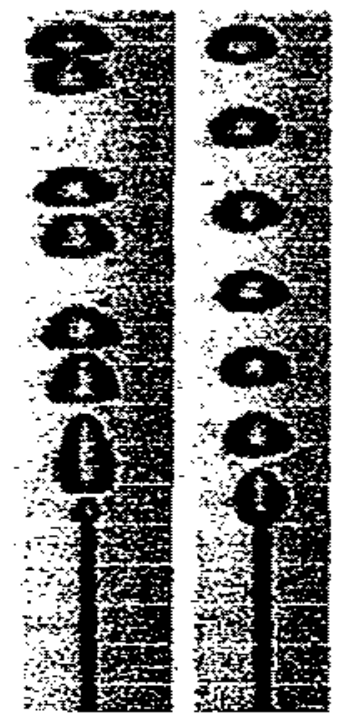

(b)

(a)

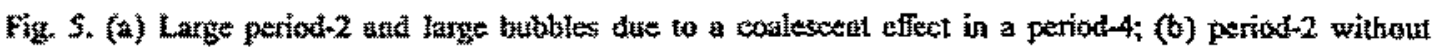

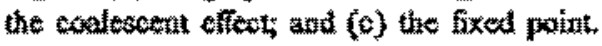

In Fig. 6 the first reurn naps a function of the sound waye amplitude are shown. In frame, the top inset shows at the left the sound wave amplitude and at the right the bubbling rate. We started at a fixed point at $f=11.282$ bubbles/s as shown in Fig. (a). By applying the sound wave, the fixcd point looses its stability and a limit cycle appears, as shown in Fig. $6(b)$ and (c), with a little increasing of the mean bubbling rate as the amplitude is raised. 

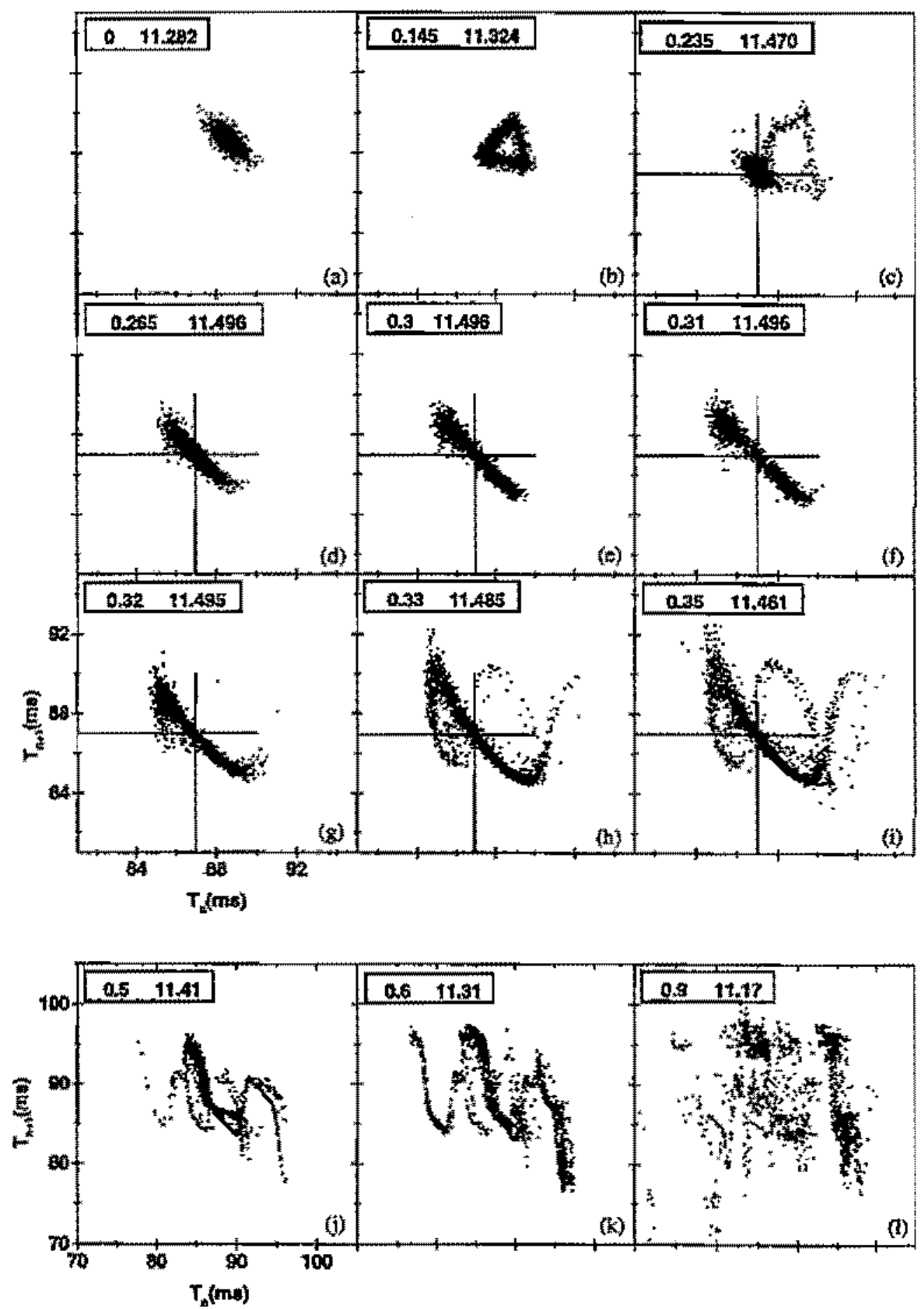

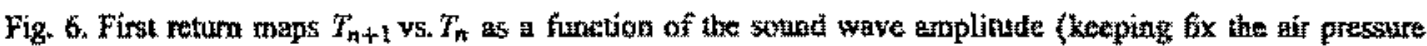

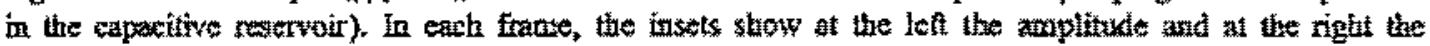

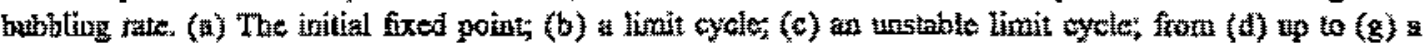

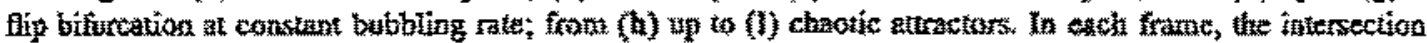

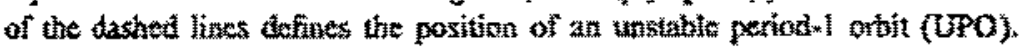


In Fig. $6(c)$ the limit cycle looses its stability and a fixed point, near $(87,87 \mathrm{~ms})$, is visited in an infernittent behavior. This fixed point position was established by a histogram plot of $T_{n}$. The Fourier transform applled to the data related to Figs. $6(\mathrm{~d})-(\mathrm{g})$ showed a noisy period-2 behavio, and without any bubbling rate variation. Therefore, as we are observing a bifurcation period-1 $\rightarrow$ period-2 (see in Fig. (c) (g) ), as a function of the sound wave amplitude, a period doubling is being hidden by the noisc. In a flip bifurcation there is an unstable fixed point between the two stable fixed. Our data shows that the vicinity of the middtle point between the stable fixed points is been visited due to noise. Consequently, our data are adequate to apply the fixed point transformation technique developed by So at al. $[10-12]$ to find unstable periodic orbits (UPO) in short series of events with unstable control parameter, briefly described below.

To extract the unstable periodic orbit with a finite amount of noisy data of a one-dimensional system, So et al. supposed that all points lying in a region around the fixed point $x^{*}=f\left(x^{*}\right)$ can be transformed to $\left\{\hat{x}_{n}\right\}$ in the vicinity of $x^{*}$. The density function $\hat{\rho}(\hat{x})$ has inverse square-root-type singularities at the fixed points, and a histogram approximation to $\hat{p}(\hat{x})$ will have a sharp peak at $\hat{x}=x^{*}$. Some spurious peaks appear in $\hat{\rho}(\hat{x})$ either due to singularities not related to fixed points, or to zeros of the derivative of the transformation function $x=g(x, b)$. They generalized the method for a system with an arbitrary embedded dimension (d) to obtain the unstable periodic orbits by doing the transformation

$$
\hat{z}_{n}=\left(1-S_{n}\right)^{-1}\left(z_{n+1}-S_{n} z_{n}\right)
$$

where

$$
\begin{aligned}
& \mathbf{S}_{n}=\left(\begin{array}{cc}
a_{n}^{1} a_{n}^{2} \ldots a_{n}^{(d-1)} & a_{n}^{d} \\
1 & 0
\end{array}\right)+k \mathbf{R}|| z_{n+1}-z_{n} \| \\
&\left(\begin{array}{c}
a_{n}^{d} \\
\cdot \\
\cdot \\
a_{n}^{d}
\end{array}\right)=\left(\begin{array}{c}
\left(z_{n}-z_{n-1}\right)^{\dagger} \\
\cdot \\
\cdot \\
\cdot \\
\left(z_{n+(d-1)}-z_{n-d}\right)^{\dagger}
\end{array}\right)^{-1}\left(\begin{array}{c}
\left(z_{n+1}^{1}-z_{n}^{1}\right)^{\dagger} \\
\cdot \\
\cdot \\
\cdot \\
\left(z_{n-(d-2)}^{1}-z_{n-(d-1)}^{1}\right)^{\dagger}
\end{array}\right)
\end{aligned}
$$

$\left\{z_{n}\right)$ are the reconstrueted vectors from sealar time series $\left\{x_{n}\right\}$,

$$
z_{n}=\left(z_{n}^{1}, z_{n}^{2}, z_{n}^{2}, \ldots, z_{n}^{d}\right)^{\dagger}=\left(x_{n}, x_{n-1}, x_{n \sim 2}^{2}, \cdots, x_{n-d-1}\right)^{\dagger}
$$

$\boldsymbol{R}$ is a $d \times d$ random matrix in the range $[-1,1]$, and $x$ is the magnitude of the randomization. The fixed points are given by the peak positions of $\hat{\rho}(\hat{z})$. As the locations of the spurious peaks depend on the parameter, they are eliminated by taking the average $\langle\hat{\rho}(\hat{\mathrm{z}}))$ for many different values picked up randomly. As the attractors reconstruction in a two-dimensional embedded space are enough unfolded, we applied this technique for $d=2$. We also chose $k=5$, and 1000 random matrices. 

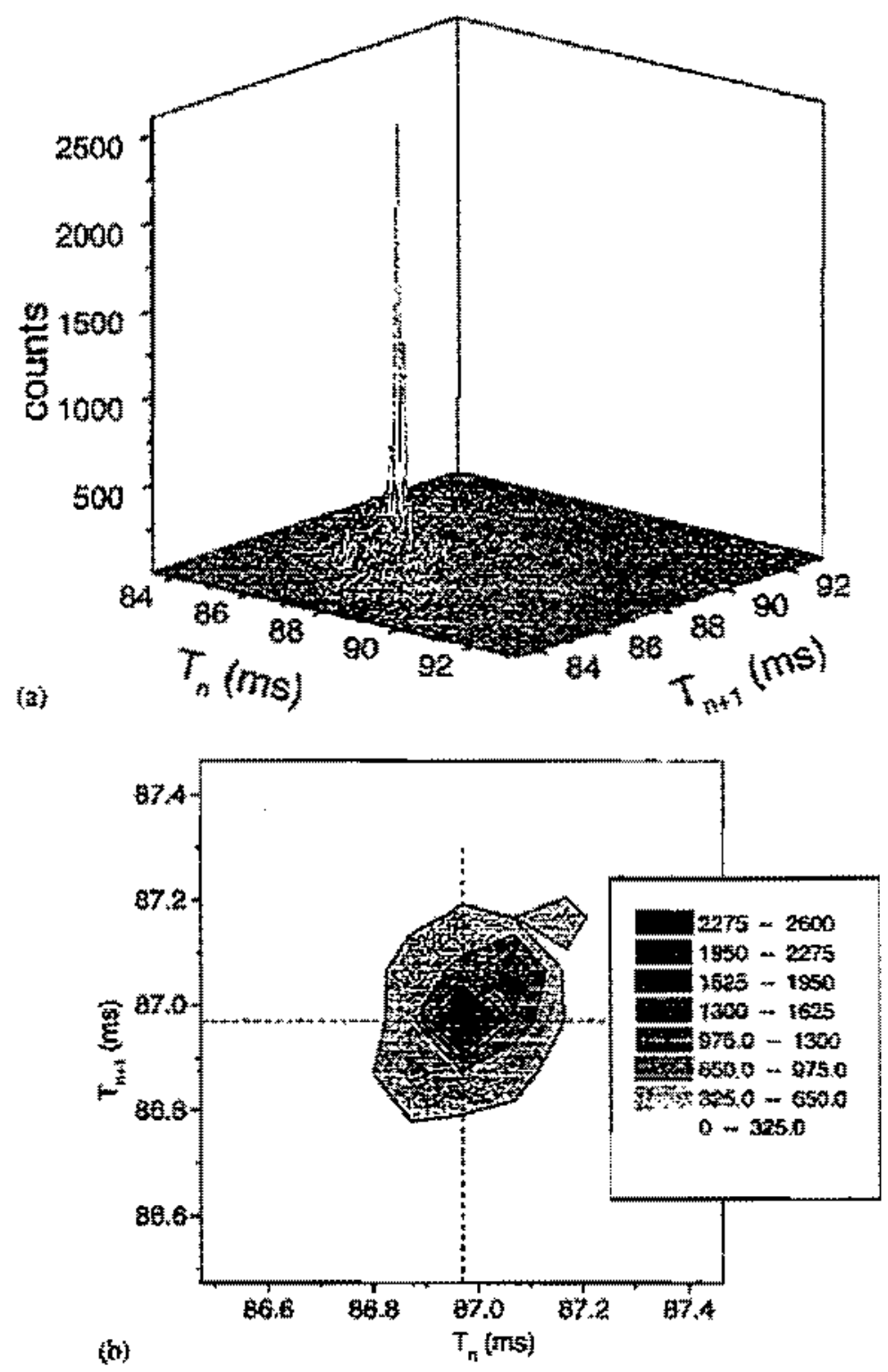

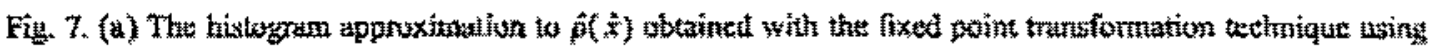

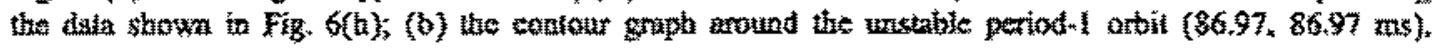

An example of our results is shown in Fig. 7(a), where is drawn the histogram approximation to $\hat{\rho}(\hat{x})$ using the data shown in Fig. $6(\mathrm{~h})$. For better visuatization of the unstable period orbit position a contan graph of the same data is shown in Fig. $7(\mathrm{~b})$. The highest prak defines an unstable period-1 orbit at $(86.99,86.99 \mathrm{~ms})$, close to the stable fixed point shown in Fig. $6(\mathrm{c})$. In this way, we found an unstable period-1 orbit, as shown by the intersection of the dashed lines in Fig. 6.

With farther amplitude increasing, we observed the appearance of a chaotic region, with stretching and folding dynamics features, as shown in Fig $6(\mathrm{~h})-(\mathrm{i})$, and with 


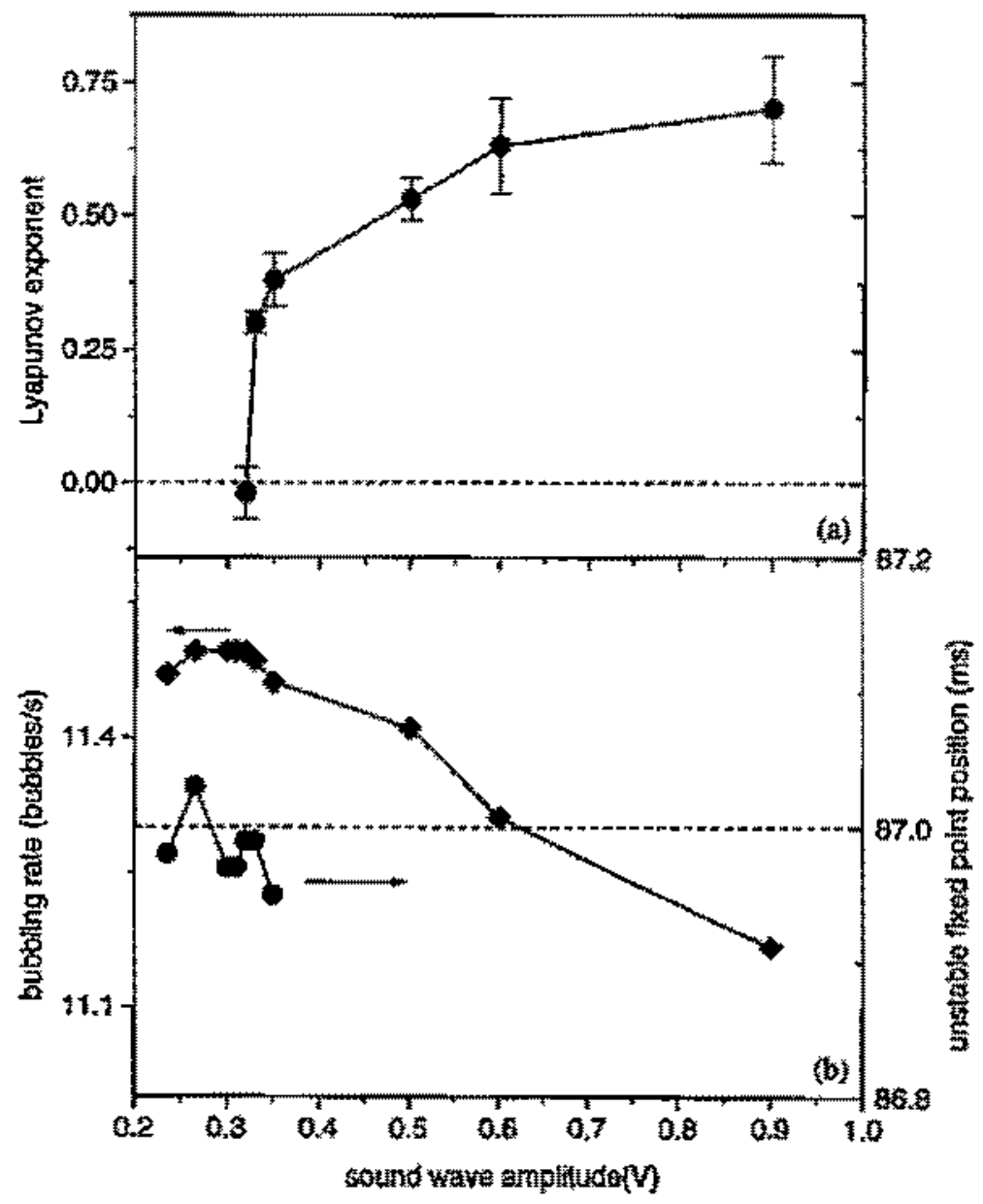

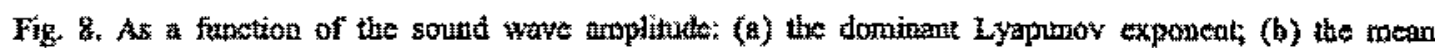
bubbling rate (left ale ) and the enstable periodit onbit (right seale). The continuous lines are guides to ayes.

little change in the bubbling frequency. The reconstructed attractors in the chaotic region were characterized by the dominant Lyapurioy exponent [13], as shown in Fig. 8(a). However, the unstable period-1 otbit remains in the chaotic region, with a little change on its position, as shown in Fig. $8(b)$ (right scale).

Continuing to increase the soum wave amplitude, with larger amplimude increments than before, we obtained the attractors shown in Fig. 9. In Fig. 9(m) the mean bubbling rate is 20.5 bubbles/s for a sound wave amplitude of $3.14 \mathrm{~V}$, and the pasition $(\sim 7.25$, $\sim 7.25 \mathrm{~ms})$, is visited in an intermittent behavior. The visitation time increases as we increase the sound wave amplitude, until the point $(\sim 7.25, \sim 7.25 \mathrm{~ms})$ becormes a stable fixed point, as shown in Fig. $Y(n)$. In this situation, the mean bubbling frecuency is $f=137.97 \pm 0.09$ bubbles/s, which is the sound wave frequency valus therefore, the bubbling becomes synchronized with the sound waye, In Fig. 10 we can see the difference between the bubbles profile in the first fxed point, as shown in Fig. 6(a), and the syuchronkzed fixed point, shown in rig. $(a)$. 


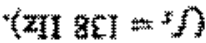

Gorom

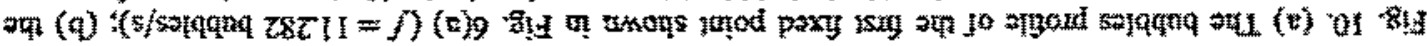

(a)

(e)
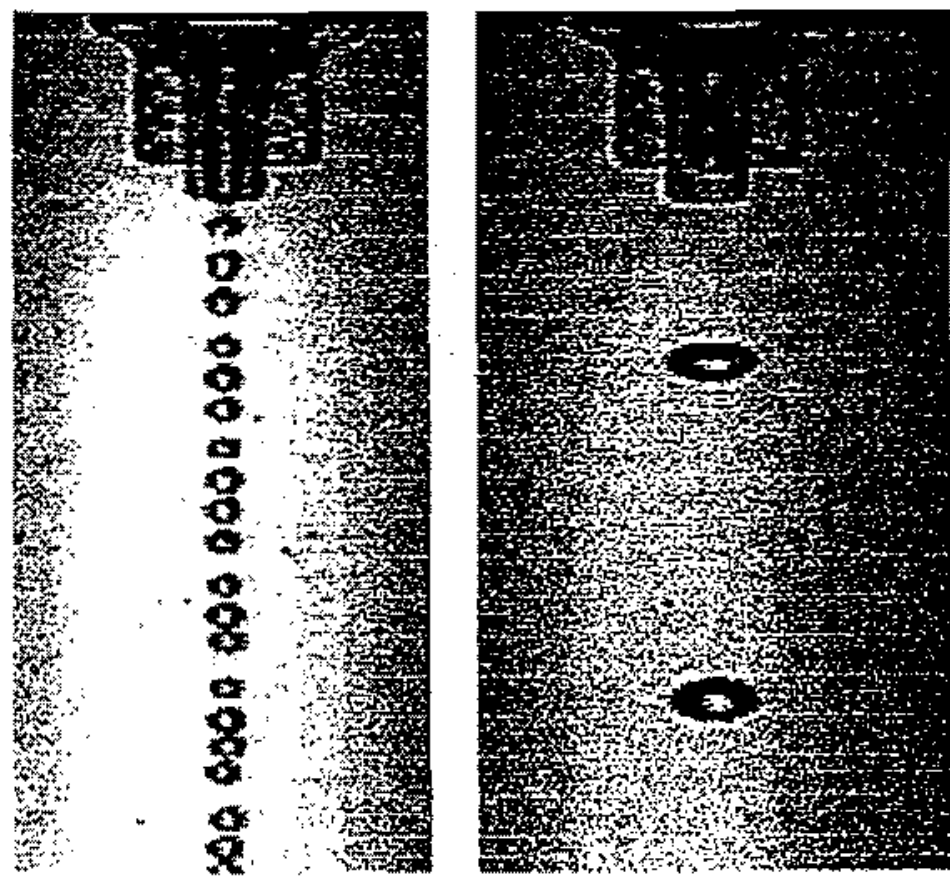

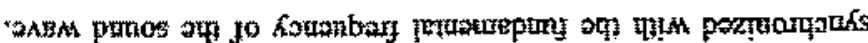

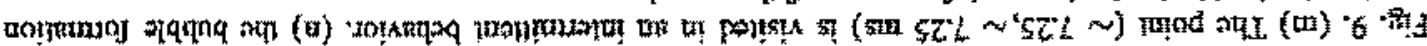

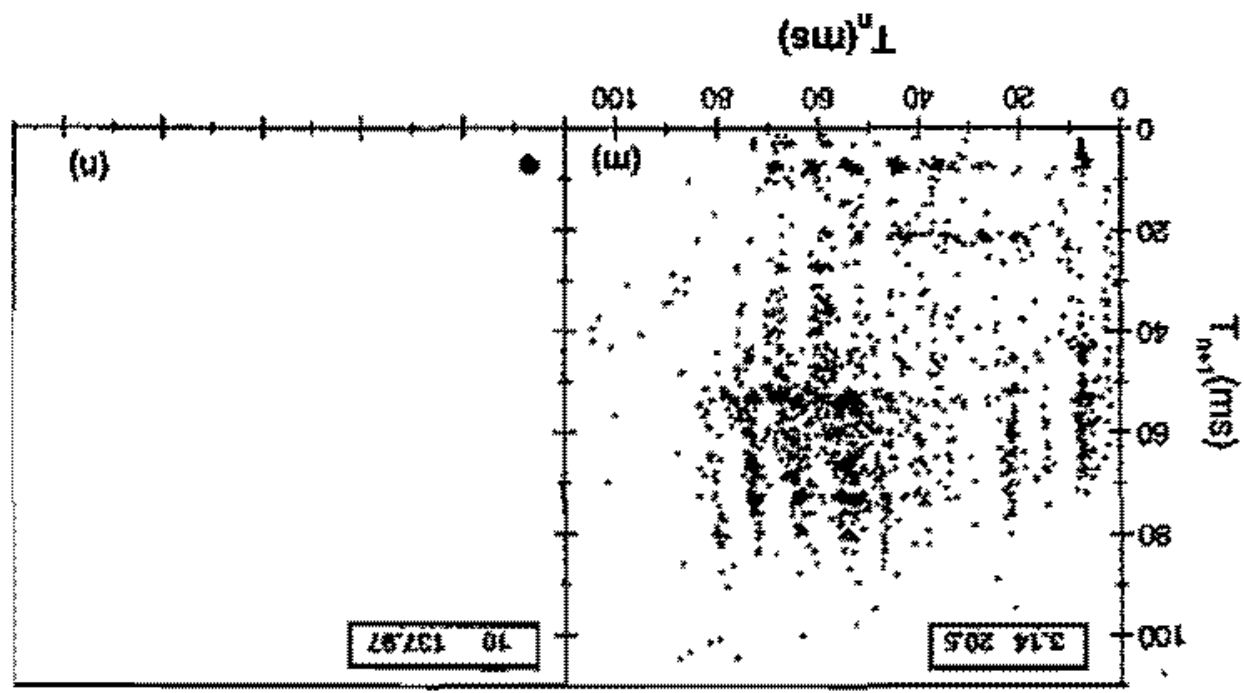




\section{Conclusion}

We observed bifurcations in a bubble gun experiment as a function of the air pressure. In one case, we observed in a period-2 movement a sudden change in the attractors size related to the bubbles size. In other case, with a different nozzle geometry, we observed a period-doubling cascade, $1 \rightarrow 2 \rightarrow 4$, followed by chaotic behavior. In both cases, we related some different dynamical behaviors to coalescent effects.

For a fixed air pressure, we used as a second control parameter the amplitude of a sound wave tuned to the fundamental frequency of the air tube above the solution. We observed as a function of increasing sound wave amplitudes, the appearance of a fixed point; a limit cycle, which looses its stability and a new fixed point appears; a flip bifurcation followed by a chaotic region with stretching and folding features. Thereafter, aew fixed point starts to be visited in an intermittent behavior, until the bubbling syehronizes with the sound wave frequency.

We applied the tecluique of the transformation of the fixed points to extract an unstable period 1 orbit embedded in noisy reconstructed attractors in the flip bifurcation region. This unstable periodm 1 orbit remains in the chaotic regime, which was characterized by the dominant Lyapunov exponent.

\section{Acknowlexgements}

We are grateful to Professor A.J. Lichtenlerg, R.D. Pinto and M.S. Baptista for their suggestions. Financial support from the Brazilian Agencies FAPESP, CNPq, and FNEEP is gatefully acknowledged.

\section{References}

[1] J.F, Davidson, B.O.G. Shüler, Trans, Inst. Chem. Eag. 38 (1960) 144.

[2] X.A. Buyevich, B.W, Webbon, Clem, Eng Sci. $\$ 1$ (1968) 4843 .

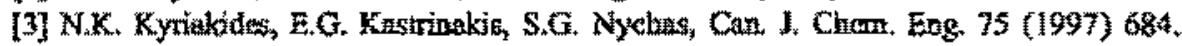

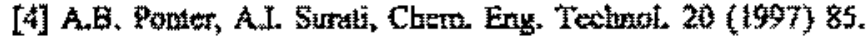

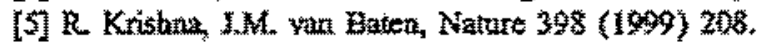

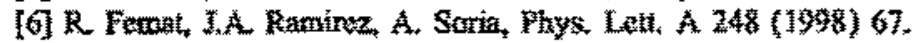

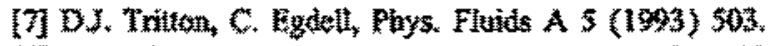

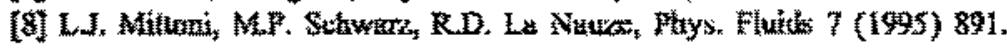

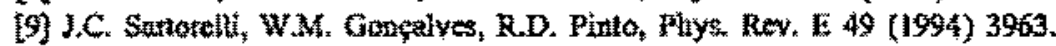

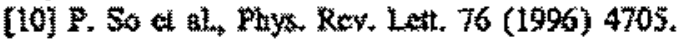

[1:] P. So at at. Fuys. Rev. E 55 (1997) 5390.

[12] $P$. So et al., Biophys. J. 74 (2776) 1998.

[13] S. Eliner, D.W. Nyychlva, A.R. Gellant, LENNS, a propram to estimate the dominant Lyapumov pponent of noisy nonlinear systems from time series data (lastifute of Statistics Mimeo Series no. 22:35 (BMA series 10. 39), Statistics Department, North Carolina State University, Raleigh, 1992). 


\section{Apêndice 3}

Hénon-like attractor in air bubble formation

A. Tufaile e J.C. Sartorelli

Physics Letters A 275 (2000) 211-217 


\title{
Hénon-like attractor in air bubble formation
}

\author{
A. Tufaile, J.C. Sartorelli*

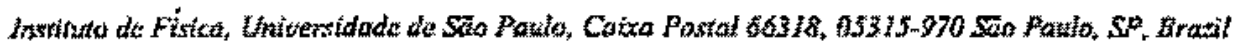

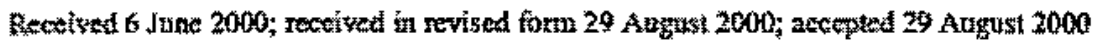

Communicated by C.R Doering

\begin{abstract}
We studiod the fonnation of air bubbles in a submerged nozzle in a water/glycerol solution inside a cylindrical tuldo, submitted to a sound wave perturtation. It was obstrexd a route to chass via period doubling as a function of the sound wave amplitucte. We applitei metrical as well as topxlogical charueterization to some chatotic attractors. We localized a flip sadile, and we also could establish relations to a Hénon-like dynamics with the constrution of sytubolie planes, 2000 Published by Filsevier Science B.Y.
\end{abstract}

PACS: DSAS.+b

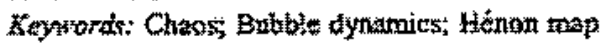

\section{Introdastion}

We reported [1] some dynamical effects of a sound wave in a bubble formation dynamics, such as a flip bifureation as a function of the increasing sound wave amplitude. Lauterborn and Patlitz [2] studied the main features of bubble oscillator, in which the size of a small bubbie in water oscillates due to a sound field. Tritton and Edgell [3] observed some attractors by detecting the bubble passage nearby a tranducer (hot-fitm anemometer) placed close to a norzle where the bubbles were issued, and they reported the existeace of a chaotic bubbling

\footnotetext{
"Cortsponding atuther. Tel. +5511818 6915; fax: +5s 11

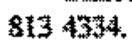

verified by visual inspections, bat without any kind of characterization of the chatic dynumics. Mittoni et al. [4] observed chaotic behavior with positive Lyapunov exponents in bubbling systems using a pressure transducer. Li et al. [S] studied the chactic behavior of bubble coulescence in non-newtonian futds. Ruzicka ef al. [6] observed type III intermittency in the transition from bubbling to jetting regime in a nitrogen-water system.

Characterization of experimental tata of nonlinear systems using symbolic dynamics has been reported by Goncalves et al. [7], in which chatic attractors from the tripping faucet experitnent were approximated to minimal machines, and the topological analysis application, by using symbolis dynamics, was mor suitable to characterize experimental data due to uts robustress to noise. Letellier et al. [8] applied topological characterization to irregulat pul- 
sations of a hydraciynamical model of an pulsating star by construeting symbolic planes.

We have sudied the air tubble tomation dynanics, in a submerged nozale in a water/glycerol solum tion inside a cylindrical tube (sed Ref. [1] tor details), as a function of a sound wave amplitude tuned in the air columa stove the solution. Using metrical and topological chanacterization we observed a tlip bifurcation which is followed by a chaotic region where some reconstructed attractors semble Hicnon-like attractors, which establish a possible nate to chatos in bubbling dynsmies.

\section{Experimental apparatus}

The experimental apparatus of the bubble gun experiment is shown in Fig. 1. The bubbles were generated by injecting air under constant flow rate conditions through a metallic nozzle immersed at the bottom of a viscous fluid column $(20 \%$ water plus $80 \%$ glycerol) maintained at a level of $12 \mathrm{~cm}$. The imer diameter of the cylindrical container is $53 \mathrm{~mm}$ and $70 \mathrm{~cm}$ in height, and the inner diameter of the norzle is $1.3 \mathrm{~mm}$. The mozzle is attached to a capacitive air reservoir, and the air flux can be set up by necdle valve, and the capacitive air reservoir is supplied by an ait compressor through a pressure reducer.

The detextion system is the stme as the drippisg faucet experiment"s $[9,10]$, A horizontal He-Ne laser beatn, foessed on a photodiode, is placed a little above the nozzle. The delay times between successive bubbles were measured with a time circuitry inserted in a PC siot, with a time tesolution equals to I $\mu$.s. The input signals are voliage pulses, induced in a resistor, defined by the beginning (endizg) of scatturing of a laser bean foctised on the photodiode (in series with the resistor) when the bubble starts (ends) to cross the laser beam. The width of pulse is the time interval $t_{n}(n$ is the bubble number), and the time delay betwen two puises is the crossing time $\left(d t_{n}\right)$ of a bubble through the laser bean, so that the total time interval is $t_{n}=t_{x}+d t_{x-}$.

Setting up the bobble rate $(f=1 /(T))$, keeping fix the air pressure in the capacitive reservoir and selecting the bubble rating by opening (closing) the needle valve, we changed the bubble formation dy. namics applying a sound wave with a loudspeaker pinced at the top of the tube. The sound wave was tuned to the fundamental frequency of the air column above the liquid and its amplitude was driven by a

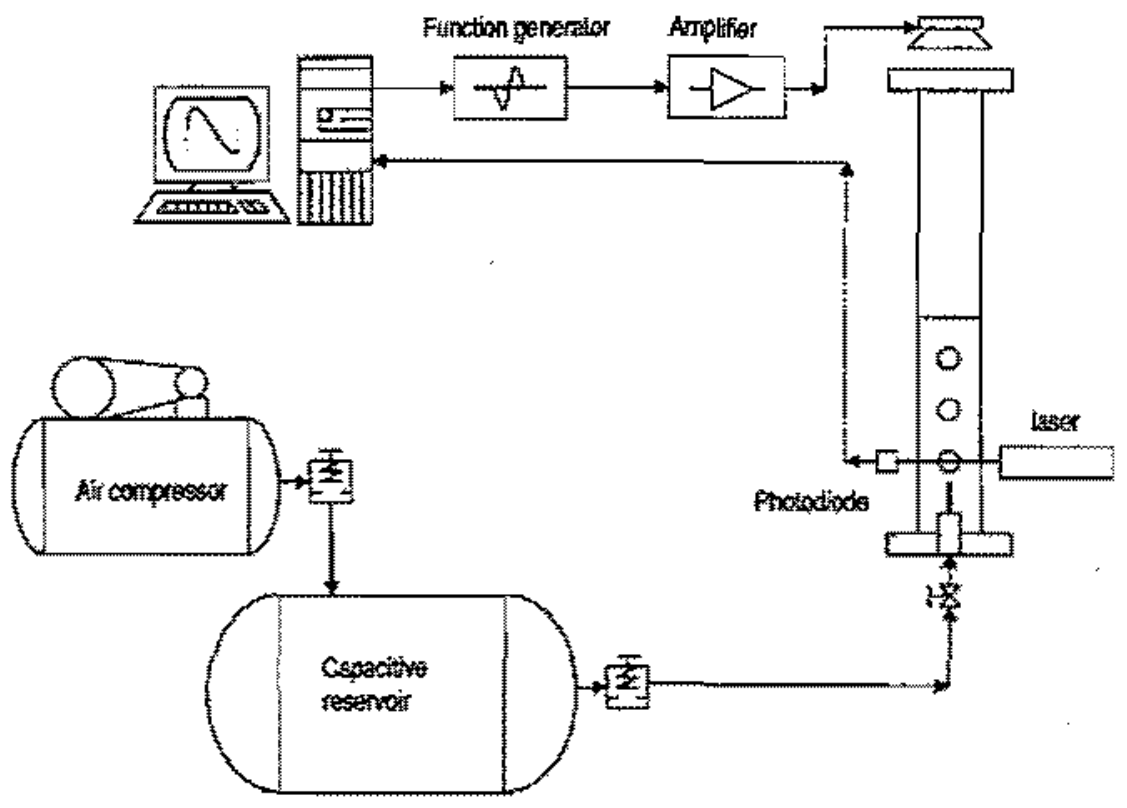

Fig. 1. Diagram of tie experincoial apparatua. 


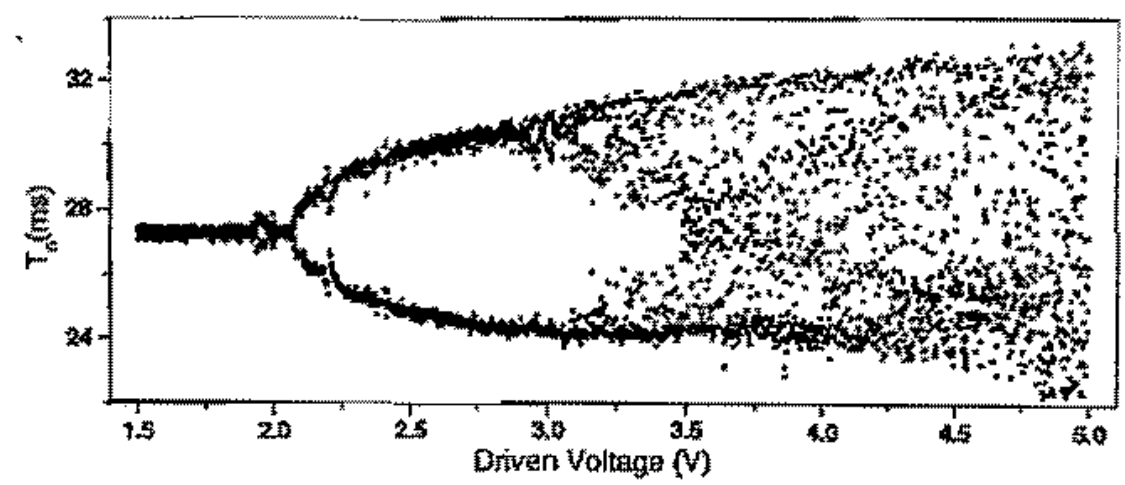

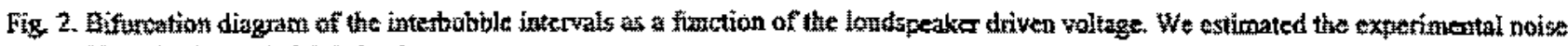
us $\sim 100$ is in the perixd I betavior.

function generator. All the measurements were done at room temperature.

\section{Results and discussion}

The air flow rate and the sound wave frequency were kept constant, at $\sim 36.6$ bubble/s and $150 \mathrm{~Hz}$, respectively. We changed the babble dynamies formation increasing the driven voltage in the loudspecker as shown by the bifurcation dixgram in Fig.
2. A period doubling accus around $2.0 \mathrm{~V}$, and the bubbles are issued in pairs until $-3.0 \mathrm{~V}$, when a noisily period four appenrs. After then, two-band behavior akes place and each band presents chaotic behavior. At $\sim 3.5 \mathrm{~V}$ the chaotic bands start to overlap and a large chaotic attractors energes.

To perform metrical and topological characterization of the bubble fomation dynamics we collezted six time series keeping fix six diven voltages, whose respective return maps $\left(T_{n+1}\right.$, versus $\left.T_{n}\right)$ are shown in Fig. 3 .

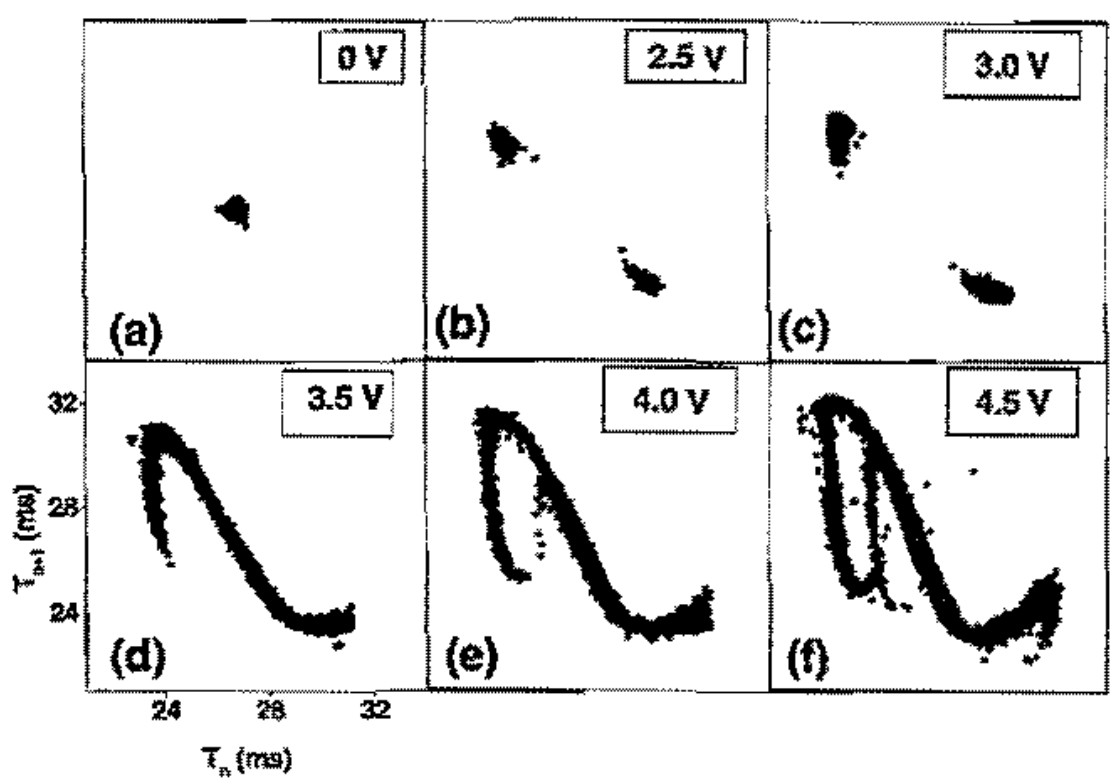

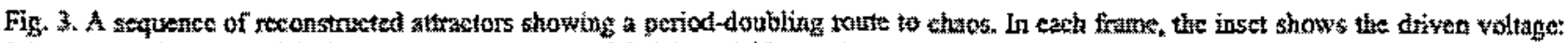

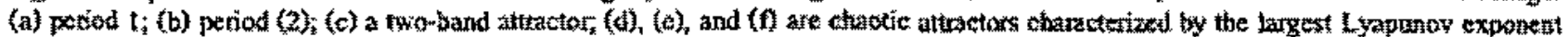

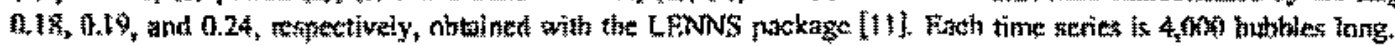




\subsection{Marical characterization}

The reconstnucted attractors in the chatic region (from Fig. 3(d) through 3(f) wite characterized by the Lyapunov exponents, by the Kaplan-Yotke dimension, and by the information dimension obtained by the TISEAN package [12]. A conjecture [13] relates the Lyapunov spectrum $\left(\lambda_{n}\right)$ and the information dimension by the Kaplan-Yorke dimension $D_{\mathrm{KX}}$ :

$D_{\mathrm{KY}}=k+\frac{\sum_{i=1}^{k} \lambda_{i}}{\left|\lambda_{k+1}\right|}$

where $z$ is the maximum integer so that stim of the $k$-largest exponents is still non-negative. This conjecture is valid for Henon atractor and it is checked on reconstructed attractors. The paramerer values obtained for the eriven voltages $Y=3.5,4.0$ and $4.5 \mathrm{~V}$ are shown in Table 1 (seck Wigs. 3(d), 3(e) and $3(\mathrm{f}))$. The Kaplan-Yorke cimensions agree with information dimensions. The two first chaotic atractors have a Lyapunov spectrum with one positive exponent and one negative exponent, while the last one, Fig. 3(f), has one positive and two negative exponents. In Table 1 we also present the results of Hézon maps $\left(f(x, y)=\left(y+1-a x^{2}, b x\right)\right)$, reconstructed as first return maps $X_{n+1}$ versus $X_{m}$ (see Fig. $4(\mathrm{a})$ ).

The atractor dimensions for driven voltages of $3.5 \mathrm{~V}$ and $4.0 \mathrm{~V}$ are close to the dimensions of the Hénon map, suggesting that they could have similar dynamics. The reconstructed attractor for $4.5 V$, see

Table 1

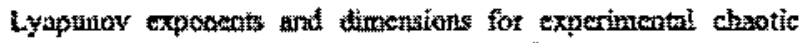
atristars and for two pains of values of Henom map parameters.

\begin{tabular}{|c|c|c|c|c|}
\hline Fig & $\begin{array}{l}\text { Driven } \\
\text { valtege } \\
\text { (V) }\end{array}$ & $\begin{array}{l}\text { L.yopusovi } \\
\text { spertras }\end{array}$ & $\begin{array}{l}\text { Kaplar-Yotke } \\
\text { diniegsion } \\
\text { (error) }\end{array}$ & $\begin{array}{l}\text { Elformation } \\
\text { fimerastoo } \\
\text { (error) }\end{array}$ \\
\hline $3(d)$ & 3.5 & $+0.11,-0.8$ & $1.15(1)$ & $1.3(3)$ \\
\hline $3(c)$ & 4.0 & $+0.12 y-0.6$ & $1.23(1)$ & $1.4(3)$ \\
\hline \multirow[t]{4}{*}{$3(10)$} & $\begin{array}{l}4.5 \\
\text { Héton }\end{array}$ & $\begin{array}{l}+0.2_{s}-0.3 s \\
-0.9\end{array}$ & $1.68(1)$ & $1.8(3)$ \\
\hline & a, b & & & \\
\hline & $1.55,0.1$ & $+0.38,-2.38$ & $1 .\left\{6^{*\}}\right.$ & $1.16(9)$ \\
\hline & $1,4,0.3$ & $+0.42,-1.62$ & $\left.1.7^{*}\right)$ & $1.19(9)$ \\
\hline
\end{tabular}

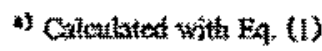
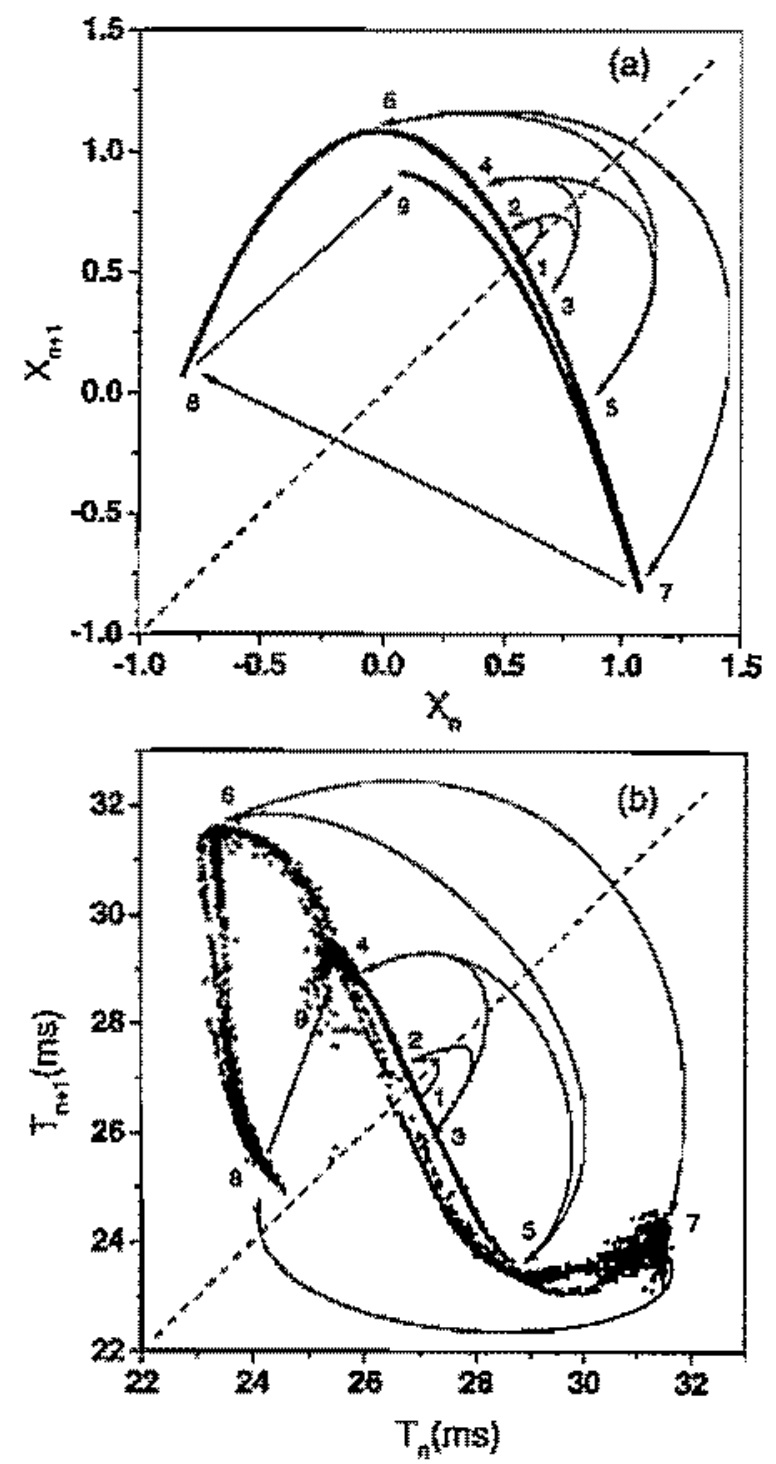

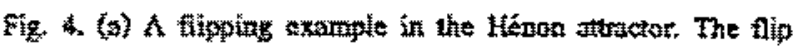

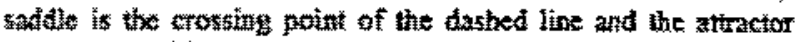

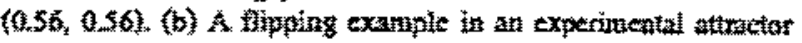
fer a diven voltage of $4.0 \mathrm{~V}$.

Fig. $3(\hat{g})$, has similar profile of the other two, as shown in $\mathrm{Fig}$ 3(d) and $3(\mathrm{e})$. However, its informathon dimension value is quite different from the other two attractors (3(d) and 3(e)) as well as different from the Henon map values, as shown in Table 1 . in addition to the three exponents of the Lyapunoy spectra, the dimension information close to two is a cue that the attractor $3(f)$ could not be untangled in wo dimenstons. 

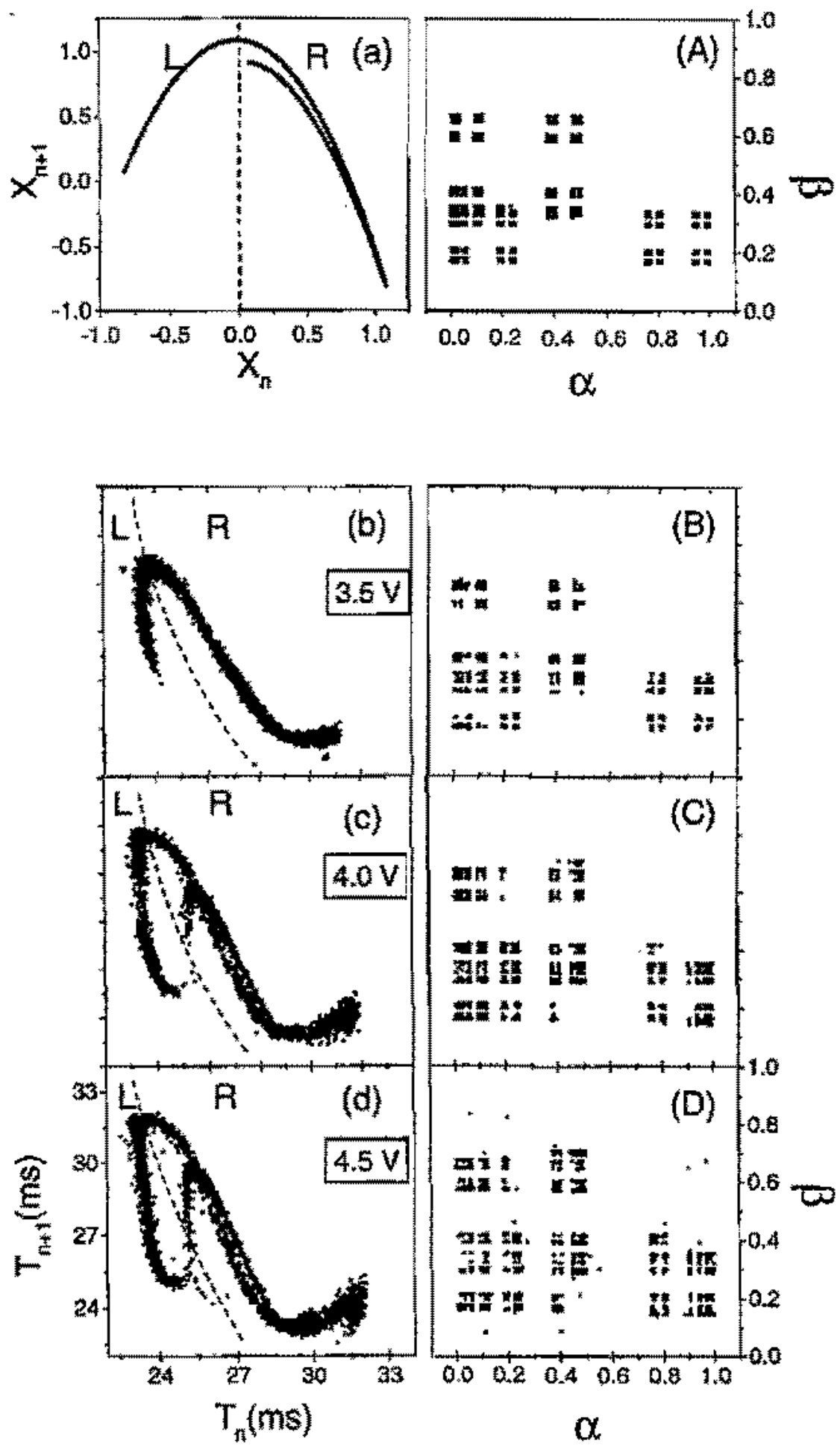

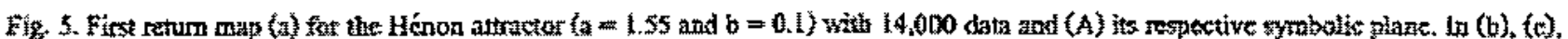

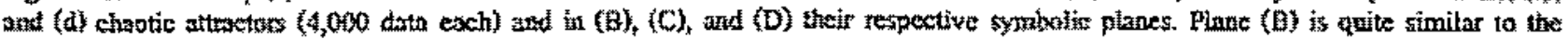

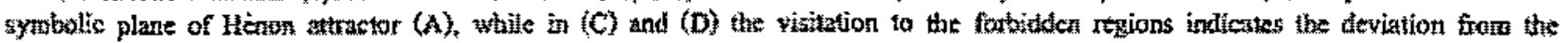

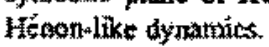


The partition is represented on each roap by dashed lines. In Fig, 5(a) is shown the Henon mapp for $a=1.55$ and $b=0.1$; the partition tsed is a vertical line that separate the single branch (L) from the folded one (R) that contzins an unstable tixed point; and the Hénon zymbolic plane $\alpha \beta b$ is shown in Fig. S(A). From Fig. $5\left(b^{\prime}\right)$ through $5(d)$ the expetimental attractors are shown. In those casts, the partition can not be done with a vertical line, so we looked for curves that could separate the single branch (L) from the folded one (R). The respective symbolic planes $\alpha \beta$ are shown in Figs. $5(\mathrm{~B}), 5(\mathrm{C})$ and $5(\mathrm{D})$.

The pattern of the three experimental symbolic planes resembles the Henon symbolic piane. The best similarity occurs for the driven voltage of $3.5 \mathrm{~V}$ whose symbolic plane has the same allowed and forbidden zones as the Hênon ones. For higher wave amplitude some forbidden regions in the symbolic planes start to be visited (for example $\alpha=0.8$ and $\beta=0.4$ in Fig. $5(D))$, showing that the bubble formation dynamics is rurning away from the Hénonm like dynamiss. In Fig. 6 it is shown the bubble trains raising through the fluid to illustrate the difference between the bubble profites in the periodic regimes and the Hexm-1ike one shown in Fig. 3.

\section{Conclusion}

We have ased metrical and topological methods to characterize the dynamies of air bubble formation. We have observed that a gradual increase in the sound wave amplitude results in a route to chaos via period doubling, We characterized some chaotic behavior with the Lyapunoy spectra, the Kaplan-Yorke dimension and the infomation dimension which led us to relate some restits to a Henot-ilike dynamics, a low dimensional dissipative system with stretching and folding mechanism. The Hénon map parameter values, $a=1.55$ and $b=0.1$, corrsspond to a more dissipative system than the classical values $a=1.4$ and $b=0.3$, coherently with the high liquid viscos-
Ity, that gentrater a less structured attractot. The establishment of a flip saddle and the construction of aymabolit planes reinforced our assumptions. Usually, two dimensional mappings are used as models of forced oscillators, therefore the bubble formation can be seen as an oscillator oriven by a sound wave.

\section{Acknowledgements}

This work was partially supported by Brazilian agencies FAPESP, CNPq, and FNEP.

\section{References}

[1] A. Tufate, 1.C. Sanoreili, Physica A 275 (2000) 376 .

[2] W. Latierbors, U. Parlitz, I. Acolst. Soc, Am. 84 (198g) 1975.

[3] D.t. Tritton, C. Edgell, Phys, Fiuids i 5 (1993) S0:

[4] L.J. Mittoni, M.P. Schwarz, R.D. La Namze, Phys. Fluids 7 (1995) 891.

[5] H.Z. Li, Y. Mouline, L. Choplin, N. Midonx, lnt. J. Malighase Flow 23 (1997) 173.

[6] M.C. Ruzicka, J. Drahos, 1. Zaluradrilk, N. Thomas, tht. J. Muliphase Flow 23 (1997) 671.

[7] W.M. Gouçalves, R.D. Pinto, J.C. Sattorelli, Phystica D 257 (1998) 385 .

(8) C. Letelies, G. Gouesbet, F. Soufi, J.R. Buchlex, Z. Kolluth, Chaos 6 (1996) 466.

[9] J.C. Sartorelli, W.M. Gonçalves, R.D. Plnte, Pbys. Rev. E 49 (1994) 3963 .

[I01 A. Tufille, R.D. Pinto, W.M. Gongalves, J.C. Sartonelli, Phys. Let, A 255 (1999) 58.

[i1] S. Ellar, D.W. Nychica, A.f Gallant, LENNS, a program to

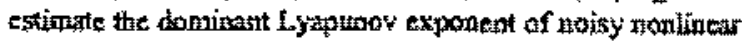
systems from time series kizat (Instritute of Statiatics Mimeo Series D. 2235 (DMA series n. 39), Statistice Departued, Noth Caroliea State University, Ratefilk 1992).

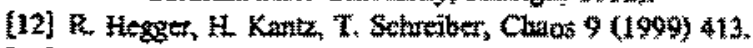

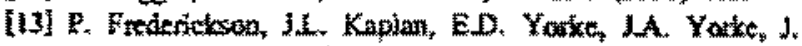
Difl. Squal, 49 (1)

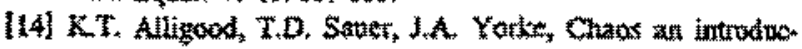

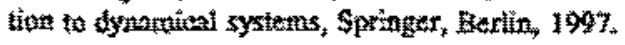

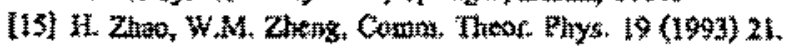

